GAS TURBINE REHEAT USING IN SITU COMBUSTION

\title{
Final Report (Draft)
}

Reporting Period Start Date - October 1, 2000

Reporting Period End Date - May 31, 2004

by

D.M. Bachovchin

T.E. Lippert

R.A. Newby

P.G.A. Cizmas (Texas A\&M)

May 17, 2004

DOE/NETL Contract No. DE-FC26-00NT40913

Submitted by :

Siemens Westinghouse Power Corporation

4400 Alafaya Trail

Orlando, FL 32826

with

Subcontractor

Texas A\&M University

College Station, TX 77843-3141

Prepared for

U.S. Department of Energy

National Energy Technology Laboratory

3610 Collins Ferry Road

P. O. Box 880

Morgantown, WV 26507-0880

Charles Alsup — DOE/NETL Project Officer 


\section{DISCLAIMER}

This report was prepared as an account of work sponsored by the United States Government. Neither the United States nor the United States Department of Energy, nor any of their employees, makes any warranty, expressed or implied, or assumes any legal liability or responsibility for the accuracy, completeness, or usefulness of any information, apparatus, product, or process disclosed, or represents that its use would not infringe privately owned rights. Reference herein to any specific commercial product, process, or service by trade name, mark, manufacturer, or otherwise, does not necessarily constitute or imply its endorsement, recommendation, or favoring by the United States Government or any agency thereof. The views and opinions of authors expressed herein do not necessarily state or reflect those of the United States Government or any agency thereof. 


\begin{abstract}
In situ reheat is an alternative to traditional gas turbine reheat design in which fuel is fed through airfoils rather than in a bulky discrete combustor separating HP and LP turbines. The goals are to achieve increased power output and/or efficiency without higher emissions. In this program the scientific basis for achieving burnout with low emissions has been explored. In Task 1, Blade Path Aerodynamics, design options were evaluated using CFD in terms of burnout, increase of power output, and possible hot streaking. It was concluded that Vane 1 injection in a conventional 4-stage turbine was preferred. Vane 2 injection after vane 1 injection was possible, but of marginal benefit. In Task 2, Combustion and Emissions, detailed chemical kinetics modeling, validated by Task 3, Sub-Scale Testing, experiments, resulted in the same conclusions, with the added conclusion that some increase in emissions was expected. In Task 4, Conceptual Design and Development Plan, Siemens Westinghouse power cycle analysis software was used to evaluate alternative in situ reheat design options. . Only single stage reheat, via vane 1, was found to have merit, consistent with prior Tasks.
\end{abstract}

Unifying the results of all the tasks, a conceptual design for single stage reheat utilizing 24 holes, $1.8 \mathrm{~mm}$ diameter, at the trailing edge of vane 1 is presented. A development plan is presented. 


\section{TABLE OF CONTENTS}

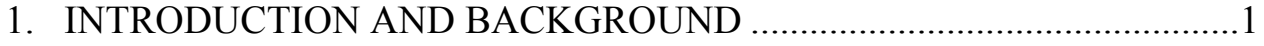

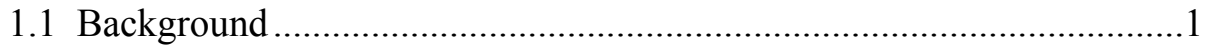

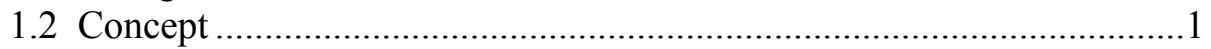

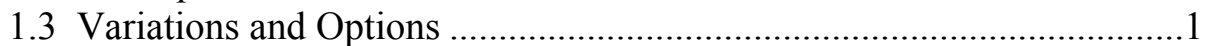

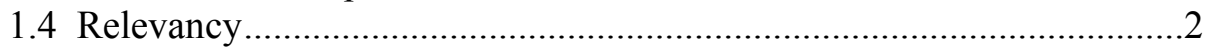

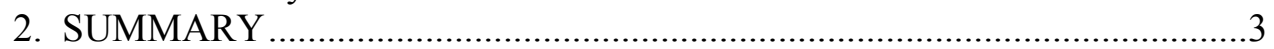

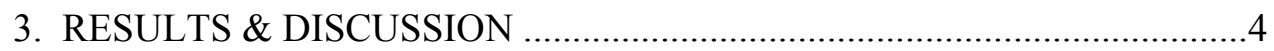

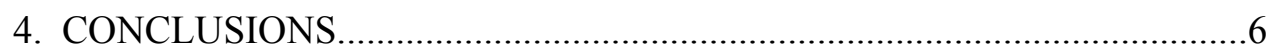

Attachment 1: Task 1 - Blade Path Aerodynamics .........................................

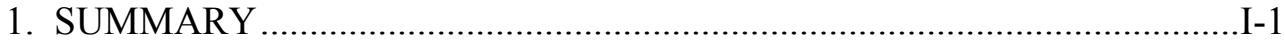

2. INTRODUCTION AND BACKGROUND ...............................................

3. GENERAL MODELING PROCEDURE......................................................

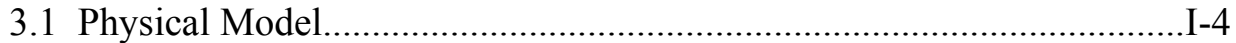

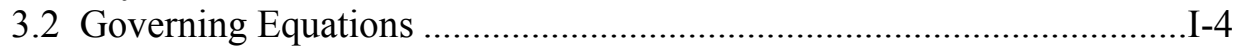

3.3 Chemistry Model ................................................................................

3.4 Numerical Model ...............................................................................

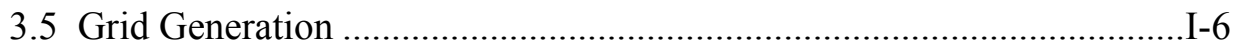

3.6 Discretization of Governing Equations.................................................

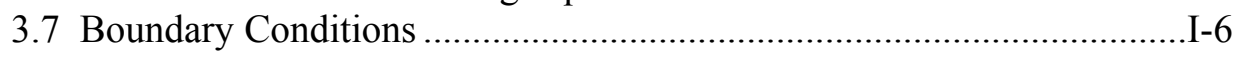

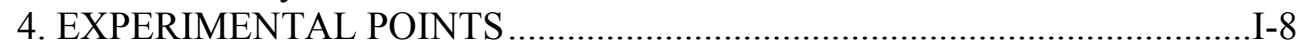

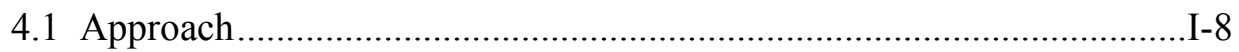

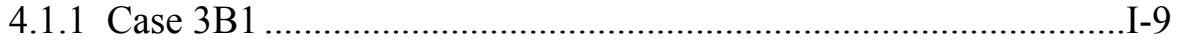

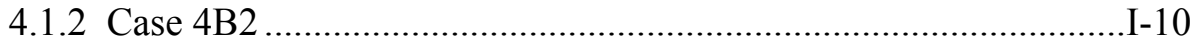

4.2 Two-Dimensional Model .................................................................. 10

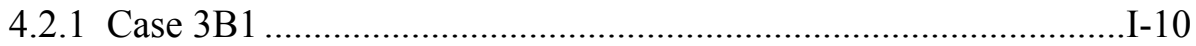

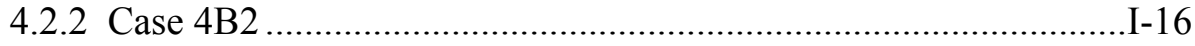

4.3 Three-Dimensional Model ............................................................... 18

5. INDUSTRIAL GAS TURBINE SIMULATION .......................................

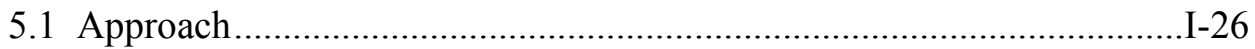

5.2 Geometry and Flow Conditions ......................................................

5.3 Accuracy of Numerical Results .......................................................

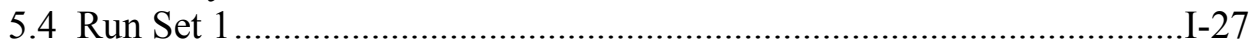

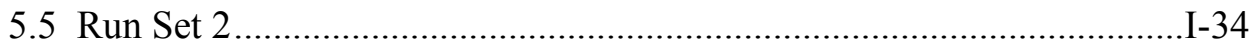

5.5.1 Four-Stage Turbine ...............................................................

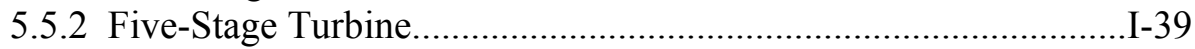

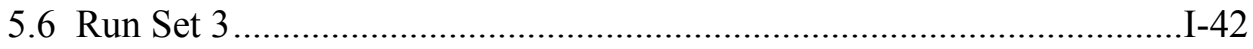

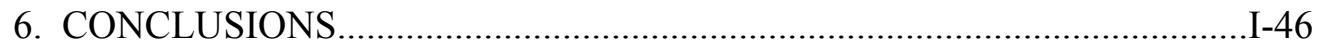

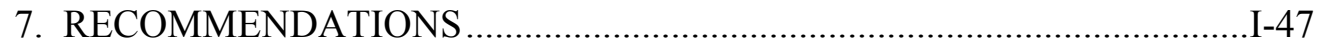

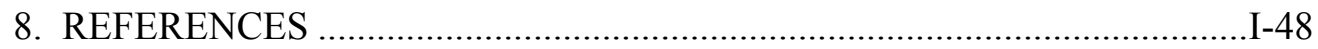

Attachment II: Task 2 - Combustion and Emissions.......................................II-1

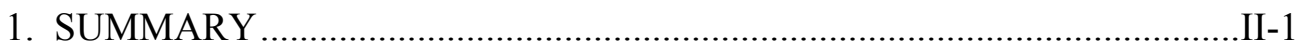

2. PRELIMINARY NON-FLAMEHOLDING ANALYSIS..............................II-2

3. NON-FLAMEHOLDING DESIGN CONCEPT ...........................................II-4

3.1 Modeling Approach ........................................................................

3.1.1 Calling Module ..........................................................................I-4 
3.1.2 Diffusion Flame Model …................................................................... II-5

3.1.3 Empirical Factors .......................................................................

3.2 Fit to Experimental Data .......................................................................II-9

3.3 Parametric Study Results ..................................................................II-12

3.3.1 Four-Stage Turbine, Vane 1 Injection .........................................II-13

3.3.2 Four-Stage Turbines, Vane 2 Injection.......................................II-17

3.3.3 Five-Stage Turbine, Vane 2 Injection ..........................................II-18

4. FLAMEHOLDING DESIGN ......................................................................II-19

4.1 Modeling Approach ...........................................................................II-19

4.2 Parametric Study Results .............................................................II-20

4.2.1 Four-Stage Turbine, Vane 1 Injection .......................................II-20

4.2.2 Four-Stage Turbine, Vane 2 Injection .......................................II-22

4.2.3 Five-Stage Turbine, Vane 2 Injection ........................................II-22

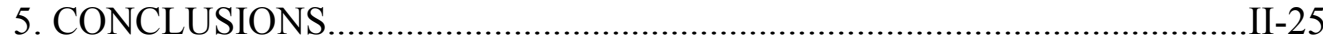

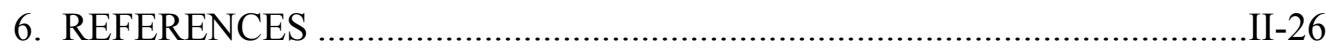

Attachment III: Task 3 - Sub-scale Testing .................................................III-1

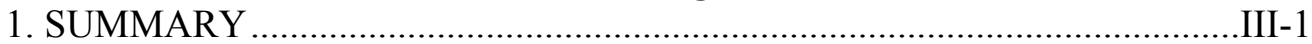

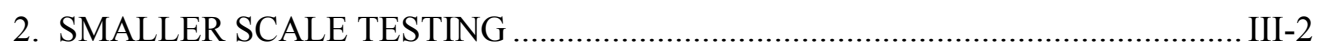

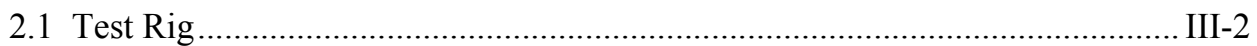

2.2 Test Results ............................................................................................

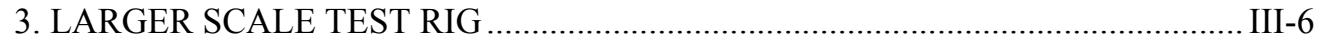

Attachment IV: Task 4 - Conceptual Design and Development Plan ....................... IV-1

1. SUMMARY ................................................................................................... IV-1

2. CONCEPTUAL EVALUATION FO ALTERNATIVE REHEAT

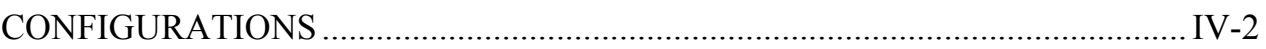

2.1 Background and Objectives .................................................................... IV-2

2.2 Reference Turbine and Performance .......................................................... IV-2

2.3 Sequential Combustion Reheat and In Situ Reheat Turbine Performance ......... IV-5

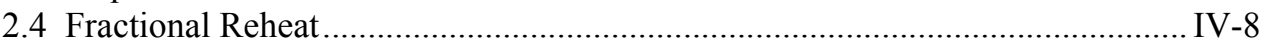

2.5 Partial Oxidation Reheat........................................................................... IV-10

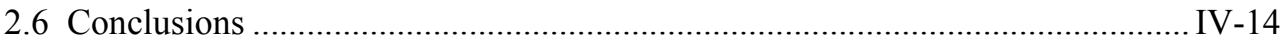

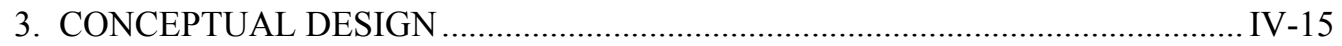

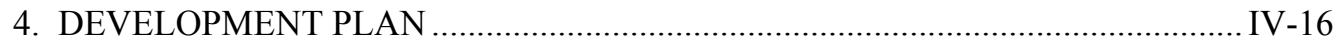

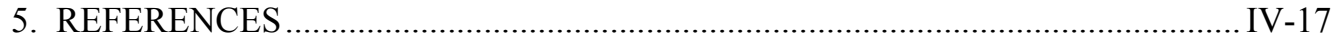




\section{INTRODUCTION}

This report documents the work conducted under Cooperative Agreement No. DE-FC2600NT40913, "Gas Turbine Reheat Using In situ Combustion," between Siemens Westinghouse Power Corporation and the United States Department of Energy. The Period of Performance was October, 1, 2000 to May 31, 2004.

The overall objective of this project is to develop a novel gas reheat concept for gas turbine engines, in which fuel is injected directly into the turbine through one or more stages of vanes and/or blades. The key research goals involved in concept selection are to understand the combustion kinetics (burnout, emissions), blade performance and effects on turbine power output and efficiency. The concept is being evaluated for maximum energy efficiency (full reheat) and as a means to achieve power boost (minimum reheat)

\subsection{Background}

Increasing gas turbine firing temperature has historically increased gas turbine efficiency and power output. This approach is limited by the generation of thermal Nox and by the need for advanced materials at higher temperatures.

A well-known alternative approach is to add reheat combustion between turbine stages to achieve higher mean temperatures at which heat is extracted, without increasing maximum temperature. More fuel is burned, to give higher power output. If this is accompanied by increased pressure ratio, or used in combined cycle with higher steam cycle inlet temperature, then cycle efficiency is also increased.

\subsection{Concept}

Prior suggested reheat schemes have used discrete reheat combustors, either within a larger shell or externally, between two separate turbines. In the concept of this work [1], reheat fuel is injected directly into the turbine flow via injection holes in the turbine vanes or blades. The possible advantages are: 1) simplicity in turbine design with no increase in casing size and no external reheat combustor and transition. 2) Lower reheat peak combustion temperature; 3) near zero reheat Nox formation, with normalized Nox (to 15\% oxygen) actually reduced; 4) reduced parasitic pressure loss; 5) substitution of fuel for some airfoil coolant flow. The key questions regarding this approach are whether there is sufficient residence time at high temperature for fuel burnout, whether increased emissions of Nox and $\mathrm{CO}$ result, and the impact of in situ combustion on blade path aerodynamics.

\subsection{Variations and Options}

Several applications of in situ reheat are possible:

- Modification of existing four-stage turbine designs to allow substitution of reheat fuel for some cooling air, thereby compensating for some efficiency loss due to cooling.

- Modification of existing four-stage turbine designs for full single-stage temperature recovery, e.g. adding enough fuel at vane 1 trailing edge to restore turbine inlet temperature. This generally represents about a $150 \mathrm{~K}$ temperature boost, and results in increased power output, and increased combined cycle efficiency. 
- New five-stage design where reheat fuel is added at the outlet of the second vane to increase the temperature to the first vane inlet and exit temperature of a four-stage engine. This would allow increased simple cycle efficiency as well.

Within these options, there are numerous design options, including:

- Row of injection

- Number and size of injection holes

- Fuel type

- Fuel injection rate

- Position and angle on row of injection

\subsection{Relevancy}

The in situ reheat concept represents a new approach that can allow gas turbine engines to move toward DOE goals of higher efficiency, higher power output, low emissions engines. This work will develop the scientific basis for the concept of in situ reheat. In particular the work will identify the combustion kinetic basis for injection, will identify practical designs (simple or flame-held) for achieving injection, and will quantify effects on airfoil aerodynamics and turbine performance. 


\section{EXPERIMENTAL}

Two test systems were prepared, and are described in Attachment III. The first, for smaller scale testing, used the existing $0.2 \mathrm{~kg} / \mathrm{sec}$ air, $200 \mathrm{psi}, 900 \mathrm{~F}$ air facility, with modified spool pieces. Testing is summarized in Section 2. Data were used for calibration of CFD and detailed kinetic models discussed in the Tasks 1 and 2 Attachments in this report.

The second was a $0.64 \mathrm{~kg} / \mathrm{sec}$ air constructed by Siemens Westinghouse for catalytic combustion testing. This unit, however, was still undergoing shakedown at the end of this project, so reheat testing was not initiated. 


\section{RESULTS AND DISCUSSION}

In this program the scientific basis for achieving burnout with low emissions has been explored. Detailed descriptions of the work in each of the tasks are presented as Attachments.

\section{$\underline{\text { Task } 1 \text { - Blade Path Aerodynamics }}$}

(Performed by Texas A\&M University).

A CFD model, CoRSI (Combustion and Rotor-Stator Interaction) was to incorporate simplified combustion kinetics with blade path flow. The model was used to investigate the effect of injection parameters (stage, fuel flow, fuel temperature, injection angle) on turbine performance (burnout location, forces on blades, power output, efficiency).

First, the combustion model was validated against Task 3 single vane experimental data. The numerical simulation proved that the combustion model is sufficiently accurate to produce reliable results for parametric studies. Then the model was used in the investigation of in situ reheat for four- and five-stage industrial turbines. The numerical simulation showed that power could be increased by up to $5 \%$ with a modest amount of fuel injected in the turbine.

The numerical simulation showed that the best location for fuel injection is at the trailing edge of the inlet guide vane. The flow conditions at the trailing edge promote combustion because (1) the gas velocity in the airfoil's wake is small and (2) the vortices shed at the trailing edge enhance mixing of fuel and oxygen. Consequently, the trailing edge acts as a good flame holder. When the fuel was injected in the second or third stages, however, the combustion either was not initiated or was slow (stretched out axially with CO survival) or incomplete (methane survival) compared to the case when the fuel was injected at the inlet guide vane. Reduced temperature and pressure adversely affected in situ reheat on second and third vanes.

Fuel injection at the leading edge of the second vane did not significantly increase power, although a counter-flow flame had some advantages. The numerical simulation showed that the location of the injection at the leading edge must be moved toward the pressure side in order to avoid the flame being swept towards the suction side. The flow unsteadiness at leading edge was another factor that adversely affected the combustion of a fuel injected with constant velocity.

\section{$\underline{\text { Task } 2-\text { Combustion and Emissions }}$}

In this task detailed chemical kinetics models were used to evaluate injection reheat

combustion. Models used included a Siemens Westinghouse diffusion flame model, the set of CHEMKIN gas-phase kinetics equation solvers, and the GRI 3.0 detailed kinetics data base. These modules are called by a reheat-specific main program, which also provides them with data, including gas path conditions that change with distance through the turbine.

Conceptually, injection could occur in either of two ways: 1) direct injection via holes in airfoil trailing edges; or 2) injection at the downstream faces of small bluff bodies placed at these edges. In the former case, combustion could occur as a diffusion flame at the hole, as a plume or streak following this zone, or as a substantially mixed out homogeneous region downstream. In the latter case, combustion could occur as a lower temperature, well-mixed, recirculating flame in the wake of the bluff body, followed by burnout in the same sequence of diffusion flame, streak, and mixed out. 
The results were as follows. In the case of a conventional four-stage engine, vane 1 trailing edge injection can be achieved with complete burnout without a flameholder. However, there are projected Nox and $\mathrm{CO}$ penalties of about 10 ppmv each. For vane 2 injection a

flameholder is necessary, although the CO survival is expected to be larger, on the order of 50 ppmv. In the case of an advanced five-stage engine, injection at vane 2 (same size and conditions, except temperature, as vane 1 of a 4-stage engine) should be with a flameholder to minimize $\mathrm{CO}$, keeping Nox and $\mathrm{CO}$ increases at about 20 and 10 ppmv respectively.

\section{$\underline{\text { Task } 3 \text { - Sub-scale Testing }}$}

Two test systems have been prepared. The first, for smaller scale testing, used the existing $0.2 \mathrm{~kg} / \mathrm{sec}$ air, $200 \mathrm{psi}, 900 \mathrm{~F}$ air facility, with modified spool pieces. Testing is summarized in Section 2. Data were used for calibration of CFD and detailed kinetic models discussed in the Tasks 1 and 2 Attachments in this report.

\section{$\underline{\text { Task } 4 \text {-Conceptual Design and Development Plan }}$}

Several Siemens Westinghouse power cycle analysis software packages were used to evaluate several in situ reheat design options in terms of increase in power output and increase in (simple and combined) cycle efficiency. Only single stage reheat, via vane 1, was found to have merit. 


\section{CONCLUSIONS}

- In situ reheat can be used to increase the power output and efficiency (with combined cycle operation or with additional turbine stage) of large power-generation gas turbines.

- A numerical, computational fluid dynamics (CFD) simulation with simple (2-step) methane combustion kinetics can adequately represent the processes occurring with in situ reheat.

- Fuel injection at the vane 1 trailing edge location can be successfully applied, based upon CFD modeling, detailed kinetic modeling, and system performance (cycle) analysis. Burnout of methane is complete, and hot streaks vanish by the next airfoil.

- Fuel injection at the vane 1 trailing edge location, by the design methods considered, results in increases of Nox and CO on the order of $10 \mathrm{ppm}$ each.

- A direct injection design utilizing 25 holes per vane, $1.8 \mathrm{~mm}$ diameter, without a flameholder, is proposed as the preferred design.

- Fuel injection at vane 2 and later locations is not practical, again based on these three forms of analysis. Either burnout is incomplete, or substantial CO survives, or there are hot streaking problems.

- A flameholding design reduces $\mathrm{CO}$ survival to about $50 \mathrm{ppmv}$ for vane 2 injection after vane 1 injection.

- Adding a fifth stage, with in situ reheat at the new second vane, is possible, but will require a flameholder design, and will result in projected penalties of $20 \mathrm{ppm}$ Nox and $10 \mathrm{ppm}$ CO.

- The following going-forward development steps are recommended:

- Experimental verification in a larger rig with actual airfoils. A scaled-down, one-and-a-half stage turbine is proposed. The existing Texas A\&M rig for this purpose from $10 \mathrm{~kg} / \mathrm{s}$ air for up to five minutes.

- Replacement of quasi-3D CFD modeling with full-3D model to capture radial effects of in situ reheat, with incorporation of more detailed kinetics.

- Exploration by CFD and detailed kinetics analyses of additional design variants, such as injection angles differing from main gas angles, and injection at mid-span locations. More low emissions design points would be sought.

- The utility of in situ reheat might be increased by utilizing injection fuels containing some hydrogen. Hydrogen has a high flame speed, and therefore might allow operation without a flameholder for more cases, and smaller flames for direct injection, resulting in more practical stages of reheat with lower emissions. Similarly, the concept may be applicable to advanced cycles incorporating coal-derived fuel gases, containing hydrogen. Investigations in these areas are recommended. 


\section{Attachment I: Task 1 - Blade Path Aerodynamics}

\section{SUMMARY}

Current conventional developments of gas turbine aero thermodynamics provide small efficiency and power increase, because with the present technology one reached an asymptotical convergence to the upper limit of the gas turbine performance. This asymptotical convergence implies that large efforts to ameliorate the aerothermodynamics result in rather small improvements. Turbine combustion provides a paradigm shift and a step change in gas turbine aerothermodynamics.

This report presents the experimental and computational investigation of in situ reheat in turbine-combustors. A turbine-combustor is defined as a turbine in which fuel is injected and combusted. The process of combustion in the turbine is called in situ reheat. Thermodynamic cycle analyses have demonstrated the benefits of using reheat in the turbine in order to increase specific power and thermal efficiency. Even better performance gains for specific power and thermal efficiency were predicted for power generation gas turbine engines when the turbine is coupled with a heat regenerator.

The report presents (1) the experimental investigation of combustion in a single-vane combustor, (2) the validation of the combustion model using single-vane combustor data, and (3) the investigation of in situ reheat for four- and five-stage industrial turbines. The numerical simulation proved that the combustion model is sufficiently accurate to produce reliable results for parametric studies. The numerical simulation showed that power could be increased by up to $5 \%$ with a modest amount of fuel injected in the turbine.

The numerical simulation showed that the best location for fuel injection is at the trailing edge of the inlet guide vane. The flow conditions at the trailing edge promote combustion because (1) the gas velocity in the airfoil's wake is small and (2) the vortices shed at the trailing edge enhance mixing of fuel and oxygen. Consequently, the trailing edge acts as a good flame holder. When the fuel was injected in the second or third stages, however, the combustion either was not initiated or was much weaker compared to the case when the fuel was injected at the inlet guide vane. Reduced temperature and pressure adversely affected in situ reheat on second and third vanes.

Fuel injection at the leading edge of the second vane did not significantly increase power, although a counter-flow flame had some advantages. The numerical simulation showed that the location of the injection at the leading edge must be moved toward the pressure side in order to avoid the flame being swept towards the suction side. The flow unsteadiness at leading edge was another factor that adversely affected the combustion of a fuel injected with constant velocity.

The most important next step is the experimental investigation of a scaled down, one and a half stage turbine-combustor. This experimental investigation will provide critical data on the interaction between the in situ reheat, the rotor/stator interaction and the combustor hot streaks. This experiment will also provide the apparatus necessary to investigate different approaches for fuel injection and blade cooling. The experiment can be done at the blow down facility of the Texas A\&M University. This facility provides approximately $10 \mathrm{~kg} / \mathrm{sec}$ at 44 bars for approximately 5 minutes. If necessary, the mass flow rate can be increased by reducing the operating time. A large variety of measurement equipment is also available, including Laser Doppler Anemometry, Particle Image Velocimetry, 18-hole omni-directional probes, etc. 
For the numerical simulation, the next step should be the replacement of the quasi-threedimensional model by a fully three-dimensional model, in order to capture the radial variation effects on in situ reheat. The modeling of the combustion process can be improved as well. One possible improvement is related to the diffusion modeling, where the constant diffusion coefficients will be replaced by binary mixture coefficients. Another improvement will be obtained by replacing the existing two-step combustion model by a five-step combustion model or, even better, by the ARM2 model, a sixteen-step combustion model. 


\section{INTRODUCTION AND BACKGROUND}

Thermodynamic cycle analysis has demonstrated the benefits of using reheat in the turbine to increase specific power and thermal efficiency. Even better performance gains for specific power and thermal efficiency are predicted for power generation gas-turbine engines when the turbine is coupled with a heat regenerator. Starting in the 1960s, several patents have been awarded for inventions that address various aspects of turbine reheat.

In spite of these advances, the technological challenges and the difficulty of predicting and understanding the details of the transport phenomena inside the reheat turbine have precluded the development of turbine-combustors. Herein, a turbine-combustor is defined as a turbine in which fuel is injected and combustion takes place. The process of combustion in the turbine is called in situ reheat.

Several challenges are associated with combustion in the turbine-burner: mixed subsonic and supersonic flows; flows with large unsteadiness due to the rotating blades; hydrodynamic instabilities and large straining of the flow due to the very large three-dimensional acceleration and stratified mixtures. The obvious drawback associated with the strained flows in the turbine-burner is that widely varying velocities can result in widely varying residence times for different flow paths and as a result there are flammability difficulties for regions with shorter residence times. In addition, transverse variation in velocity and kinetic energy can cause variations in entropy and stagnation entropy that impact heat transfer. The heat transfer and mixing could be enhanced by increasing interface area due to strained flows.

The experimental investigation and numerical simulations performed in this study explore: (1) the validity of the combustion model on a simple combustion probe for which experimental data were generated, and (2) the influence of various fuel injection parameters on the performance of a turbine-combustor based on a gas turbine power plant. The parameters that were varied in this set of calculations are: (1) injection velocity, (2) fuel temperature, (3) injection hole size, (4) airfoil injection location, (5) injection row, and (6) direction of fuel injection velocity. The calculated output for each case includes the turbine-combustor power increase, the volume and mass fraction of the species, total temperature and enthalpy, and mixedness across the main stream of the total enthalpy and temperature (relative for rotors and absolute for stators) as well as mass fractions for $\mathrm{CO}$ and $\mathrm{CH}_{4}$. 


\section{GENERAL MODELING PROCEDURE}

\subsection{Physical Model}

The flow and combustion through a multi-row turbine-burner with arbitrary blade counts is modeled by the Reynolds-averaged Navier-Stokes equations and the species conservation equations. To reduce the computational time of the in situ reheat in the multi-stage turbineburner, the flow and combustion are modeled as quasi-three-dimensional. The calibration of the combustion model against the experimental data was done using two-dimensional and three-dimensional models. This section will present the details of the governing equations and the chemistry model.

\subsection{Governing Equations}

The unsteady, compressible flow through the turbine-combustor is modeled by the Reynoldsaveraged Navier-Stokes equations. The flow is assumed to be fully turbulent and the kinematic viscosity is computed using Sutherland's law. The Reynolds-averaged NavierStokes equations and species conservation equations are simplified by using the thin-layer assumption.

In the hypothesis of unity Lewis number, both the Reynolds-averaged Navier-Stokes and species equations can be written as:

$$
\frac{\partial Q}{\partial \tau}+\frac{\partial F}{\partial \xi}+\frac{\partial G}{\partial \eta}=\frac{\sqrt{\gamma_{\infty}} M_{\infty}}{\operatorname{Re}_{\infty}} \frac{\partial S}{\partial \eta}+S_{c h}
$$

Note that equation (1) is written in the body-fitted curvilinear coordinate system $(\xi, \eta, \tau)$.

The state and flux vectors of the Reynolds-averaged Navier-Stokes equations in the Cartesian coordinates are

$$
q^{n s}=\left[\begin{array}{c}
\rho \\
\rho u \\
\rho v \\
e
\end{array}\right], \quad f^{n s}=\left[\begin{array}{c}
\rho u \\
\rho u^{2}+p \\
\rho u v \\
(e+p) u
\end{array}\right], \quad g^{n s}=\left[\begin{array}{c}
\rho v \\
\rho u v \\
\rho v^{2}+p \\
(e+p) v
\end{array}\right] .
$$

The state and flux vectors of the species conservation equations in the Cartesian coordinates are

$$
q^{s p}=\left[\begin{array}{c}
\rho y_{1} \\
\rho y_{2} \\
\mathrm{M} \\
\rho y_{N}
\end{array}\right], \quad f^{s p}=\left[\begin{array}{c}
\rho u y_{1} \\
\rho u y_{2} \\
\mathrm{M} \\
\rho u y_{N}
\end{array}\right], \quad g^{s p}=\left[\begin{array}{c}
\rho v y_{1} \\
\rho v y_{2} \\
\mathrm{M} \\
\rho v y_{N}
\end{array}\right] .
$$

Further details on the description of the viscous terms and chemical source terms are presented in [2]. 


\subsection{Chemistry Model}

The chemistry model used herein to simulate the in situ reheat is a two-step, global, finite rate combustion model [3] for methane and combustion gases

$$
\begin{gathered}
\mathrm{CH}_{4}+1.5 \mathrm{O}_{2} \rightarrow \mathrm{CO}+2 \mathrm{H}_{2} \mathrm{O} \\
\mathrm{CO}+0.5 \mathrm{O}_{2} \rightarrow \mathrm{CO}_{2} .
\end{gathered}
$$

The rate of progress (or Arrhenius-like reaction rate) for methane oxidation is given by:

$$
q_{1}=A_{1} \exp \left(E_{1} / R_{M} / T\right)\left[C_{4}\right]^{-0.3}\left[O_{2}\right]^{1.3},
$$

where $A_{1}=2.8 \cdot 10^{9} \mathrm{~s}^{-1}, E_{1} / R_{M}=24360 \mathrm{~K}$. The reaction rate for the $\mathrm{CO} / \mathrm{CO}_{2}$ equilibrium is:

$$
q_{2}=A_{2} \exp \left(E_{2} / R_{M} / T\right)[C O]\left[O_{2}\right]^{0.25}\left[H_{2} O\right]^{0.5}
$$

with $A_{2}=2.249 \cdot 10^{12}\left(\mathrm{~m}^{3} / \mathrm{kmol}\right)^{0.75} \mathrm{~s}^{-1}$ and $E_{2} / R_{M}=20130 \mathrm{~K}$. The symbols in the square brackets represent local molar concentrations of various species. The net formation/destruction rate of each species due to all reactions is:

$$
W_{i}=\sum_{k=1}^{N f} M_{i} V_{i k} q_{k}
$$

where $v_{i k}$ are the generalized stoichiometric coefficients. Note that the generalized stoichiometric coefficient is $v_{i k}=v_{i k}^{\prime \prime}-v_{i k}^{\prime}$ where $v_{i k}^{\prime}$ and $v_{i k}^{\prime \prime}$ are stoichiometric coefficients for species $i$ in reaction $k$ appearing as reactant or as a product. Additional details on the implementation of the chemistry model can be found in [2].

\subsection{Numerical Model}

The numerical model used herein is based on an existing algorithm developed for unsteady flows in turbomachinery [1]. The Reynolds-averaged Navier-Stokes equations and the species equations are written in the strong conservation form. The fully implicit, finite-difference approximation is solved iteratively at each time level, using an approximate factorization method. Three Newton-Raphson sub-iterations are used to reduce the linearization and factorization errors at each time step. The convective terms are evaluated using a third-order accurate upwind-biased Roe scheme. The viscous terms are evaluated using second-order accurate central differences. The scheme is second-order accurate in time.

\subsection{Grid Generation}

The computational domain used to simulate the flow inside the turbine-combustor is reduced by taking into account flow periodicity. Two types of grids are used to discretize the flow field surrounding the rotating and stationary airfoils, as shown in Figure 17. An O-grid is used to resolve the governing equations near the airfoil, where the viscous effects are important. An H-grid is used to discretize the governing equations away from the airfoil. The 
$\mathrm{O}$-grid is generated using an elliptical method. The $\mathrm{H}$-grid is algebraically generated. The $\mathrm{O}-$ and $\mathrm{H}$-grids are overlaid. The flow variables are communicated between the $\mathrm{O}$ - and $\mathrm{H}$-grids through bilinear interpolation. The $\mathrm{H}$-grids corresponding to consecutive rotor and stator airfoils are allowed to slip past each other to simulate the relative motion.

\subsection{Discretization of Governing Equations}

The transport of chemical species is modeled by the mass, momentum, energy and species balance equations. These gas-dynamics and chemistry governing equations are solved herein using a fully decoupled implicit algorithm. Further discussions on the coupled vs. decoupled algorithms for combustion problems can be found in [2]. A correction technique has been developed to enforce the balance of mass fractions. The governing equations are discretized using an implicit, approximate-factorization, finite difference scheme in delta form. The discretized operational form of both the Reynolds-averaged Navier-Stokes (RANS) and species conservation equations, combined in a Newton-Raphson algorithm, is:

$$
\begin{aligned}
& {\left[I+\frac{\Delta \tau}{\Delta \xi}\left(\Delta_{\xi}\left(A^{-}\right)^{\nu}+\nabla_{\xi}\left(A^{*}\right)^{\rho}\right)\right]\left[I+\Delta \tau \frac{\hat{c}}{\rho_{\infty}} \sqrt{\frac{\rho_{\infty}}{p_{\infty}}} C_{b j}^{\nu}++\frac{\Delta \tau}{\Delta \eta}\left(\Delta_{\eta}\left(B^{-}\right)^{\rho}+\nabla_{\eta}\left(B^{+}\right)^{\rho}-\frac{\sqrt{\gamma_{\infty}} M_{\infty}}{R_{e}} \delta_{\eta}(Y)^{\rho}\right)\right]} \\
& \left(Q_{i, j}^{p+1}-Q_{i, j}^{p}\right)=-\left(1.5 Q_{i, j}^{p}-2.0 Q_{i, j}^{n}+0.5 Q_{i, j}^{n-1}\right)-\frac{\Delta \tau}{\Delta \xi}\left(\hat{F}_{i+\frac{1}{2}, j}^{p}-\hat{F}_{i-\frac{1}{2}, j}^{p}\right)-\frac{\Delta \tau}{\Delta \eta}\left(\hat{G}_{i, j+\frac{1}{2}}^{p}-\hat{G}_{i, j-\frac{1}{2}}^{p}\right)+ \\
& +\sqrt{\gamma_{\infty}} M_{\infty} R e^{-1} \frac{\Delta \tau}{\Delta \eta}\left(S_{i+\frac{\xi}{2}, j}^{\rho}-S_{i-\frac{1}{2}, j}^{\rho}\right)+\left(S_{c h}^{\rho}\right)_{i, j}
\end{aligned}
$$

where $A$ and $B$ are the flux Jacobian matrices $A=\partial F / \partial Q, B=\partial G / \partial Q$. The $Y$ and $C$ matrices are $Y=\partial S / \partial Q$ and $C=\partial S_{c h} / \partial Q$. Note that the flux Jacobian matrices are split into $A=A^{+}+A^{-}$, where $A^{ \pm}=P \Lambda^{ \pm} P^{-1} . \Lambda$ is the spectral matrix of $A$, and $P$ is the modal matrix of $A$. The spectral matrix $\Lambda$ is split into $\Lambda=\Lambda^{+}+\Lambda^{-}$, where the components of $\Lambda^{+}$and $\Lambda^{-}$are $\lambda_{i}^{-}=0.5\left(\lambda_{i}-\left|\lambda_{i}\right|\right)$ and $\lambda_{i}^{+}=0.5\left(\lambda_{i}+\left|\lambda_{i}\right|\right)$, respectively. The same flux vector splitting approach is applied to the matrix $B$. In equation (5), $\Delta, \nabla$ and $\delta$ are forward, backward and central differences operators, respectively. $Q^{p}$ is an approximation of $Q^{n+1}$. At any time step $n$, the value of $Q^{p}$ varies from $Q^{n}$ at first internal iteration when $p=0$, to $Q^{n+1}$ when integration of equation (5) has converged. Additional details on the implementation of the inter-cell numerical fluxes and on the Roe's approximate Riemann solver are presented in [2].

\subsection{Boundary Conditions}

Two classes of boundary conditions must be enforced on the grid boundaries: (1) natural boundary conditions, and (2) zonal boundary conditions. The natural boundaries include inlet, outlet, periodic and the airfoil surfaces. The zonal boundaries include the patched and overlaid boundaries.

The inlet boundary conditions include the specification of the flow angle, average total pressure and downstream propagating Riemann invariant. The upstream propagating Riemann invariant is extrapolated from the interior of the domain. At the outlet, the average static pressure is specified, while the downstream propagating Riemann invariant, circumferential velocity, and entropy are extrapolated from the interior of the domain. 
Periodicity is enforced by matching flow conditions between the lower surface of the lowest $\mathrm{H}$-grid of a row and the upper surface of the top most H-grid of the same row. At the airfoil surface, the following boundary conditions are enforced: the "no slip" condition, the adiabatic wall condition, and the zero normal pressure gradient condition.

For the zonal boundary conditions of the overlaid boundaries, data are transferred from the Hgrid to the O-grid along the O-grid's outermost grid line. Data are then transferred back to the H-grid along its inner boundary. At the end of each iteration, an explicit, corrective, interpolation procedure is performed. The patch boundaries are treated similarly, using linear interpolation to update data between adjoining grids. 


\section{EXPERIMENTAL POINTS}

This section presents the experimental data obtained for a single-vane burner operating at conditions similar to the inlet guide vane of a typical power generation turbine. Because of experimental limitations, the total pressure upstream of the combustion probe was smaller than the total pressure upstream of the inlet guide vane of a typical power generation turbine. These experimental data were compared against the numerical results corresponding to twodimensional and three-dimensional models. The comparison between the experimental data and the numerical results was done in order to validate the combustion model.

\subsection{Approach}

To verify the validity of the methane combustion model to in situ reheat applications, a single-vane burner was experimentally investigated and numerically simulated. In-situ reheat tests were run in the Siemens Westinghouse small-scale, full-pressure, combustion test facility, shown in Figure 1. Preheated air $(0.20 \mathrm{~kg} / \mathrm{s})$ and natural gas were delivered to a lowNox burner section, which was run at full pressure (typically 14 bar). Air preheat temperature and fuel/air ratio were adjusted to give an exhaust gas stagnation temperature and composition corresponding to a selected location in a turbine cascade. The exhaust gas was then passed through a pressure-reducing orifice to increase the Mach number in the injection and sampling sections to typical turbine levels. A back pressure control valve was used to set the sampling section pressure.

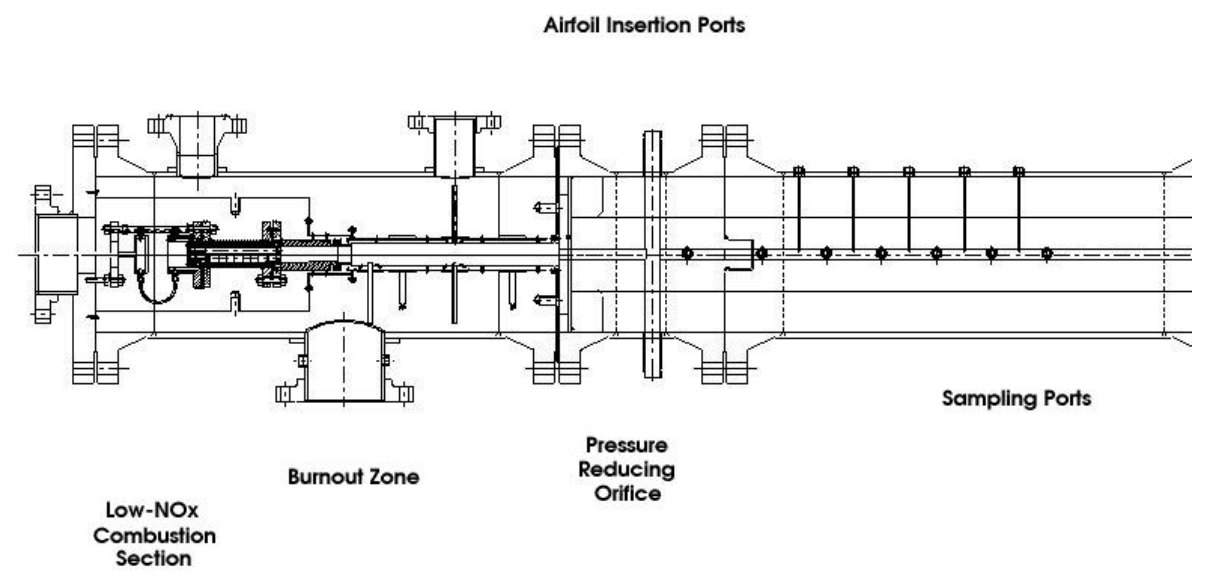

Figure 1 - Experimental apparatus. 

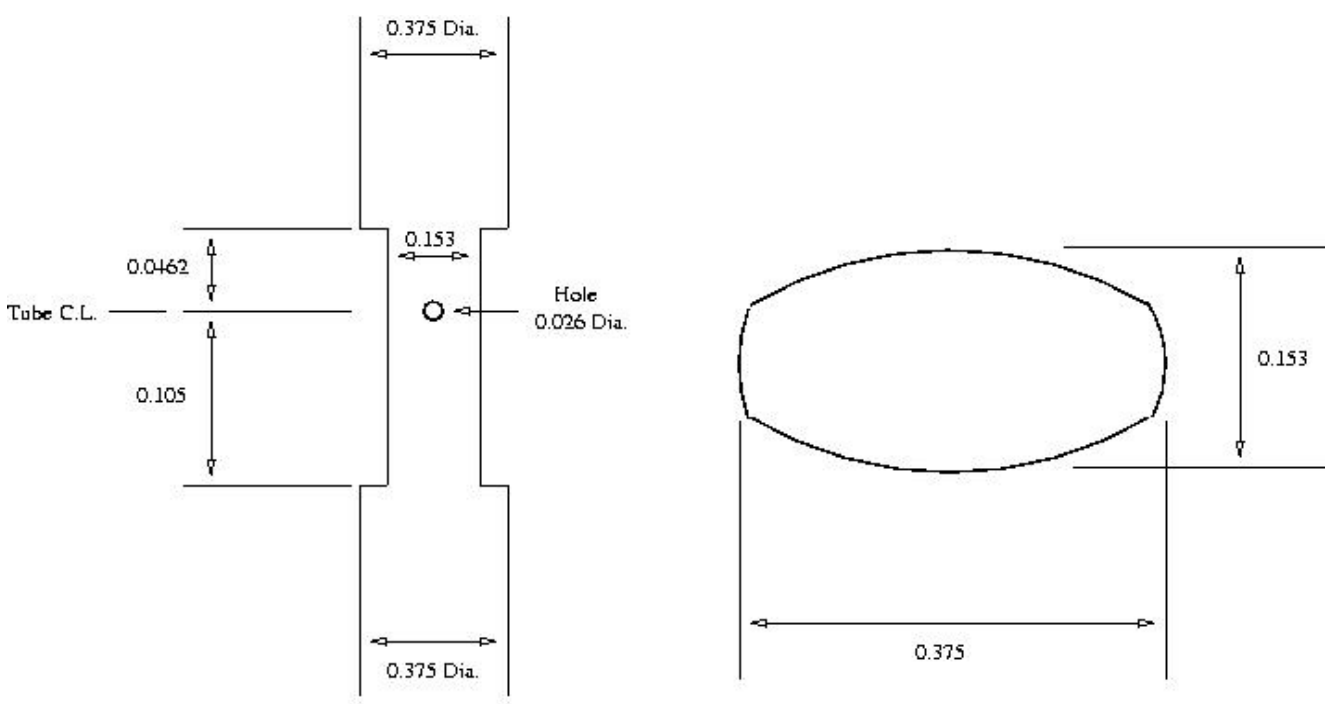

NOTE: Al] Lengths Shown in Inches

Drawing Not To Scale

Figure 2 - Combustion probe.

Air flow to the system was measured using a calibrated orifice plate, and natural gas flow with a mass flow controller with accuracies of 2 and $1 \%$ respectively. Gases were sampled at various locations downstream of the injection point, and compositions determined using a gas chromatograph, with error limits of $\pm 5 \%$.

The geometry of the combustion probe is shown in Figure 2. Fuel was injected through a 0.66 $\mathrm{mm}$ diameter hole. The probe was inserted into a 1.0 inch $(2.54 \mathrm{~cm}) \times 0.7$ inch $(1.78 \mathrm{~cm})$ channel, which necked down to a 0.7 x 0.7 channel immediately downstream. Temperature and gas composition were measured at several locations downstream of the fuel injector. Tests simulating vane 1 trailing edge injection produced complete burnout at the first sample location. Two flow cases are presented herein: 3B1 (Blade 1 trailing edge conditions) and 4B2 (Vane 2 trailing edge conditions). The flow parameters were calculated first for the probe without fuel injection. This simulation provided the static pressure value at the fuel injection location. Consequently, it was assumed that static pressure at fuel injection location was equal in the cases with and without fuel injection. The fuel density was calculated knowing the pressure, temperature and fuel composition. The injection velocity was the same as in the experimental investigation.

\subsubsection{Case 3B1}

Fuel was injected in a gas mixture that had a total pressure of 6.26 bar and total temperature of $1507 \mathrm{~K}$. The mass flow rate of gas mixture upstream of the injector was $0.1345 \mathrm{~kg} / \mathrm{s}$. The composition of this gas mixture is given in Table 1.

Table 1 - Gas mixture molar composition \%, case 3B1

$\begin{array}{lc}\mathrm{CO} 2 & 4.84 \\ \mathrm{H} 2 \mathrm{O} & 10.59 \\ \mathrm{~N} 2 & 73.48 \\ \mathrm{O} 2 & 10.21 \\ \mathrm{Ar} & 0.88\end{array}$


The composition of the injection fuel is given in Table 2. In the numerical simulation it was assumed that the fuel injected was pure $\mathrm{CH} 4$. The temperature of the fuel was $289 \mathrm{~K}$ and the mass flow rate was $0.416 \mathrm{~g} / \mathrm{s}$. The static pressure at the exit from the 0.7 in $\times 0.7$ in tube was 4.6 bar.

Table 2 - Injection fuel molar composition \%, case 3B1

$\begin{array}{lc}\mathrm{CH} 4 & 96.1 \\ \mathrm{C} 2 \mathrm{H} 6 & 2.0 \\ \mathrm{C} 3 \mathrm{H} 8 & 0.9 \\ \mathrm{CO} 2 & 0.5 \\ \mathrm{~N} 2 & 0.5\end{array}$

\subsubsection{Case 4B2}

Fuel was injected in a gas mixture that had a total pressure of 6.27 bar and total temperature of $1336 \mathrm{~K}$. The mass flow rate of gas mixture downstream of the injector was $0.1542 \mathrm{~kg} / \mathrm{s}$. The composition of the gas mixture at inlet in the 1 in $x 0.7$ in tube is given in Table 3 .

Table 3 - Gas mixture molar composition \%, case 4B2

$\begin{array}{lc}\mathrm{CO} 2 & 4.36 \\ \mathrm{H} 2 \mathrm{O} & 9.64 \\ \mathrm{~N} 2 & 73.85 \\ \mathrm{O} 2 & 11.27 \\ \mathrm{Ar} & 0.88\end{array}$

The composition of the injection fuel is given in Table 4. In the numerical simulation it was assumed that the fuel injected was pure $\mathrm{CH} 4$. The temperature of the fuel was $289 \mathrm{~K}$ and the mass flow rate was $0.528 \mathrm{~g} / \mathrm{s}$. The static pressure at the exit from the $0.7 \mathrm{in} \times 0.7$ in tube was 4.6 bar.

Table 4 - Injection fuel molar composition \%, case 4B2

$\begin{array}{ll}\text { CH4 } & 96.1 \\ \text { C2H6 } & 2.0 \\ \text { C3H8 } & 0.9 \\ \text { CO2 } & 0.5 \\ \text { N2 } & 0.5\end{array}$

\subsection{TWO-DIMENSIONAL MODEL}

\subsubsection{Case 3B1}

The parameters at fuel injection location are: temperature, $T=289 \mathrm{~K}$, pressure, $p=5.84 \mathrm{bar}$, molecular mass, $M=16.24 \mathrm{~kg} / \mathrm{kmol}$, fuel density, $\rho=3.948 \mathrm{~kg} / \mathrm{m} 3$, and velocity, $V=308$ $\mathrm{m} / \mathrm{s}$. The three-dimensional effects of the flow and combustion downstream of the injector are important. The numerical simulation presented in this section was, however, twodimensional. Three cases were considered in the numerical simulation: (1) the length of the injector equal to the diameter of the hole, that is, $0.66 \mathrm{~mm}$, (2) the length of the injector equal 
to the area of the hole from the experiment divided by the height of the tube $(0.7 \mathrm{in})$, that is, $0.019 \mathrm{~mm}$, and (3) the length of the injector equal to the geometrical average of the lengths used in cases (1) and (2). A good two-dimensional approximation of the three-dimensional solution should be situated in between the extreme values of the injector lengths. Note that the small length injector is just a model and not an engineering solution.

\section{Large Injector Length}

In the two-dimensional simulation, the length of the injector hole was equal to the diameter of the hole, that is, $0.66 \mathrm{~mm}$. As a result, the ratio of inlet gases and fuel injection mass flow rates is larger than the actual value in the three-dimensional case. The mass flow rate of fuel per unit length is $0.802 \mathrm{~kg} / \mathrm{s}$.

Table 5 - Species mole fraction \% at $0.311 \mathrm{~m}$ downstream for case 3B1 while using large size injector

\begin{tabular}{lcccc}
\hline Parameter & Experimental & Centerline & $\begin{array}{c}\text { Area-weighted } \\
\text { average }\end{array}$ & $\begin{array}{c}\text { Mass-weighted } \\
\text { average }\end{array}$ \\
\hline $\mathrm{CH}_{4}$ & 0.35 & 22.97 & 14.51 & 16.53 \\
$\mathrm{CO}$ & 0.16 & 0.10 & 0.13 & 0.14 \\
$\mathrm{CO}_{2}$ & N.A. & 4.55 & 6.69 & 6.24 \\
$\mathrm{O}_{2}$ & N.A. & 5.62 & 2.89 & 3.45 \\
$\mathrm{H}_{2} \mathrm{O}$ & N.A. & 9.71 & 14.22 & 13.32 \\
\hline
\end{tabular}

Table 6 - Species mole fraction \% at $0.654 \mathrm{~m}$ downstream for case 3B1 while using large size injector

\begin{tabular}{lcccc}
\hline Parameter & Experimental & Centerline & $\begin{array}{c}\text { Area-weighted } \\
\text { average }\end{array}$ & $\begin{array}{c}\text { Mass-weighted } \\
\text { average }\end{array}$ \\
\hline $\mathrm{CH}_{4}$ & 0.08 & 19.00 & 15.38 & 15.95 \\
$\mathrm{CO}$ & 0.27 & 0.059 & 0.063 & 0.068 \\
$\mathrm{CO}_{2}$ & N.A. & 5.98 & 7.21 & 7.04 \\
$\mathrm{O}_{2}$ & N.A. & 3.47 & 1.69 & 1.95 \\
$\mathrm{H}_{2} \mathrm{O}$ & N.A. & 12.68 & 15.10 & 14.75 \\
\hline
\end{tabular}

Table 7 - Temperature values for large size injector, case 3B1. Experimental value at $0.836 \mathrm{~m}$ is $1478 \mathrm{~K}$.

\begin{tabular}{cccc}
\hline & $0.311 \mathrm{~m}$ & $0.654 \mathrm{~m}$ & $0.836 \mathrm{~m}$ \\
\hline Centerline & & & \\
Static Temperature [K] & 1159 & 1408 & 1512 \\
Total Temperature [K] & 1204 & 1474 & 1578 \\
Area-weighted average & & & \\
Static Temperature [K] & 1680 & 1716 & 1744 \\
Total Temperature [K] & 1716 & 1760 & 1794 \\
Mass-weighted average & & & \\
Static Temperature [K] & 1572 & 1671 & 1718 \\
Total Temperature [K] & 1608 & 1718 & 1770 \\
\hline
\end{tabular}




\section{Small Injector Length}

In the two-dimensional simulation, the length of the injector hole was equal to the area of the injector hole from the experiment divided by the height of the tube $(0.7$ in $)$, that is, $0.019 \mathrm{~mm}$. As a result, the ratio between the inlet gases and fuel injection mass flow rates is larger than the actual value in the three-dimensional case. The mass flow rate of fuel per unit length is $0.023 \mathrm{~kg} / \mathrm{s}$.

Table 8 - Species mole fraction \% at $0.311 \mathrm{~m}$ downstream for case $3 \mathrm{~B} 1 \mathrm{using}$ small size injector

\begin{tabular}{lcccc}
\hline Parameter & Experimental & Centerline & $\begin{array}{c}\text { Area-weighted } \\
\text { average }\end{array}$ & $\begin{array}{c}\text { Mass-weighted } \\
\text { average }\end{array}$ \\
\hline $\mathrm{CH}_{4}$ & 0.35 & 0.0 & $1.11 \mathrm{e}-03$ & $1.17 \mathrm{e}-03$ \\
$\mathrm{CO}$ & 0.16 & 0.016 & $6.52 \mathrm{e}-03$ & $6.87 \mathrm{e}-03$ \\
$\mathrm{CO}_{2}$ & N.A. & 5.97 & 5.68 & 5.70 \\
$\mathrm{O}_{2}$ & N.A. & 7.46 & 8.20 & 8.16 \\
$\mathrm{H}_{2} \mathrm{O}$ & N.A. & 12.75 & 12.27 & 12.30 \\
\hline
\end{tabular}

Table 9 - Species mole fraction \% at $0.654 \mathrm{~m}$ downstream for case $3 \mathrm{~B} 1 \mathrm{using}$ small size injector

\begin{tabular}{lcccc}
\hline Parameter & Experimental & Centerline & $\begin{array}{c}\text { Area-weighted } \\
\text { average }\end{array}$ & $\begin{array}{c}\text { Mass-weighted } \\
\text { average }\end{array}$ \\
\hline $\mathrm{CH}_{4}$ & 0.08 & 0.00 & $1.29 \mathrm{e}-06$ & $1.40 \mathrm{e}-06$ \\
$\mathrm{CO}$ & 0.27 & 0.00 & $1.47 \mathrm{e}-05$ & $1.60 \mathrm{e}-05$ \\
$\mathrm{CO}_{2}$ & N.A. & 5.73 & 5.71 & 5.71 \\
$\mathrm{O}_{2}$ & N.A. & 7.97 & 8.16 & 8.15 \\
$\mathrm{H}_{2} \mathrm{O}$ & N.A. & 12.31 & 12.31 & 12.31 \\
\hline
\end{tabular}

Table 10 - Temperature values for small size injector, case 3B1. Experimental value at $0.836 \mathrm{~m}$ is $1478 \mathrm{~K}$.

\begin{tabular}{cccc}
\hline & $0.311 \mathrm{~m}$ & $0.654 \mathrm{~m}$ & $0.836 \mathrm{~m}$ \\
\hline Centerline & & & \\
Static Temperature [K] & 1682 & 1621 & 1621 \\
Total Temperature [K] & 1745 & 1698 & 1698 \\
Area-weighted average & & & \\
Static Temperature [K] & $\mathrm{I}-16$ & 1619 & 1620 \\
Total Temperature [K] & & 1679 & 1683 \\
Mass-weighted average & & & \\
Static Temperature [K] & 1625 & 1620 & 1621 \\
Total Temperature [K] & 1682 & 1682 & 1686 \\
\hline
\end{tabular}




\section{Medium Injector Length}

The injection length was the geometrical average between the large and small injectors used in the previous sections. As a result, the injector length was equal to $0.112 \mathrm{~mm}$. The mass flow rate of fuel per unit length is $0.133 \mathrm{~kg} / \mathrm{s}$.

Table 11 - Species mole fraction \% at $0.311 \mathrm{~m}$ downstream for case $3 \mathrm{~B} 1 \mathrm{using}$ the medium size injection

\begin{tabular}{ccccc}
\hline Parameter & Experimental & Centerline & $\begin{array}{c}\text { Area-weighted } \\
\text { average }\end{array}$ & $\begin{array}{c}\text { Mass-weighted } \\
\text { average }\end{array}$ \\
\hline $\mathrm{CH}_{4}$ & 0.35 & 0.0 & 0.15 & 0.15 \\
$\mathrm{CO}$ & 0.16 & 0.75 & 0.35 & 0.35 \\
$\mathrm{CO}_{2}$ & N.A. & 8.45 & 7.82 & 7.84 \\
$\mathrm{O}_{2}$ & N.A. & 0.61 & 2.85 & 2.80 \\
$\mathrm{H}_{2} \mathrm{O}$ & N.A. & 19.07 & 17.18 & 17.22 \\
\hline
\end{tabular}

Table 12 - Species mole fraction \% at $0.654 \mathrm{~m}$ downstream for case $3 \mathrm{~B} 1 \mathrm{using}$ the medium size injection.

\begin{tabular}{ccccc}
\hline Parameter & Experimental & Centerline & $\begin{array}{c}\text { Area-weighted } \\
\text { average }\end{array}$ & $\begin{array}{c}\text { Mass-weighted } \\
\text { average }\end{array}$ \\
\hline $\mathrm{CH}_{4}$ & 0.08 & 0.0 & $5.15 \mathrm{e}-04$ & $5.59 \mathrm{e}-04$ \\
$\mathrm{CO}$ & 0.27 & 0.0 & $3.37 \mathrm{e}-03$ & $3.65 \mathrm{e}-03$ \\
$\mathrm{CO}_{2}$ & N.A. & 8.62 & 8.34 & 8.36 \\
$\mathrm{O}_{2}$ & N.A. & 1.63 & 2.36 & 2.31 \\
$\mathrm{H}_{2} \mathrm{O}$ & N.A. & 18.09 & 17.53 & 17.57 \\
\hline
\end{tabular}

Table 13 - Temperature values for medium size injector, case 3B1. Experimental value at $0.836 \mathrm{~m}$ is $1478 \mathrm{~K}$.

\begin{tabular}{cccc}
\hline & $0.311 \mathrm{~m}$ & $0.654 \mathrm{~m}$ & $0.836 \mathrm{~m}$ \\
\hline Centerline & & & \\
Static Temperature [K] & 2208 & 2168 & 2109 \\
Total Temperature [K] & 2278 & 2257 & 2196 \\
Area-weighted average & & & \\
Static Temperature [K] & 2055 & 2104 & 2102 \\
Total Temperature [K] & 2112 & 2170 & 2172 \\
Mass-weighted average & & & \\
Static Temperature [K] & 2059 & 2108 & 2104 \\
Total Temperature [K] & 2118 & 2177 & 2175 \\
\hline
\end{tabular}



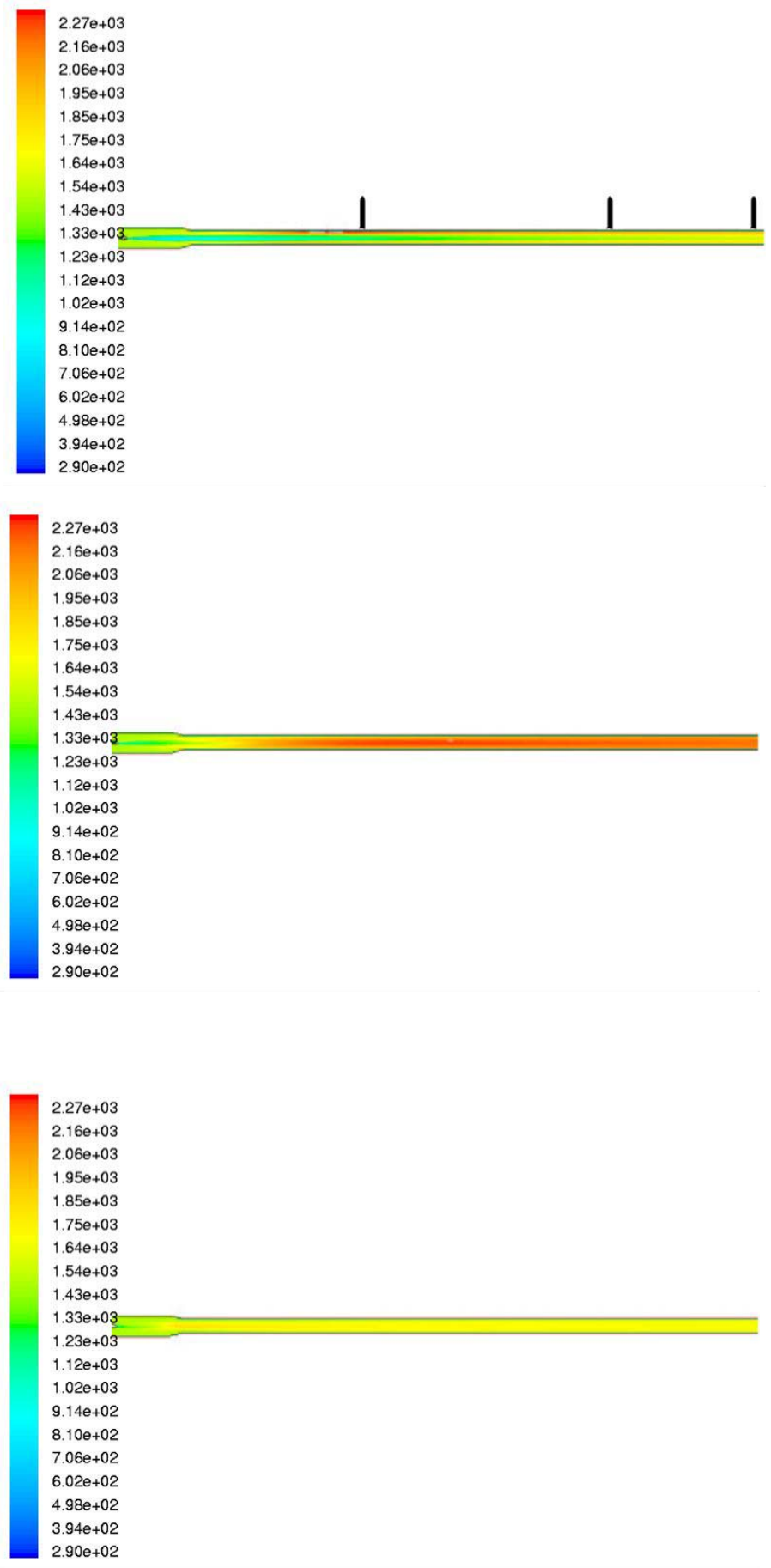

Figure 3 - Total temperature contours for case 3B1. Top: large width, middle: medium width, bottom: small width injector. 


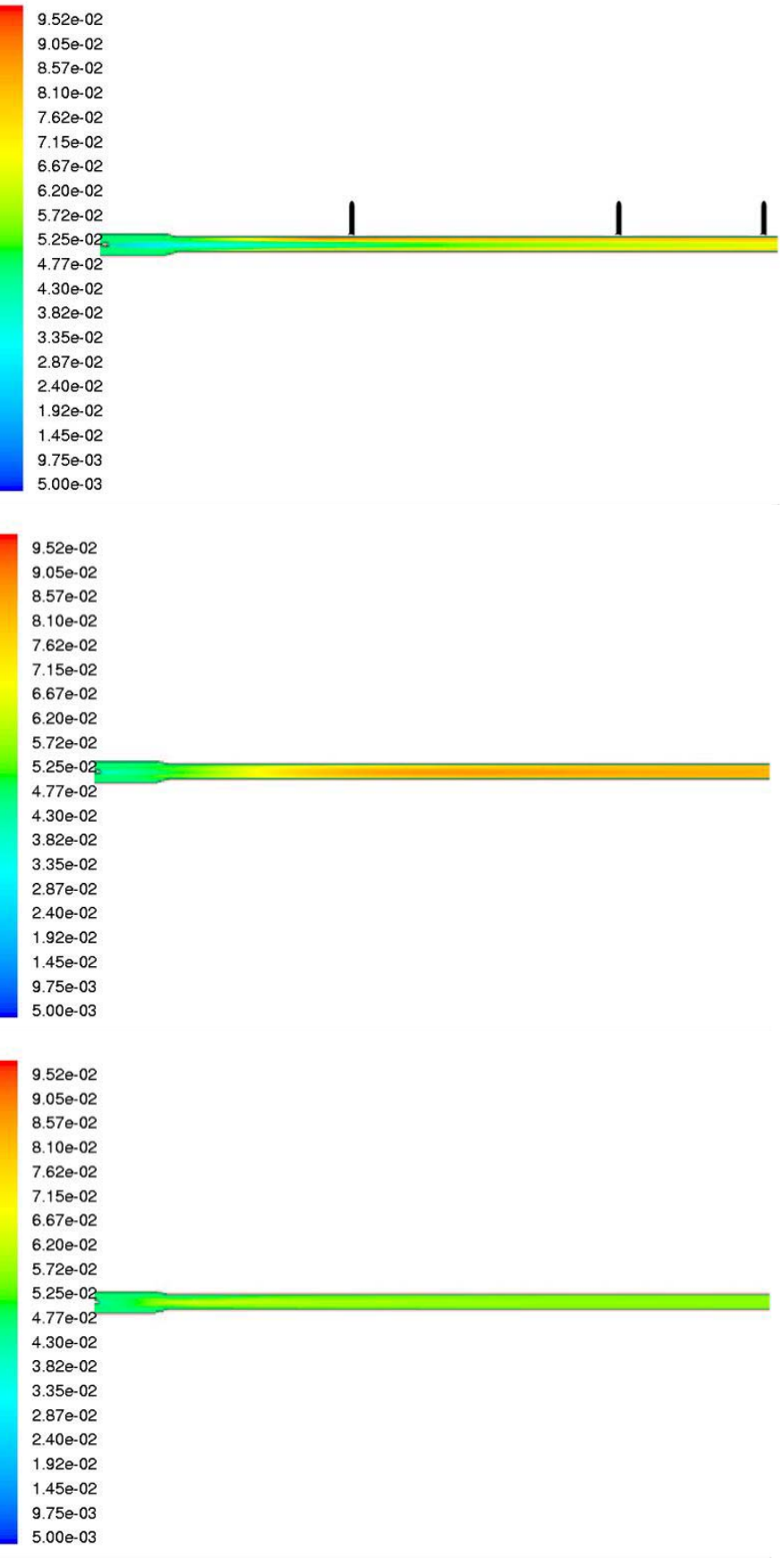

Figure 4 -Mole fraction contours for case 3B1. Top: large width, middle: medium width, bottom: small width injector.

The larger injector introduced too much fuel and combustion conditions existed only along the walls. Most of the middle portion of the tube did not react. Consequently, not all the fuel was burned, as shown in Figure 5.

The medium injector produced the largest temperature increase. The flame was situated in the middle of the tube. All the methane was burned, as shown in Figure 5. 
The small injector produced the smallest temperature increase. The flame was situated at the inlet in the sample section, that is, the 0.7 in by 0.7 in tube. All the methane was burned upstream of the $0.311 \mathrm{~m}$ location, as shown in Figure 5.
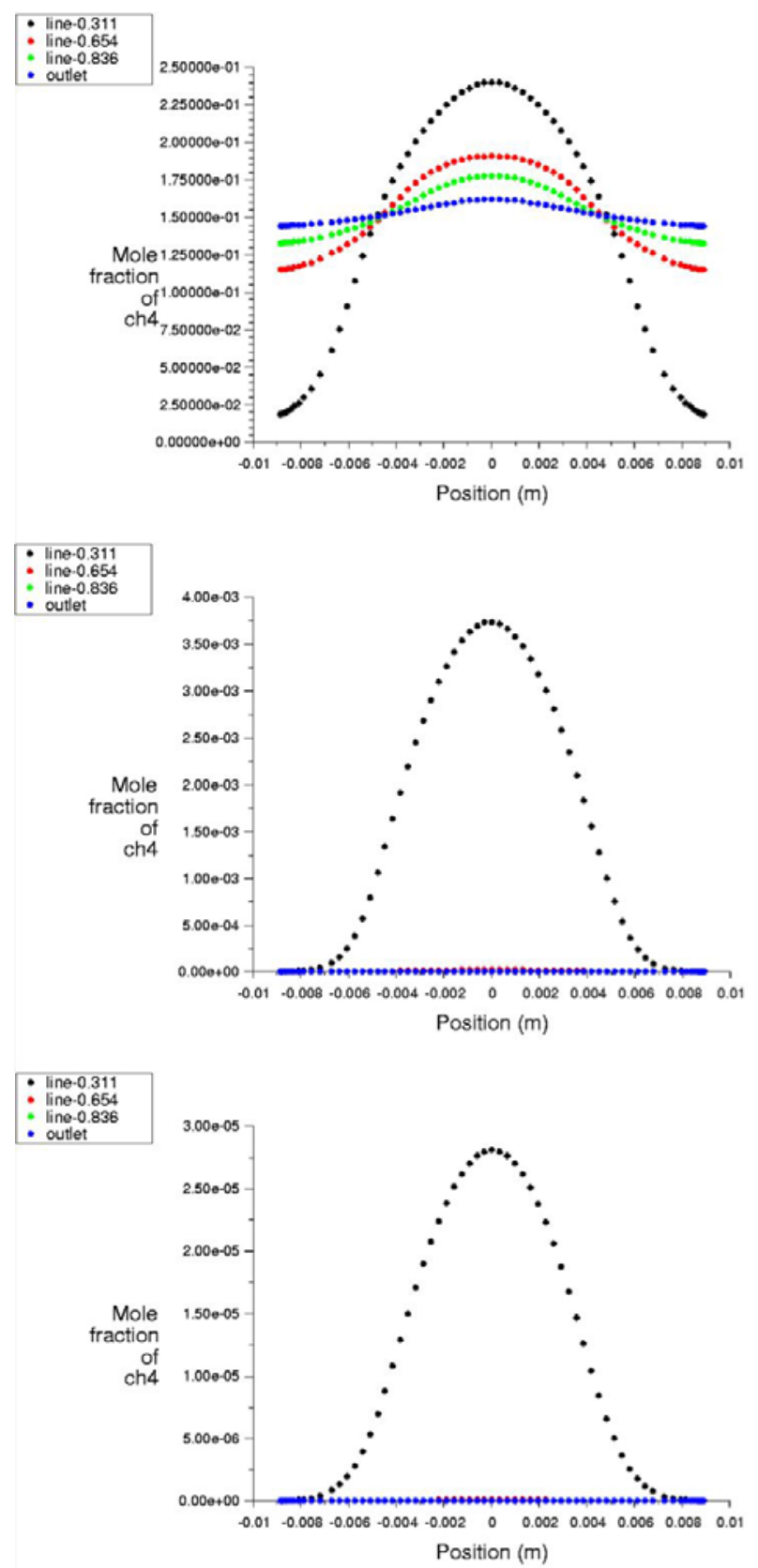

Figure 5 - Methane mole fraction at several locations along the sample section. Top: large width, middle: medium width, bottom: small width injector.

\subsubsection{Case 4B2}

The parameters at fuel injection location are: temperature, $T=289 \mathrm{~K}$, pressure, $p=5.79 \mathrm{bar}$, molecular mass, $M=16.24 \mathrm{~kg} / \mathrm{kmol}$, fuel density, $\rho=3.914 \mathrm{~kg} / \mathrm{m} 3$, and velocity, $V=$ $394.3 \mathrm{~m} / \mathrm{s}$. Two cases were considered in the numerical simulation: (1) the length of the injector equal to the diameter of the hole, that is, $0.66 \mathrm{~mm}$, and (2) the length of the injector 
equal to the area of the hole from the experiment divided by the height of the tube ( $0.7 \mathrm{in})$, that is, $0.019 \mathrm{~mm}$. A good two-dimensional approximation of the three-dimensional solution is situated in between the two injector lengths. Note that the small length injector is just a model and not an engineering solution.

\section{Large Injector Length}

The length of the injector in this case was equal to the diameter of the injector hole, that is, $0.66 \mathrm{~mm}$. The mass flow rate of fuel per unit length is $1.018 \mathrm{~kg} / \mathrm{s}$.

Table 14 - Species mole fraction $\%$ at $0.765 \mathrm{~m}$ downstream for case 4B2

\begin{tabular}{ccccc}
\hline Parameter & Experimental & Centerline & $\begin{array}{c}\text { Area-weighted } \\
\text { average }\end{array}$ & $\begin{array}{c}\text { Mass-weighted } \\
\text { average }\end{array}$ \\
\hline $\mathrm{CH}_{4}$ & 0.45 & 16.00 & 15.43 & 15.50 \\
$\mathrm{CO}$ & 0.17 & 0.02 & 0.02 & 0.02 \\
$\mathrm{CO}_{2}$ & N.A. & 3.76 & 3.84 & 3.84 \\
$\mathrm{O}_{2}$ & N.A. & 9.07 & 9.22 & 9.21 \\
$\mathrm{H}_{2} \mathrm{O}$ & N.A. & 8.17 & 8.35 & 8.34 \\
\hline
\end{tabular}

Table 15 - Species mole fraction $\%$ at 1.059 m downstream for case 4B2

\begin{tabular}{ccccc}
\hline Parameter & Experimental & Centerline & $\begin{array}{c}\text { Area-weighted } \\
\text { average }\end{array}$ & $\begin{array}{c}\text { Mass-weighted } \\
\text { average }\end{array}$ \\
\hline $\mathrm{CH}_{4}$ & 0.41 & 15.00 & 15.49 & 15.50 \\
$\mathrm{CO}$ & 0.18 & 0.019 & 0.019 & 0.02 \\
$\mathrm{CO}_{2}$ & N.A. & 3.79 & 3.85 & 3.84 \\
$\mathrm{O}_{2}$ & N.A. & 9.19 & 9.21 & 9.21 \\
$\mathrm{H}_{2} \mathrm{O}$ & N.A. & 8.27 & 8.35 & 8.34 \\
\hline
\end{tabular}

Table 16 - Temperature values at requested locations for case 4B2. Experimental value at $0.84 \mathrm{~m}$ is $1252 \mathrm{~K}$.

\begin{tabular}{cccc}
\hline & $0.765 \mathrm{~m}$ & $0.840 \mathrm{~m}$ & $1.059 \mathrm{~m}$ \\
\hline Centerline & & & \\
Static Temperature [K] & 1049 & 1049 & 1059 \\
Total Temperature [K] & 1108 & 1108 & 1129 \\
Area-weighted average & & & \\
Static Temperature [K] & 1078 & 1076 & 1071 \\
Total Temperature [K] & 1126 & 1126 & 1125 \\
Mass-weighted average & & & \\
Static Temperature [K] & 1076 & 1075 & 1071 \\
Total Temperature [K] & 1125 & 1126 & 1126 \\
\hline
\end{tabular}

\section{$\underline{\text { Small Injector Length }}$}

The length of the injector in this case was equal to the area of the injector hole from the experiment divided by the height of the tube $(0.7 \mathrm{in})$, that is, $0.019 \mathrm{~mm}$. The mass flow rate of fuel per unit length is $0.029 \mathrm{~kg} / \mathrm{s}$. 
Table 17 - Species mole fraction $\%$ at $0.765 \mathrm{~m}$ downstream for case 4B2

\begin{tabular}{ccccc}
\hline Parameter & Experimental & Centerline & $\begin{array}{c}\text { Area-weighted } \\
\text { average }\end{array}$ & $\begin{array}{c}\text { Mass-weighted } \\
\text { average }\end{array}$ \\
\hline $\mathrm{CH}_{4}$ & 0.45 & 0.0 & $1.58 \mathrm{e}-04$ & $1.73 \mathrm{e}-04$ \\
$\mathrm{CO}$ & 0.17 & $2.7 \mathrm{e}-03$ & $1.02 \mathrm{e}-03$ & $1.12 \mathrm{e}-03$ \\
$\mathrm{CO}_{2}$ & N.A. & 5.31 & 5.30 & 5.31 \\
$\mathrm{O}_{2}$ & N.A. & 8.96 & 9.11 & 9.10 \\
$\mathrm{H}_{2} \mathrm{O}$ & N.A. & 11.57 & 11.51 & 11.52 \\
\hline
\end{tabular}

Table 18 - Species mole fraction $\%$ at 1.059 m downstream for case $4 \mathrm{~B} 2$

\begin{tabular}{ccccc}
\hline Parameter & Experimental & Centerline & $\begin{array}{c}\text { Area-weighted } \\
\text { average }\end{array}$ & $\begin{array}{c}\text { Mass-weighted } \\
\text { average }\end{array}$ \\
\hline $\mathrm{CH}_{4}$ & 0.41 & 0.0 & $2.71 \mathrm{e}-07$ & $2.95 \mathrm{e}-07$ \\
$\mathrm{CO}$ & 0.18 & 0.0 & $3.25 \mathrm{e}-06$ & $3.54 \mathrm{e}-06$ \\
$\mathrm{CO}_{2}$ & N.A. & 05.31 & 05.31 & 05.31 \\
$\mathrm{O}_{2}$ & N.A. & 09.07 & 09.10 & 09.10 \\
$\mathrm{H}_{2} \mathrm{O}$ & N.A. & 11.45 & 11.51 & 11.52 \\
\hline
\end{tabular}

Table 19 - Temperature values at requested locations for case 4B2. Experimental value at $0.84 \mathrm{~m}$ is $1252 \mathrm{~K}$.

Centerline

$0.765 \mathrm{~m} \quad 0.840 \mathrm{~m} \quad 1.059 \mathrm{~m}$

$\begin{array}{cccc}\text { Static Temperature [K] } & 1467 & 1467 & 1454 \\ \text { Total Temperature [K] } & 1543 & 1543 & 1543 \\ \text { Area-weighted average } & & & \\ \text { Static Temperature [K] } & 1467 & 1465 & 1460 \\ \text { Total Temperature [K] } & 1532 & 1532 & 1532 \\ \text { Mass-weighted average } & & & \\ \text { Static Temperature [K] } & 1467 & 1466 & 1460 \\ \text { Total Temperature [K] } & 1534 & 1534 & 1534\end{array}$

\subsection{Three-Dimensional Model}

This section presents the validation of the combustion model against the experimental data for a single-vane burner using a three-dimensional flow and combustion model. 


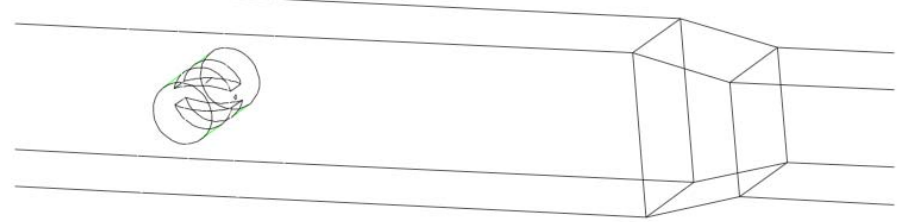

\section{1.}

Figure 6 -Detail of the computational domain of the single-vane burner.

The computational domain extended $0.115 \mathrm{~m}$ upstream from the vane injection location and $1.071 \mathrm{~m}$ downstream. A detail of the computational domain is shown in Figure 6. The shape of the vane burner was defined by the intersection of two radii. The injection hole had a diameter of $0.66 \mathrm{~mm}$. The injection hole was located at the center of the pipe, however, the shoulders of the vane were not equally-spaced with respect to the injection hole. A detail of the computational grid of the single-vane burner is shown in Figure 7.

Wall functions were utilized to reduce the number of grid points in the boundary layer regions. Consequently, the number of grid cells was limited to approximately 2.2 million. The grid is unstructured and was generated with Gambit.

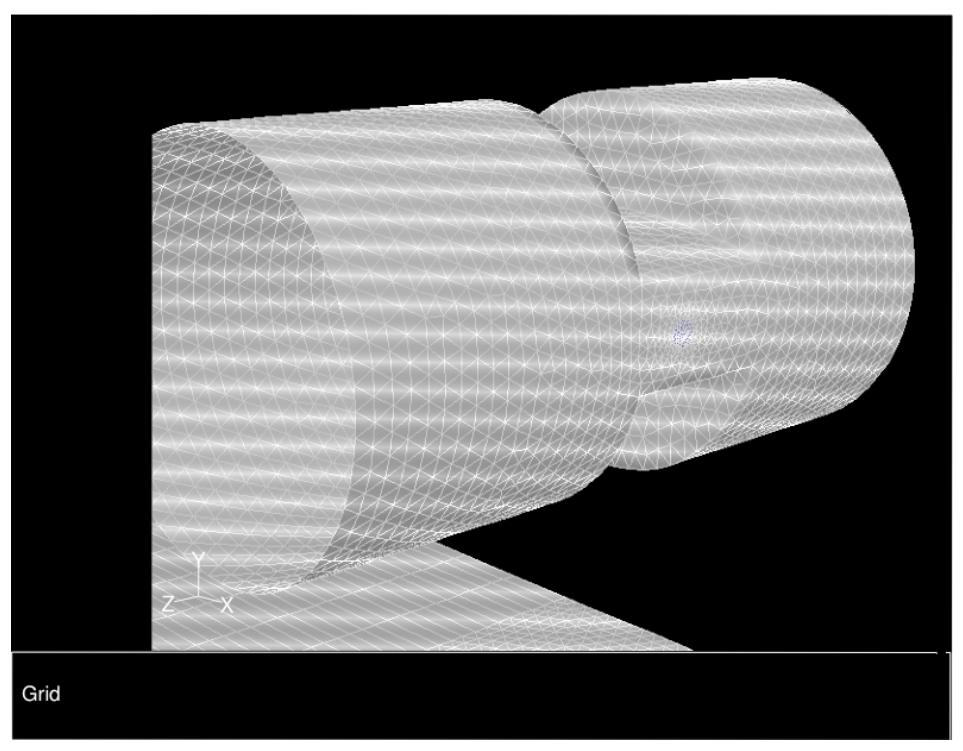

Figure 7 - Detail of the single-vane burner grid.

The chemistry model used to simulate the in situ reheat was the two-step finite rate combustion model for methane and combustion gases described by equations 2 and 3 . The 
flow and combustion in the single-vane burner were modeled with Fluent as opposed to the four-stage turbine-burner which was modeled with the CoRSI code described in the previous sections. Both Fluent and CoRSI codes had an identical chemistry model.

At the inlet in the computational domain, upstream from the injection vane, the input data specified total pressure, initial static pressure, total temperature, turbulence intensity, hydraulic diameter, and the composition of the gas mixture, as shown in . The input data at the injector location specified the same list of variables as at inlet. The values of these variables are also shown in

. Note that the small quantities of ethane and propane were lumped into methane in order to be able to use the two-reaction model presented above. The mass fraction of $N_{2}$ is not an input data for the problem. The value of the $N_{2}$ is calculated such that the sum of all mass fraction species equals 1. At the outlet, the static pressure value of $4.6 \mathrm{bar}$ was specified.

Table 20 - Input data for the vane-burner.

\begin{tabular}{lll}
\hline Parameter & Inlet & Injection \\
\hline Total pressure [ bar ] & 6.26 & 7.95 \\
Initial static pressure [ bar ] & 5.93 & 5.84 \\
Total temperature [ $\mathrm{K}$ ] & 1507 & 311 \\
Turbulence intensity [\%] & 10 & 10 \\
Hydraulic diameter [ $\mathrm{m}$ ] & 0.0254 & 0.00066 \\
Mass fraction & & \\
$\mathrm{CH}_{4}$ & 0.0 & 0.9778 \\
$\mathrm{O}_{2}$ & 0.115 & 0.0 \\
$\mathrm{CO}_{2}$ & 0.0754 & 0.01355 \\
$\mathrm{CO}_{\mathrm{H}} \mathrm{O}$ & 0.0 & 0.0 \\
$\mathrm{~N}_{2}$ & 0.06755 & 0.0 \\
\hline
\end{tabular}

The results shown herein illustrate the spatial variation of methane, $\mathrm{CO}_{2}$ and total temperature. Figure 8 shows the variation of methane along the $z=0$ plane of the combustor and at four planes perpendicular to the $x$-axis located at 12, 15, 20 and $35 \mathrm{~mm}$ downstream of the injector. The methane completely burned at approximately $70 \mathrm{~mm}$ downstream of the injector. Figure 9 shows methane variation in the four planes described above. The lack of symmetry of the methane contour plots is due to the lightly off-center position of the vane. All other variables show a similar lack of symmetry. 


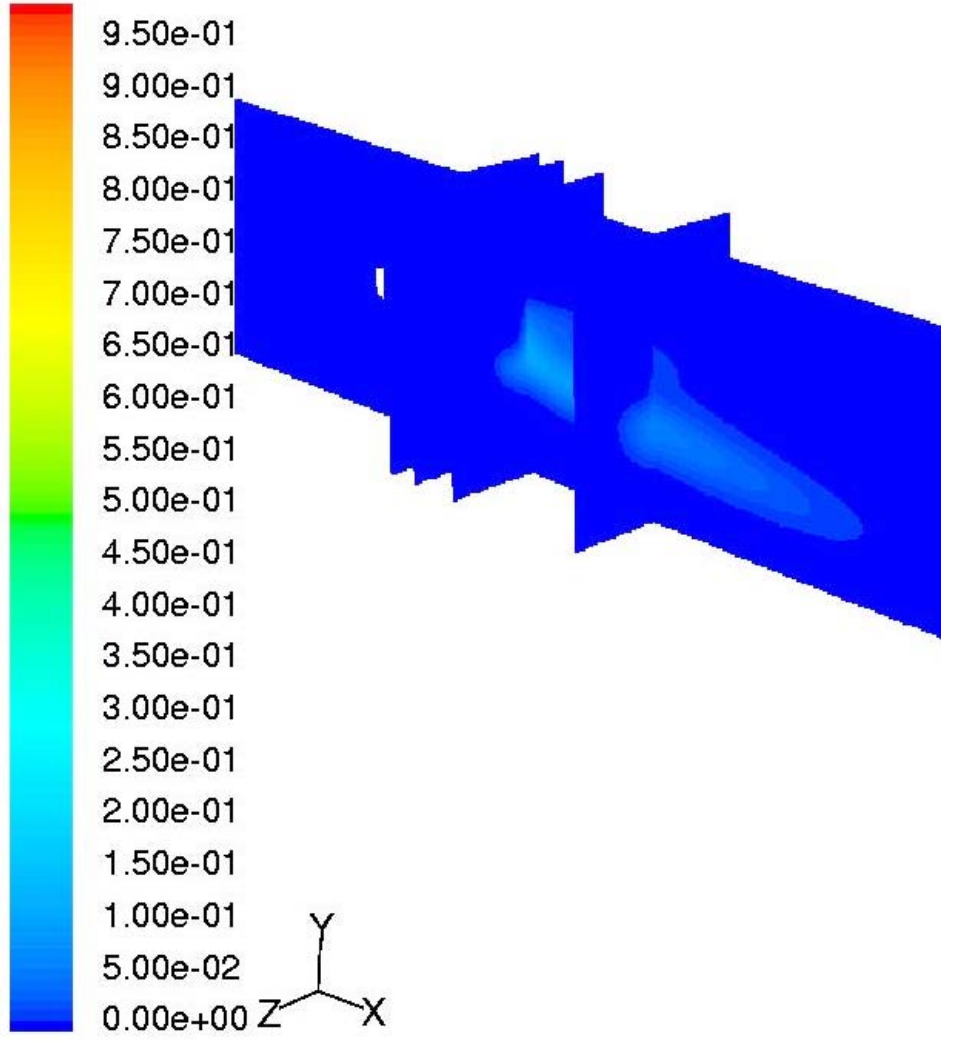

Figure 8 - Contour plots of methane.

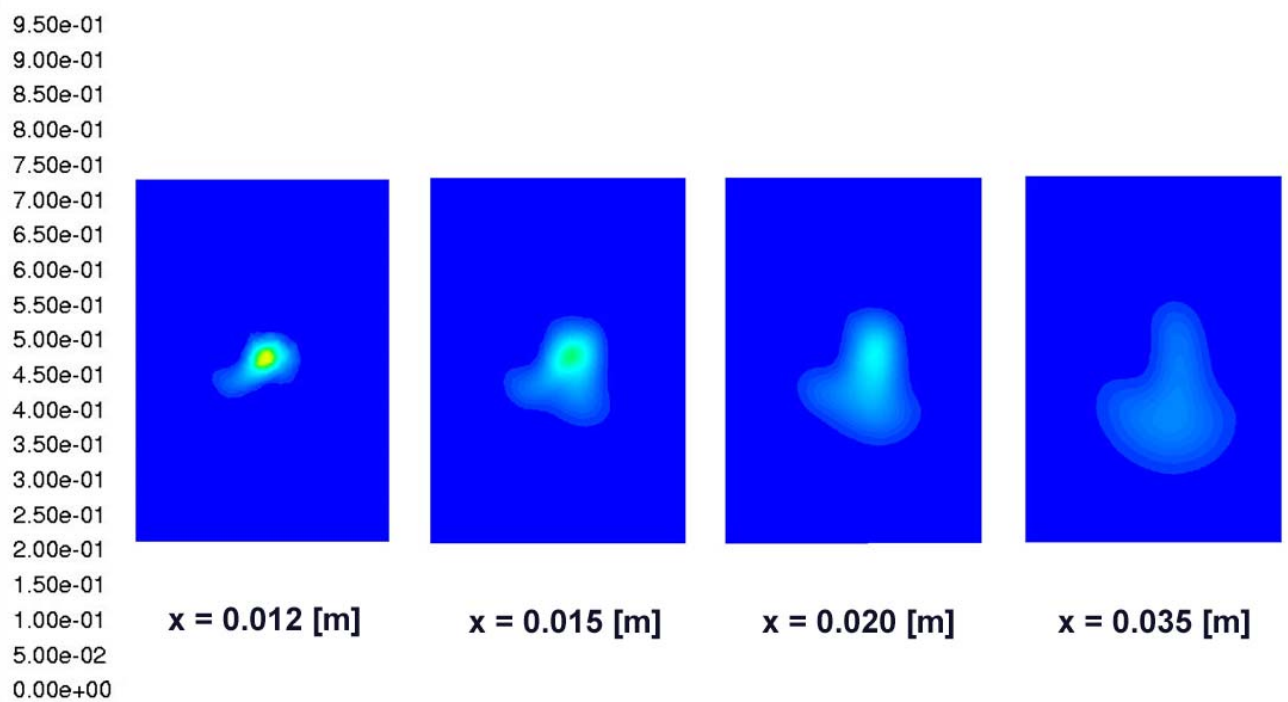

Figure 9 - Contour plots of methane at $x=$ constant planes. 


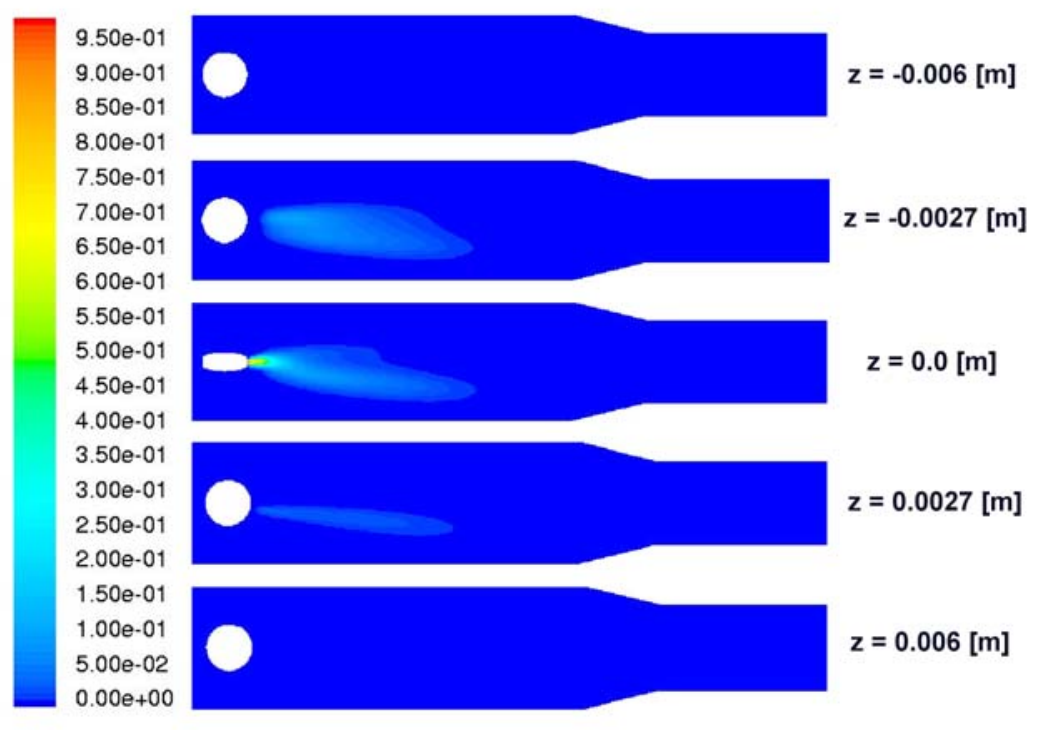

Figure 10 - Methane mole fraction z-plane contour plots. The $z=0.0$ is the same as shown in Figure 8.

Figure 11 shows the variation of $C O$ along the $z=0$ plane of the combustor and at five planes perpendicular to the $x$-axis located at 12, 35, 45, 79 and $94 \mathrm{~mm}$ downstream of the injector. The flame is off-center and closer to the lower wall. Figure 12 shows $C O$ variation in the five planes described above. Note that the last plane, located at $94 \mathrm{~mm}$ downstream of the injector, is situated in the smaller section part of the pipe $(0.7$ in by $0.7 \mathrm{in})$.

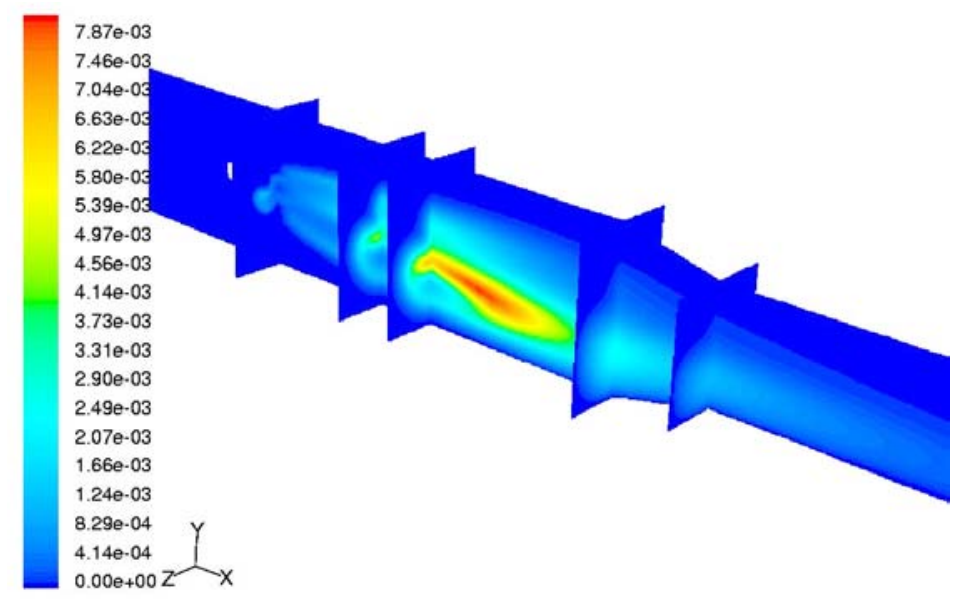

Figure 11 - Contour plots of $C O$. 


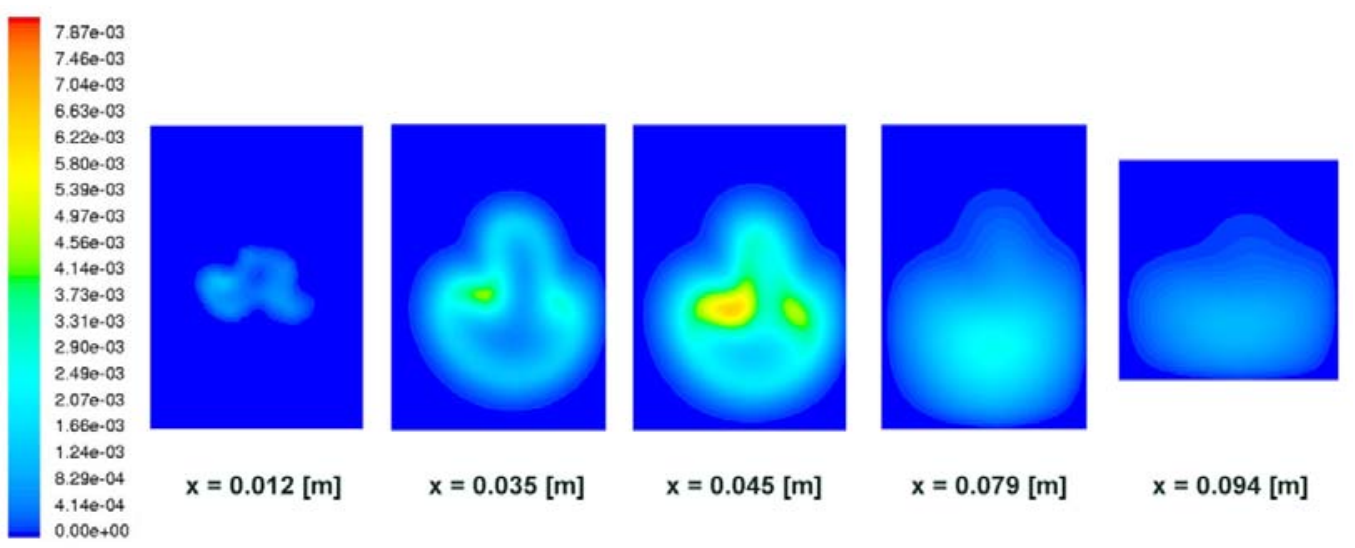

Figure 12 - Contour plots of $C O$ at $x=$ constant planes.

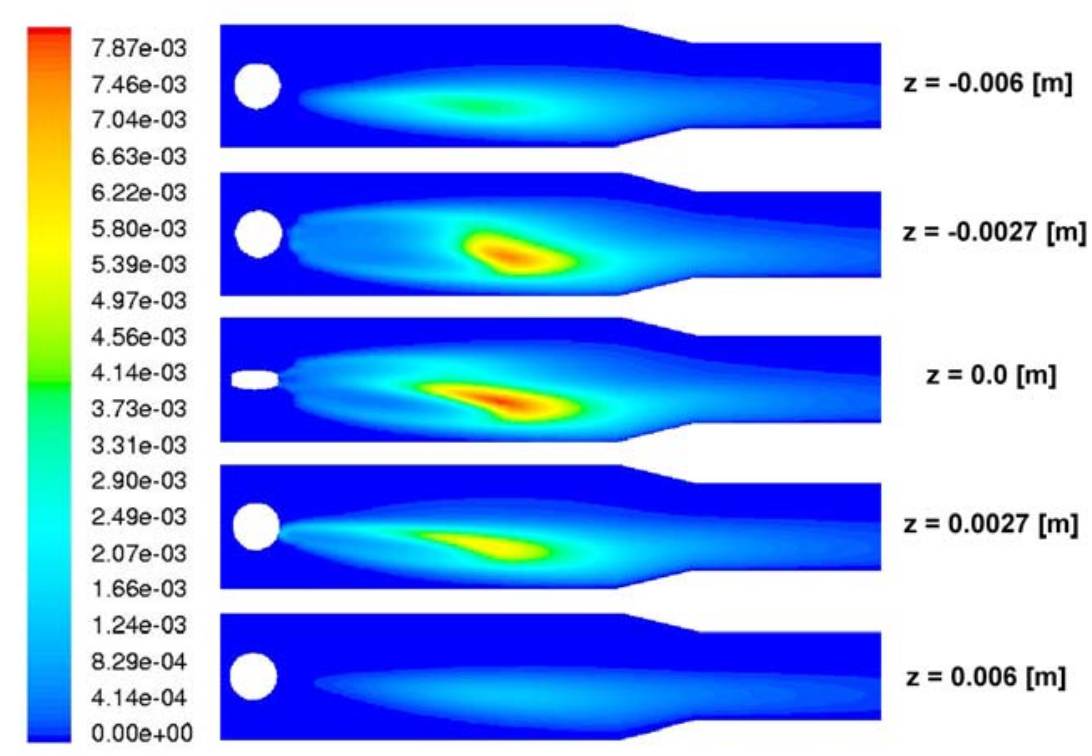

Figure 13 - Carbon monoxide mole fraction $z$-plane contour plots. The $z=0.0$ is the same as shown in Figure 11.

Figure 14 shows the variation of total temperature along the $z=0$ plane of the combustor and at five planes perpendicular to the $x$-axis located at 12,35, 79, 94 and $120 \mathrm{~mm}$ downstream of the injector. The maximum total temperature is approximately $1970 \mathrm{~K}$. Figure 15 shows total temperature variation in the five planes described above. The static temperature predicted by the numerical simulation at the centerline at $836 \mathrm{~mm}$ downstream of the injector is $1536 \mathrm{~K}$. The measured temperature at the same location is $1478 \mathrm{~K}$. The predicted temperature is $58 K$ higher than the measured temperature. There are several possible reasons for the temperature difference, such as: (1) simplified kinetic scheme, (2) limitations of the turbulence model, and (3) limitations due to using binary diffusion coefficients. In our opinion, the most important (and likely) reason for the $58 \mathrm{~K}$ temperature difference is the use of adiabatic boundary conditions that neglected the heat transfer at the wall surface. The gas chromatograph found small traces of $\mathrm{CH}_{4}(0.35 \%)$ and $\mathrm{CO}(0.16 \%)$ at $0.311 \mathrm{~m}$ downstream of the injector. The numerical simulation predicted values close to zero (smaller than $10^{-4} \%$ ) for both $\mathrm{CH}_{4}$ and $\mathrm{CO}$ at the same location. 
The numerical simulation was done on an IBM Regatta pSeries 690 computer using 4 processors. The computation converged in approximately 3,500 iterations. The wall clock time for this run was approximately 195 hours.

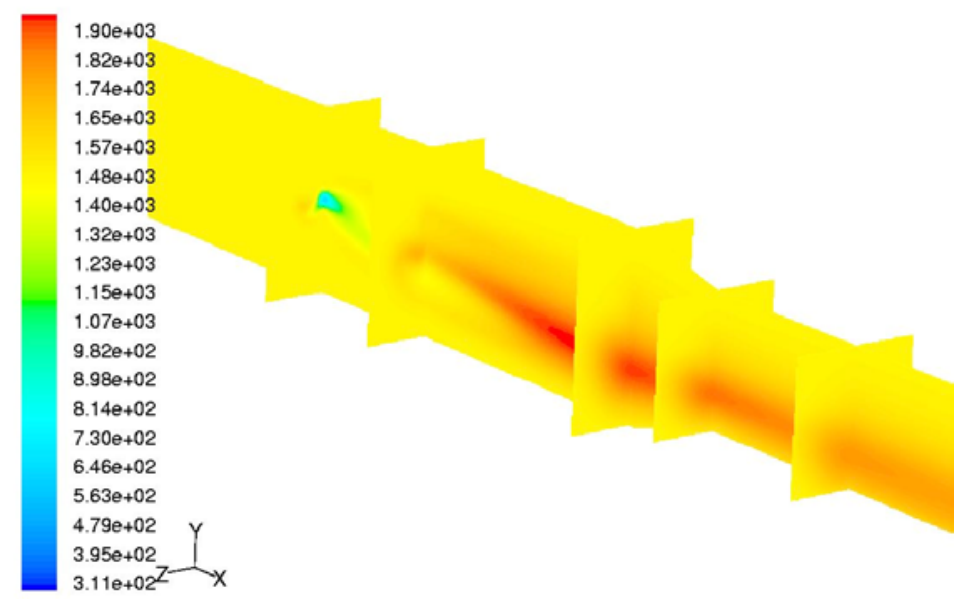

Figure 14 - Contour plots of total temperature.
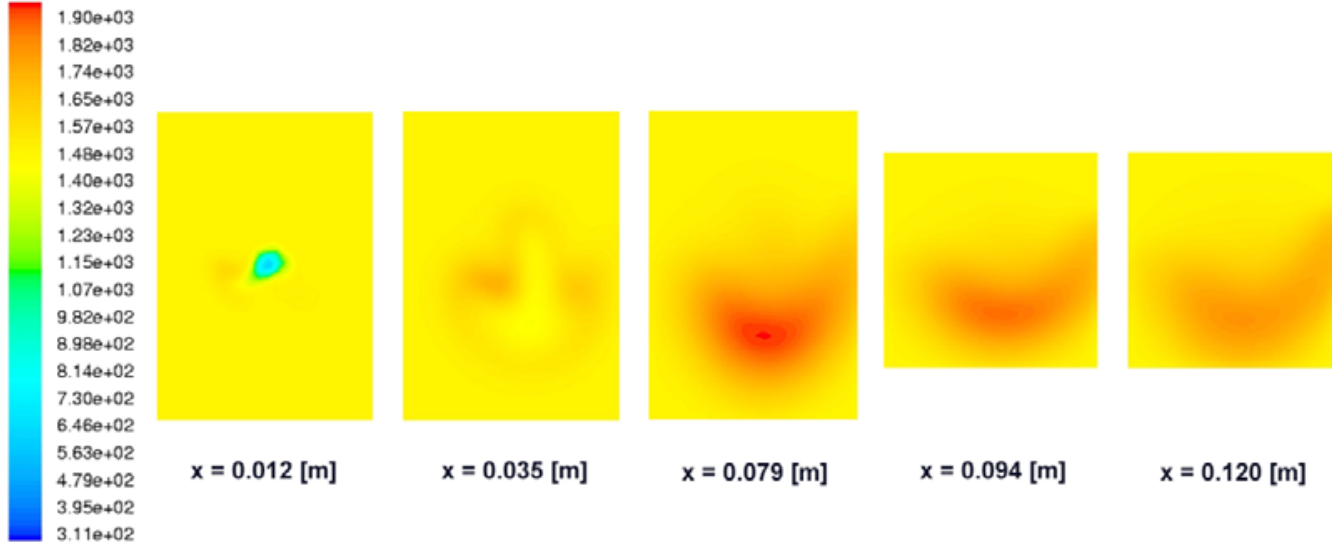

Figure 15 - Contour plots of total temperature at $x=$ constant planes. 


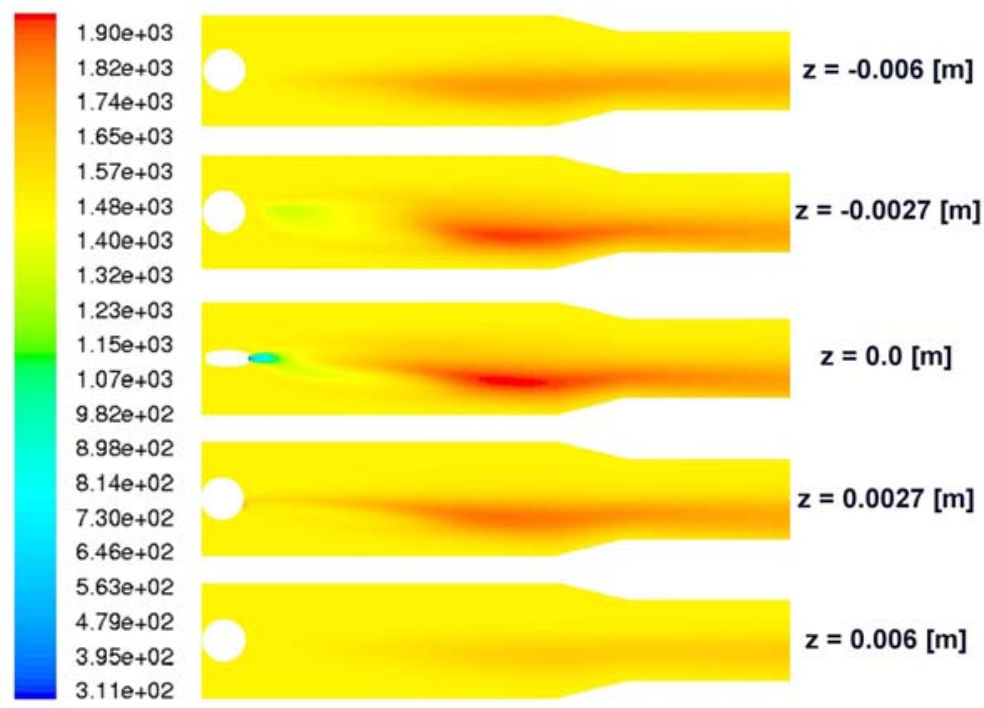

Figure 16 - Total temperature z-plane contour plots. The $z=0.0$ is the same as shown in Figure 14. 


\section{INDUSTRIAL GAS TURBINE SIMULATION}

This section presents the numerical simulation of in situ reheat in four- and a five-stage large industrial gas turbines. The numerical simulation included both in situ reheat cases and a case without combustion. The flow in the turbine without combustion was simulated first in order to provide reference values, particularly the power and the fuel injection pressure at the trailing edge of the inlet guide vane. The simulations use blade path dimensions and shapes representative of a large industrial gas turbine.

\subsection{Approach}

Once the combustion model was validated for the single-vane burner, the next step was to investigate a four-stage turbine-burner. The purpose of this numerical investigation was to determine the influence of several fuel injection parameters on the flow and combustion in the turbine-burner. Since the computational time of a three-dimensional model for the four-stage turbine-burner would exceed the computational time of the single-vane burner by a factor of four, and since a parametric analysis of the turbine-burner was necessary, it was decided to replace the three-dimensional model by a less computational expensive quasi-three-dimensional model. A quasi-three-dimensional, as opposed to a two-dimensional model, was needed in order to take into account the large radial variation of the four-stage turbine. Since Fluent does not have a quasi-threedimensional model, the CoRSI code was used instead.

\subsection{Geometry and Flow Conditions}

The blade count of the four-stage turbine-combustor required a full-annulus simulation for a dimensionally accurate computation. To reduce the computational effort, it was assumed that there were an equal number of airfoils in each turbine row. As a result, all airfoils except for the inlet guide vane airfoils were rescaled by factors equal to the number of airfoils per row divided by the number of airfoils per row one. An investigation of the influence of airfoil count on the turbine flow showed that the unsteady effects were amplified when a simplified airfoil count 1:1 was used [1]. Consequently, the results obtained using the simplified airfoil count represent an upper limit for the unsteady effects.

\subsection{Accuracy of Numerical Results}

To validate the accuracy of the numerical results corresponding to the governing equations used, it was necessary to show that the results were independent of the grid which discretizes the computational domain. The verification of grid independence results was presented in [2], where a one-stage turbine-combustor was simulated. Note that the grids were generated such that, for the given flow conditions, the $y^{+}$number was less than 1 . Approximately 20 grid points were used to discretize the boundary layer regions.

Based on the conclusions of accuracy investigation presented in [2], the medium grid was used herein since it provided the best compromise between accuracy and computational cost. This grid had 53 grid points normal to the airfoil and 225 grid points along the airfoil in the O-grid, and 75 grid points in the axial direction and 75 grid points in the circumferential direction in the $\mathrm{H}$-grid. The stator airfoils and rotor airfoils had the same number of grid points. The inlet and outlet $\mathrm{H}$-grids each had 36 grid points in the axial direction and 75 grid points in the circumferential direction. The grid is shown in Figure 17, where for clarity every other grid point in each direction is shown. 


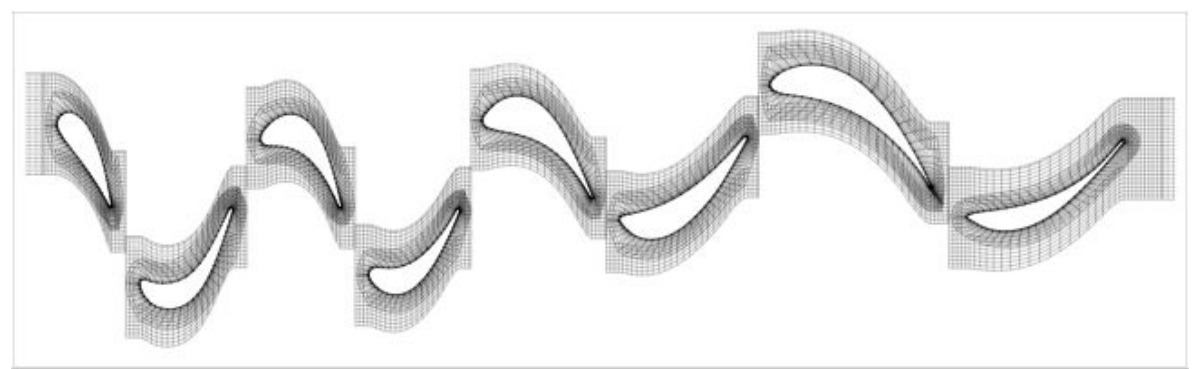

Figure 17 - Detail of the medium grid (every other grid point in each direction shown).

The results presented in this report were computed using three Newton sub-iterations per time-step and 3000 time-steps per cycle. Here, a cycle is defined as the time required for a rotor to travel a distance equal to the pitch length at mid-span. To ensure time-periodicity, each simulation was run in excess of 80 cycles. The numerical simulations were run on a 64processor SGI Origin 3800 computer, a 32-processor IBM Regatta pSeries 690 computer and a Power Mac G5 computer. The computational time for a cycle was approximately 2.5 hours on a Power Mac G5 computer. Approximately 50 cycles are necessary to obtain a converged solution.

\subsection{Run Set 1}

The species mass fractions of the gas mixture at the inlet were:

$$
\begin{aligned}
X_{\mathrm{CH}_{4}} & =0.0 \\
X_{\mathrm{CO}_{2}} & =0.0775 \\
X_{\mathrm{CO}} & =5.979 \times 10^{-6} \\
X_{\mathrm{H}_{2} \mathrm{O}} & =0.0680 \\
X_{\mathrm{N}_{2}} & =0.7288 \\
X_{\mathrm{O}_{2}} & =0.1131 \\
X_{A r} & =0.0124 \\
X_{\mathrm{H}_{2}} & =2.536 \mathrm{\times} \times 10^{-7}
\end{aligned}
$$

for all cases with and without combustion. The inlet flow parameters were: the static temperature $T_{-\infty}=1840 \mathrm{~K}$, the static pressure $p_{-\infty}=18.6621 \mathrm{bar}$, the axial Mach number $M_{-\infty}=0.1528$ and the inlet flow was axial. The resulting inlet Reynolds number based on the first vane axial chord was $R e_{-\infty}=825,235$. At the exit, the static pressure $p_{\text {exit }}$ was imposed through the ratio $p_{\text {exit }} / p_{-\infty}^{*}=0.054$, where $p_{-\infty}^{*}$ is the total inlet pressure. The turbine speed was equal to 3,600 rpm and the stream surface for the two-dimensional calculations was taken at the midspan radius of $1.025 \mathrm{~m}$. The stream tube thickness variation was considered in order to incorporate quasi-three-dimensional effects. The mass flow rate of gases at turbine inlet was $88.085 \times 10^{-3} \mathrm{~kg} / \mathrm{s}$ per vane and per mm of vane span. 


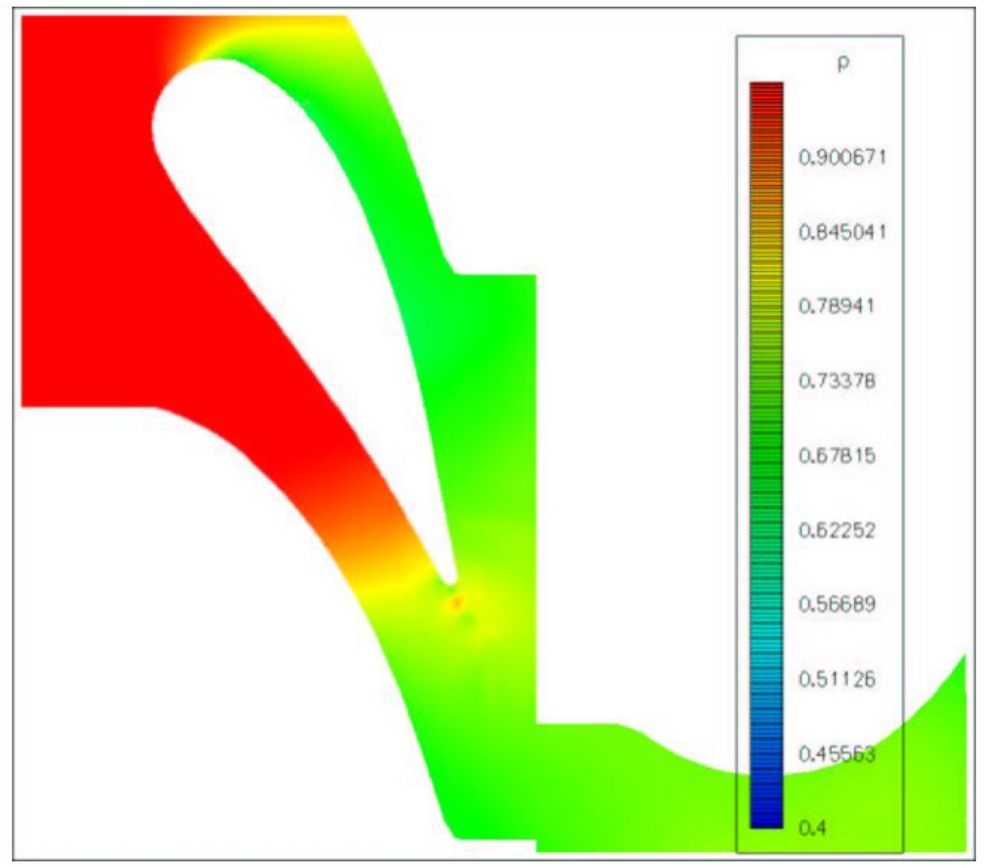

Figure 18 - Static pressure on first row of vanes in the case without combustion.

The base case for the fuel injection simulations is designated as C1Y and involves a low temperature, low fuel flow injection of pure methane at the trailing edge of each vane in the first row, with a jet oriented along its chord. At the injection hole the imposed static temperature, injection velocity and methane mass concentration were $T_{\text {hole }}=313 \mathrm{~K}$, $V_{\text {hole }}=77.32 \mathrm{~m} / \mathrm{s}$ and $X_{\mathrm{CH}_{4}}=1.0$, respectively. An equivalent hole width of $0.55 \mathrm{~mm}$ was considered which is the physical hole width corrected for the injection velocity nonuniformity. The static pressure at fuel injection location was assumed equal to the static pressure in the case without combustion, $p_{\text {hole }}=14.88$ bar. The pressure variation for the case without combustion is shown in Figure 18. The mass flow of injected methane per mm vane span and vane for case $\mathrm{C} 1 \mathrm{Y}$ was $\dot{w}_{\mathrm{CH}_{4}}=0.4846 \times 10^{-3} \mathrm{~kg} / \mathrm{s} / \mathrm{mm} / \mathrm{vane}$.

Case C1YHF had the same parameters as case C1Y, except for the injection velocity which was $V_{\text {hole }}=270.6 \mathrm{~m} / \mathrm{s}$. Case C5TYHF had the same parameters as C1YHF except for the fuel temperature that was $T_{\text {hole }}=590 \mathrm{~K}$. Case C1YMA had the same parameters as case C1Y except that the fuel injection velocity was deflected $60 \mathrm{deg}$ toward the pressure side. Case $\mathrm{C} 1 \mathrm{YHL}$ had the same parameters as case $\mathrm{C} 1 \mathrm{Y}$ except that the injection length was $1.36 \mathrm{~mm}$. The parameters of the five cases presented above are summarized in Table 20. 


\begin{tabular}{llllll}
\hline Parameter & C1Y & C1YHF & C5TYHF & C1YMA & C1YHL \\
\hline Injection velocity [m/s] & 77 & 270.6 & 270.6 & 77 & 77 \\
Pressure [bar] & 14.88 & 14.88 & 14.88 & 14.88 & 14.88 \\
Temperature [K] & 313 & 313 & 590 & 313 & 313 \\
Injection slot size [mm] & 0.55 & 0.55 & 0.55 & 0.55 & 1.36 \\
Fuel velocity incidence [deg ] & 0 & 0 & 0 & 60 & 0 \\
\hline
\end{tabular}

Table 20 - Parameters of Fuel Injection.

The power increase due to in situ reheat varied between $0.3 \%$ and $4.9 \%$, as shown in Table 21. The largest power increase corresponded to the largest mass flow rate of fuel, $W_{\mathrm{CH} 4}=13.5 \times 10^{-4} \mathrm{~kg} / \mathrm{s}$ per vane and mm length of vane. The smallest power increase corresponded to the smallest mass flow rate of fuel, $W_{C H 4}=1.9 \times 10^{-4} \mathrm{~kg} / \mathrm{s}$ per vane and $\mathrm{mm}$ length of vane. Note that the correlation between the fuel mass flow rate and the power increase (and implicit temperature increase) is different from the results obtained on the combustion probe.

\begin{tabular}{llllll}
\hline & C1Y & C1YHF & C5TYHF & C1YMA & C1YHL \\
\hline $\begin{array}{l}\text { Fuel mass flow rate } \\
\left.\quad 3 \times 10^{-4} \mathrm{~kg} / \mathrm{s} / \mathrm{vane} / \mathrm{mm}\right]\end{array}$ & 3.8 & 13.5 & 7.2 & 1.9 & 9.6 \\
$\begin{array}{l}\text { Power increase [\%] } \\
\text { Power }\end{array}$ & 0.8 & 4.9 & 3.9 & 0.3 & 3.1 \\
\hline
\end{tabular}

\section{Table 21 - Power Increase.}

The variation of total enthalpy for the three in situ reheat cases and for the no combustion case is shown in Figure 19. For clarity, only three combustion cases C1YHF, C5TYHF and C1YHL are shown. The abscissa indicates the axial location. S1 denotes stator 1, R1 denotes rotor 1, etc. The total enthalpy is calculated at inlet and outlet of each row. Depending on the row type, that is, stator or rotor, the total enthalpy is calculated using either the absolute or the relative velocity. The switch between using absolute or relative velocities generates discontinuities between rows. As shown in Figure 19, for all fuel injection cases the total enthalpy increases compared to the no combustion case. The largest enthalpy increase is located on the first rotor, where most of the combustion takes place. The combustion and heat release continue throughout the second stator and rotor, as indicated by the total enthalpy variation shown in Figure 19. 


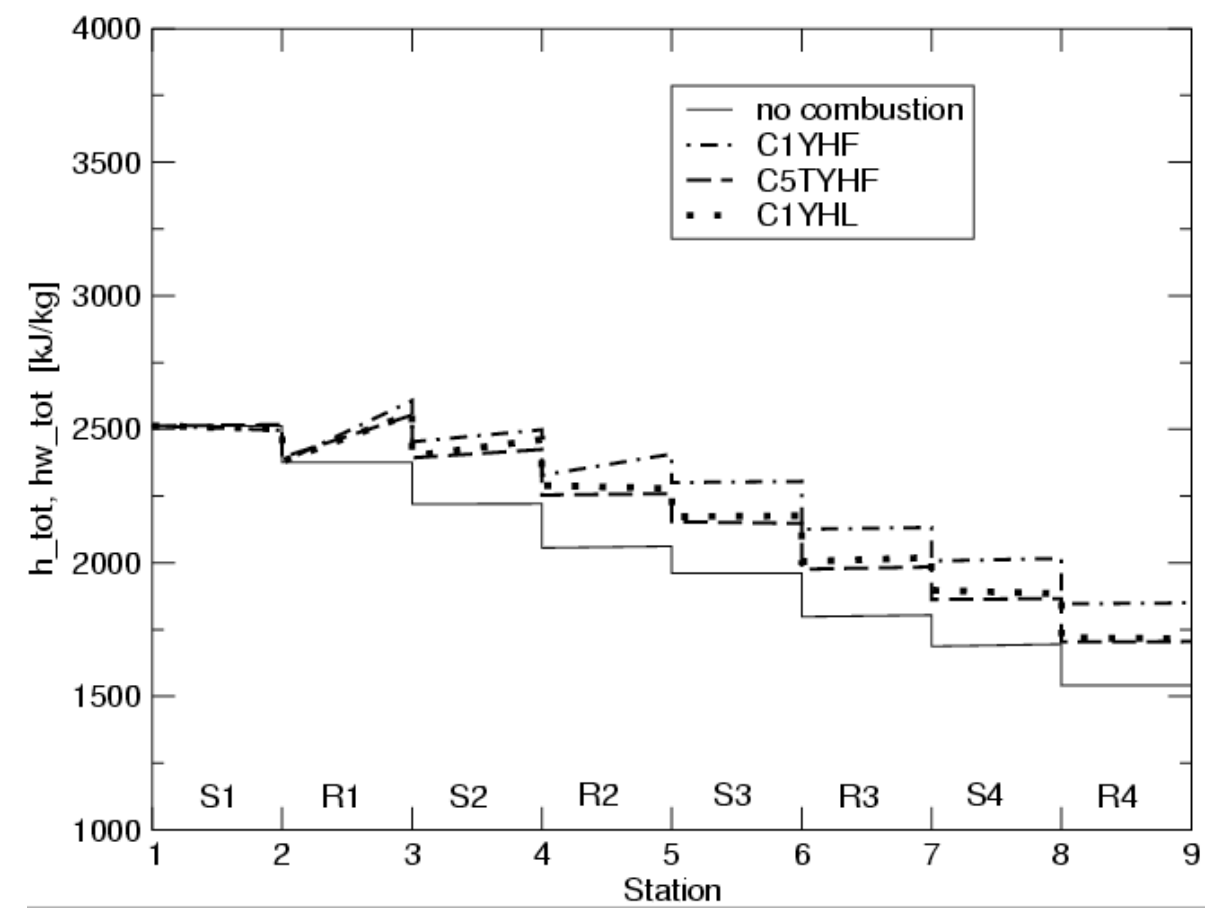

Figure 19 - Variation of averaged total enthalpy (absolute or relative).

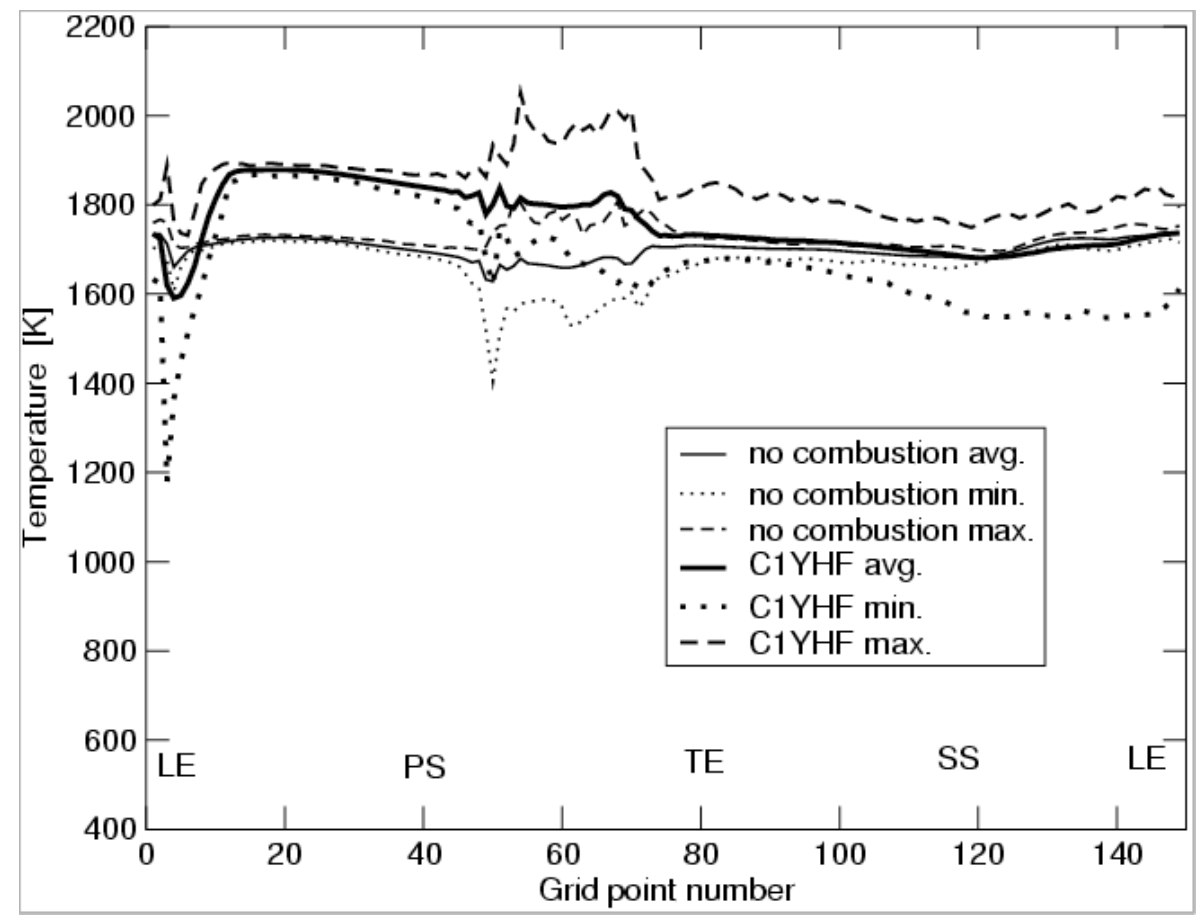

Figure 20 - Variation of stagnation temperature along first row of rotors for case without combustion and case C1YHF of in situ reheat.

The stagnation temperature variation along the first row of rotors is strongly influenced by the in situ reheat, as shown in Figure 20. Figure 20 shows the averaged, minimum and maximum stagnation temperature for the flow without combustion and for case C1YHF of flow with combustion. On the pressure side, the averaged temperature of case C1YHF is 
approximately $180 \mathrm{~K}$ larger than the no combustion case temperature. At the leading edge, however, the averaged temperature of case $\mathrm{C} 1 \mathrm{YHF}$ is approximately $70 \mathrm{~K}$ lower than in the no combustion case. On the suction side, the averaged temperature of case C1YHF is slightly higher than in the no combustion case. On most of the suction side, the averaged temperature of case $\mathrm{C} 1 \mathrm{YHF}$ is approximately 15 to $20 \mathrm{~K}$ larger than the no combustion case temperature.

The averaged temperature indicates that combustion takes place on the pressure side of the rotor airfoil. The existence of small regions where the averaged temperature of the case with combustion is lower than the average temperature of the case without combustion indicates that combustion is not completed. Consequently, the low enthalpy of the fuel injected reduces locally the airfoil temperature. The maximum temperature in the case with combustion is larger than the maximum temperature in the case without combustion, at any point on the airfoil. On the pressure side, the minimum temperature of the case with combustion is larger than the minimum temperature of the case without combustion. On most of the suction side, however, the minimum temperature of the case with combustion is smaller than the minimum temperature of the case without combustion, indicating that the unburned, cold fuel injected is affecting this region.

The variation of the mass flow rates of species is shown in Figure 21. The mass flow rates of species

$$
W_{C H 4}=\rho u Y A=\rho_{8} u A
$$

was used to assess the variation of the amount of reactants and products. In this assessment done at the postprocessing stage, the diffusion velocity was assumed to be constant and for this reason it was not included in equation (6). For methane, this assumption is less accurate near the injection location where there is a large gradient of the methane mass fraction. Consequently, the mass flow rate of methane in the first stage should be slightly larger compared to the values generated by equation (6).

The variation of the mass flow rate of methane between injection location (more precisely, half a chord downstream of the trailing edge of vane 1) and the exit from the turbine is shown in Table 22 as $\Delta W_{\mathrm{CH}_{4}} / W_{\mathrm{CH}_{4}}$ inlet. If the variation of the diffusion velocity would be accounted for, the values of $\Delta W_{\mathrm{CH}_{4}} / W_{\mathrm{CH}_{4} \text { inlet }}$ would increase. The reference mass flow rate in Table 22 is $W_{\text {ref }}=\rho_{-\infty} V_{\text {ref }}$ (axial chord) $)^{2}$, where $V_{r e f}=\sqrt{p_{-\infty} / \rho_{-\infty}}$.

These results indicate that approximately $80 \%$ of the methane does not burn. Table 22 also shows that the amount of methane injected in case C1YHF is more than double (more precisely 2.25 and 2.33) compared to cases C5TYHF and C1YHL. The highest mass flow rate of burned methane is in case C1YHF, but the highest power increase per mass flow rate of methane injected and the highest power increase per mass flow rate of methane burned are in case C5TYHF. 5 


\begin{tabular}{cccc}
\hline Case & C1YHF & C5TYHF & C1YHL \\
\hline$W_{\mathrm{CH}_{4}} / W_{\mathrm{CH} 4 \text { ref }}$ & 14.2 & 6.32 & 6.08 \\
$\Delta W_{\mathrm{CH} 4} / W_{\mathrm{CH} 4 \text { inlet }[\%]}$ & 15 & 20.9 & 21.0 \\
$\Delta W_{\mathrm{CH} 4} / W_{\mathrm{CH} 4 \text { ref }}$ & 2.13 & 1.32 & 1.28 \\
$\Delta P / \Delta W_{\mathrm{CH} 4}$ & 2.3 & 2.95 & 2.42 \\
$\Delta P / \Delta W_{\mathrm{CH} 4}$ & 0.345 & 0.617 & 0.510 \\
\hline
\end{tabular}

Table 22 - Methane variation.

The degree of mixedness is estimated through the mixedness parameter $\mathrm{S}$ :

$$
S=\frac{1}{\bar{\phi}} \int_{y=0}^{S_{b l}}[\phi(y)-\bar{\phi}]^{2} d y \quad(\bar{\phi} \neq 0)
$$

with $\bar{\phi}$ being the space averaged value along the region where the integration is performed. It is calculated here for several parameters of interest, such as $X_{\mathrm{CH}_{4}}, X_{C O}, T_{w}^{*}$ or $T^{*}$, whose distributions are investigated in the cross stream direction between rows, along the $y$ axis. In regions of high non-uniformity values for $\mathrm{S}$ are high while in regions of constant $\phi$ the parameter $\mathrm{S}$ becomes zero. As the code used is unsteady, the space dependent quantities (i.e., $\Phi(y))$ were time averaged over a cycle. The values given in Table 23 show the largest values of $\mathrm{S}$ for $\mathrm{CH}_{4}, T_{w}^{*}$ and $T^{*}$ obtained at the exit of the injection row. A similar remark applies for $C O$. 


\begin{tabular}{|c|c|c|c|c|c|c|}
\hline Case & no combustion & cly & clyhf & c5tyhf & clyma & clyhl \\
\hline \multicolumn{7}{|l|}{ CO mixedness } \\
\hline mix_CO_exit_Vane 1 & 0.0 & 7.33E-03 & $3.15 \mathrm{E}-03$ & $5.22 \mathrm{E}-03$ & $3.68 \mathrm{E}-03$ & $5.06 \mathrm{E}-03$ \\
\hline mix_CO_exit_Blade 1 & 0.0 & $6.80 \mathrm{E}-04$ & $6.27 \mathrm{E}-04$ & $3.44 \mathrm{E}-04$ & $8.97 \mathrm{E}-05$ & $3.76 \mathrm{E}-04$ \\
\hline mix_CO_exit_Vane2 & 0.0 & $2.91 \mathrm{E}-04$ & 1.34E-04 & $2.40 \mathrm{E}-04$ & $1.26 \mathrm{E}-04$ & $1.90 \mathrm{E}-04$ \\
\hline mix_CO_exit_Blade2 & 0.0 & $1.12 \mathrm{E}-04$ & $1.03 \mathrm{E}-04$ & $4.58 \mathrm{E}-04$ & $5.65 \mathrm{E}-05$ & $3.21 \mathrm{E}-04$ \\
\hline mix_CO_exit_Vane3 & 0.0 & $2.41 \mathrm{E}-05$ & $5.12 \mathrm{E}-05$ & $3.41 \mathrm{E}-05$ & $2.85 \mathrm{E}-05$ & 5.82E-05 \\
\hline mix_CO_exit_Blade3 & 0.0 & $1.38 \mathrm{E}-05$ & $1.01 \mathrm{E}-05$ & $1.36 \mathrm{E}-04$ & $2.27 \mathrm{E}-05$ & 8.11E-05 \\
\hline mix_CO_exit_Vane4 & 0.0 & $3.62 \mathrm{E}-05$ & $2.47 \mathrm{E}-05$ & $3.00 \mathrm{E}-05$ & $8.06 \mathrm{E}-06$ & $2.05 \mathrm{E}-05$ \\
\hline mix_CO_exit_Blade4 & 0.0 & $7.88 \mathrm{E}-06$ & $1.50 \mathrm{E}-05$ & $4.7 \mathrm{lE}-05$ & $1.92 \mathrm{E}-06$ & $1.40 \mathrm{E}-05$ \\
\hline \multicolumn{7}{|l|}{ CH4 mixedness } \\
\hline mix_CH4_exit_Vane 1 & 0.0 & $6.24 \mathrm{E}-01$ & $2.63 \mathrm{E}+00$ & $1.35 \mathrm{E}+00$ & $3.05 \mathrm{E}-01$ & $1.26 \mathrm{E}+00$ \\
\hline mix_CH4_exit_Blade 1 & 0.0 & 4.12E-02 & $1.52 \mathrm{E}-01$ & $7.29 \mathrm{E}-02$ & 8.87E-03 & $7.61 \mathrm{E}-02$ \\
\hline mix_CH4_exit_Vane2 & 0.0 & $1.73 \mathrm{E}-02$ & $3.55 \mathrm{E}-02$ & $1.62 \mathrm{E}-02$ & 8.97E-03 & $9.97 \mathrm{E}-03$ \\
\hline mix_CH4_exit_Blade2 & 0.0 & $5.63 \mathrm{E}-03$ & $1.22 \mathrm{E}-01$ & $2.53 \mathrm{E}-02$ & $3.80 \mathrm{E}-03$ & $1.75 \mathrm{E}-02$ \\
\hline mix_CH4_exit_Vane3 & 0.0 & $1.58 \mathrm{E}-03$ & $2.22 \mathrm{E}-02$ & $1.99 \mathrm{E}-03$ & $2.46 \mathrm{E}-03$ & $2.76 \mathrm{E}-03$ \\
\hline mix_CH4_exit_Blade3 & 0.0 & 8.33E-04 & $1.20 \mathrm{E}-02$ & $6.78 \mathrm{E}-03$ & $1.88 \mathrm{E}-03$ & $4.20 \mathrm{E}-03$ \\
\hline mix_CH4_exit_Vane4 & 0.0 & $2.17 \mathrm{E}-03$ & $8.41 \mathrm{E}-03$ & $1.44 \mathrm{E}-03$ & $7.50 \mathrm{E}-04$ & $1.12 \mathrm{E}-03$ \\
\hline mix_CH4_exit_Blade4 & 0.0 & $4.78 \mathrm{E}-04$ & $2.38 \mathrm{E}-03$ & $2.27 \mathrm{E}-03$ & $1.50 \mathrm{E}-04$ & $6.75 \mathrm{E}-04$ \\
\hline \multicolumn{7}{|c|}{ T_stagnation mixedness (sse Note) } \\
\hline mix_Tstag_exit_Vane 1 & $9.61 \mathrm{E}-05$ & $1.43 \mathrm{E}-02$ & $3.61 \mathrm{E}-01$ & $8.36 \mathrm{E}-02$ & $7.16 \mathrm{E}-03$ & $9.82 \mathrm{E}-02$ \\
\hline mix_Tstag_exit_Blade 1 & 1.31E-03 & $2.74 \mathrm{E}-03$ & $3.37 \mathrm{E}-02$ & $3.71 \mathrm{E}-03$ & $1.64 \mathrm{E}-03$ & $3.89 \mathrm{E}-03$ \\
\hline mix_Tstag_exit_Vane2 & $3.82 \mathrm{E}-04$ & 5.50E-04 & $1.39 \mathrm{E}-02$ & $2.05 \mathrm{E}-03$ & $6.24 \mathrm{E}-04$ & $1.57 \mathrm{E}-03$ \\
\hline mix_Tstag_exit_Blade2 & $8.27 \mathrm{E}-04$ & $1.03 \mathrm{E}-03$ & $3.42 \mathrm{E}-02$ & 7.09E-03 & $6.32 \mathrm{E}-04$ & 5.99E-03 \\
\hline mix_Tstag_exit_Vane3 & $9.90 \mathrm{E}-04$ & $1.64 \mathrm{E}-03$ & $8.54 \mathrm{E}-03$ & $2.94 \mathrm{E}-03$ & $5.01 \mathrm{E}-04$ & $2.19 \mathrm{E}-03$ \\
\hline mix_Tstag_exit_Blade3 & $1.60 \mathrm{E}-03$ & $3.89 \mathrm{E}-03$ & $3.23 \mathrm{E}-03$ & 5.38E-03 & $2.64 \mathrm{E}-03$ & $5.76 \mathrm{E}-03$ \\
\hline mix_Tstag_exit_Vane4 & $1.84 \mathrm{E}-03$ & $4.25 \mathrm{E}-03$ & $5.86 \mathrm{E}-03$ & $4.78 \mathrm{E}-03$ & $8.26 \mathrm{E}-04$ & $3.94 \mathrm{E}-03$ \\
\hline mix_Tstag_exit_Blade4 & $1.96 \mathrm{E}-03$ & $3.17 \mathrm{E}-03$ & $1.01 \mathrm{E}-03$ & 4.91E-03 & $3.55 \mathrm{E}-03$ & $8.92 \mathrm{E}-04$ \\
\hline
\end{tabular}

Table 23 - Mixedness Projection 

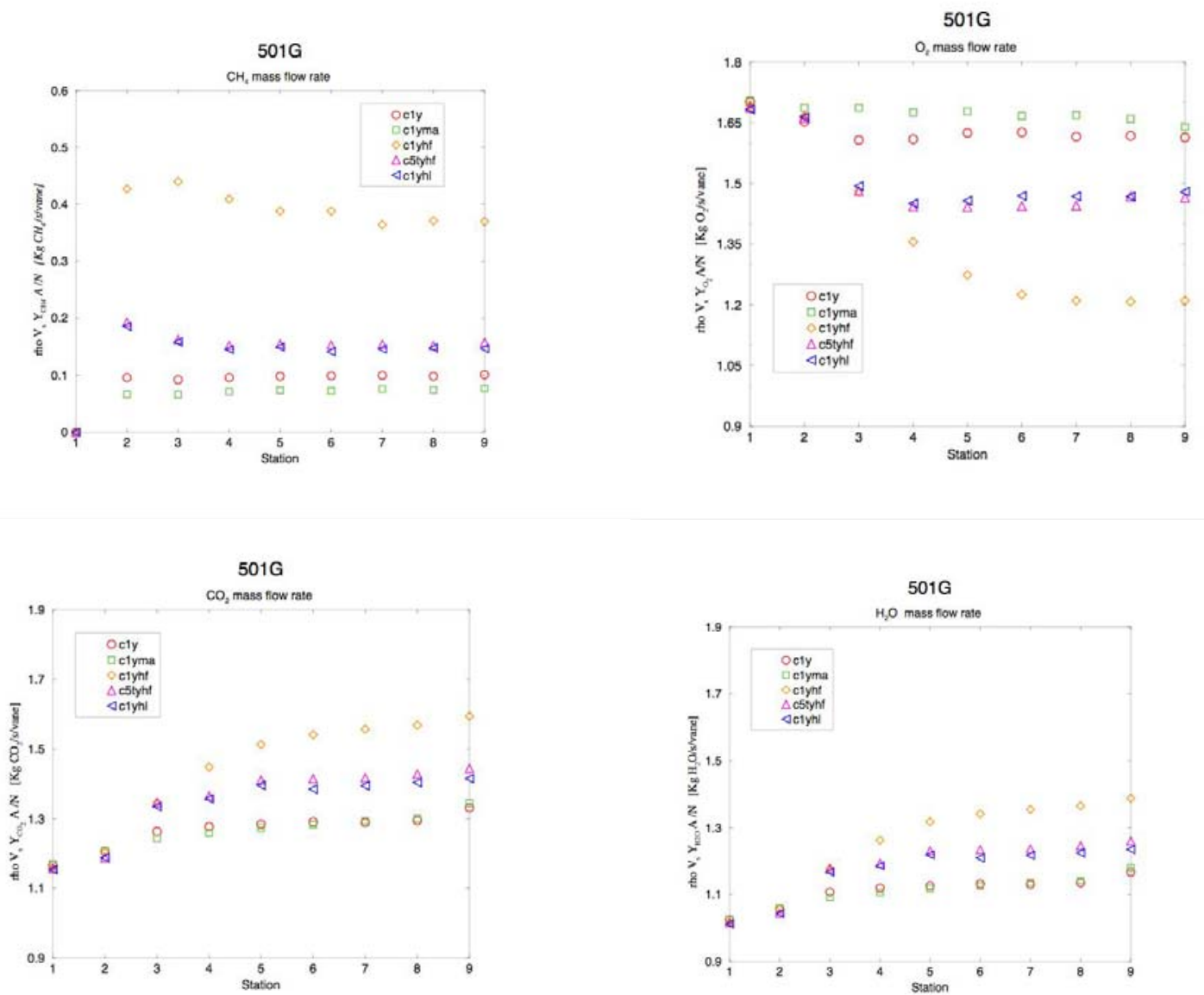

Figure 21 - Variation of $\mathrm{CH}_{4}, \mathrm{O}_{2}, \mathrm{CO}_{2}$ and $\mathrm{H}_{2} \mathrm{O}$ mass fractions along the turbine.

\subsection{Run Set 2}

This section presents and compares the effects of in situ reheat in four-stage and five-stage turbines. For each turbine, at least four cases of in situ reheat were calculated. The main cases are presented in Table 24.

Cases 1 through 5 cover the four-stage turbine. Cases 6 through 10 cover the five-stage turbine. For the five-stage turbine, only the last four stages are simulated. The first stage in the simulation is the second stage of the five-stage turbine. As a result, what is referred herein as the $I$-th stage of the five-stage turbine is in fact the $I+1$-stage. Cases 1 and 6 represent the no combustion cases for the four-stage and five-stage turbines. In cases 2, 2wide and 7 the fuel injection is done at the trailing edge of vane one. In the cases 2 and 2 wide, the mass flow rate of fuel is kept constant while the injection hole diameter and the injection velocity are varied. In cases 3 and 8 the fuel injection is done at the leading edge of the second vane. In cases 4 and 9 the fuel injection is done at the trailing edge of the second vane. In cases 5 and 10 the fuel injection is done at the trailing edge of the third vane.

The effects of in situ reheat were investigated by comparing the performances of the turbinecombustor for various cases of fuel injection against the performance of the same turbine without combustion. Pure methane was injected in all the cases of in situ reheat presented herein. The composition of the gas at inlet in the turbine varied slightly for each case. 


\begin{tabular}{|c|c|c|c|c|c|c|c|c|c|c|c|c|}
\hline 1 & Case & $\rightarrow$ & $\rightarrow$ & 2oride & $\rightarrow$ & $\rightarrow$ & 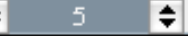 & 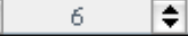 & $\rightarrow$ & 8 & 9 & 10 \\
\hline$\frac{2}{3}$ & $\begin{array}{l}\text { Engine } \\
\text { Inj. hole location }\end{array}$ & G LE & G TE & VI TE & 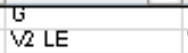 & $\stackrel{5}{\mathrm{G}} \mathrm{TE}$ & G TE & $M L E$ & $\mathrm{~T}_{\mathrm{V} / \mathrm{TE}}^{\mathrm{G3}}$ & $T_{V / 2 L E}^{53}$ & $\mathrm{~T}_{\mathrm{V} / \mathrm{TE}}^{\mathrm{GS}}$ & $\mathrm{T}_{\mathrm{B}}^{\mathrm{G5}} \mathrm{TE}$ \\
\hline 4 & Injection angle, (rel to vane $\mathrm{CL}$ ) & NA & . & th & 20 & the & 0 & NA & A & g & 0 & ) \\
\hline 5 & Hole witth (mm) & NA & 0.508 & 0.508 & 0.508 & 0.508 & 0.508 & NA & 0.508 & 0.508 & 0.508 & 0.508 \\
\hline 6 & Main Gas Properties & & & & & & & & & & & \\
\hline 7 & we frac 02 & 0.110 & 0.116 & 0.116 & 0.129 & 0.133 & 0.135 & 0.110 & 0.116 & 0.129 & 0.133 & 0.135 \\
\hline 8 & wt frac 002 & 0.079 & 0.074 & 0.074 & 0.066 & 0.063 & 0.062 & 0.079 & 0.074 & 0.066 & 0.063 & 0.062 \\
\hline 9 & wt frac 820 & 0.070 & 0.067 & 0.067 & 0.060 & 0.058 & 0.057 & 0.070 & 0.067 & 0.060 & 0.058 & 0.057 \\
\hline 10 & $w t$ frac N2 & 0.729 & 0.730 & 0.730 & 0.733 & 0.733 & 0.734 & 0.729 & 0.730 & 0.733 & 0.733 & 0.734 \\
\hline 11 & wt frac Ar & 0.012 & 0.012 & 0.012 & 0.013 & 0.013 & 0.013 & 0.012 & 0.012 & 0.013 & 0.013 & 0.013 \\
\hline 12 & Temperature, $K$ & 1783 & 1610 & 1610 & 1445 & 1324 & 1106 & 1783 & 1415 & 1274 & 1167 & 974 \\
\hline 13 & pressure (bar abs) & 18.1 & 12.9 & 12.9 & 9.0 & 6.4 & 3 & 17.8 & 12.1 & 8.5 & 6.0 & 2.0 \\
\hline 14 & gas angle (rel to axis), " & 0.0 & 73.0 & 73.0 & -30.0 & 69.0 & 64 & 0.0 & 73.0 & -24.0 & 69.0 & 64.0 \\
\hline 15 & gas velocity (parallel to vane), m/s & 122 & 581 & 581 & 257 & 557 & 597 & 122 & 580 & 228 & 522 & 556 \\
\hline 16 & Injection Gas Properties & & & & & & & & & & & \\
\hline 17 & wt frac Ch4 & NA & $i$ & 1 & $\hat{1}$ & $\hat{t}$ & $\hat{t}$ & N/A & $\hat{t}$ & 1 & $\hat{i}$ & 1 \\
\hline 18 & we frac air & N/A & 0 & 0 & 0 & 0 & 0 & N/A & 0 & 0 & 0 & 0 \\
\hline 19 & Temperature @ hade [K] & $N A$ & 700 & 700 & 580 & 580 & 600 & NA & 700 & 580 & 580 & 600 \\
\hline 20 & (kg injected)(kg main gas) & 0.000 & 0.005 & 0.005 & 0.005 & 0.005 & 0.005 & 0.000 & 0.010 & 0.010 & 0.010 & 0.010 \\
\hline 21 & & & & & & & & & & & & \\
\hline 22 & Temperature in'et upstream $[K]$ & 1710 & 1710 & 1710 & 1710 & 1710 & 1710 & 1470 & 1470 & 1470 & 1470 & 1470 \\
\hline 23 & Stagnation pressure inlet upstream (abs, bar) & 17.54 & 17.54 & 17.54 & 17.54 & 17.54 & 17.54 & 16.95 & 16.95 & 16.95 & 16.95 & 16.95 \\
\hline 24 & Pressure ratio, pexit static/p indet total [.] & 0.0570 & 0.0570 & 0.0570 & 0.0570 & 0.0570 & 0.0570 & 0.0590 & 0.0590 & 0.0590 & 0.0590 & 0.0590 \\
\hline 25 & Pressure @ hole (abs) bar] & NA & 13.77 & 13.77 & 9.82 & 6.79 & 3.02 & NA & 13.58 & 8.98 & 6 & 2.68 \\
\hline 26 & Pressure (i) hole / piniet total $[4$ & N/A & 0.7851 & 0.7851 & 0.5599 & 0.3871 & 0.1722 & NA & 0.8012 & 0.5298 & 0.3540 & 0.1581 \\
\hline 27 & u-velocityls wht(pinfirthoint) @ hode [-] & NAA & 0.0745 & 0.0436 & -0.2853 & 0.1508 & 0.2838 & NA & 0.1832 & -0.757 & 0.4143 & 0.7745 \\
\hline 28 & sqrt(́pinfithoinf) @ hole [m/s] & 709.86 & 709.28 & 709.28 & 708.97 & 708.41 & 708.29 & 658.16 & 657.63 & 657.34 & 656.82 & 656.71 \\
\hline 29 & U-welocity @Q hole [m/s] & NA & 52.84 & 30.92 & .202 .27 & 106.83 & 201.01 & NA & 120.48 & .497 .60 & 272.12 & 508.62 \\
\hline 30 & Inj. Welocity. $\vee[m / s]$ & NA & 180.73 & 105.77 & -233.56 & 298.10 & 458.55 & NA & 412.07 & -544.70 & 759.34 & 1160.25 \\
\hline 31 & inj. hole iocation, l-station & NA & $\pi$ & $\pi$ & 1 & $\pi$ & 70 & NA & $\pi$ & 1 & $\pi$ & 70 \\
\hline 32 & Inj. hode iocation, grid number & $N / A$ & 2 & 2 & 6 & 6 & 10 & $N / A$ & 2 & 6 & 6 & 10 \\
\hline 33 & Gas constant, R [J/ $\left.\left./ \mathrm{kg}^{\pi} \mathrm{K}\right)\right]$ & 294.68 & 294.2 & 294.2 & 293.94 & 293.48 & 293.38 & 294.68 & 294.2 & 293.94 & 293.48 & 293.38 \\
\hline 34 & Oynamic viscosity @ hole / Oyn. visc. Iriet [-] & N/.0 & 0.589 & 0.589 & 0.521 & 0.521 & 0.534 & NNA & 0.641 & 0.567 & 0.567 & 0.581 \\
\hline 35 & Oynamic viscosity @ indet upstream [Pas] & $5.58 E-05$ & $5.58 E-05$ & $5.58 E-05$ & $5.58 E-05$ & $5.58 E-05$ & $5.58 E-05$ & $5.13 E-05$ & $5.13 E-05$ & $5.13 E-05$ & $5.13 E-05$ & $5.13 E-05$ \\
\hline 36 & Density @indet unstream [kgim3] & 3.481 & 3.487 & 3.487 & 3.490 & 3.495 & 3.496 & 3.913 & 3.919 & 3.923 & 3.929 & 3.930 \\
\hline 37 & Density [0 hole $[\mathrm{kg} / \mathrm{m} 3]$ & NA & 3.796 & 3.796 & 3.267 & 2.259 & 0.971 & NA & 3.743 & 2.987 & 1.996 & 0.862 \\
\hline 38 & Turbine indet isch number [.] & 0.152 & 0.152 & 0.152 & 0.152 & 0.152 & 0.152 & 0.164 & 0.164 & 0.164 & 0.164 & 0.164 \\
\hline 39 & Velocity at turbine inlet [m/s] & 107.90 & 107.81 & 107.81 & 107.76 & 107.68 & 107.66 & 107.94 & 107.85 & 107.80 & 107.72 & 107.70 \\
\hline 40 & Reynod's number (turbine indet] & 738636 & 739238 & 739238 & 739565 & 740145 & 740271 & 903498 & 904235 & 904634 & 905343 & 905497 \\
\hline 41 & Turbine flow coefficient [] & 0.2792 & 0.2790 & 0.2790 & 0.2789 & 0.2787 & 0.2786 & 0.2793 & 0.2791 & 0.2790 & 0.2788 & 0.2787 \\
\hline 42 & Inj. hade diameter use as innut firmi & NA & 0.3 & 0.508 & 0.45 & 0.3 & 0.3 & NA & 0.3 & 0.45 & 0.3 & 0.3 \\
\hline 43 & Inj. hole effective diameter [ [mT] & NA & 0.544 & 0.931 & 0.489 & 0.554 & 0.839 & NA & 0.544 & 0.516 & 0.554 & 0.839 \\
\hline 44 & Whain gas mass flow rate $[\mathrm{kg} / \mathrm{s}]$ & 74.67 & 74.68 & 74.68 & 74.67 & 74.68 & 74.68 & 83.94 & 83.94 & 83.94 & 83.94 & 83.94 \\
\hline 45 & Fuel inj. mass flow rate $[\mathrm{kg} / \mathrm{s}]$ & NA & 0.3732 & 0.3738 & 0.3731 & 0.3731 & 0.3736 & NA & 0.8391 & 0.8395 & 0.8397 & 0.8391 \\
\hline 46 & Fuel inj. / main gas [-] & NA & 0.00500 & 0.00501 & 0.00500 & 0.00500 & 0.00500 & NA & 0.01000 & 0.01000 & 0.01000 & 0.01000 \\
\hline 47 & Power increase ["] & 0 & 2.6 & 1.5 & 0.3 & 0.2 & -0.1 & 0 & 0.1 & -0.8 & -0.6 & 0 \\
\hline 48 & Power inclrease / fuel injection mass flow rate & 0 & 0.03482 & 0.02009 & 0.00402 & 0.00268 & -0.00134 & 0.00000 & 0.00119 & -0.00953 & -0.00715 & 0.00000 \\
\hline * & & & & & & & & & & & & \\
\hline
\end{tabular}

Table 24 - Parameter variation for the main cases of $i n$ situ reheat 


\subsubsection{Four-Stage Turbine}

The largest power increase was obtained by injecting fuel at the trailing edge of the first vane of the four-stage turbine, case 2 . The power increase relative to the no combustion case is $2.6 \%$, as shown in Table 24 . A smaller power increase $(1.5 \%)$ was obtained when the injection velocity was reduced from $180 \mathrm{~m} / \mathrm{s}$ in case 2 to $106 \mathrm{~m} / \mathrm{s}$ in case 2 wide, while keeping the fuel mass flow rate constant. The details of the oxygen variation and velocity vectors near the fuel injection location at the trailing edge of the first vane are shown in Figure 22. The combustion is clustered next to the injection location when the velocity is 106 $\mathrm{m} / \mathrm{s}$, while for the larger velocity the combustion extends further away from the vane.

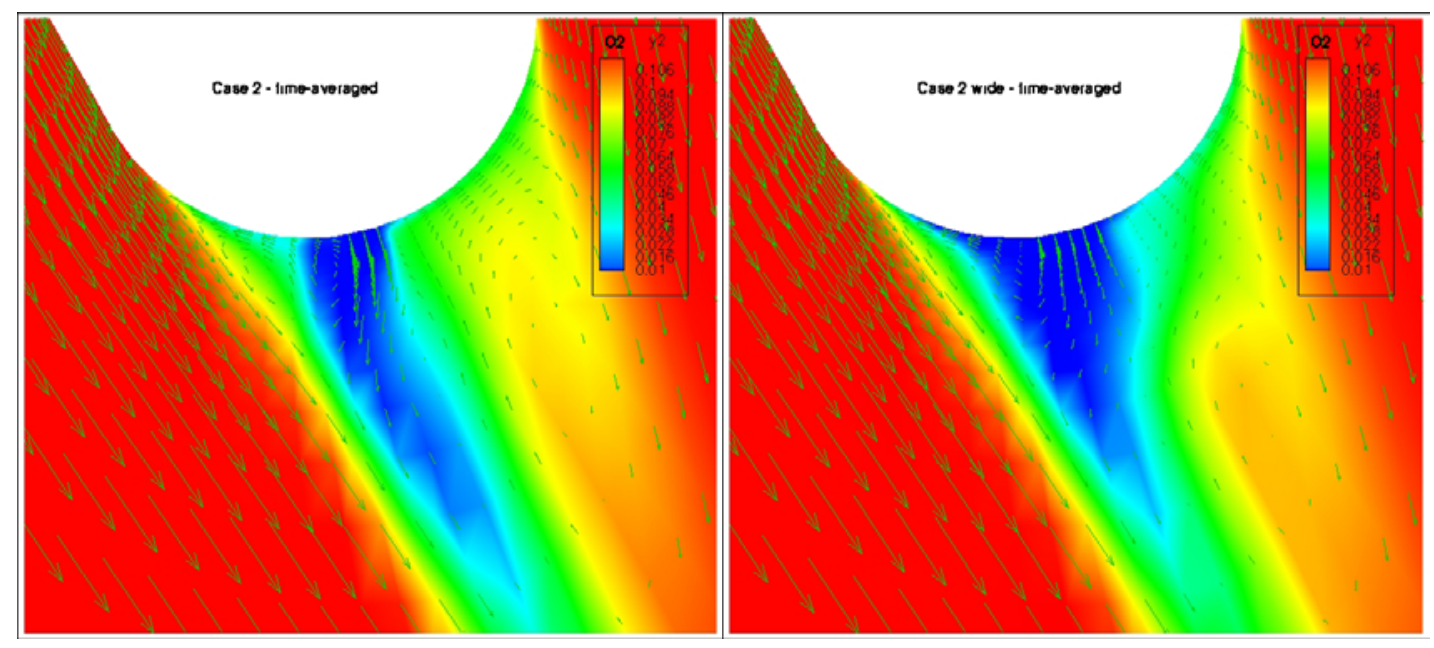

Figure 22 - Oxygen contours and velocity vectors near the injection location for cases 2 and 2 wide.

The oxygen contours indicate where combustion takes place, as shown in Figure 23. The combustion is clearly the strongest in case 2 and consequently the power increase is the largest. The oxygen variation is rather small in cases 3 and 5, indicating that combustion is insignificant. A detail of the oxygen contours near the injection location shows that in case 4 the reaction is restricted to a very small region, as shown in Figure 24. 


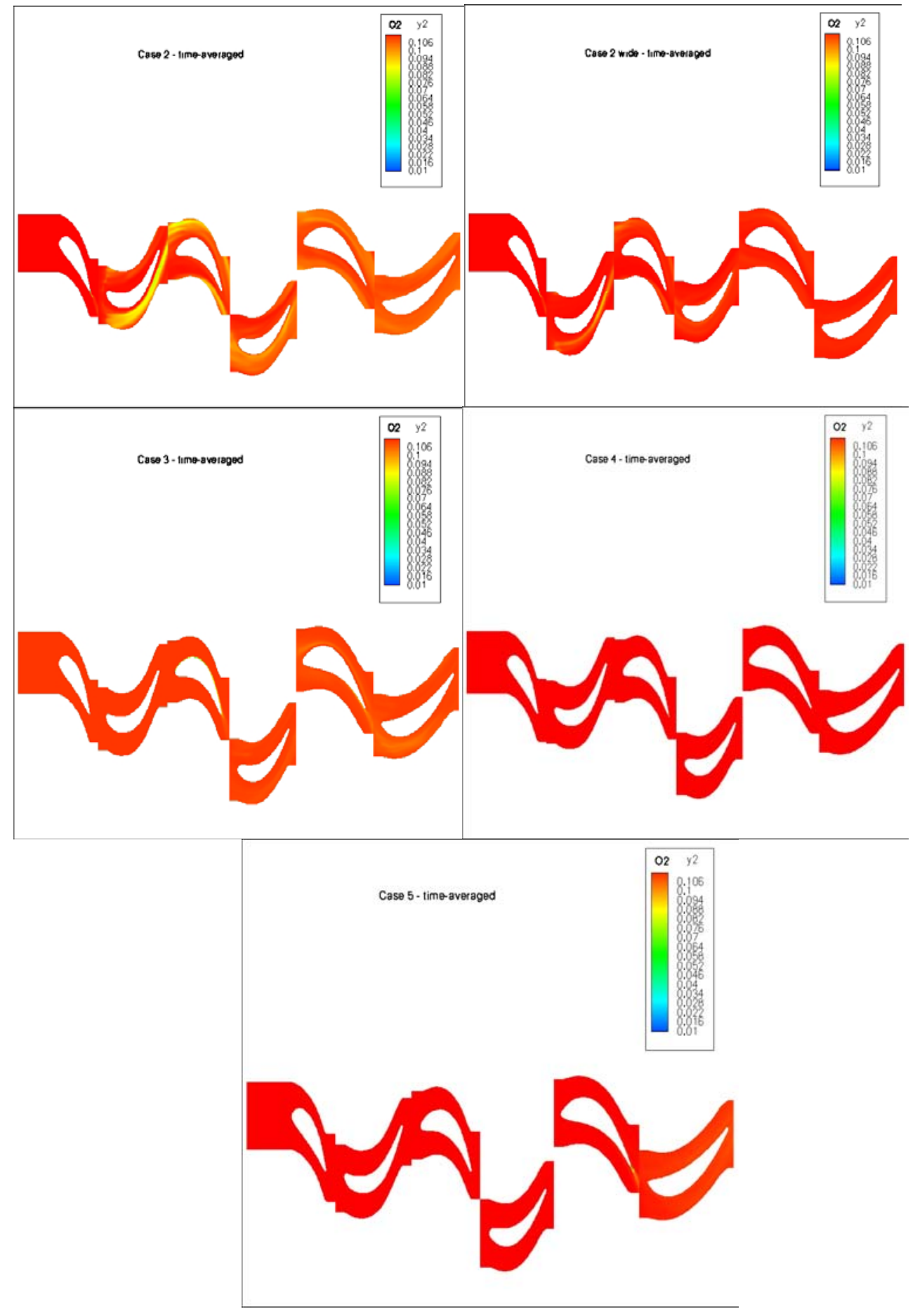

Figure 23 - Oxygen contours for cases 1 through 5. 


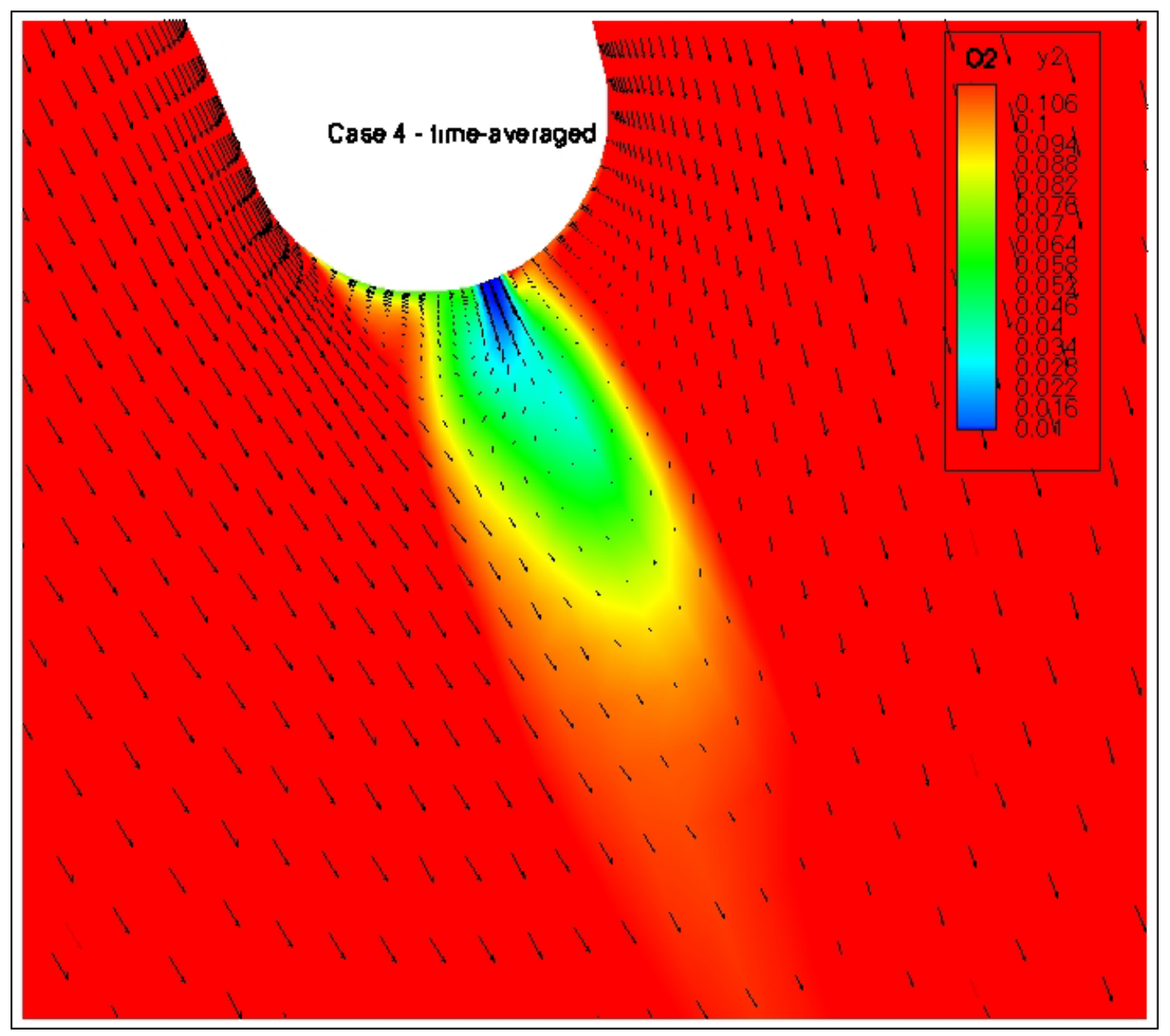

Figure 24 - Oxygen contours and velocity vectors near the injection location for case 4.

The temperature variation for cases 1 through 5 is shown in Figure 25. In cases 2 and 2 wide, fuel injection increases the temperature in the first rotor and second stator rows. Temperature does not increase downstream of the injection location in cases 3 through 5 because the fuel does not ignite (or combustion is very localized). Consequently, power increases most in cases 2 and 2 wide. Depending on the balance between the entropy increase due to (localized) combustion and the entropy decrease due to the cold fuel injection, the power slightly increases or decreases in cases 3 through 5, as shown in Table 24. 


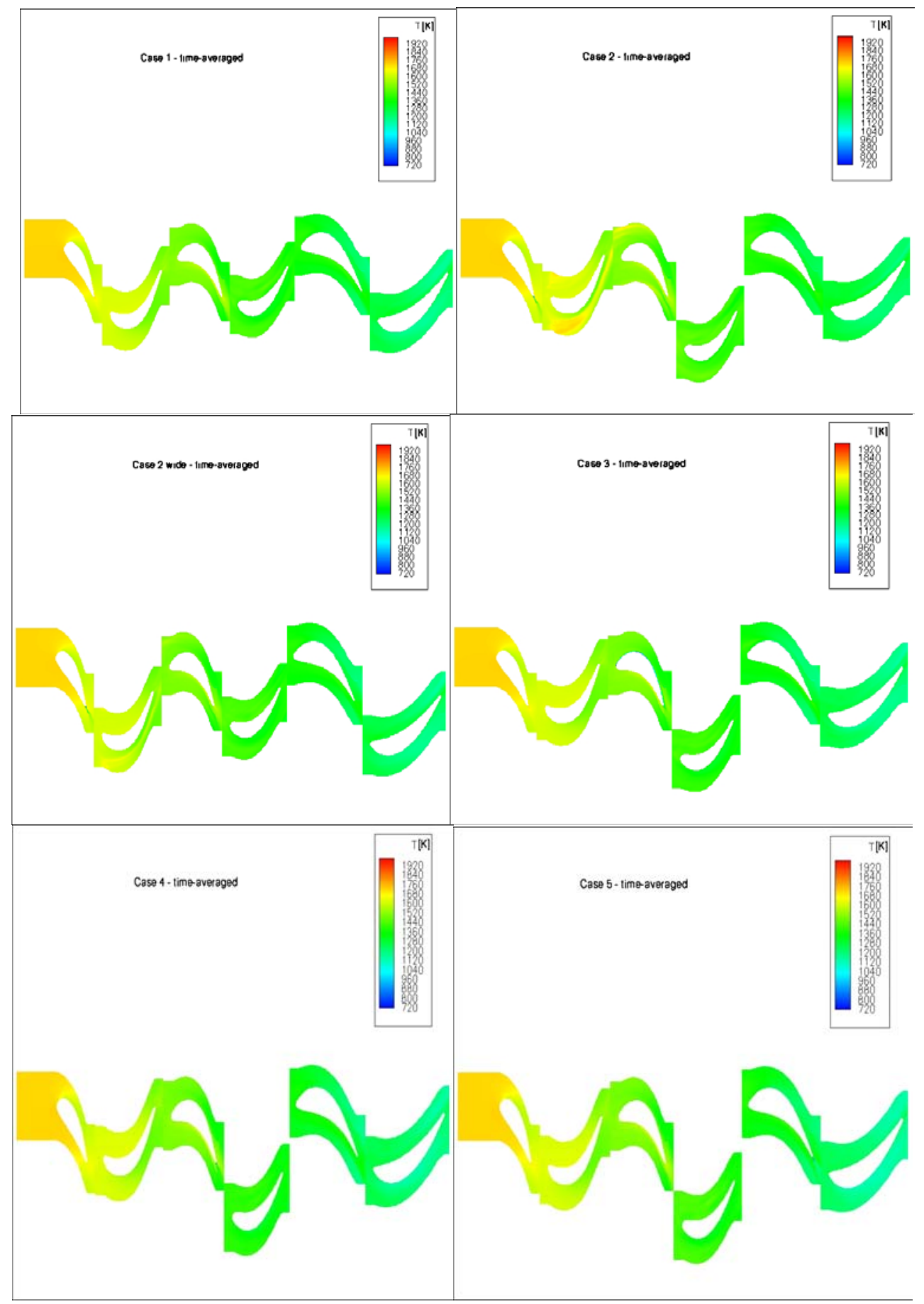

Figure 25 - Temperature contours for cases 1 through 5.

\subsubsection{Five-Stage Turbine}

Stages 2 through 5 of a five-stage turbine were simulated herein. The mass flow rate of the fuel injected in the turbine was equal to $1 \%$ of the mass flow rate of gas entering the turbine. The fuel was injected at the leading edge of the second vane (i.e., the first vane in the numerical simulation - case 6 in Table 24), at the leading edge and trailing edge of the third vane (i.e., second vane in the numerical simulation - cases 7 and 8), at the trailing edge of the 
fourth vane (i.e., third vane in the numerical simulation - case 9), and at the trailing edge of the fifth vane (i.e., fourth vane in the numerical simulation - case 10). The power variation shown in Table 24 indicates a smaller power increase compared to the four-stage turbine in spite of the doubled fuel mass flow rate for the five-stage turbine compared to the four-stage turbine.

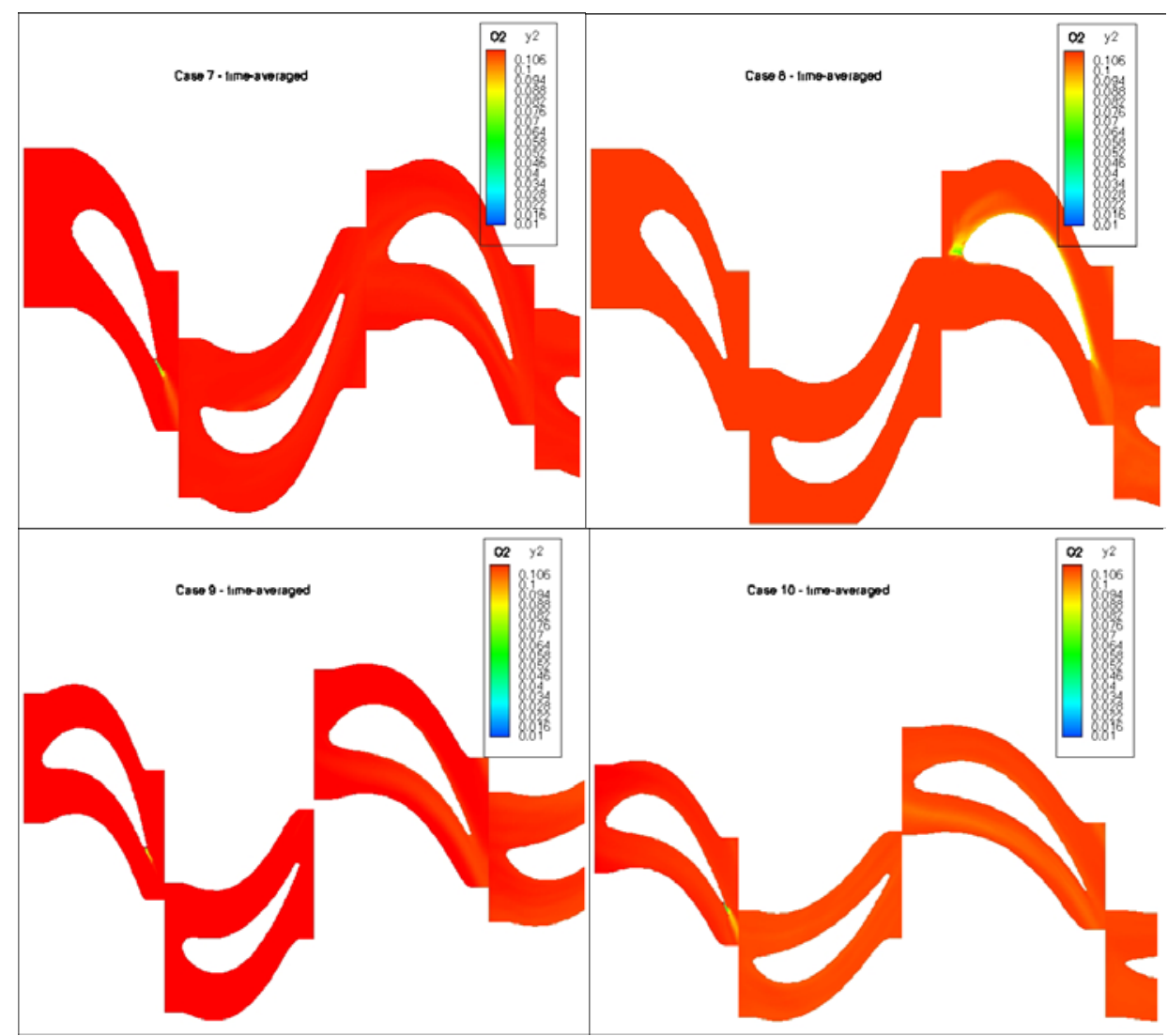

Figure 26 - Oxygen contours for cases 7 through 10.

The variation of the oxygen shown in Figure 26 indicates that combustion is very weak for all the cases of the five-stage turbine. The same conclusion is supported by the temperature contours shown in Figure 27. 


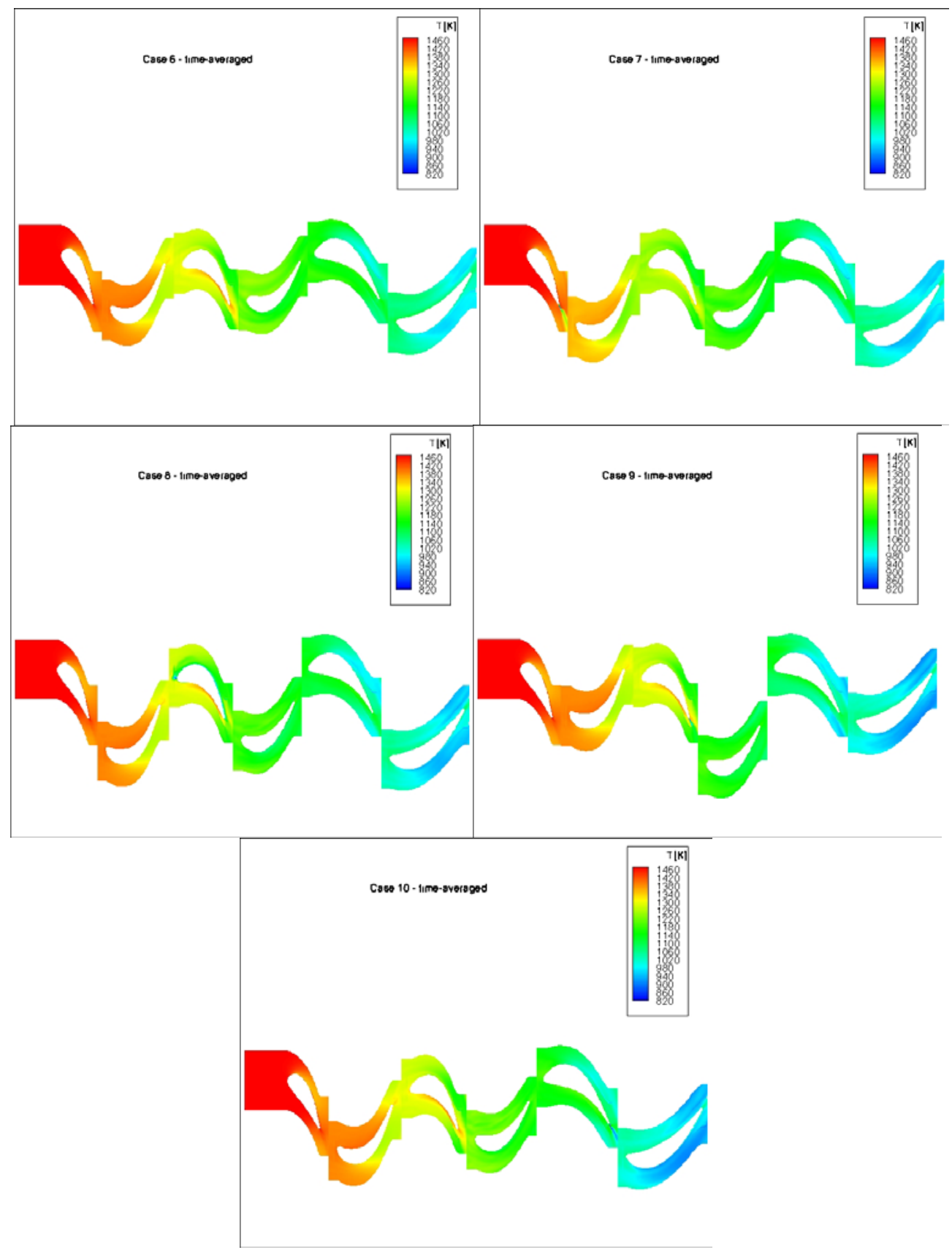

Figure 27 - Temperature contours for cases 6 through 10.

The details of the oxygen variation near the fuel injection situated at leading edge (cases 3 and 8) indicate that the methane flows only on suction side of the vane, as shown in Figure 28. To produce a counter-flow flame, that would have better chances for combustion, the injection location needs to be moved toward the pressure side. A simulation of a new injection location near the leading edge with different injection velocities is necessary in order to determine the parameters needed to anchor the flame. 


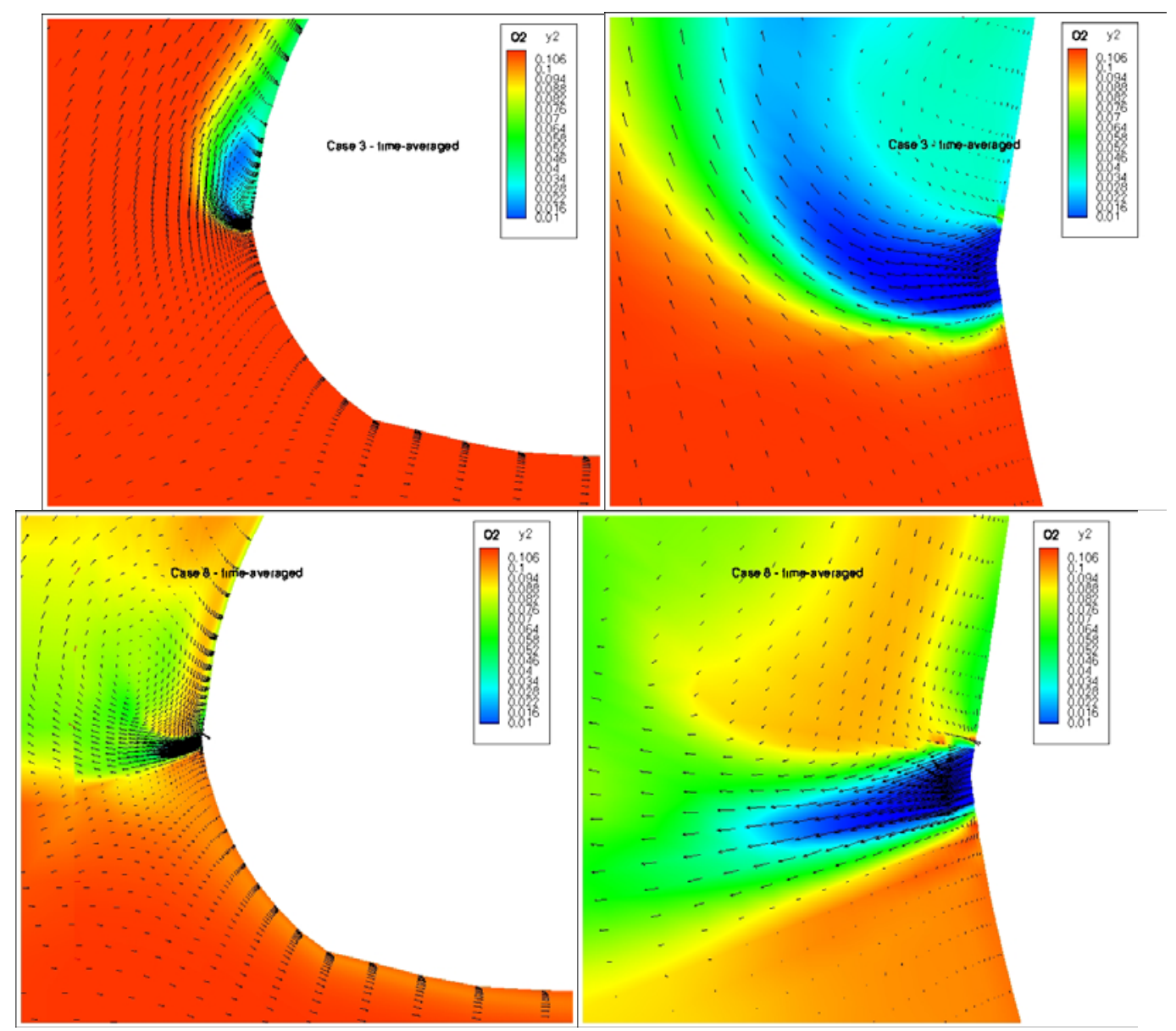

Figure 28 - Oxygen contours and velocity vectors for cases 3 and 8.

\subsection{Run Set 3}

Ten additional cases were investigated and are presented in this section. These cases, B through $\mathrm{K}$, are similar to the cases 1 through 10 presented above. Case $\mathrm{B}$ is similar to case 1 , case $\mathrm{C}$ is similar to case 2, etc. The differences between cases 1 through 10 and cases $\mathrm{B}$ through $\mathrm{K}$ consist of small variations of the flow coefficient, fuel injection incidence angle and velocity magnitude. The fuel mass flow rates were similar, except for case $\mathrm{K}$, where the fuel mass flow rate was approximately half the mass flow rate of case 10 . The input parameters and the power variation are presented in Table 25.

Similar to the results presented for the cases 1 through 10, the largest power increase was obtained when the fuel was injected at the trailing edge of the first vane, case B. For the other cases, the power increase was significantly smaller. In case I, the fuel did not ignite. As a result, the power variation was negative because of the reduced enthalpy of the fuel.

The difference of the combustion strength between cases $\mathrm{C}$ through $\mathrm{K}$ is illustrated in Figure 29.

Temperature variation is shown in Figure 30. Clearly the temperature increases most in case $\mathrm{C}$ and consequently the power variation is the largest. 


\begin{tabular}{|c|c|c|c|c|c|c|c|c|c|c|c|}
\hline 1 & Case & B & $\mathrm{C}$ & D & $\hat{\nabla}$ & $\mathrm{F}$ & G & $\mathrm{H}$ & $\boldsymbol{\nabla}$ & 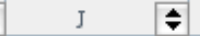 & $\mathrm{K}$ \\
\hline 2 & Engine & $G$ & G & G & $\mathrm{G}$ & 6 & G5 & TG5 & TG5 & TS5 & IG5 \\
\hline 4 & Injection angle, (rel to vane $\mathrm{CL}$ ) & N/A & (3the & $-L$ & $0-12$ & to & N/A & (210 & 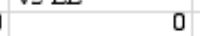 & 0 & 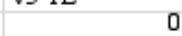 \\
\hline 5 & Main Gas Properties & & & & & & & & & & \\
\hline 6 & wt frac $\mathrm{O} 2$ & 0.110 & 0.116 & 0.129 & 0.133 & 0.1346 & 0.110 & 0.116 & 0.129 & 0.133 & 0.135 \\
\hline 7 & wh frac $\mathrm{CO}_{2}$ & 0.079 & 0.074 & 0.066 & 0.063 & 0.0623 & 0.079 & 0.074 & 0.066 & 0.063 & 0.062 \\
\hline 8 & wt frac $\mathrm{H} 2 \mathrm{O}$ & 0.070 & 0.067 & 0.060 & 0.058 & 0.057 & 0.070 & 0.067 & 0.060 & 0.058 & 0.057 \\
\hline 9 & wt frac N2 & 0.729 & 0.730 & 0.733 & 0.733 & 0.7336 & 0.729 & 0.730 & 0.733 & 0.733 & 0.734 \\
\hline 10 & wt frac Ar & 0.012 & 0.012 & 0.013 & 0.013 & 0.0125 & 0.012 & 0.012 & 0.013 & 0.013 & 0.013 \\
\hline 11 & Injection Gas Properties & & & & & & & & & & \\
\hline 12 & wt frac $\mathrm{CH} 4$ & N/A & 1 & 1 & 1 & 1 & N/A & 1 & 1 & 1 & 1 \\
\hline 13 & wt frac air & N/A & 0 & 0 & 0 & 0 & N/A & 0 & 0 & 0 & 0 \\
\hline 14 & Temperature@ hole, K & N/A & 700 & 580 & 580 & 600 & N/A & 700 & 580 & 580 & 600 \\
\hline 15 & & & & & & & & & & & \\
\hline 16 & Temperature inlet upstre am [K] & 1710 & 1710 & 1710 & 1710 & 1710 & 1470 & 1470 & 1470 & 1470 & 1470 \\
\hline 17 & Stagnation pressure inlet upstre am (abs, bar) & 17.54 & 17.54 & 17.54 & 17.54 & 17.54 & 16.95 & 16.95 & 16.95 & 16.95 & 16.95 \\
\hline 18 & Inj. incidence (Q) hole [deg] & N/A & 69.6 & 0 & 69.6 & 60 & N/A & 69.6 & 0 & 69.6 & 60 \\
\hline 19 & pressure hole (abs, bar) & N/A & 13.77 & 9.82 & 6.79 & 3.02 & N/A & 13.58 & 8.98 & 6 & 2.68 \\
\hline 20 & U-velocity/s qtitpinfirhoinf) @ hole [-] & N/A & 0.101 & -0.323 & 0.168 & 0.369 & N/A & 0.249 & -0.86 & 0.459 & 0.45 \\
\hline 21 & sqtípint'thoinf) QQ hole [m/s] & N/A & 717.20 & 717.20 & 717.20 & 717.20 & N/A & 665.25 & 665.25 & 665.25 & 665.25 \\
\hline 22 & u-velocity (Q) hole [m/s] & N/A & 72.44 & .231 .65 & 120.49 & 264.65 & N/A & 165.65 & .572 .12 & 305.35 & 299.36 \\
\hline 23 & Inj. Velocity, V [m's] & N/A & 207.81 & .231 .65 & 345.66 & 529.29 & N/A & 475.22 & .572 .12 & 876.00 & 598.73 \\
\hline 24 & Inj. hole location, I-station & N/A & 77 & 1 & 77 & 70 & N/A & 77 & 1 & 77 & 70 \\
\hline 25 & Inj. hole location, grid number & N/A & 2 & 6 & 6 & 10 & N/A & 2 & 6 & 6 & 10 \\
\hline 26 & & & & & & & & & & & \\
\hline 27 & Dynamic viscosity (o. hole / Dyn. visc. Inlet fl] & N/A & 0.589 & 0.521 & 0.521 & 0.534 & N/A & 0.641 & 0.567 & 0.567 & 0.581 \\
\hline 28 & Dynamic viscosity @e inlet upstream [Pas] & $5.58 \mathrm{E}-05$ & $5.58 \mathrm{E}-05$ & $5.58 \mathrm{E}-05$ & $5.58 \mathrm{E}-05$ & $5.58 \mathrm{E}-05$ & $5.13 \mathrm{E}-05$ & $5.13 \mathrm{E}-05$ & $5.13 \mathrm{E}-05$ & $5.13 \mathrm{E}-05$ & $5.13 \mathrm{E}-05$ \\
\hline 29 & 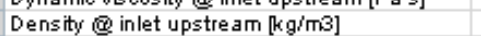 & 3.41 & 3.41 & 3.41 & 3.41 & 3.41 & 3.83 & 3.83 & 3.83 & 3.83 & 3.83 \\
\hline 30 & Density @ hole [kg/m3] & N/A & 3.796 & 3.267 & 2.259 & 0.971 & N/A & 3.743 & 2.987 & 1.996 & 0.862 \\
\hline 31 & Inj. hole diameter use as input [mm] & N/A & 0.3 & 0.45 & 0.3 & 0.3 & N/A & 0.3 & 0.45 & 0.3 & 0.002 \\
\hline 32 & Inj. hole effective diameter [mm] & N/A & 0.541 & 0.566 & 0.554 & 0.838 & N/A & 0.541 & 0.566 & 0.554 & 0.838 \\
\hline 33 & Main gas mass flow rate $[\mathrm{kg} / \mathrm{s}]$ & 74.67 & 74.68 & 74.67 & 74.68 & 74.68 & 83.94 & 83.94 & 83.94 & 83.94 & 83.94 \\
\hline 34 & Fuel inj. mass flow rate $[\mathrm{kg} / \mathrm{s}]$ & N/A & 0.4268 & 0.4284 & 0.4326 & 0.4307 & N/A & 0.9623 & 0.9672 & 0.9687 & 0.4325 \\
\hline 35 & Fuel inj. / main gas [-] & N/A & 0.00571 & 0.00574 & 0.00579 & 0.00577 & N/A & 0.01146 & 0.01152 & 0.01154 & 0.00515 \\
\hline 36 & Power increase [\%] & 0 & 5.5 & 0.5 & 0.3 & 0.2 & 0 & 0.6 & 0.07 & 0.07 & 0.2 \\
\hline 37 & Power inclre ase / fuel injection mass flow rate & 0 & 0.07365 & 0.00670 & 0.00402 & 0.00268 & 0.00000 & 0.00715 & -0.00596 & 0.00477 & 0.00238 \\
\hline
\end{tabular}

Table 25 - Parameter variation for the additional cases of in situ reheat 

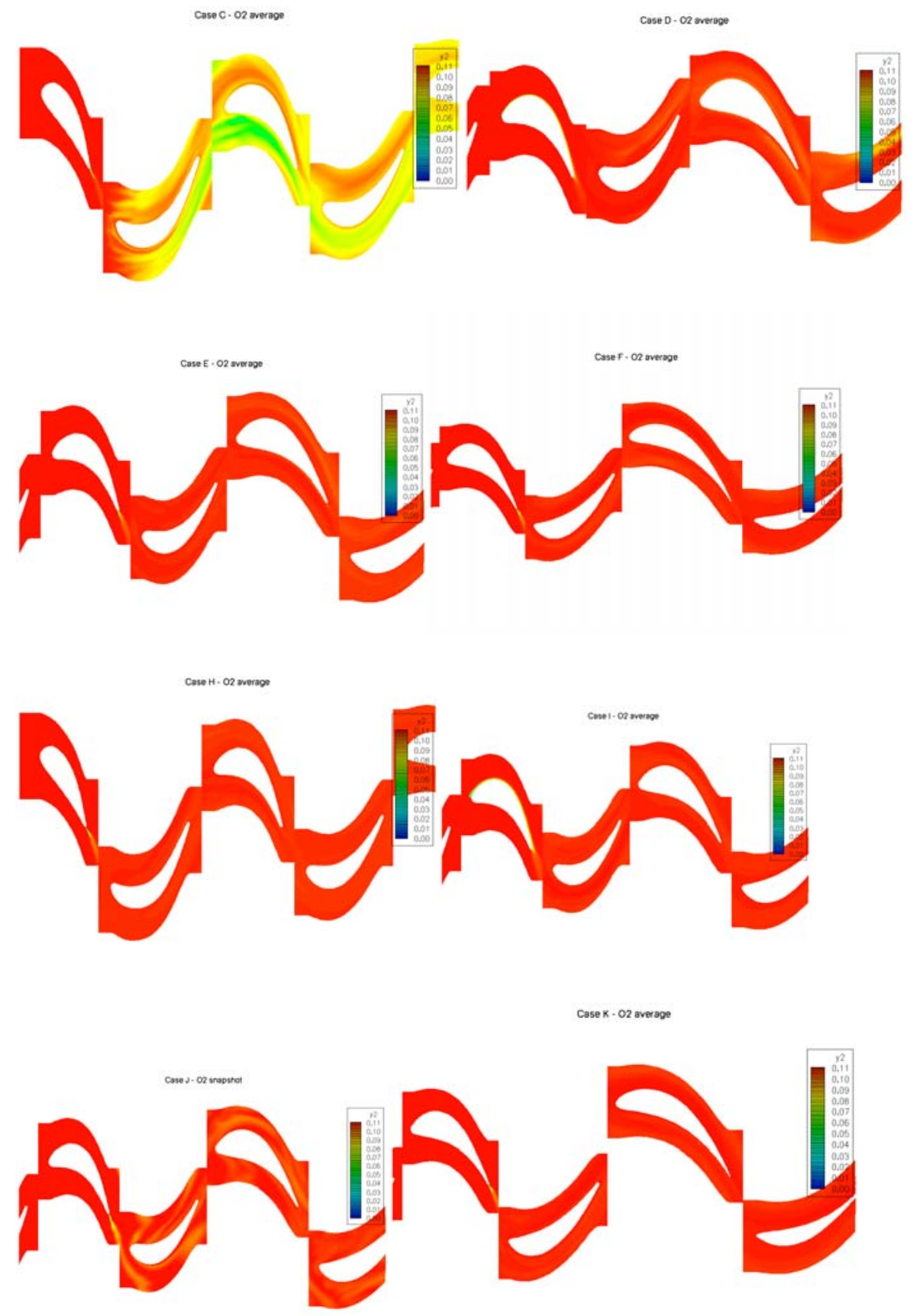

Figure 29 - Oxygen contours for cases $\mathrm{C}$ through $\mathrm{K}$. 

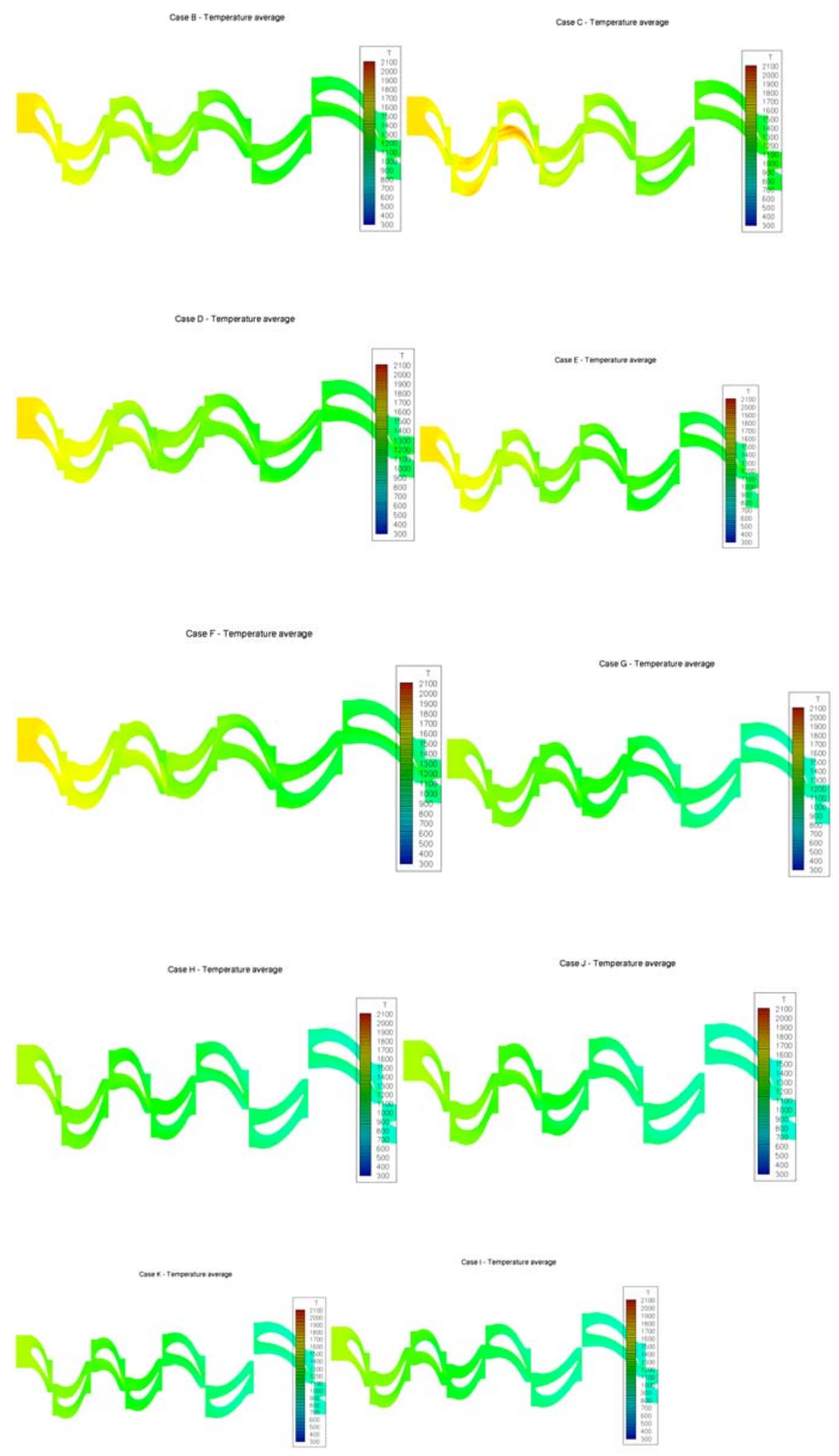

Figure 30 - Temperature contours for cases B through $\mathrm{K}$. 


\section{CONCLUSIONS}

The numerical simulation proved that the combustion model is sufficiently accurate to produce reliable results for parametric studies. The same conclusion results from an on going calibration of the combustion model against detailed experimental data provided by Sandia [4]. The numerical simulation showed that power can be increased by up to $5 \%$ with a modest amount of fuel injected in the turbine.

The numerical simulation showed that the best location for fuel injection is at the trailing edge of the inlet guide vane. The flow conditions at the trailing edge promote combustion because (1) the gas velocity in the airfoil's wake is small and (2) the vortices shed at the trailing edge enhance mixing or fuel and oxygen. Consequently, the trailing edge acts as a good flame holder. When the fuel was injected in the second or third stages, however, the combustion either was not initiated or was much weaker compared to the case when the fuel was injected at the inlet guide vane. Reduced temperature and pressure adversely affected in situ reheat on second and third vanes.

Fuel injection at the leading edge of second vane did not significantly increase power, although a counter-flow flame has some advantages. The numerical simulation showed that the location of the injection at the leading edge needs to be moved toward the pressure side in order to avoid the flame being swept towards the suction side. The flow unsteadiness at leading edge was another factor that adversely affected the combustion of a fuel injected with constant velocity. 


\section{RECOMMENDATIONS}

The numerical investigation, calibrated by experimental data, showed that combustion in the turbine is possible and that in situ reheat increases significantly the power of the turbine. The numerical simulation, however, did not take into account the radial variation effects on in situ reheat. Consequently, an important next step in the numerical simulation is the replacement of the quasi-three-dimensional model by a fully three-dimensional model. This will allow to properly capture the radial variation effects on in situ reheat. The modeling of the combustion process can be improved as well. One possible improvement is related to the diffusion modeling, where the constant diffusion coefficients will be replaced by binary mixture coefficients. Another improvement will be obtained by replacing the existing two-step combustion model by a five-step combustion model or, even better, by the ARM2 model, a sixteen-step combustion model.

Although the numerical simulation is important, the most important next step is the experimental investigation of a scaled down, one and a half stage turbine-combustor. This experimental investigation will provide critical data on the interaction between the in situ reheat, the rotor/stator interaction and the combustor hot streaks. This experiment will also provide the apparatus necessary to investigate different approaches for fuel injection and blade cooling. The experiment can be done at the blow down facility of the Texas A\&M University. This facility provides approximately $10 \mathrm{~kg} / \mathrm{sec}$ at 44 bar for approximately 5 minutes. If necessary, the mass flow rate can be increased by reducing the operating time. A large variety of measurement equipment is also available, including Laser Doppler Anemometry, Particle Image Velocimetry, 18-hole omni-directional probes, etc. 


\section{REFERENCES}

1. Cizmas, P., 1999, Transition and blade count influence on steam turbine clocking, Tech. Rep., Texas Engineering Experiment Station, College Station, Texas.

2. Isvoranu, D. and Cizmas, P, 2003, Numerical simulation of combustion and rotorstator interaction in a turbine combustor, International Journal of Rotating Machinery, 9 (5), pp. 363-374.

3. Westbrook, C. and Dryer, F., 1981, "Simplified Reaction Mechanisms for the Oxidation of Hydrocarbon Fuels in Flames," Combustion Science and Technology, 27, pp. 31-43.

4. Barlow, R., Sandia National Laboratories, Private communication. 


\section{Attachment II: Task 2 - Combustion and Emissions}

\section{SUMMARY}

Gas turbine reheat is a well-known technique for increasing the power output of gas turbine, as well as the efficiency in combined cycle operation with higher heat recovery inlet temperatures. The technique also could allow development of an advanced high efficiency turbine with an additional stage, but without a higher inlet temperature. A novel reheat approach, with fuel added via internal passages in turbine airfoils, has been proposed [1]. This avoids the bulky and possible high-Nox discrete reheat combustors used in traditional approaches. The key questions regarding this approach are whether there is sufficient residence time at high temperature for fuel burnout, and whether increased emissions of Nox and $\mathrm{CO}$ result. This project examines the chemical kinetics basis of these questions.

In the present task detailed chemical kinetics models were used to evaluate injection reheat combustion. Models used included a Siemens Westinghouse diffusion flame model, the set of CHEMKIN gas-phase kinetics equation solvers, and the GRI 3.0 detailed kinetics data base. These modules are called by a reheat-specific main program, which also provides them with data, including gas path conditions that change with distance through the turbine.

Conceptually, injection could occur in either of two ways: 1) direct injection via holes in airfoil trailing edges; or 2) injection at the downstream faces of small bluff bodies placed at these edges. In the former case, combustion could occur as a diffusion flame at the hole, as a plume or streak following this zone, or as a substantially mixed out homogeneous region downstream. In the latter case, combustion could occur as a lower temperature, well-mixed, recirculating flame in the wake of the bluff body, followed by burnout in the same sequence of diffusion flame, streak, and mixed out.

The results were as follows. In the case of a conventional four-stage engine, vane 1 trailing edge injection can be achieved with complete burnout without a flameholder. However, there are projected Nox and $\mathrm{CO}$ penalties of about 10 ppmv each. For vane 2 injection a flameholder is necessary, although the CO survival is expected to be larger, on the order of 50 ppmv. In the case of an advanced five-stage engine, injection at vane 2 (same size and conditions, except temperature, as vane 1 of a 4-stage engine) should be with a flameholder to minimize $\mathrm{CO}$, keeping Nox and $\mathrm{CO}$ increases at about 20 and 10 ppmv respectively. 


\section{PRELIMINARY NON-FLAMEHOLDING ANALYSIS}

The CHEMKIN detailed kinetic model, one-dimensional plug-flow, was used with the GRI detailed kinetics database to characterize burnout as a function of conditions in the blade path. In these calculations, complete mixing of the fuel and main gas was assumed to occur at the injection point. Furthermore, these injections were assumed to occur without the benefit of a flameholder, i.e. a geometry that would provide a sheltered recirculation zone.

Figures $1 \mathrm{a}$ and $1 \mathrm{~b}$ show burnout with injection at the trailing edge of a typical first stage vane, and with injection at the trailing edge of a second stage vane after first stage injection. For first stage injection there is an ignition lag that causes fuel burnout around the following blade. For second stage injection following first stage injection, burnout begins in the vicinity of the blade, but is slow and is not complete until the flow approaches the leading edge of the next vane. Non-flameholder ignition for second stage injection without first stage injection is not predicted.

No Nox formation occurs with this injection, for these assumptions, so that total molar Nox emissions are the same as for no reheat. Since Nox emissions are normalized to $15 \%$ oxygen (to make Nox emissions per mole of fuel the emissions criteria), the normalized emissions go down with reheat. For one and two stages of reheat the normalized Nox emissions are $15 \%$ and $26 \%$ lower than for no reheat.

Figure 2 summarizes temperature and Nox effects.

Added CO for one stage of reheat, by the end of fuel burnout are about $+10 \mathrm{ppmv}$. This will likely burnout in the balance of the turbine. Added $\mathrm{CO}$ for a second stage of reheat by the end of fuel burnout is about +100 ppmv, and burnout downstream is problematic.
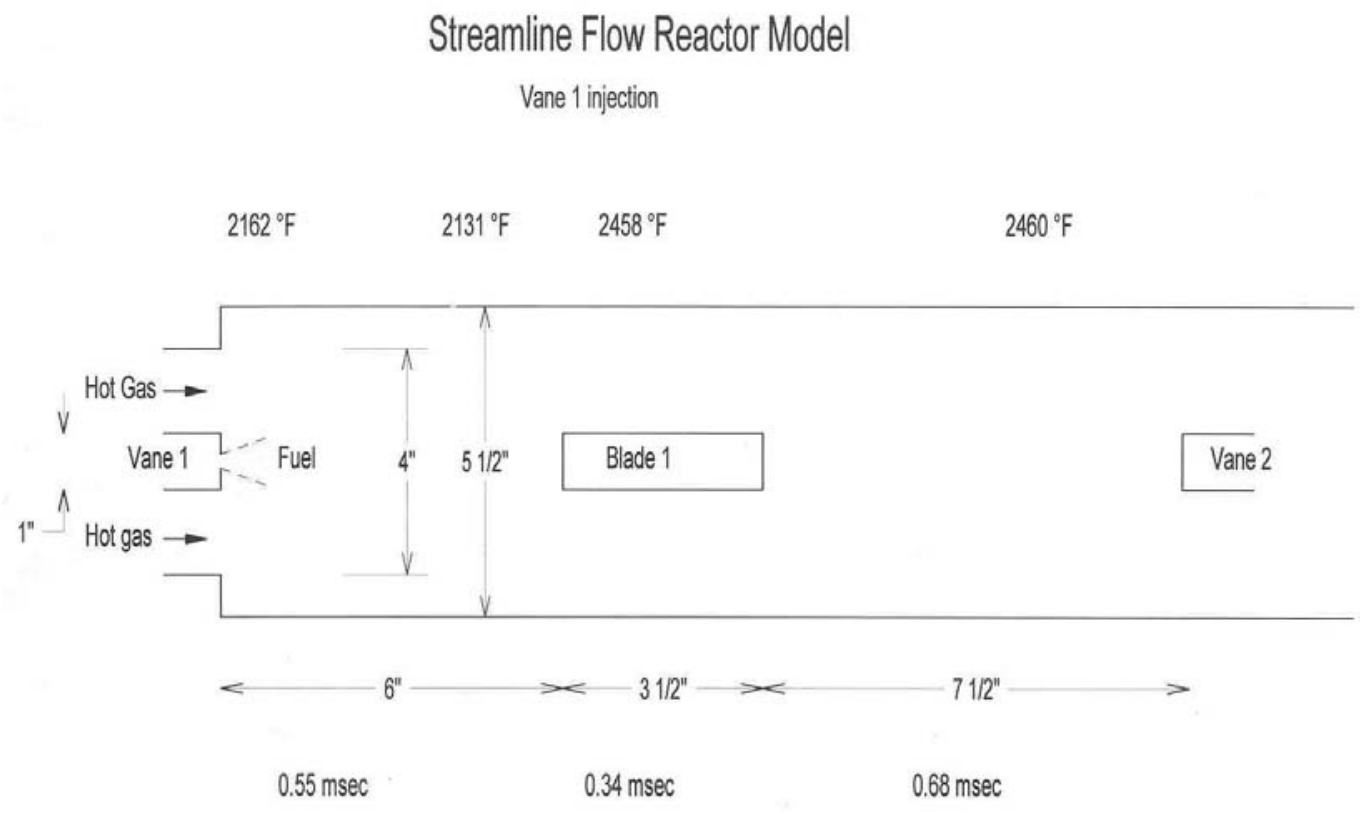

Figure 1a-Vane 1 Injection Kinetics. 


\section{Streamline Flow Reactor Model}

Vane 2 injection after Vane 1 injection

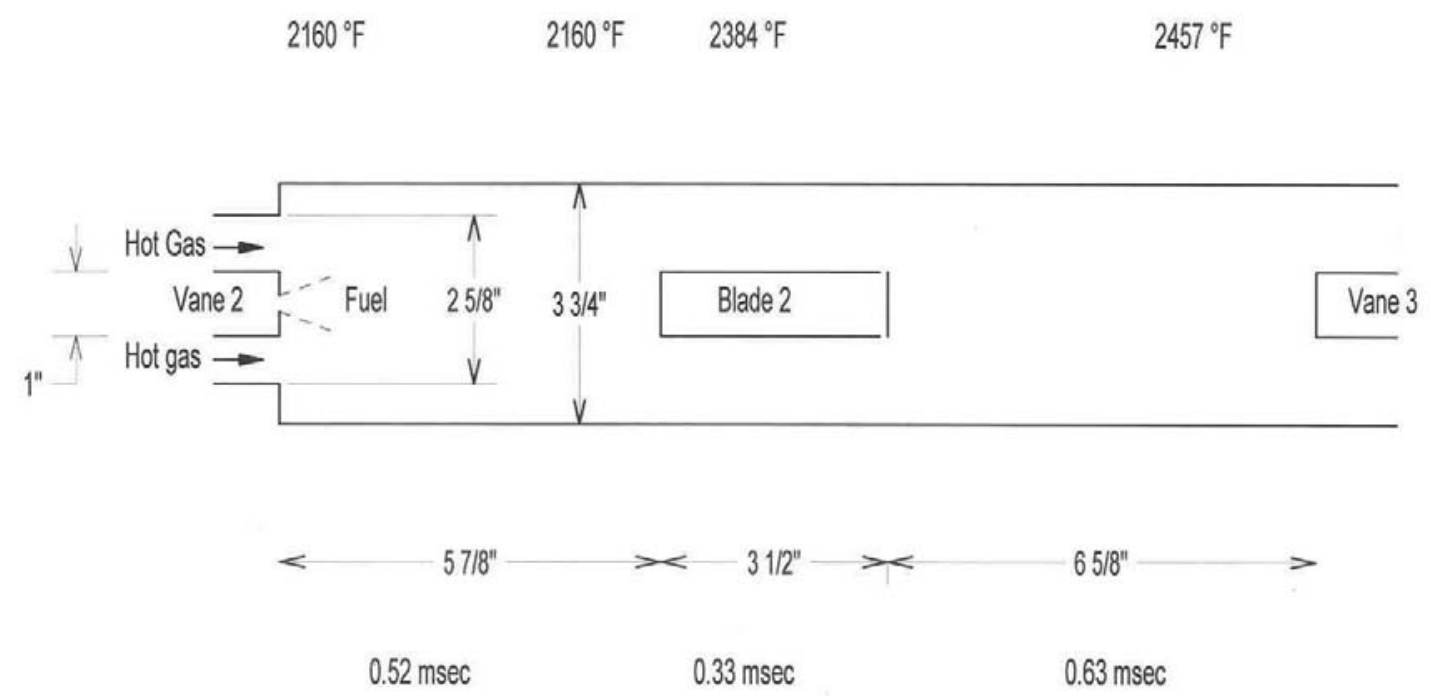

Figure $1 \mathrm{~b}-$ Vane 2 Injection Kinetics.

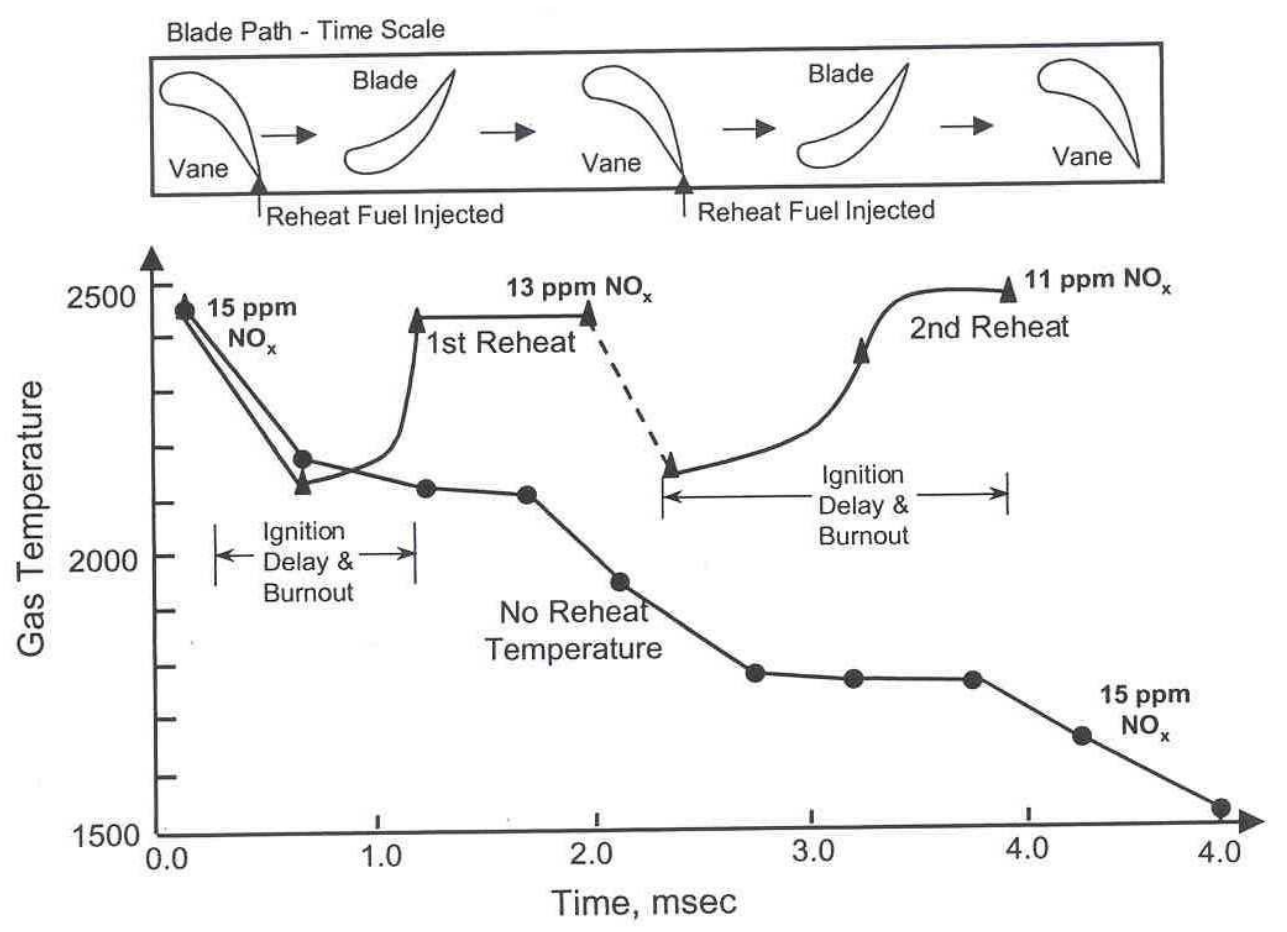

Figure 2 - Blade Path Temperature and Nox with 2-stage Reheat. 


\section{NON-FLAMEHOLDING DESIGN CONCEPT}

\subsection{Modeling Approach}

For non-flameholding design concepts, fuel is injected directly through small holes in the trailing edges of blades or vanes. The chemical kinetics versus length through the turbine for this case were estimated using a proprietary Siemens Westinghouse computer model, DFLAME, for calculating flame sizes, residence times, and chemical kinetics of diffusion flames. The reheat calling program provides blade path conditions varying with axial position to DFLAME, and calculates post-flame continuation of combustion, to estimate burnout, emissions, and possible streaking.

The burnout kinetics for the post-flame zone were calibrated using the test data from the present project. Then, the overall model was used to project performance and emissions for a variety of parametric cases.

\subsubsection{Calling Module}

The main module for reheat kinetic calculations follows the progress of the injected fuel and jet-entrained bulk gas, until the identity of these jets vanishes; and then follows the resulting total bulk gas mixture to the end of the turbine, calculating kinetics as it goes. In this way final conversion and emissions are determined, and streaking is identified by the way the jet flames and plumes.

The program proceeds by the following steps:

1) Input parameters are read: reheat fuel composition, flow rate, temperature; number and size of holes per vane; main gas flow and composition into vane 1.

2) Also read are path conditions at each station: axial position, gas angle, flow area normal to axis, static pressure, static temperature, cumulative cooling air flow, and number of airfoils. Stations are the leading and trailing edge axial locations for each airfoil.

3) The initial velocity and density of the injected fuel are determined, as limited for sonic flow.

4) The diffusion flame model (DFLAME, see Section 3.1.2) is repeatedly used to determine diffusion flame length (stoichiometric entrained main gas/fuel ratio) and final width, plume length and width, and resulting composition and temperature for each. The diffusion flame is defined as the stoichiometric mixture of reheat fuel and entrained bulk gas. It may or may not be lit, as determined by DFLAME. The "plume" is defined as the continuation of the diffusion flame by addition of entrained main gas in increments until the jets merge. The calling program provides an effectiveness factor, i.e. a residence time multiplier used to account for imperfect mixing, to DFLAME for plume increments. At each increment, conditions, both jet and surrounding, are recorded. These include: axial location, jet mass flow, cumulative jet gas residence time, jet temperature, bulk gas temperature, carbon conversion, and CO and Nox raw ppmv. The jet gas composition is recorded at the end of the diffusion flame and at the end of the plume. 
5) The remaining bulk gas at the end of the plume is mixed into the plume product gas to form the initial total gas mixture.

6) The total gas mixture is followed through the rest of the turbine, station by station. The gas mixture temperature (initially higher than for non-reheat operation) and pressure are assumed to fall in increments as per the non-reheat case. For each such step (plume to next station and then station to station) : -.. ' - ing air is mixed in, the residence time is determined, and chemical kinetis II-4 d using the CHEMKIN plug flow module with GRI 3.0 kinetics, resulting 1 and additional temperature change. An effectiveness factor is deter $\mathrm{h}$ increment conditions are recorded, including: station number, axial location, mass flow, cumulative gas residence time after plume, gas temperature, carbon conversion, and CO and Nox raw ppmv. The final station gas composition is then recorded, as well as the normalized $(15 \% \mathrm{O} 2$, dry) $\mathrm{CO}$ and Nox.

\subsubsection{Diffusion Flame Model}

\section{Overall Structure.}

The model (DLAME) calls several modules of the CHEMKIN Collection, which uses the GRI 3.0 kinetic database. It proceeds according to the following steps. Italicized statements indicate functions of the calling program external to DFLAME.

1) For each jet length increment, steps 2 through 10 are executed. Recall that the first increment corresponds to the diffusion flame, and subsequent increments to portions of the plume.

2) The total jet length through this increment is guessed. The end position blade path conditions are provided by the calling module.

3) The composition of the total bulk gas (initial bulk gas and incremental cooling air) is calculated.

4) The jet equivalence ratio for the increment is known from the definition of the increment. The bulk gas entrainment to achieve this equivalence ratio is determined.

5) The mass flow, composition, and temperature of the mixture are calculated. For the first increment (diffusion flame) this is the mixture of fuel and entrained gas. For subsequent increments this is the mixture of the reacted product from the previous increment and the additional entrained gas.

6) The equilibrium composition and temperature are calculated.

7) The diffusion flame (or flame plus plume) length and width are calculated based on the methods in the following subsections.

8) This length is compared to that guessed in step 2. If they are the same, the calling program uses the sequence of gas angles to calculate the axial end location for the increment, and DFLAME proceeds to step 9. If not, a new length is guessed and DFLAME returns to step 2. 
9) The volume of the increment and the residence time of gases in it are calculated using this volume, the flow rate from step 5, and the temperature and molecular weight from step 6.

10) The kinetics of the jet flame is calculated using the CHEMKIN code, the GRI 3.0

kinetic database, the initial composition and temperature from step 5, and the residence time from step 8 . For the first (diffusion flame) increment only this residence time is divided into a well-stirred portion followed by a plug-flow portion. For plume increments the residence time is all plug-flow. This residence time is multiplied by an "effectiveness factor" to account for im! effectiveness factor is internal to DLAN

The diffusion flame this effectiveness factor is provided by $t_{1}$ ior data. For the plume segments ram.

\section{$\underline{\text { Jet Diameter }}$}

A jet of the nozzle fluid reactant (usually fuel) issues from a nozzle into a stream of flowing mainstream reactant (usually oxidant). The model for circular turbulent jet flames into a stagnant main stream is that of Hawthorne, Weddell, and Hottel [2]. Expansion of the model to a co-flowing main stream has been added.

A mass balance on nozzle fluid at constant pressure on nozzle fluid gives

$$
\frac{D^{2} V C \alpha}{T}=\frac{D_{n}^{2} V_{n}}{T_{n}}
$$

A momentum balance from the nozzle plane gives

$$
D^{2} V^{2} \rho=D_{n}^{2} V_{n}^{2} \rho_{n}+\left(D^{2}-D_{n}^{2}\right) V_{a}^{2} \rho_{a}
$$

and the density ratios are

$$
\frac{\rho}{\rho_{n}}=\left[C+\frac{M_{a}}{M_{n}}(1-C)\right] \frac{\alpha T_{n}}{T}
$$

and

$$
\frac{\rho_{a}}{\rho_{n}}=\frac{M_{a}}{M_{n}} \frac{T_{n}}{T_{a}}
$$

At the nozzle plane,

$$
\begin{array}{ll}
\mathrm{D}_{\mathrm{n}} & =\text { nozzle inside diameter } \\
\mathrm{V}_{\mathrm{n}} & =\text { velocity of nozzle fluid exiting nozzle } \\
\mathrm{T}_{\mathrm{n}} & =\text { temperature of nozzle fluid } \\
\mathrm{M}_{\mathrm{n}} & =\text { molecular weight of nozzle fluid } \\
\rho_{\mathrm{n}} & =\text { density of nozzle fluid } \\
\mathrm{V}_{\mathrm{a}} & =\text { velocity of entrained main-stream fluid } \\
\mathrm{T}_{\mathrm{a}} & =\text { temperature of entrained main-stream fluid } \\
\mathrm{M}_{\mathrm{a}} & =\text { molecular weight of entrained main-stream fluid }
\end{array}
$$




$$
\rho_{\mathrm{a}} \quad=\text { density of entrained main-stream fluid }
$$

and, at any height of interest

$$
\begin{array}{ll}
\mathrm{D} & =\text { jet diameter } \\
\mathrm{V} & =\text { velocity of (reacted) jet fluid } \\
\mathrm{T} & =\text { (reacted) mixture temperature }
\end{array}
$$

4. = density of (reacted) mixture

$\mathrm{C} \quad=$ moles of nozzle fluid per mole of unreacted mixture

5. $=$ moles of reactants per mole of product

Combining equations 1 through 4 gives

$$
\text { II-6 }
$$

$$
D=D_{n} \sqrt{ } x
$$

the equation for the jet diameter at any stoichiometry (defined by $\mathrm{C}$ and $\alpha$ ), where $\mathrm{x}$ is a root of

$$
a x^{2}+b x+c=0
$$

in which

$$
\begin{aligned}
& a=\left(\frac{V_{a}}{V_{n}}\right)^{2} \frac{M_{a} T_{n}}{M_{n} T_{a}} \\
& b=1-a \\
& c=-\frac{1}{C^{2}}\left[C+\frac{M_{a}}{M_{n}}(1-C)\right] \frac{T}{\alpha T_{n}}
\end{aligned}
$$

Note that Equations 5 through 9 reduce to the solution by Hawthorne et al. [ref. 2, eq. 32] for a stagnant main stream if $\mathrm{V}_{\mathrm{a}}=0$.

Hawthorne et al. [2] originally applied this model to what we call in this report the diffusion flame, i.e. the region containing stoichiometric fuel and air. There is no reason it cannot be applied to other stoichiometries, representing the plume increments in this case, as we have done simply by using the appropriate values of $\mathrm{C}$ and $\alpha$.

For reheat applications, the calling program scales the final diameter by the ratio of the projected area along the flow path at the end of the jet to the projected area along the flow path at the beginning of the jet.

\section{$\underline{\text { Jet Length }}$}

Wohl, Gazley, and Kapp [3] developed a theoretical expression for lengths of laminar diffusion flames. In DFLAME, this is used for turbulent diffusion flames, with substitution of the eddy diffusivity for molecular diffusivity.

The flame length is then 


$$
H=\frac{Q}{-4 \pi K \ln (1-C)}
$$

where

$$
\begin{aligned}
& \mathrm{H}=\text { flame length } \\
& \mathrm{Q}=\text { volumetric flow rate of nozzle fluid (fuel) } \\
& \mathrm{C}=\text { moles of nozzle fluid per mole of the unreacted mixture } \\
& \mathrm{K} \text { = eddy diffusivity }
\end{aligned}
$$

The eddy diffusivity definition used is bas II-7 ]:

$$
K=0.0^{\prime} \cdots \cdot e^{x}
$$

Turns's development is for a jet into a stagnant medium, so his $\mathrm{V}_{\mathrm{e}}$ is the nozzle velocity. In the present case, the jet is into a co-flowing stream, and we have found that the appropriate representative velocity for use in eq. (11) is

$$
V_{e}=\sqrt{V_{n} \cdot \mid\left(V_{a}-V_{n} \mid\right.}
$$

This accounts for both the kinetic energy of the nozzle fluid and the shear between nozzle fluid and surrounding fluid.

Again $\mathrm{C}$ is adjusted for the stoichiometry of the increment.

\section{Jet Volume and Reactant Residence Time}

The jet volume is determined by the conic frustum with one base area $\left(\mathrm{A}_{1}\right)$ equal to the nozzle diameter and the other $\left(\mathrm{A}_{2}\right)$ by the final jet width:

$$
\text { Volume }=H / 3 \cdot\left(A_{1}+A_{2}+\sqrt{A_{1} A_{2}}\right)
$$

The jet is assumed to expand and contract along its path in proportion to the projected cross-sectional area along the path, which changes because of expansion of turbine crosssection and variation of gas angle. The final volume is adjusted by the calling program to account for this.

\subsubsection{Empirical Factors}

The experimental data from the present project (Task 3, see Section 3.2 below) was used to calibrate the reheat model. The effectiveness factor used as a multiplier for residence times in plume and post-plume kinetic calculations was used as the empirical factor. It may be interpreted as a fall-off in rate due to mixing limitations, with products insulating the surviving fuel pockets from the surrounding oxygen supply.

$$
\eta=(1-X)^{n}
$$

where

$$
\eta=\text { effectiveness factor }
$$




$$
\begin{aligned}
& \mathrm{X}=\text { fractional carbon conversion } \\
& \mathrm{n}=\text { empirical constant, found to be } 1.6
\end{aligned}
$$

with $\eta$ limited to a minimum value of 0.06 .

\subsection{Fit to Experimental Data}

In Task 3 of this program subscale testing test rig is shown schematically in Figure 3. II-8

ut kinetics was conducted. The at conditions of up to $755 \mathrm{~K}\left(900^{\circ} \mathrm{F}\right)$ and 1 ow of up to $0.2 \mathrm{~kg} / \mathrm{s}(0.44 \mathrm{lb} / \mathrm{sec})$ natural gas-fired dump combustor to gener ia) fired a full pressure (14 bar) temperature are varied to give product temperatures and compositions corresponding to typical turbine locations as a function of blade path position. In each case the product mixture is passed through a pressure-reducing orifice (to about 5.5 bar (80 psia)) to raise the Mach number in the test channel to a level representative of an industrial gas turbine. This is necessary because the available air flow precludes maintaining both pressure and velocity in a channel of acceptable size.

The gas mixture enters a rectangular $1.78 \mathrm{~cm} \times 2.54 \mathrm{~cm}(0.7$ in $\times 1.0$ in) channel and passes a probe that crosses the centerline of the channel. The probe is used to inject fuel via a hole in its trailing edge. The geometry of the probe is shown in Figure 4. Fuel is injected through a $0.66 \mathrm{~mm}(0.026 \mathrm{in})$ diameter hole. Following the probe, the gas and fuel jet enter a $1.78 \times 1.78 \mathrm{~cm}(0.7$ in $\times 0.7$ in) test channel. Temperature and gas composition are measured with centerline sampling probes at several locations in the test section.

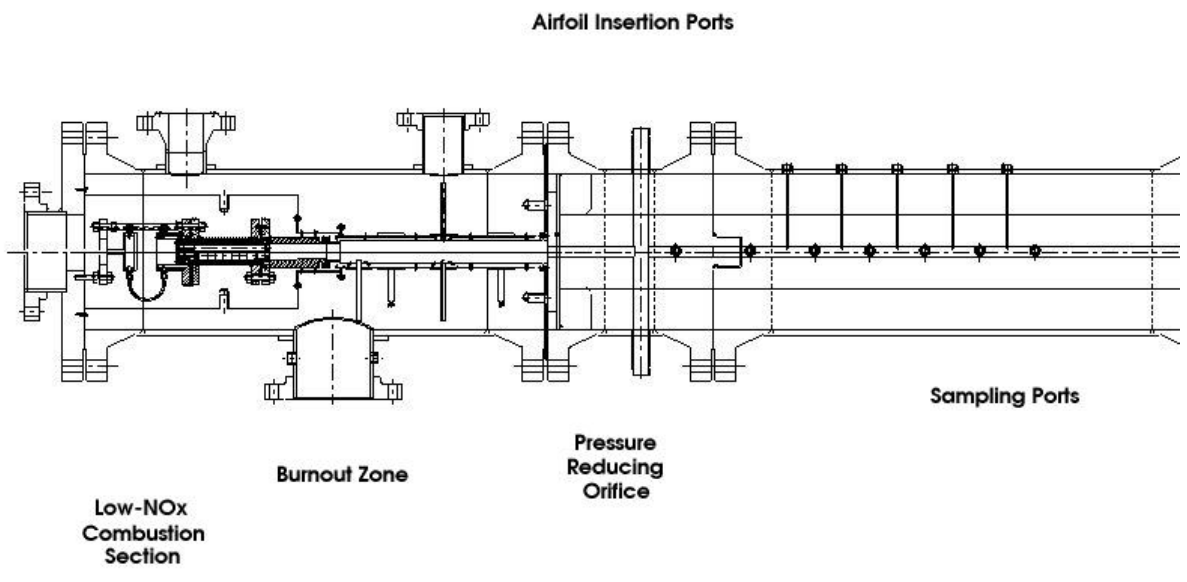

Figure 3 - Experimental Apparatus. 

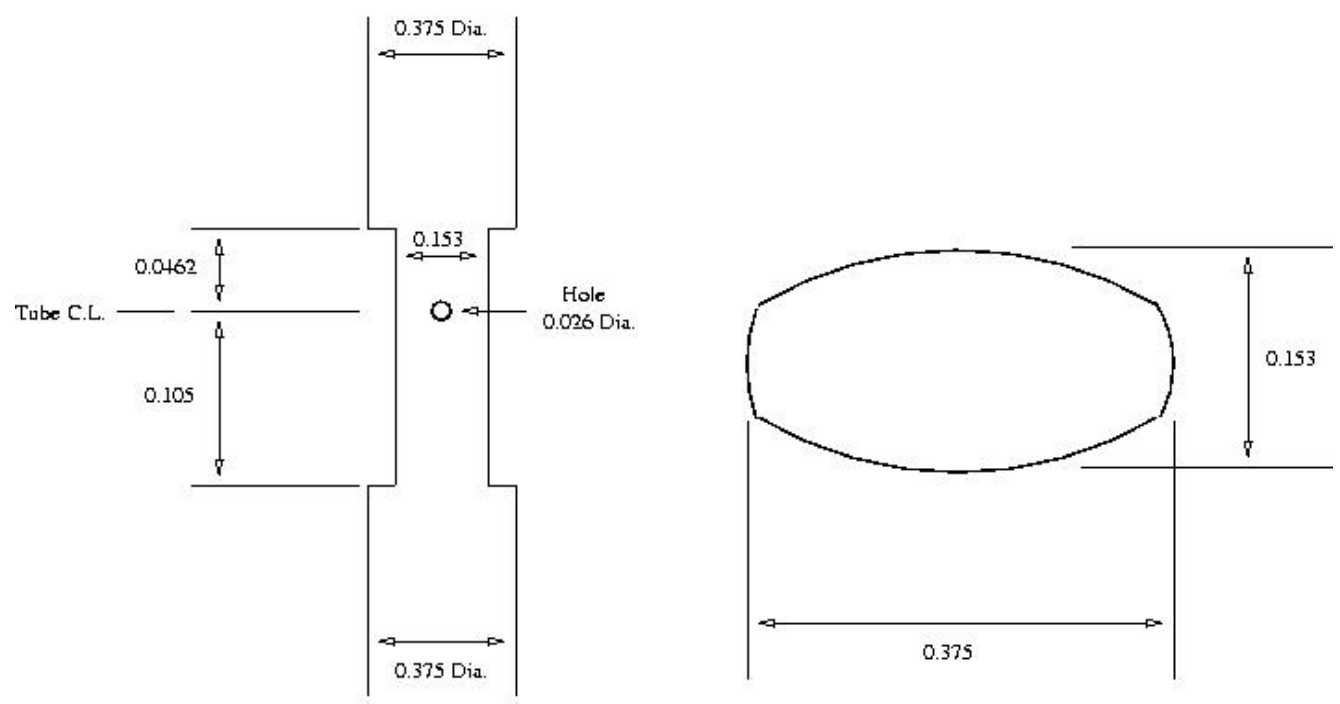

NOTE: Al] Lengths Shown in Lnches

Deawing Not To Scale

Figure 4 - Combustion Probe.

With fuel injection at conditions corresponding to V1 trailing edge and B1 mid way, burnout was complete prior to the first sampling probe, so these could not be used to calibrate the model. With injection at conditions corresponding to B1 trailing edge and V2 trailing edge, combustion was incomplete, so these points could be so used. Table 1 presents some conditions for several such runs. The natural gas was at $289 \mathrm{~K}$, with a mole percent composition of approximately $96.1 \mathrm{CH} 4,2.0 \mathrm{C} 2 \mathrm{H} 6,0.9 \mathrm{C} 3 \mathrm{H} 8,0.5 \mathrm{CO} 2$, and $0.5 \mathrm{~N} 2$. 
Table 1 - Test Conditions

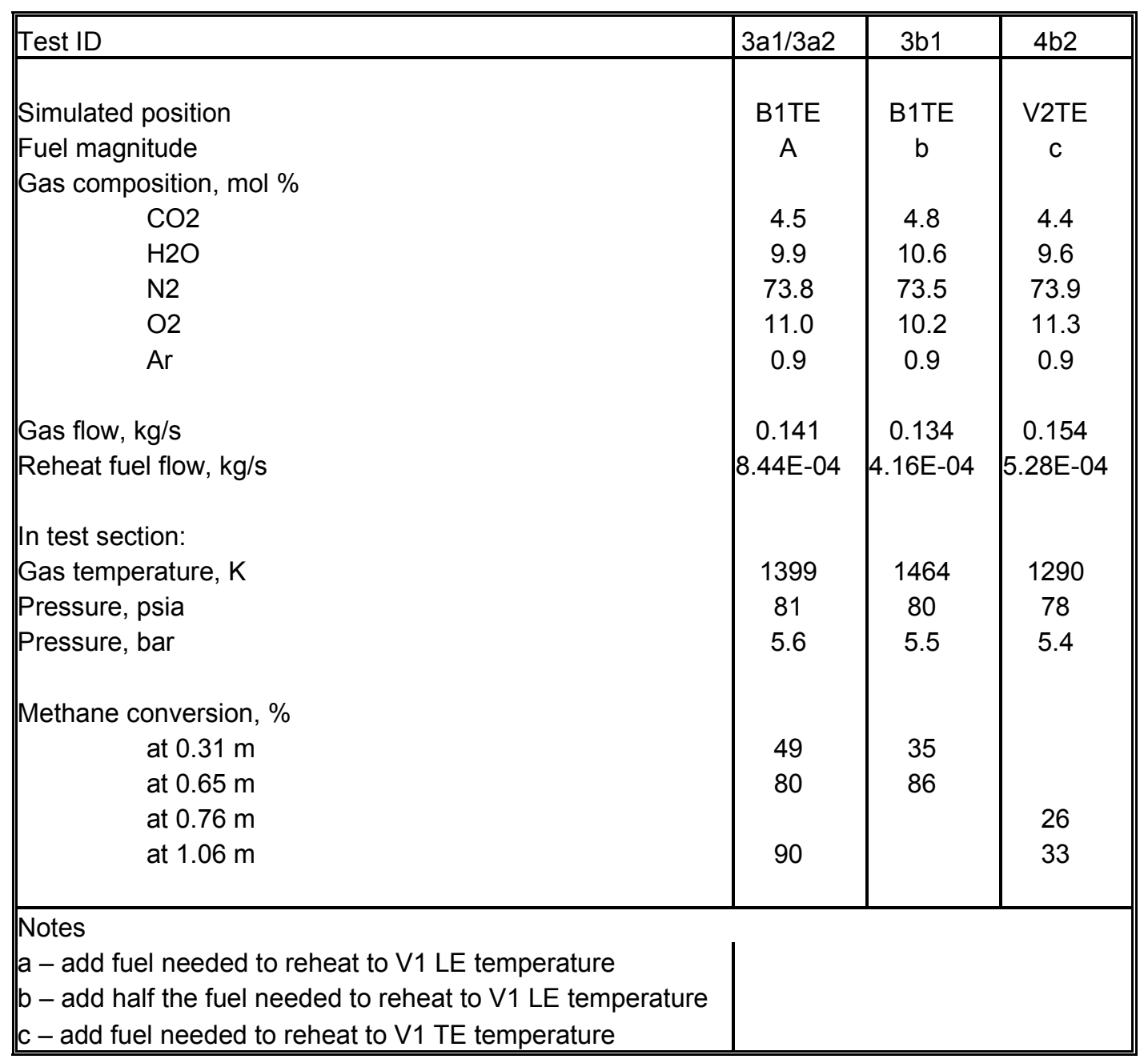


Figure 5 presents the fit of the test data (squares) with the model projections, using the empirical factors from Section 3.1.3 above.
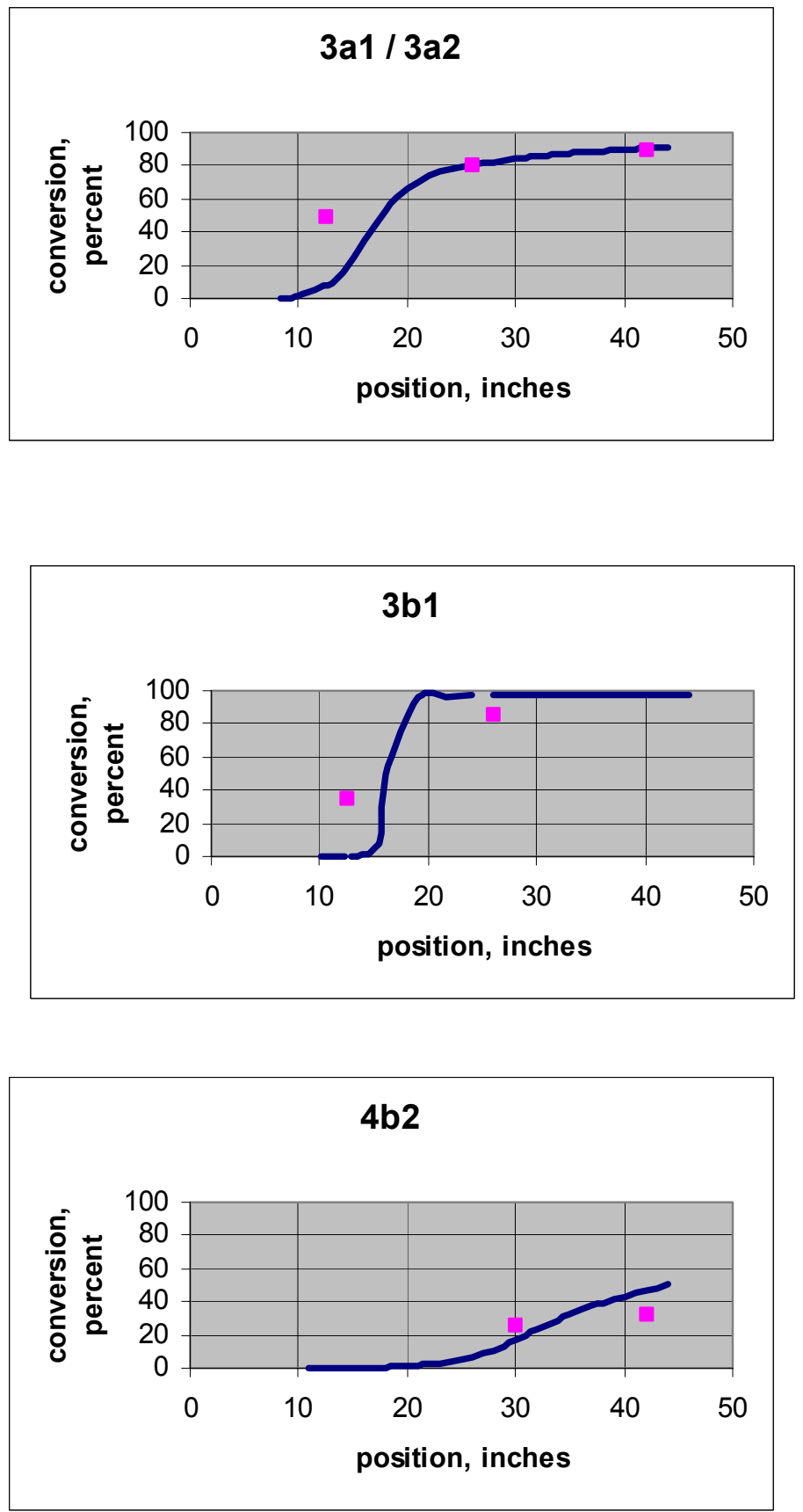

Figure 5 - Carbon Conversion - Model vs Data

\subsection{Parametric Study Results}

The model presented and calibrated in Sections 3.1 and 3.2 was used to explore reheat performance in terms of burnout, streaking, and emissions as functions of location (station) of fuel injection, amount of fuel, hole size, and number of holes. Recall that the diffusion 
flame is defined as that structure contain fuel and a stoichiometric amount of entrained main gas; and that it may or may not be lit, as determined by kinetics.

In all of the following cases it is assumed that the main gas entering the turbine has no CO, and has sufficient Nox to give 8 ppmv normalized Nox at the exit of the turbine after mixing with all cooling air and without reheat.

\subsubsection{Four-Stage Turbine, Vane 1 Injection}

Table 2 and Figures 6 through 9 summarize calculations for injecting sufficient fuel at the vane 1 trailing edge to achieve a $150 \mathrm{C}$ temperature boost, i.e. to return the gas stream temperature to about the vane 1 inlet temperature.

The first five of the six blocks of data in Table 2 show how reheat proceeds as a function of hole size and number $(\mathrm{N})$ at constant total fuel flow. In the first block, the hole size varies, and the number of holes also varies in order to keep the fuel flux (fuel per second per unit total hole area). Thus each block is at a constant fuel velocity. Figures 6 and 7 show how emissions are projected to vary.

At constant velocity (fuel flux), each dimension of the diffusion flame scales (approximately) with hole size, so the diffusion flame volume scales (approximately) with the cube of hole size. Also, the volumetric flow scales with the square of hole diameter. Therefore, the residence time (volume $\div$ volumetric flow) scales linearly with hole size. This is evident in each of the first five blocks in Table 2.

In the first block (number of holes varies to keep fuel flux at $0.08 \mathrm{~kg} / \mathrm{s}-\mathrm{cm} 2$ ), the injected fuel burns as a diffusion flame when using a $3.2 \mathrm{~mm}$ hole size, since there is sufficient high temperature residence time to ignite, resulting in significant Nox emissions. When the hole size is reduced, there is insufficient residence time to hold a lit diffusion flame, and burnout occurs slightly downstream. By this time the jet has been diluted with more entrained gas, resulting in cooler burning, with lower Nox, which continues to decrease with decreasing hole size because of the lower residence time in the plume which follows the same rules as residence time in the diffusion flame. Burnout location (defined here as where $50 \%$ conversion has occurred) also moves upstream in the turbine, so that hotter gases are entrained and burnout zone temperatures become higher. Eventually the effect of hotter burning overcomes the effect of reduced residence time, and Nox begins to increase again. The second $(0.095 \mathrm{~kg} / \mathrm{s}-\mathrm{cm} 2)$ and third $(0.12 \mathrm{~kg} / \mathrm{s}-\mathrm{cm} 2)$ blocks, with fewer holes, follow the same pattern.

For CO, there is also a trade-off, for opposite reasons. Smaller holes mean less residence time for $\mathrm{CO}$ burnout, but higher burnout temperatures for more rapid burnout. Again there is an optimum, as seen in the second and third blocks.

The change in gas angles through the turbine can influence emissions. This is seen in the fourth block in Table 2. A diffusion flame is normally not stable for hole sizes below 1 $\mathrm{mm}$, following the same trend as previous blocks. However, there is an apparently anomalous lack of diffusion flame at the $2.2 \mathrm{~mm}$ hole size. The reason is a local minimum in residence time. This is explained with reference to Figure 8. The volume of the 8-hole flame is almost as low as the volume of the 12 hole flame. This is because the end of the flame lies along the trailing edge the first rotor where the gas angle with respect to the axis is high and the projected cross-sectional area along this path is low; the end of this flame contributes little volume and hence residence time.

The fifth block in Table 2 and Figure 9 show the effect of number of holes at constant hole size. Note that as the number of holes decreases, the velocity issuing from the holes 
increases. As velocity increases there is less shear with the surrounding high velocity gas stream, so the flame spreads more slowly, becoming longer and wider. Jet volume per hole increases more rapidly that flow per hole, the residence time increases. There is again a tradeoff of time and temperature causing minima in emissions for both $\mathrm{CO}$ and Nox in the cases where the diffusion flame is not lit.

Table 3 shows that increasing reheat fuel will cause an increase in emissions.

In summary, for Vane 1 reheat without flameholding, there is projected to be an optimum design with a hole size of about $1.8 \mathrm{~mm}$ and a fuel flux of $0.12 \mathrm{~kg} / \mathrm{s}-\mathrm{cm} 2$ (i.e. 24 holes per vane). Nox and $\mathrm{CO}$ are higher by about $6 \mathrm{ppmv}$ and $9 \mathrm{ppmv}$ (corrected), respectively, than without reheat (bulk 8 ppm $\mathrm{NO}_{\mathrm{x}}, 0 \mathrm{ppm} \mathrm{CO}$ assumed). Also, contrary to initial hypothesis, there is not always an advantage to go to a smaller hole size. There is actually an optimum hole size. This means that design will be more sensitive and uncertain, given uncertainties in the modeling. Further, emissions will increase for increasing reheat rates.

Table 2 - Vane 1 Trailing Edge Reheat, Fuel for 150 C Boost

\begin{tabular}{|c|c|c|c|c|c|c|c|c|c|c|c|c|c|}
\hline Point & $\mathrm{N}$ & $\begin{array}{r}\text { hole size } \\
\mathrm{mm}\end{array}$ & $\begin{array}{r}\text { fuel flow } \\
\mathrm{kg} / \mathrm{s}\end{array}$ & $\begin{array}{l}\text { area } \\
\mathrm{cm} 2\end{array}$ & $\begin{array}{l}\text { Fuel flux } \\
\mathrm{kg} / \mathrm{s}-\mathrm{cm} 2\end{array}$ & $\begin{array}{r}\text { Flame } \\
\text { length } \\
\mathrm{cm}\end{array}$ & \begin{tabular}{|r|} 
Flame \\
width \\
$\mathrm{cm}$ \\
\end{tabular} & $\begin{array}{r}\text { Flame } \\
\text { r.t. } \\
\text { msec } \\
\end{array}$ & $\begin{array}{r}\text { D Flame } \\
\text { lit? }\end{array}$ & $\begin{array}{r}\text { Burnout } \\
\text { loc. } \\
\mathrm{cm}\end{array}$ & \begin{tabular}{|r|} 
Plume \\
end loc. \\
$\mathrm{cm}$ \\
\end{tabular} & $\begin{array}{l}\text { NOx } \\
\text { ppm }\end{array}$ & $\begin{array}{l}\mathrm{CO} \\
\mathrm{ppm}\end{array}$ \\
\hline \multicolumn{14}{|c|}{ Vane 1- Base fuel } \\
\hline 16 & 12 & 3.2 & 2.40 & 30.4 & 0.079 & 15.7 & 2.2 & 0.40 & $\mathrm{y}$ & & 25.9 & 24 & 9 \\
\hline 17 & 18 & 2.6 & 2.40 & 30.4 & 0.079 & 13.0 & 1.7 & 0.30 & $\mathrm{n}$ & 15.5 & 24.6 & 15 & 8 \\
\hline 18 & 24 & 2.2 & 2.40 & 30.1 & 0.080 & 11.3 & 1.4 & 0.25 & $\mathrm{n}$ & 15.2 & 23.9 & 16 & 11 \\
\hline 19 & 36 & 1.8 & 2.40 & 30.3 & 0.079 & 9.1 & 1.1 & 0.19 & $\mathrm{n}$ & 14.7 & 22.1 & 16 & 24 \\
\hline 20 & 48 & 1.6 & 2.40 & 29.9 & 0.080 & 8.1 & 0.9 & 0.15 & $\mathrm{n}$ & 14.5 & 20.6 & 16 & 48 \\
\hline 21 & 72 & 1.3 & 2.40 & 30.4 & 0.079 & 7.1 & 0.8 & 0.13 & $\mathrm{n}$ & 14.2 & 18.5 & 12 & 97 \\
\hline 22 & 15 & 2.6 & 2.40 & 25.3 & 0.095 & 14.7 & 1.9 & 0.35 & $\mathrm{n}$ & 16.0 & 25.4 & 23 & 8 \\
\hline 23 & 20 & 2.2 & 2.40 & 25.1 & 0.096 & 13.0 & 1.6 & 0.29 & $\mathrm{n}$ & 15.5 & 24.6 & 15 & 9 \\
\hline 24 & 30 & 1.8 & 2.40 & 25.2 & 0.095 & 10.4 & 1.2 & 0.22 & $\mathrm{n}$ & 15.0 & 23.4 & 14 & 15 \\
\hline 25 & 40 & 1.6 & 2.40 & 24.9 & 0.096 & 9.1 & 1.1 & 0.18 & $\mathrm{n}$ & 14.7 & 22.1 & 20 & 25 \\
\hline 1 & 8 & 3.2 & 2.40 & 20.3 & 0.119 & 21.4 & 3.0 & 0.64 & $y$ & & 26.9 & 37 & 13 \\
\hline 2 & 12 & 2.6 & 2.40 & 20.2 & 0.119 & 17.6 & 2.2 & 0.45 & $y$ & & 26.4 & 29 & 11 \\
\hline 3 & 16 & 2.2 & 2.40 & 20.1 & 0.120 & 15.3 & 1.9 & 0.37 & $\mathrm{n}$ & & 25.7 & 27 & 9 \\
\hline 4 & 24 & 1.8 & 2.40 & 20.2 & 0.119 & 12.5 & 1.4 & 0.28 & $n$ & 15.5 & 24.5 & 14 & 9 \\
\hline 5 & 32 & 1.6 & 2.40 & 19.9 & 0.121 & 10.9 & 1.2 & 0.23 & $\mathrm{n}$ & 15.2 & 23.6 & 16 & 12 \\
\hline 6 & 48 & 1.3 & 2.40 & 20.2 & 0.119 & 8.9 & 1.0 & 0.17 & $\mathrm{n}$ & 14.7 & 21.8 & 14 & 30 \\
\hline 7 & 96 & 0.9 & 2.40 & 20.2 & 0.119 & 6.4 & 0.6 & 0.10 & $\mathrm{n}$ & 14.0 & 16.8 & 20 & 181 \\
\hline 8 & 4 & 3.2 & 2.40 & 10.1 & 0.237 & 54.2 & 4.6 & 1.60 & $y$ & & 79.5 & 40 & 6 \\
\hline 9 & 6 & 2.6 & 2.40 & 10.1 & 0.238 & 44.9 & 3.3 & 1.09 & $y$ & & 78.5 & 29 & 5 \\
\hline 10 & 8 & 2.2 & 2.40 & 10.0 & 0.239 & 40.1 & 2.0 & 0.75 & $\mathrm{n}$ & & 82.8 & 32 & 5 \\
\hline 11 & 12 & 1.8 & 2.40 & 10.1 & 0.238 & 32.7 & 2.3 & 1.01 & $y$ & & 45.7 & 34 & 12 \\
\hline 12 & 16 & 1.6 & 2.40 & 10.0 & 0.241 & 29.2 & 2.2 & 0.98 & $\mathrm{y}$ & & 43.9 & 34 & 13 \\
\hline 13 & 24 & 1.3 & 2.40 & 10.1 & 0.238 & 23.1 & 1.8 & 0.72 & $y$ & & 27.2 & 33 & 15 \\
\hline 14 & 48 & 0.9 & 2.40 & 10.1 & 0.238 & 16.8 & 1.1 & 0.40 & $\mathrm{n}$ & 16.5 & 26.2 & 22 & 9 \\
\hline 15 & 96 & 0.7 & 2.40 & 10.5 & 0.229 & 11.7 & 0.7 & 0.24 & $\mathrm{n}$ & 15.2 & 24.1 & 19 & 11 \\
\hline 26 & 2 & 3.2 & 2.40 & 5.1 & 0.475 & 142.2 & 6.4 & 4.00 & $y$ & & >end & & \\
\hline 27 & 3 & 2.6 & 2.40 & 5.1 & 0.475 & 116.8 & 5.7 & 3.49 & $\mathrm{y}$ & & >end & & \\
\hline 7 & 96 & 0.9 & 2.40 & 20.2 & 0.119 & 6.4 & 0.6 & 0.11 & $\mathrm{n}$ & 14.0 & 16.8 & 20 & 181 \\
\hline 57 & 72 & 0.9 & 2.40 & 15.1 & 0.159 & 8.4 & 0.8 & 0.15 & $\mathrm{n}$ & 14.5 & 21.1 & 16 & 43 \\
\hline 58 & 60 & 0.9 & 2.40 & 12.6 & 0.191 & 10.7 & 0.9 & 0.21 & $\mathrm{n}$ & 15.0 & 23.4 & 19 & 14 \\
\hline 59 & 54 & 0.9 & 2.40 & 11.3 & 0.212 & 12.7 & 1.0 & 0.27 & $\mathrm{n}$ & 15.5 & 24.6 & 13 & 9 \\
\hline 60 & 48 & 0.9 & 2.40 & 10.1 & 0.238 & 16.8 & 1.1 & 0.40 & $n$ & 16.5 & 26.2 & 22 & 9 \\
\hline 61 & 32 & 0.9 & 2.40 & 6.7 & 0.358 & 43.9 & 1.3 & 1.00 & $\mathrm{y}$ & & 79.0 & 14 & 6 \\
\hline 62 & 24 & 0.9 & 2.40 & 5.0 & 0.477 & 43.9 & 1.6 & 0.99 & $y$ & & 79.0 & 14 & 6 \\
\hline
\end{tabular}




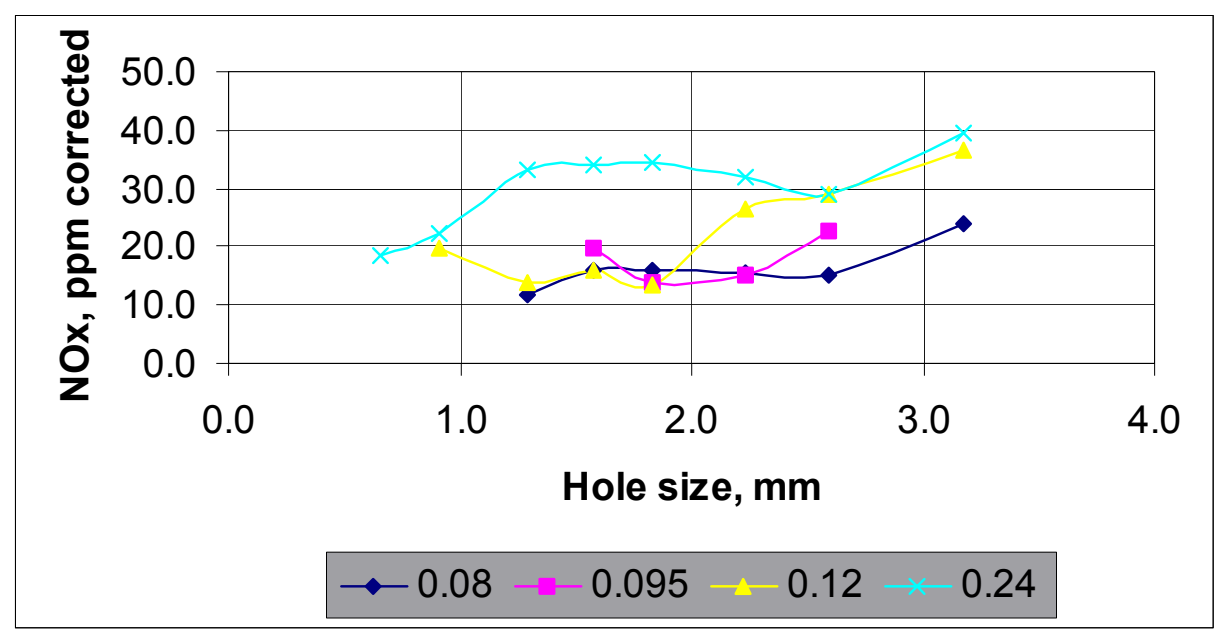

Figure 6 - Projected Nox Emissions - Vane $1 \mathrm{TE}$ reheat for $150 \mathrm{C}$ boost. (Legend is fuel flux, $\mathrm{kg} / \mathrm{m} 2 \mathrm{sec}$, and represents varying the number of holes per vane while keeping total fuel constant)

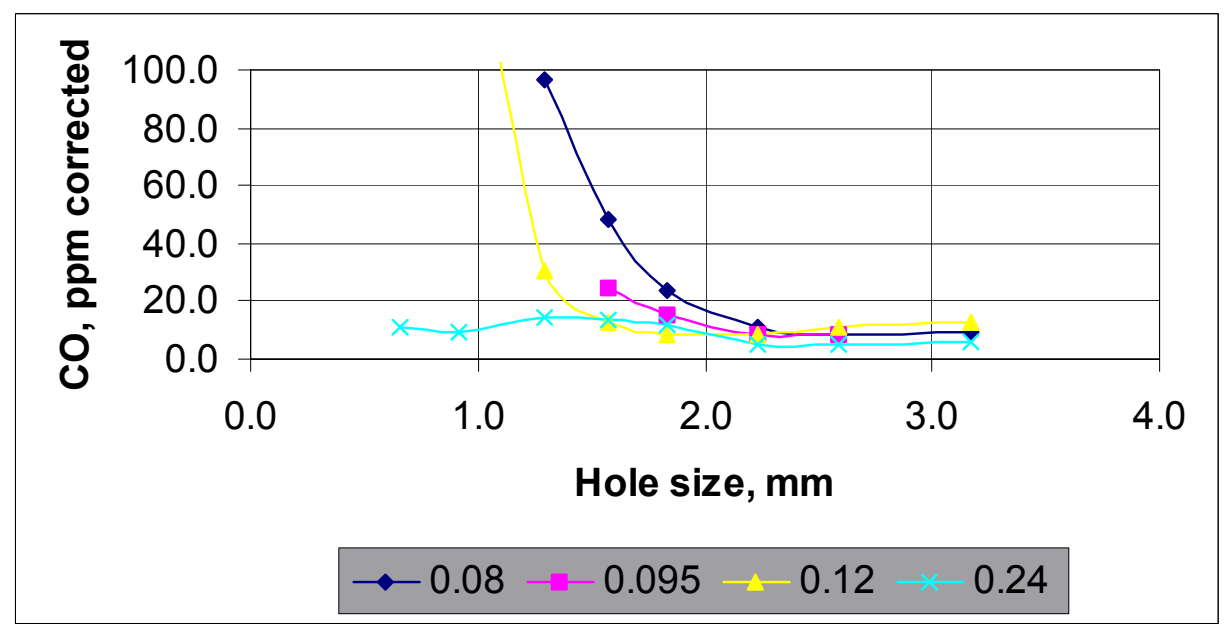

Figure 7 - Projected CO Emissions - Vane $1 \mathrm{TE}$ reheat for $150 \mathrm{C}$ boost. (Legend is fuel flux, $\mathrm{kg} / \mathrm{m} 2 \mathrm{sec}$, and represents varying the number of holes per vane while keeping total fuel constant) 


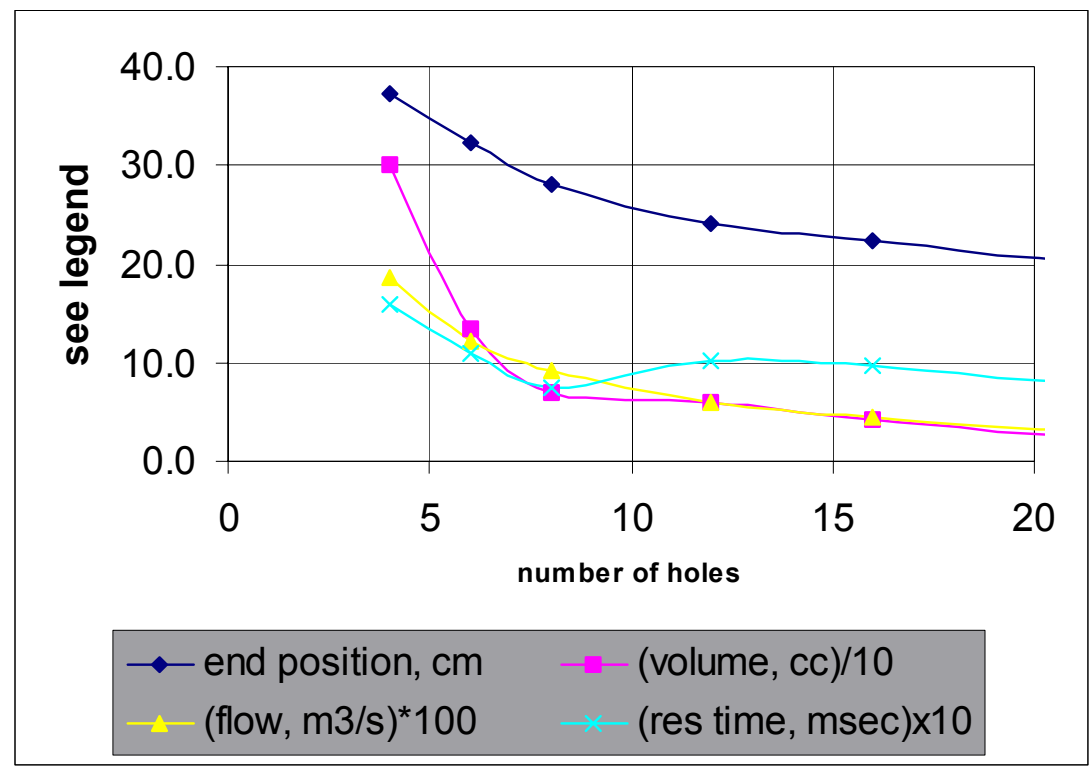

Figure 8 - Local Minimum in Residence Time - Vane 1 TE Reheat for 150 C Boost.

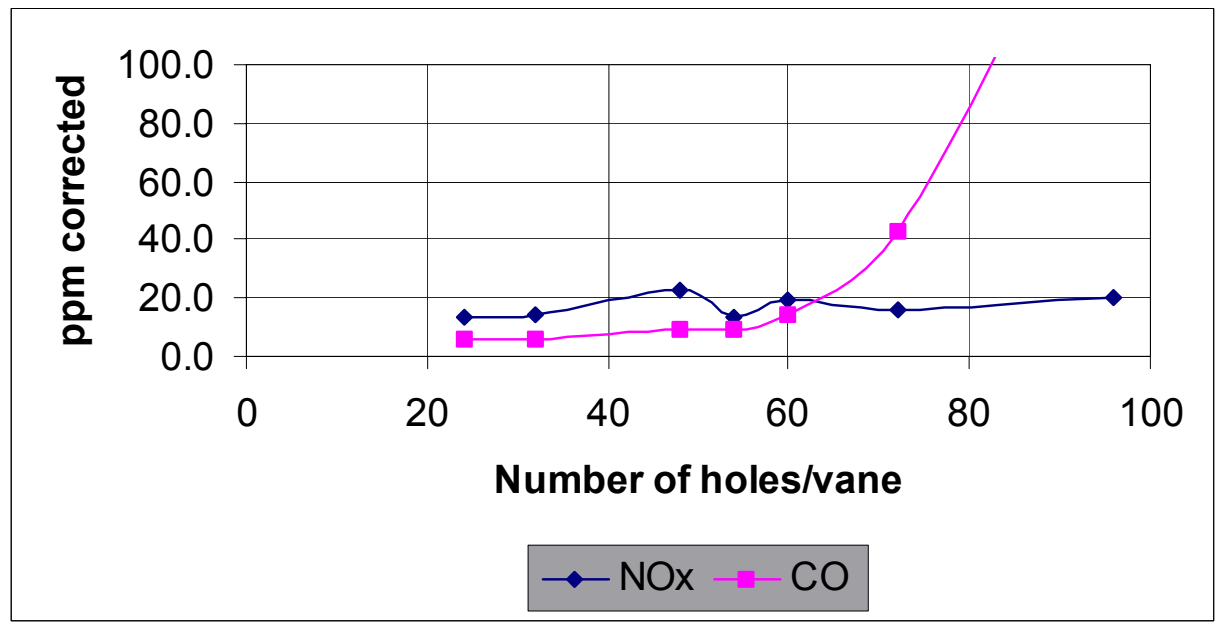

Figure 9 - Projected Nox and CO Emissions as a Function of Number of Holes at Constant $0.9 \mathrm{~mm}$ Hole Size - Vane 1 TE Reheat for 150C Boost. 
Table 3 - Vane 1 Trailing Edge Reheat, Fuel for 300 C Boost

\begin{tabular}{|c|c|c|c|c|c|c|c|c|c|c|c|c|c|}
\hline Point & $\mathrm{N}$ & $\begin{array}{r}\text { hole size } \\
\mathrm{mm} \\
\end{array}$ & $\begin{array}{r}\text { fuel flow } \\
\mathrm{kg} / \mathrm{s} \\
\end{array}$ & $\begin{array}{l}\text { area } \\
\mathrm{cm} 2 \\
\end{array}$ & $\begin{array}{r}\text { Fuel flux } \\
\mathrm{kg} / \mathrm{s}-\mathrm{mm} 2\end{array}$ & $\begin{array}{r}\text { Flame } \\
\text { length } \\
\mathrm{cm}\end{array}$ & $\begin{array}{r}\text { Flame } \\
\text { width } \\
\mathrm{cm}\end{array}$ & $\begin{array}{r}\text { Flame } \\
\text { r.t. } \\
\text { msec }\end{array}$ & $\begin{array}{r}\text { F Flame } \\
\text { lit? }\end{array}$ & $\begin{array}{r}\text { Burnout } \\
\text { loc. } \\
\mathrm{cm} \\
\end{array}$ & $\begin{array}{r}\text { Plume } \\
\text { end loc. } \\
\mathrm{cm} \\
\end{array}$ & $\begin{array}{l}\text { NOx } \\
\text { ppm }\end{array}$ & $\begin{array}{l}\mathrm{CO} \\
\mathrm{ppm}\end{array}$ \\
\hline \multicolumn{14}{|c|}{ Vane 1 - Double fuel } \\
\hline 34 & 24 & 2.6 & 4.81 & 40.5 & 0.119 & 17.5 & 2.2 & 0.45 & $\mathrm{y}$ & & 23.9 & 39 & 20 \\
\hline 35 & 48 & 1.8 & 4.81 & 40.3 & 0.119 & 12.4 & 1.4 & 0.28 & $\mathrm{n}$ & 15.5 & 20.8 & 17 & 21 \\
\hline 36 & 64 & 1.6 & 4.81 & 39.9 & 0.121 & 10.9 & 1.2 & 0.23 & $\mathrm{n}$ & 15.2 & 18.8 & 17 & 36 \\
\hline 31 & 18 & 2.6 & 4.81 & 30.4 & 0.158 & 23.1 & 2.9 & 0.73 & $\mathrm{y}$ & & 25.1 & 52 & 25 \\
\hline 32 & 24 & 2.2 & 4.81 & 30.1 & 0.160 & 20.3 & 2.3 & 0.56 & $y$ & & 24.6 & 42 & 23 \\
\hline 33 & 36 & 1.8 & 4.81 & 30.3 & 0.159 & 16.5 & 1.8 & 0.40 & $\mathrm{n}$ & 16.5 & 23.4 & 40 & 19 \\
\hline 28 & 8 & 3.2 & 4.81 & 20.3 & 0.237 & 54.1 & 4.6 & 1.60 & $y$ & & 46.2 & 60 & 23 \\
\hline 29 & 12 & 2.6 & 4.81 & 20.2 & 0.238 & 45.0 & 3.3 & 1.08 & $\mathrm{y}$ & & 45.7 & 52 & 20 \\
\hline 30 & 16 & 2.2 & 4.81 & 20.1 & 0.239 & 40.1 & 2.0 & 0.75 & $\mathrm{n}$ & & 75.9 & 50 & 13 \\
\hline
\end{tabular}

\subsubsection{Four-Stage Turbine, Vane 2 Injection}

Table 4 presents results for injection at the trailing edge of vane 2 . Without simultaneous vane 1 reheat, burnout does not occur. With simultaneous vane 1 reheat, burnout occurs, except that $\mathrm{CO}$ emissions are high. There appears to be a narrow optimum for 8 holes of 2.6 $\mathrm{mm}$ hole size. However, even here the hot streak survive until station 11 (rotor 3 ), which is not desirable.

Table 4 - Vane 2 Trailing Edge Reheat, Fuel for 75 C Boost

\begin{tabular}{|c|c|c|c|c|c|c|c|c|c|c|c|c|c|}
\hline Point & $\mathrm{N}$ & $\begin{array}{r}\text { hole size } \\
\mathrm{mm} \\
\end{array}$ & $\begin{array}{r}\text { fuel flow } \\
\mathrm{kg} / \mathrm{s} \\
\end{array}$ & $\begin{array}{l}\text { area } \\
\mathrm{cm} 2 \\
\end{array}$ & $\begin{array}{r}\text { Fuel flux } \\
\mathrm{kg} / \mathrm{s}-\mathrm{mm} 2\end{array}$ & \begin{tabular}{|r|}
$\begin{array}{r}\text { Flame } \\
\text { length } \\
\mathrm{cm}\end{array}$ \\
\end{tabular} & \begin{tabular}{|r|} 
Flame \\
width \\
$\mathrm{cm}$ \\
\end{tabular} & \begin{tabular}{r|} 
Flame \\
r.t. \\
$\mathrm{msec}$
\end{tabular} & $\begin{array}{r}\text { Flame } \\
\text { lit? } \\
\end{array}$ & \begin{tabular}{|r|}
$\begin{array}{r}\text { Burnout } \\
\text { loc. } \\
\mathrm{cm}\end{array}$ \\
\end{tabular} & \begin{tabular}{|r|}
$\begin{array}{r}\text { Plume } \\
\text { end loc. } \\
\mathrm{cm}\end{array}$ \\
\end{tabular} & $\begin{array}{l}\mathrm{NOx} \\
\mathrm{ppm}\end{array}$ & $\begin{array}{c}\mathrm{CO} \\
\mathrm{ppm}\end{array}$ \\
\hline \multicolumn{14}{|c|}{ Vane 2 - Half fuel } \\
\hline 39 & 32 & 3.2 & 1.20 & 91.2 & 0.013 & 7.6 & 1.1 & 0.20 & & \multirow{2}{*}{\begin{tabular}{l|l}
$>$ end \\
\end{tabular}} & 61.0 & & \\
\hline 42 & 64 & 2.2 & 1.20 & 90.4 & 0.013 & 5.6 & 0.7 & 0.12 & & & 58.4 & & \\
\hline & & & & & & & & & & & & & \\
\hline 38 & 16 & 3.2 & 1.20 & 45.6 & 0.026 & 11.4 & 1.7 & 0.31 & & $n>$ >end & 63.5 & & \\
\hline 41 & 32 & 2.2 & 1.20 & 45.2 & 0.027 & 8.1 & 1.1 & 0.19 & $\mathrm{n}$ & \multirow{2}{*}{\begin{tabular}{|l} 
>end \\
>end
\end{tabular}} & 61.0 & & \\
\hline 44 & 64 & 1.6 & 1.20 & 44.9 & 0.027 & 5.8 & 0.7 & 0.12 & & & 58.4 & & \\
\hline 37 & 8 & 3.2 & 1.20 & 22.8 & 0.053 & 18.5 & 2.5 & |0.61 & $\mathrm{n}$ & > >end & 81.3 & & \\
\hline 40 & 16 & 2.2 & 1.20 & 22.6 & 0.053 & 13.2 & 1.7 & 0.36 & $\mathrm{n}$ & \multirow{2}{*}{\begin{tabular}{|l|} 
>end \\
>end
\end{tabular}} & 76.2 & & \\
\hline 43 & 32 & 1.6 & 1.20 & 22.4 & 0.054 & 9.4 & 1.1 & 0.22 & $\mathrm{n}$ & & 61.0 & & \\
\hline \multicolumn{14}{|c|}{ Vane 2 after Vane 1 - Half fuel } \\
\hline 47 & 32 & 3.2 & 1.20 & 91.2 & 0.013 & 8.6 & 1.2 & 0.24 & $\mathrm{n}$ & & 60.7 & \multirow{2}{*}{\begin{tabular}{|l|}
18 \\
15
\end{tabular}} & \multirow{2}{*}{$\begin{array}{l}422 \\
478 \\
\end{array}$} \\
\hline 51 & 64 & 2.2 & 1.20 & 90.4 & 0.013 & 6.1 & 0.8 & 0.15 & $\mathrm{n}$ & 50.8 & 58.2 & & \\
\hline 46 & 16 & 32 & 120 & 456 & 0026 & 130 & 19 & 0.38 & $n$ & 56.4 & 630 & 15 & 596 \\
\hline 50 & 32 & 2.2 & 1.20 & 45.2 & 0.027 & 9.1 & 1.2 & 0.23 & $\frac{m}{n}$ & \begin{tabular}{l|l} 
& 50.4 \\
7 & 54.1
\end{tabular} & 61.2 & \multirow{2}{*}{\begin{tabular}{l|}
13 \\
18 \\
\end{tabular}} & 492 \\
\hline 53 & 64 & 1.6 & 1.20 & 44.9 & 0.027 & 6.6 & 0.8 & 0.14 & & 52.1 & 58.7 & & 508 \\
\hline 45 & 8 & 3.2 & 1.20 & 22.8 & $\begin{array}{ll}0.053 \\
\end{array}$ & 20.8 & 2.7 & 0.70 & $\mathrm{n}$ & 622 & 81.3 & 17 & 425 \\
\hline 56 & 12 & 2.6 & 1.20 & 22.8 & 0.053 & 17.0 & 2.3 & 0.56 & $\mathrm{n}$ & i >end & 77.7 & 17 & 771 \\
\hline 49 & 16 & 2.2 & 1.20 & 22.6 & 0.053 & 14.7 & 1.9 & 0.45 & $\mathrm{n}$ & \begin{tabular}{l|l} 
& 57.9 \\
\end{tabular} & 75.4 & 14 & 702 \\
\hline 52 & 32 & 1.6 & 1.20 & 22.4 & \begin{tabular}{l|}
0.054 \\
\end{tabular} & 10.4 & 1.3 & 0.26 & $\mathrm{n}$ & $\begin{array}{l}55.1 \\
\end{array}$ & 62.0 & 20 & 590 \\
\hline 54 & 8 & 2.6 & 1.20 & 15.2 & 0.079 & 25.1 & 2.5 & 0.75 & $\mathrm{n}$ & 74.9 & 96.0 & 15 & 11 \\
\hline 48 & 4 & 3.2 & 1.20 & 11.4 & 0.105 & 47.5 & 3.9 & 1.33 & $\bar{n}$ & 95.0 & >end & & \\
\hline 55 & 6 & 2.6 & 1.20 & 11.4 & 0.106 & 38.9 & 3.3 & 1.07 & $\mathrm{n}$ & \begin{tabular}{|l|}
81.8 \\
\end{tabular} & 136.1 & 12 & 1721 \\
\hline
\end{tabular}




\subsubsection{Five-Stage Turbine, Vane 2 Injection}

A possible design application of in-situ reheat is in the design of a higher efficiency, higher pressure ratio, 5-stage turbine. In this design concept, the second of the five stages is about the same size as the first stage of a 4-stage turbine, and operates at about the same conditions except that the temperature is lower. Therefore, in the 5-stage turbine, vane 2 trailing edge reheat could be used to reheat the gas up to the inlet temperature of the first rotor of the 4-stage engine.

Performance of this reheat concept is projected in Table 5. It is seen that the diffusion flame is never lit, and that in general $\mathrm{CO}$ emissions are high. The temperature here is too low for non-flameholding burnout. There appear to be several narrow windows for low $\mathrm{CO}$ emissions, but these might be hard to attain in design.

Table 5 - Vane 2 Trailing Edge Reheat for a 5-Stage Turbine

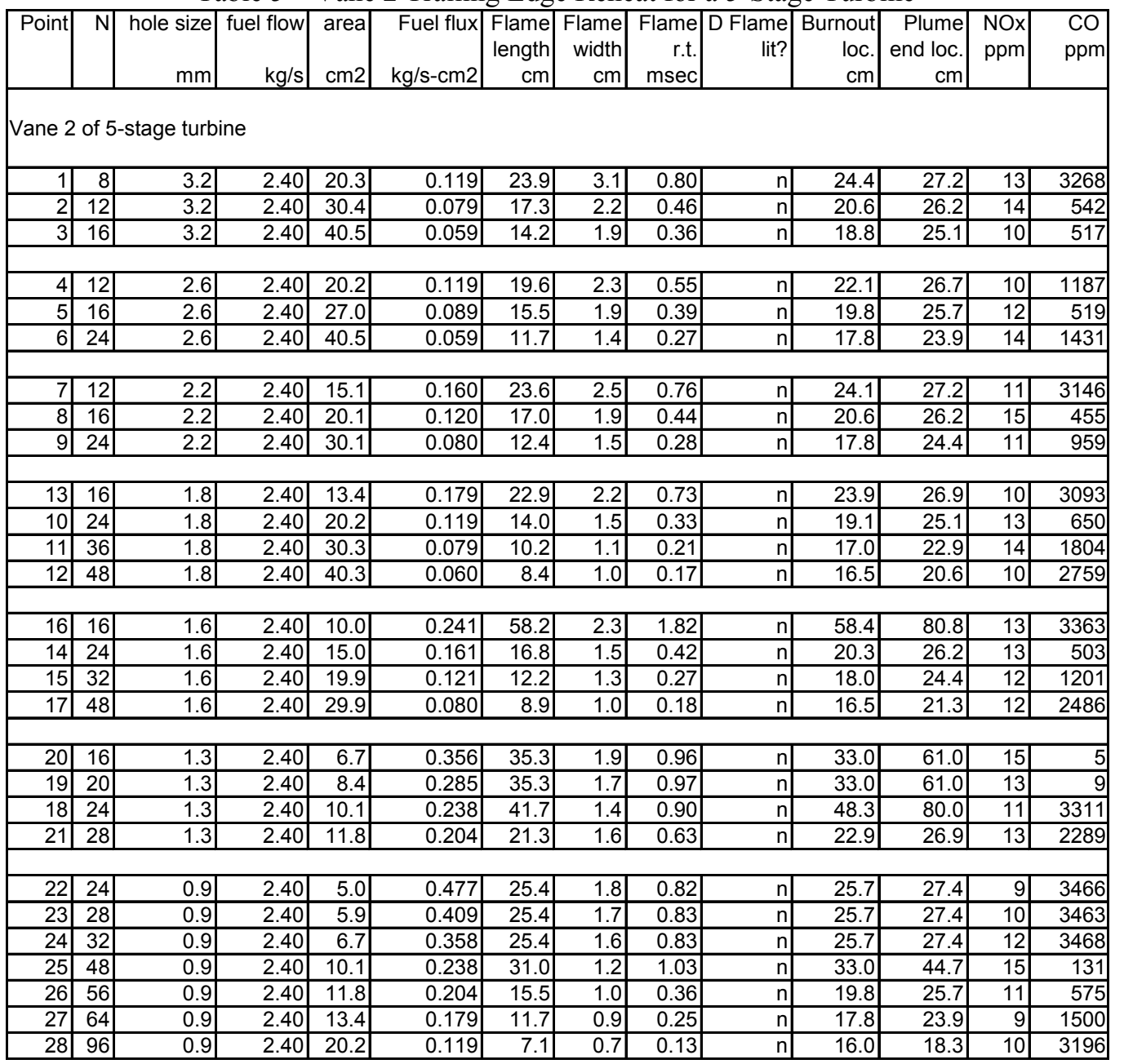




\section{FLAMEHOLDING DESIGN}

\subsection{Modeling Approach}

In cases where injected fuel gas does not burn as a diffusion flame, and does not burn downstream in either a partially mixed (plume) or fully mixed state, a flameholder might be used to stabilize a flame at the injection point. The simplest such design would be to inject the fuel in the wake of a blunt body. In this case the blunt body is a "button" on the trailing edge, with the fuel injection hole at its downstream center. Depending on the fuel flow rate, ambient gas temperature, and button size the resulting "wake flame" may or may not be lit. The purpose of the wake flame is provide a larger stirred reaction zone, and larger residence time, so that burning will occur. At the same time, the wake can be made to provide a leaner burning mixture than a diffusion flame, such that the temperature is lower and Nox is minimized.

While it is not desirable from a turbine blade design point of view to have such objects, even with the upstream edges somehow streamlined and blended with the blade, the concept is examined to see if flame holding has any merit for in situ reheat - if so, then the design can be refined.

Several authors have looked at fuel injection into bluff body wakes. We use the work of Winterfeld [5] who, like other authors, provides dimensions of the recirculation zone, but in addition provides residence times. According to him the volume of the recirculation zone (wake flame) is

$$
V=0.66 \cdot(B / d)^{2} \cdot(L / d) D^{3}
$$

where

$$
\begin{aligned}
& \mathrm{D}=\text { diameter of the "button" } \\
& \mathrm{B} / \mathrm{d}=\text { dimensionless diameter of recirculation zone }=1.2 \text { for a conical shaped, } \\
& \text { smooth approach to the button }
\end{aligned}
$$

$\mathrm{L} / \mathrm{d}=$ dimensionless length of the recirculation zone $=2.5$ for a flame with this same approach design

Also, the residence time of the mixed gases in the wake flame, where the button occupies only a small part of the overall cross-section, is given by

$$
\tau \cdot v / d=20
$$

where

$$
\begin{aligned}
& \tau=\text { residence time } \\
& \mathrm{v}=\text { velocity of approach of the main gas stream upstream of the button } \\
& \mathrm{d}=\text { button diameter }
\end{aligned}
$$

Given these assumptions, the possible presence of a wake flame is modeled as follows.

1) The calling program (same as for diffusion flame) checks input to determine whether a flameholder is being used and, if so, the diameter of the button. All other parameters are the same as for the non-flameholding design. There is assumed to be one button per hole. 
2) The wake flame residence time and volume are calculated from equations (14) and (15). The volumetric flow of main gas/fuel mixture is calculated from these. Then the fuel flow is subtracted to give the main gas flow entrained.

3) The DFLAME model is called for this mixture and residence time. The residence time is assumed to be divided into a perfectly stirred half, followed by a plug flow half. DFLAME determines if the wake flame is lit and, if so, the products and temperature.

4) The calling program then uses the end of the wake flame as the effective source of a potential diffusion flame. The location and diameter of the effective fuel jet for the diffusion flame are given as the end location of the wake flame and the diameter of the wake flame. The flow rate, composition, and temperature of the effective fuel jet are those of the product of the wake flame.

5) The normal diffusion flame steps (Section 3.1.1, steps 4 to 6) are then executed.

This approach was used to evaluate the in situ reheat flameholding concept. There were no experimental data for validation.

\subsection{Parametric Study Results}

In all of the following cases it is assumed that the main gas entering the turbine has no CO, and has sufficient Nox to give 8 ppmv normalized Nox at the exit of the turbine after mixing with all cooling air and without reheat.

\subsubsection{Four-Stage Turbine, Vane 1 Injection}

Table 6 summarizes the calculations for using a button type flameholder with vane 1 trailing edge reheat. The first line for each "Point" is the same as in Table 2. Subsequent lines for said point then show what happens if the flameholder of the stated diameter is added. Of course, the temperatures around V1TE are high enough that we would like to operate without a flameholder, as shown in several instances in Table 2; but we will examine use of flameholder to see if there is any non-obvious advantage.

Note that for all points in Table 6, and subsequent tables 7 through 10, the wake mixture is rich, usually very rich as shown by the low adiabatic flame temperature. This means that it is not likely to ignite except when the largest wakes are used, which form mixtures nearest to stoichiometric. Also, the maximum button size shown for each point is limited by getting one button per each of $\mathrm{N}$ holes on each vane; so larger sizes than shown on the tables are not possible.

For point 16, the diffusion flame lights even without a flameholder, so the use of a flameholder has little effect, until the wake flame is lit for the largest holder size, $12.7 \mathrm{~mm}$, at which point the Nox emissions rise. Similarly, for other points in Table 6, the button can cause the diffusion flame to light, or the wake flame to light, or both to light, or neither to light. In each case there is either no significant change in emissions, or an increase in emissions. And the diffusion flame to light, with the same effect on Nox. We conclude that a flameholding design is disadvantageous for the vane 1 trailing edge, which works fine without a flameholder in most cases. Table 7 shows no benefit for higher fuel injection rates.

Another effect seen in Table 6 is for point 27, where a few large injection holes are used. Without a flameholder the flame and plume extend to the end of the turbine, so combustion 
is incomplete. With a flameholder, combustion is pulled back and is completed in the turbine, but Nox emissions are high.

Table 6 - Vane 1 Trailing Edge with Flameholding

\begin{tabular}{|c|c|c|c|c|c|c|c|c|c|c|c|c|}
\hline Point & $\mathrm{N}$ & $\begin{array}{r}\text { hole size } \\
\mathrm{mm} \\
\end{array}$ & $\begin{array}{r}\text { fuel flow } \\
\mathrm{kg} / \mathrm{s}\end{array}$ & $\begin{array}{l}\text { Fuel flux } \\
\mathrm{kg} / \mathrm{s}-\mathrm{cm} 2\end{array}$ & $\begin{array}{r}\text { Button } \\
\text { diam } \\
\text { mm }\end{array}$ & $\begin{array}{r}\text { Wake } \\
\text { Taf } \\
\mathrm{K} \\
\end{array}$ & $\begin{array}{r}\text { Wake } \\
\text { flame } \\
\text { r.t. } \\
\text { msec } \\
\end{array}$ & $\begin{array}{r}\text { Wake } \\
\text { flame } \\
\text { lit? }\end{array}$ & $\begin{array}{r}\text { Diff } \\
\text { flame } \\
\text { r.t. } \\
\text { msec } \\
\end{array}$ & $\begin{array}{r}\text { Diff } \\
\text { flame } \\
\text { lit? }\end{array}$ & $\begin{array}{l}\mathrm{NOx} \\
\mathrm{ppm}\end{array}$ & $\begin{array}{l}\mathrm{CO} \\
\mathrm{ppm}\end{array}$ \\
\hline \multicolumn{13}{|c|}{ Vane 1- Base fuel } \\
\hline \multirow[t]{6}{*}{16} & 12 & 3.2 & 2.40 & 0.079 & & & & & 0.40 & $\mathrm{y}$ & 24 & 9 \\
\hline & & & & & 3.8 & 868 & 0.14 & $\mathrm{n}$ & 0.52 & $\mathrm{y}$ & 30 & 12 \\
\hline & & & & & 5.1 & 979 & 0.18 & $\mathrm{n}$ & 0.52 & $\mathrm{y}$ & 32 & 9 \\
\hline & & & & & 6.4 & 1061 & 0.23 & $\mathrm{n}$ & 0.51 & $\mathrm{y}$ & 29 & 8 \\
\hline & & & & & 9.7 & 1344 & 0.34 & $\mathrm{n}$ & 0.51 & $\mathrm{y}$ & 32 & 8 \\
\hline & & & & & 12.7 & 1754 & 0.46 & $\mathrm{y}$ & 0.67 & $\mathrm{y}$ & 45 & 7 \\
\hline \multirow[t]{4}{*}{18} & 24 & 2.2 & 2.40 & 0.080 & & & & & 0.25 & $\mathrm{n}$ & 16 & 11 \\
\hline & & & & & 3.0 & 917 & 0.11 & $\mathrm{n}$ & 0.32 & $\mathrm{n}$ & 19 & 9 \\
\hline & & & & & 4.6 & 1066 & 0.16 & $\mathrm{n}$ & 0.31 & $\mathrm{n}$ & 16 & 11 \\
\hline & & & & & 6.4 & 1259 & 0.23 & $\mathrm{n}$ & 0.31 & $\mathrm{y}$ & 29 & 16 \\
\hline \multirow[t]{3}{*}{21} & 72 & 1.3 & 2.40 & 0.079 & & & & & 0.13 & $\mathrm{n}$ & 12 & 97 \\
\hline & & & & & 1.8 & 897 & 0.06 & $\mathrm{n}$ & 0.16 & $\mathrm{n}$ & 15 & 72 \\
\hline & & & & & 2.3 & 993 & 0.08 & $\mathrm{n}$ & 0.16 & $\mathrm{n}$ & 17 & 114 \\
\hline \multirow[t]{4}{*}{22} & 15 & 2.6 & 2.40 & 0.095 & & & & & 0.35 & $\mathrm{n}$ & 23 & 8 \\
\hline & & & & & 5.1 & 1019 & 0.18 & $\mathrm{n}$ & 0.44 & $\mathrm{y}$ & 30 & 8 \\
\hline & & & & & 7.6 & 1202 & 0.27 & $\mathrm{n}$ & 0.43 & $\mathrm{y}$ & 29 & 8 \\
\hline & & & & & 10.9 & 1699 & 0.39 & $y$ & 0.57 & $\mathrm{y}$ & 40 & 8 \\
\hline \multirow[t]{4}{*}{24} & 30 & 1.8 & 2.40 & 0.095 & & & & & 0.22 & $\mathrm{n}$ & 14 & 15 \\
\hline & & & & & 2.5 & 889 & 0.09 & $\mathrm{n}$ & 0.27 & $\mathrm{n}$ & 19 & 11 \\
\hline & & & & & 3.8 & 1041 & 0.14 & $\mathrm{n}$ & 0.27 & $\mathrm{n}$ & 18 & 17 \\
\hline & & & & & 5.5 & 1224 & 0.20 & $\mathrm{n}$ & 0.27 & $\mathrm{y}$ & 20 & 24 \\
\hline \multirow[t]{4}{*}{4} & 24 & 1.8 & 2.40 & 0.119 & & & & & 0.28 & $\mathrm{n}$ & 14 & 9 \\
\hline & & & & & 3.0 & 917 & 0.11 & $\mathrm{n}$ & 0.31 & $\mathrm{n}$ & 19 & 9 \\
\hline & & & & & 5.1 & 1105 & 0.18 & $\mathrm{n}$ & 0.31 & $\mathrm{y}$ & 21 & 12 \\
\hline & & & & & 6.9 & 1368 & 0.25 & $\mathrm{n}$ & 0.32 & $\mathrm{y}$ & 26 & 21 \\
\hline \multirow[t]{3}{*}{7} & 96 & 0.9 & 2.40 & 0.119 & & & & & 0.10 & $\mathrm{n}$ & 20 & 181 \\
\hline & & & & & 1.3 & 843 & 0.05 & $\mathrm{n}$ & 0.12 & $\mathrm{n}$ & 16 & 182 \\
\hline & & & & & 1.7 & 959 & 0.06 & $\mathrm{n}$ & 0.12 & $\mathrm{n}$ & 20 & 217 \\
\hline \multirow[t]{3}{*}{27} & 3 & 2.6 & 2.40 & 0.475 & & & & & 3.49 & $\mathrm{y}$ & >past en & \\
\hline & & & & & 6.4 & 791 & 0.23 & $\mathrm{n}$ & 0.82 & $\mathrm{y}$ & 28 & 6 \\
\hline & & & & & 8.9 & 928 & 0.32 & $\mathrm{n}$ & 0.99 & $\mathrm{y}$ & 30 & 4 \\
\hline \multirow[t]{4}{*}{57} & 72 & 0.9 & 2.40 & 0.159 & & & & & 0.15 & $\mathrm{n}$ & 16 & 43 \\
\hline & & & & & 1.3 & 782 & 0.05 & $\mathrm{n}$ & 0.15 & $\mathrm{n}$ & 15 & 76 \\
\hline & & & & & 1.8 & 921 & 0.06 & $\mathrm{n}$ & 0.15 & $\mathrm{n}$ & 23 & 113 \\
\hline & & & & & 2.3 & 1014 & 0.08 & $\mathrm{n}$ & 0.15 & $\mathrm{n}$ & 15 & 148 \\
\hline \multirow[t]{3}{*}{59} & 54 & 0.9 & 2.40 & 0.212 & & & & & 0.27 & $\mathrm{n}$ & 13 & 9 \\
\hline & & & & & 2.0 & 917 & 0.07 & $\mathrm{n}$ & 0.18 & $\mathrm{n}$ & 17 & 48 \\
\hline & & & & & 3.0 & 1066 & 0.11 & $\mathrm{n}$ & 0.18 & $\mathrm{n}$ & 23 & 101 \\
\hline
\end{tabular}


Table 7 - Vane 1 Trailing Edge with Flameholding - Increased Fuel

\begin{tabular}{|c|c|c|c|c|c|c|c|c|c|c|c|c|}
\hline Point & $\mathrm{N}$ & hole size & fuel flow & $\begin{array}{l}\text { Fuel flux } \\
\mathrm{kg} / \mathrm{s}-\mathrm{cm} 2\end{array}$ & $\begin{array}{r}\begin{array}{r}\text { Button } \\
\text { diam }\end{array} \\
\mathrm{mm} \\
\end{array}$ & $\begin{array}{r}\text { Wake } \\
\text { Taf } \\
\mathrm{K} \\
\end{array}$ & $\begin{array}{r}\text { Wake } \\
\text { flame } \\
\text { r.t. } \\
\text { msec }\end{array}$ & $\begin{array}{r}\text { Wake } \\
\text { flame } \\
\text { lit? }\end{array}$ & $\begin{array}{r}\text { Diff } \\
\text { flame } \\
r . t . \\
\text { msec }\end{array}$ & $\begin{array}{r}\text { Diff } \\
\text { flame } \\
\text { lit? }\end{array}$ & $\begin{array}{l}\text { NOx } \\
\text { ppm }\end{array}$ & $\begin{array}{l}\mathrm{CO} \\
\mathrm{ppm}\end{array}$ \\
\hline \multicolumn{13}{|c|}{ Vane 1 -Double fuel } \\
\hline \multirow[t]{3}{*}{35} & 48 & 1.8 & 4.81 & 0.119 & & & & & 0.28 & $\mathrm{n}$ & 17 & 21 \\
\hline & & & & & 2.5 & 843 & 0.09 & $\mathrm{n}$ & 0.32 & $\mathrm{n}$ & 27 & 21 \\
\hline & & & & & 3.4 & 962 & 0.12 & $\mathrm{n}$ & 0.32 & $\mathrm{n}$ & 25 & 25 \\
\hline \multirow{5}{*}{28} & & & & & & & & & & & & \\
\hline & 8 & 3.2 & 4.81 & 0.237 & & & & & 1.60 & $\mathrm{y}$ & 60 & 23 \\
\hline & & & & & 6.4 & 852 & 0.23 & $\mathrm{n}$ & 1.10 & $\mathrm{y}$ & 58 & 67 \\
\hline & & & & & 12.7 & 1112 & 0.45 & $\mathrm{n}$ & 1.30 & $\mathrm{y}$ & 67 & 37 \\
\hline & & & & & 20.6 & 1662 & 0.74 & $y$ & 1.70 & $\mathrm{y}$ & 122 & 34 \\
\hline \multirow[t]{3}{*}{30} & 16 & 2.2 & 4.81 & 0.239 & & & & & 0.75 & $\mathrm{n}$ & 50 & 13 \\
\hline & & & & & 3.8 & 782 & 0.14 & $\mathrm{n}$ & 0.78 & $\mathrm{y}$ & 58 & 26 \\
\hline & & & & & 7.0 & 1021 & 0.25 & $\mathrm{n}$ & 0.76 & $\mathrm{y}$ & 53 & 22 \\
\hline
\end{tabular}

\subsubsection{Four-Stage Turbine, Vane 2 Injection}

Table 8 (compare top of Table 4) shows that using a relatively large flameholder for vane 2 trailing edge fuel injection enables burnout in some cases not possible without flameholding. However, these cases may have 50 to 100 ppmv CO survival. With Vane 2 injection after Vane 1 injection (Table 9 compared to bottom of Table 4) the flameholder shortens the flame and reduces $\mathrm{CO}$ by an order of magnitude, but it is still about $50 \mathrm{ppmv}$.

\subsubsection{Five-Stage Turbine, Vane 2 Injection}

Table 10 shows flameholding for vane 2 injection in a high pressure ration 5 -stageturbine, and should be compared to Table 5. It is seen that large diameter buttons enable ignition of wake flames, permitting reasonable operation, with complete burnout but with Nox levels a bit higher than desirable. In cases where the button size is limited by the need to put a large number of holes along a blade, there is no wake ignition and there is poor downstream combustion. 
Table 8 - Vane 2 Trailing Edge with Flameholding

\begin{tabular}{|c|c|c|c|c|c|c|c|c|c|c|c|c|}
\hline Point & $\mathrm{N}$ & $\begin{array}{r}\text { hole size } \\
\mathrm{mm} \\
\end{array}$ & $\begin{array}{r}\text { fuel flow } \\
\mathrm{kg} / \mathrm{s}\end{array}$ & $\begin{array}{c}\text { Fuel flux } \\
\mathrm{kg} / \mathrm{s}-\mathrm{cm} 2\end{array}$ & $\begin{array}{r}\text { Button } \\
\text { diam } \\
\mathrm{mm}\end{array}$ & $\begin{array}{r}\text { Wake } \\
\text { Taf } \\
\mathrm{K} \\
\end{array}$ & $\begin{array}{r}\text { Wake } \\
\text { flame } \\
\text { r.t. } \\
\text { msec }\end{array}$ & $\begin{array}{r}\text { Wake } \\
\text { flame } \\
\text { lit? }\end{array}$ & $\begin{array}{r}\text { Diff } \\
\text { flame } \\
\text { r.t. } \\
\text { msec }\end{array}$ & $\begin{array}{r}\text { Diff } \\
\text { flame } \\
\text { lit? }\end{array}$ & $\begin{array}{l}\mathrm{NOx} \\
\mathrm{ppm}\end{array}$ & $\begin{array}{l}\mathrm{CO} \\
\mathrm{ppm}\end{array}$ \\
\hline \multicolumn{13}{|c|}{ Vane 2 - Half fuel } \\
\hline \multirow[t]{4}{*}{39} & 32 & 3.2 & 1.20 & 0.013 & & & & & 0.20 & $\mathrm{n}$ & >past end & \\
\hline & & & & & 4.6 & 1057 & 0.17 & $\mathrm{n}$ & 0.23 & $\mathrm{n}$ & >past end & \\
\hline & & & & & 6.1 & 1330 & 0.23 & $\mathrm{n}$ & 0.25 & $\mathrm{n}$ & >past end & \\
\hline & & & & & 8.1 & 1738 & 0.30 & $\mathrm{n}$ & 0.29 & $\mathrm{n}$ & >past end & \\
\hline \multirow[t]{3}{*}{42} & 64 & 2.2 & 1.20 & 0.013 & & & & & 0.12 & $\mathrm{n}$ & >past end & \\
\hline & & & & & 3.0 & 1036 & 0.11 & $\mathrm{n}$ & 0.14 & $\mathrm{n}$ & >past end & \\
\hline & & & & & 4.1 & 1251 & 0.15 & $\mathrm{n}$ & 0.15 & $\mathrm{n}$ & $>$ past end & \\
\hline \multirow[t]{4}{*}{38} & 16 & 3.2 & 1.20 & 0.026 & & & & & 0.31 & $\mathrm{n}$ & >past end & \\
\hline & & & & & 5.1 & 978 & 0.19 & $\mathrm{n}$ & 0.37 & $\mathrm{n}$ & $>$ past end & \\
\hline & & & & & 10.2 & 1556 & 0.38 & $\mathrm{n}$ & 0.42 & $\mathrm{n}$ & $>$ past end & \\
\hline & & & & & 16.3 & 2161 & 0.61 & $\mathrm{y}$ & 0.74 & $\mathrm{y}$ & \begin{tabular}{r|r}
14 \\
\end{tabular} & 94 \\
\hline \multirow[t]{2}{*}{41} & 32 & 2.2 & 1.20 & 0.027 & & & & & 0.19 & $\mathrm{n}$ & >past end & \\
\hline & & & & & 8.1 & 1738 & 0.30 & $\mathrm{n}$ & 0.29 & $\mathrm{n}$ & $>$ past end & \\
\hline \multirow[t]{3}{*}{44} & 64 & 1.6 & 1.20 & 0.027 & & & & & 0.12 & $\mathrm{n}$ & $>$ past end & \\
\hline & & & & & 3.0 & 1036 & 0.11 & $\mathrm{n}$ & 0.14 & $\mathrm{n}$ & $>$ past end & \\
\hline & & & & & 4.1 & 1251 & 0.15 & $\mathrm{n}$ & 0.15 & $\mathrm{n}$ & $>$ past end & \\
\hline \multirow[t]{5}{*}{37} & 8 & 3.2 & 1.20 & 0.053 & & & & & 0.61 & $\mathrm{n}$ & >past end & \\
\hline & & & & & 6.4 & 936 & 0.24 & $\mathrm{n}$ & 0.67 & $\mathrm{n}$ & $>$ past end & \\
\hline & & & & & 12.7 & 1387 & 0.47 & $\mathrm{n}$ & 0.66 & $\mathrm{y}$ & \begin{tabular}{|r|r|}
17 \\
\end{tabular} & 54 \\
\hline & & & & & 19.1 & 1941 & 0.71 & $\mathrm{y}$ & 1.08 & $\mathrm{y}$ & 14 & 54 \\
\hline & & & & & 25.4 & 2261 & 0.95 & $\mathrm{y}$ & 0.99 & $\mathrm{y}$ & 23 & 77 \\
\hline \multirow[t]{5}{*}{40} & 16 & 2.2 & 1.20 & 0.053 & & & & & 0.36 & $\mathrm{n}$ & $>$ past end & \\
\hline & & & & & 5.1 & 978 & 0.19 & $\mathrm{n}$ & 0.37 & $\mathrm{n}$ & $>$ past end & \\
\hline & & & & & 10.2 & 1556 & 0.38 & $\mathrm{n}$ & 0.42 & $\mathrm{n}$ & $>$ past end & \\
\hline & & & & & 13.2 & 1913 & 0.49 & $\mathrm{y}$ & 0.65 & $\mathrm{y}$ & \begin{tabular}{r|r|}
19 \\
\end{tabular} & 71 \\
\hline & & & & & 16.3 & 2161 & 0.61 & $\mathrm{y}$ & 0.74 & $\mathrm{y}$ & \begin{tabular}{|r|r|}
14 \\
\end{tabular} & 94 \\
\hline \multirow[t]{5}{*}{43} & 32 & 1.6 & 1.20 & 0.054 & & & & & 0.22 & $\mathrm{n}$ & $>$ past end & \\
\hline & & & & & 3.0 & 921 & 0.11 & $\mathrm{n}$ & 0.23 & $\mathrm{n}$ & $>$ past end & \\
\hline & & & & & 4.1 & 1016 & 0.15 & $\mathrm{n}$ & 0.23 & $\mathrm{n}$ & >past end & \\
\hline & & & & & 6.1 & 1330 & 0.23 & $\mathrm{n}$ & 0.25 & $\mathrm{n}$ & $>$ past end & \\
\hline & & & & & 8.1 & 1738 & 0.30 & $\mathrm{n}$ & 0.29 & $\mathrm{n}$ & $>$ past end & \\
\hline
\end{tabular}


Table 9 - Vane 2 Trailing Edge Injection after Vane 1 Trailing Edge Injection, with Flameholding

\begin{tabular}{|c|c|c|c|c|c|c|c|c|c|c|c|c|}
\hline Point & $\mathrm{N}$ & $\begin{array}{r}\text { hole size } \\
\mathrm{mm} \\
\end{array}$ & $\begin{array}{r}\text { fuel flow } \\
\mathrm{kg} / \mathrm{s}\end{array}$ & $\begin{array}{l}\text { Fuel flux } \\
\mathrm{kg} / \mathrm{s}-\mathrm{cm} 2\end{array}$ & $\begin{array}{r}\text { Button } \\
\text { diam } \\
\mathrm{mm}\end{array}$ & $\begin{array}{r}\text { Wake } \\
\text { Taf } \\
\mathrm{K}\end{array}$ & $\begin{array}{r}\text { Wake } \\
\text { flame } \\
\text { r.t. } \\
\text { msec }\end{array}$ & $\begin{array}{r}\text { Wake } \\
\text { flame } \\
\text { lit? }\end{array}$ & $\begin{array}{r}\text { Diff } \\
\text { flame } \\
\text { r.t. } \\
\text { msec } \\
\end{array}$ & $\begin{array}{r}\text { Diff } \\
\text { flame } \\
\text { lit? }\end{array}$ & $\begin{array}{l}\mathrm{NOx} \\
\mathrm{ppm}\end{array}$ & $\begin{array}{l}\mathrm{CO} \\
\mathrm{ppm}\end{array}$ \\
\hline \multicolumn{13}{|c|}{ Vane 2 after Vane 1 - Half fuel } \\
\hline \multirow[t]{4}{*}{47} & 32 & 3.2 & 1.20 & 0.013 & & & & & 0.24 & $\mathrm{n}$ & 18 & 422 \\
\hline & & & & & 4.1 & 1019 & 0.15 & $\mathrm{n}$ & 0.29 & $\mathrm{n}$ & 19 & 182 \\
\hline & & & & & 6.1 & 1324 & 0.22 & $\mathrm{n}$ & 0.29 & $\mathrm{n}$ & 14 & 402 \\
\hline & & & & & 8.1 & 1714 & 0.30 & $\mathrm{n}$ & 0.34 & $\mathrm{y}$ & 16 & 91 \\
\hline \multirow[t]{2}{*}{51} & 64 & 2.2 & 1.20 & 0.013 & & & & & 0.15 & $\mathrm{n}$ & 15 & 478 \\
\hline & & & & & 4.1 & 1259 & 0.15 & $\mathrm{n}$ & 0.18 & $\mathrm{n}$ & & \\
\hline \multirow[t]{6}{*}{46} & 16 & 3.2 & 1.20 & 0.026 & & & & & 0.38 & $\mathrm{n}$ & 15 & 596 \\
\hline & & & & & 4.1 & 906 & 0.15 & $\mathrm{n}$ & 0.51 & $\mathrm{n}$ & 12 & 650 \\
\hline & & & & & 8.1 & 1261 & 0.30 & $\mathrm{n}$ & 0.46 & $\mathrm{y}$ & 17 & 43 \\
\hline & & & & & 10.2 & 1561 & 0.37 & $\mathrm{n}$ & 0.49 & $\mathrm{y}$ & 18 & 49 \\
\hline & & & & & 12.2 & 1796 & 0.45 & $\mathrm{y}$ & 0.66 & $\mathrm{y}$ & 23 & 41 \\
\hline & & & & & 16.3 & 2149 & 0.60 & $\mathrm{y}$ & 0.79 & $\mathrm{y}$ & 20 & 54 \\
\hline \multirow[t]{5}{*}{45} & 8 & 3.2 & 1.20 & 0.053 & & & & & 0.70 & $\mathrm{n}$ & 17 & 425 \\
\hline & & & & & 6.4 & 938 & 0.23 & $\mathrm{n}$ & 0.80 & $\mathrm{y}$ & 19 & 48 \\
\hline & & & & & 12.7 & 1394 & 0.47 & $\mathrm{n}$ & 0.81 & $\mathrm{y}$ & 18 & 43 \\
\hline & & & & & 19.1 & 1928 & 0.70 & $\mathrm{y}$ & 1.16 & $\mathrm{y}$ & 21 & 46 \\
\hline & & & & & 25.4 & 2246 & 0.94 & $\mathrm{y}$ & 1.20 & $\mathrm{y}$ & 26 & 49 \\
\hline \multirow[t]{4}{*}{49} & 16 & 2.2 & 1.20 & 0.053 & & & & & 0.45 & $\mathrm{n}$ & 14 & 702 \\
\hline & & & & & 4.1 & 906 & 0.15 & $\mathrm{n}$ & 0.51 & $\mathrm{n}$ & 12 & 650 \\
\hline & & & & & 8.1 & 1261 & 0.30 & $\mathrm{n}$ & 0.46 & $\mathrm{y}$ & 17 & 43 \\
\hline & & & & & 12.2 & 1796 & 0.45 & $\mathrm{y}$ & 0.66 & $\mathrm{y}$ & 23 & 41 \\
\hline \multirow[t]{4}{*}{54} & 8 & 2.6 & 1.20 & 0.079 & & & & & 0.75 & $\mathrm{n}$ & 15 & 11 \\
\hline & & & & & 6.4 & 938 & 0.23 & $\mathrm{n}$ & 0.80 & $\mathrm{y}$ & 19 & 48 \\
\hline & & & & & 12.7 & 1394 & 0.47 & $\mathrm{n}$ & 0.81 & $\mathrm{y}$ & 18 & 43 \\
\hline & & & & & 19.1 & 1928 & 0.70 & $\mathrm{y}$ & 1.16 & $\mathrm{y}$ & 21 & 46 \\
\hline
\end{tabular}


Table 10 - Vane 2 Trailing Edge Injection for a 5-Stage Turbine, with Flameholding

\begin{tabular}{|c|c|c|c|c|c|c|c|c|c|c|c|c|}
\hline Point & $\mathrm{N}$ & \begin{tabular}{|r|} 
hole size \\
$\mathrm{mm}$ \\
\end{tabular} & $\begin{array}{r}\text { fuel flow } \\
\mathrm{kg} / \mathrm{s} \\
\end{array}$ & $\begin{array}{l}\text { Fuel flux } \\
\mathrm{kg} / \mathrm{s}-\mathrm{cm} 2 \\
\end{array}$ & 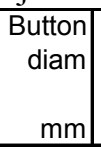 & $\begin{array}{r}\text { Wake } \\
\text { Taf } \\
\text { K } \\
\end{array}$ & $\begin{array}{r}\text { Wake } \\
\text { flame } \\
\text { r.t. } \\
\text { msec } \\
\end{array}$ & $\begin{array}{r}\text { Wake } \\
\text { flame } \\
\text { lit? }\end{array}$ & $\begin{array}{r}\text { Diff } \\
\text { flame } \\
\text { r.t. } \\
\text { msec } \\
\end{array}$ & $\begin{array}{r}\text { Diff } \\
\text { flame } \\
\text { lit? }\end{array}$ & $\begin{array}{l}\mathrm{NOx} \\
\mathrm{ppm}\end{array}$ & $\begin{array}{l}\mathrm{CO} \\
\mathrm{ppm}\end{array}$ \\
\hline \multicolumn{13}{|c|}{ Vane 2 of 5-stage turbine } \\
\hline \multirow[t]{5}{*}{1} & 8 & 3.2 & 2.40 & 0.119 & & & & & 0.80 & $\mathrm{n}$ & 13 & 3268 \\
\hline & & & & & 5.1 & 866 & 0.19 & $\mathrm{n}$ & 0.82 & $\mathrm{n}$ & 12 & 2612 \\
\hline & & & & & 10.2 & 1112 & 0.39 & $\mathrm{n}$ & 0.70 & $\mathrm{y}$ & 19 & 14 \\
\hline & & & & & 15.2 & 1563 & 0.58 & $\mathrm{y}$ & 1.03 & $\mathrm{y}$ & 28 & 11 \\
\hline & & & & & 20.6 & 1951 & 0.78 & $\mathrm{y}$ & 1.15 & $\mathrm{y}$ & 26 & 11 \\
\hline \multirow[t]{4}{*}{2} & 12 & 3.2 & 2.40 & 0.079 & & & & & 0.46 & $\mathrm{n}$ & 14 & 542 \\
\hline & & & & & 5.1 & 942 & 0.19 & $\mathrm{n}$ & 0.54 & $\mathrm{n}$ & 16 & 361 \\
\hline & & & & & 10.2 & 1292 & 0.39 & $\mathrm{n}$ & 0.53 & $\mathrm{n}$ & 11 & 781 \\
\hline & & & & & 13.7 & 1699 & 0.52 & $\mathrm{y}$ & 0.77 & $\mathrm{y}$ & 37 & 16 \\
\hline \multirow[t]{4}{*}{3} & 16 & 3.2 & 2.40 & 0.059 & & & & & 0.36 & $\mathrm{n}$ & 10 & 517 \\
\hline & & & & & 5.1 & 991 & 0.19 & $\mathrm{n}$ & 0.44 & $\mathrm{n}$ & 11 & 486 \\
\hline & & & & & 7.6 & 1145 & 0.29 & $\mathrm{n}$ & 0.42 & $\mathrm{n}$ & 14 & 1030 \\
\hline & & & & & 10.2 & 1489 & 0.39 & $\mathrm{n}$ & 0.45 & $\mathrm{n}$ & 10 & 2180 \\
\hline & & & & & & & & & & & & \\
\hline \multirow[t]{5}{*}{4} & 12 & 2.6 & 2.40 & 0.119 & & & & & 0.55 & $\mathrm{n}$ & 10 & 1187 \\
\hline & & & & & 5.1 & 942 & 0.19 & $\mathrm{n}$ & 0.54 & $\mathrm{n}$ & 16 & 361 \\
\hline & & & & & 10.2 & 1292 & 0.39 & $\mathrm{n}$ & 0.53 & $\mathrm{n}$ & 11 & 781 \\
\hline & & & & & 13.7 & 1699 & 0.52 & $\mathrm{y}$ & 0.77 & $\mathrm{y}$ & 37 & 16 \\
\hline & & & & & & & & & & & & \\
\hline \multirow[t]{4}{*}{5} & 16 & 2.6 & 2.40 & 0.089 & & & & & 0.39 & $\mathrm{n}$ & 12 & 519 \\
\hline & & & & & 5.1 & 991 & 0.19 & $\mathrm{n}$ & 0.44 & $\mathrm{n}$ & 11 & 486 \\
\hline & & & & & 7.6 & 1145 & 0.29 & $\mathrm{n}$ & 0.42 & $\mathrm{n}$ & 14 & 1029 \\
\hline & & & & & 10.2 & 1489 & 0.39 & $\mathrm{n}$ & 0.46 & $\mathrm{n}$ & 10 & 2180 \\
\hline & & & & & & & & & & & & \\
\hline \multirow[t]{4}{*}{7} & 12 & 2.2 & 2.40 & 0.160 & & & & & 0.76 & $\mathrm{n}$ & 11 & 3146 \\
\hline & & & & & 5.1 & 942 & 0.19 & $\mathrm{n}$ & 0.54 & $\mathrm{n}$ & 16 & 361 \\
\hline & & & & & 10.2 & 1292 & 0.39 & $n$ & 0.53 & $\mathrm{n}$ & 11 & 781 \\
\hline & & & & & \begin{tabular}{ll|}
13.7 \\
\end{tabular} & 1699 & 0.52 & $y$ & 0.77 & $\mathrm{y}$ & 37 & 16 \\
\hline \multirow[t]{4}{*}{13} & 16 & 1.8 & 2.40 & 0.179 & & & & & 0.73 & $\mathrm{n}$ & 10 & 3093 \\
\hline & & & & & 5.1 & 991 & 0.19 & $\mathrm{n}$ & 0.44 & $\mathrm{n}$ & 11 & 486 \\
\hline & & & & & 7.6 & 1145 & 0.29 & $\mathrm{n}$ & 0.42 & $\mathrm{n}$ & 14 & 1029 \\
\hline & & & & & 10.2 & 1489 & 0.39 & $\mathrm{n}$ & 0.45 & $\mathrm{n}$ & 10 & 2180 \\
\hline \multirow{4}{*}{20} & 16 & 1.3 & 2.40 & 0.356 & & & & & 0.96 & $\mathrm{n}$ & 15 & 5 \\
\hline & & & & & 5.1 & 991 & 0.19 & $\mathrm{n}$ & 0.44 & $\mathrm{n}$ & 11 & 486 \\
\hline & & & & & 7.6 & 1145 & 0.29 & $\mathrm{n}$ & 0.42 & $\mathrm{n}$ & 14 & 1029 \\
\hline & & & & & 10.2 & 1489 & 0.39 & $\mathrm{n}$ & 0.45 & $\mathrm{n}$ & 10 & 2180 \\
\hline \multirow{5}{*}{22} & & & & & & & & & 1 & & & 20 \\
\hline & 24 & 0.9 & 2.40 & 0.477 & & & & & 0.82 & $\mathrm{n}$ & 9 & 3466 \\
\hline & & & & & 2.5 & 808 & 0.10 & $\mathrm{n}$ & 0.34 & $\mathrm{n}$ & 10 & 810 \\
\hline & & & & & 5.1 & 1058 & 0.19 & $\mathrm{n}$ & 0.32 & $\mathrm{n}$ & 10 & 1819 \\
\hline & & & & & 6.9 & 1234 & 0.26 & $\mathrm{n}$ & 0.32 & $\mathrm{n}$ & 10 & 2736 \\
\hline \multirow[t]{3}{*}{24} & 32 & 0.9 & 2.40 & 0.358 & & & & & 0.83 & $\mathrm{n}$ & 12 & 3468 \\
\hline & & & & & 2.5 & 866 & 0.10 & $\mathrm{n}$ & 0.27 & $\mathrm{n}$ & 15 & 1605 \\
\hline & & & & & 5.1 & 1112 & 0.19 & $\mathrm{n}$ & 0.26 & $\mathrm{n}$ & 10 & 2934 \\
\hline \multirow[t]{4}{*}{25} & 48 & 0.9 & 2.40 & 0.238 & & & & & 1.03 & $\mathrm{n}$ & 15 & 131 \\
\hline & & & & & 1.8 & 806 & 0.07 & $\mathrm{n}$ & 0.21 & $\mathrm{n}$ & 11 & 2302 \\
\hline & & & & & 2.5 & 942 & 0.10 & $\mathrm{n}$ & 0.21 & $\mathrm{n}$ & 13 & 2734 \\
\hline & & & & & 3.3 & 1031 & 0.13 & $\mathrm{n}$ & 0.20 & $\mathrm{n}$ & 12 & 3188 \\
\hline
\end{tabular}




\section{CONCLUSIONS}

\section{Conventional Four-Stage Turbine}

Reheat fuel addition via the vane 1 trailing edge results in burnout of fuel, with resulting increased power output and, for combined cycle operation, increased cycle efficiency.

Vane 1 trailing edge reheat should be done without a flameholder. Such reheat should have an optimum hole size - small enough to prevent diffusion flame formation, but not so small as to allow insufficient high temperature residence time for $\mathrm{CO}$ burnout. Both Nox and $\mathrm{CO}$ emissions are increased by about $10 \mathrm{ppmv}$ with an optimized design

Without the use of a flameholder, reheat fuel added at the vane 2 trailing edge will not burn, unless it is done after vane 1 reheat to turbine inlet temperature, in which case there will be high ( $\sim 500$ ppmv) CO emissions.

With a flameholder, reheat fuel added at vane 2 can be made to burn with or without vane 1 reheat, but Nox will increase by about $10 \mathrm{ppmv}$, and $\mathrm{CO}$ by about 40 to $50 \mathrm{ppmv}$.

\section{High pressure ratio five-stage turbine}

Task 2 - Blade Path Aeo Reheat fuel injected without a flameholder at the vane 2 (same size and conditions, except temperature, as vane 1 of a 4 -stage engine) will burn, but with high CO.

With a flameholder, Nox and CO increases can be kept at about 20 and 10 ppmv respectively. 


\section{REFERENCES}

1. E.V. Carelli, R.D. Holm, T.E. Lippert, and D.M. Bachovchin, Reheat Combustor for Gas Combustion Turbine, U.S. Patent 6,619,026, Siemens Westinghouse Power Corporation, September 16, 2003.

2. W. R. Hawthorne, D.S. Weddell, and H.C. Hottel, "Mixing and Combustion in Turbulent Gas Jets." Third Symposium on Combustion, Flame and Explosion Phenomena. Williams and Wilkins Company, Baltimore, 1949. pp. 267-288.

3. K. Wohl, C. Gazley, and N. Kapp, "Diffusion Flames." Third Symposium on Combustion, Flame and Explosion Phenomena. Williams and Wilkins Company, Baltimore, 1949. pp. 288-299.

4. S.R. Turns, An Introduction to Combustion, Concepts and Applications. McGrawHill, New York, 2000. p. 443.

5. G. Winterfeld, "On Processes of Turbulent Exchange Behind Flame Holders." Tenth Symposium (International) on Combustion. The Combustion Institute, Pittsburgh, 1965. pp. 1265-1275. 


\section{Attachment III: Task 3 - Sub-Scale Testing}

\section{SUMMARY}

Two test systems have been prepared. The first, for smaller scale testing, used the existing $0.2 \mathrm{~kg} / \mathrm{sec}$ air, $200 \mathrm{psi}, 900 \mathrm{~F}$ air facility, with modified spool pieces. Testing is summarized in Section 2. Data were used for calibration of CFD and detailed kinetic models discussed in the Tasks 1 and 2 Attachments in this report.

The second was a $0.64 \mathrm{~kg} / \mathrm{sec}$ air built with Siemens Westinghouse capital for catalytic combustion testing. This unit was still undergoing shakedown at the end of this project, so reheat testing was not initiated. 


\section{SMALLER SCALE TESTING}

\subsection{Test Rig}

The test rig is shown schematically in Figure 1. A full pressure (14 bar) natural gas fired dump combustor, with air flow of up to $0.2 \mathrm{~kg} / \mathrm{s}(0.44 \mathrm{lb} / \mathrm{sec})$ at conditions of up to $755 \mathrm{~K}$ $\left(900^{\circ} \mathrm{F}\right)$ and $13.8 \mathrm{bar}(200 \mathrm{psia})$ was used to generate a hot flue gas. Fuel/air ratio and air inlet temperature (from an air preheater) were varied to give product temperatures and compositions corresponding to typical turbine locations as a function of blade path position. In each case the product mixture was passed through a pressure-reducing orifice (to about 5.5 bar ( $80 \mathrm{psia})$ ) to raise the Mach number in the test channel to a level representative of an industrial gas turbine. This was necessary because the available air flow precluded maintaining both pressure and velocity in a channel of acceptable size.

The gas mixture entered a rectangular $1.78 \mathrm{~cm}$ x $2.54 \mathrm{~cm}(0.7$ in $\times 1.0$ in) channel and passed a probe that crossed the centerline of the channel. The probe was used to inject fuel via a hole in its trailing edge. The natural gas was at $289 \mathrm{~K}$, with a mole percent composition of approximately $96.1 \mathrm{CH} 4,2.0 \mathrm{C} 2 \mathrm{H} 6,0.9 \mathrm{C} 3 \mathrm{H} 8,0.5 \mathrm{CO} 2$, and $0.5 \mathrm{~N} 2$. The geometry of the probe is shown in Figure 2. Fuel was injected through a $0.66 \mathrm{~mm}(0.026$ in) diameter hole.

Following the probe, the gas and fuel jet entered a $1.78 \times 1.78 \mathrm{~cm}(0.7$ in $\times 0.7 \mathrm{in})$ test channel. Temperature and product gas composition were measured with centerline sampling probes at several locations in the test section.

\subsection{Test Results}

The test conditions and results are summarized in Table 1. Conditions were planned to simulate the four indicated blade path locations, but varied somewhat because of rig limitations. At each condition two reheat fuel injection rates were run, and for each injection rate two runs were made with sampling locations at different downstream distances. Methane conversions were calculated based on known inlet fuel rate and GC-measured composition at the sampling points. The locations of the sampling point in terms of axial distance from the injection point are given at the top of each methane conversion column. Also given there is an approximate time of flight, or residence time between the injection and sampling points.

It is seen that with fuel injection at conditions corresponding to V1 trailing edge and B1 midspan, burnout was complete prior to the first sampling probe, so these could not be used to calibrate the model. With injection at conditions corresponding to B1 trailing edge and V2 trailing edge, combustion was incomplete, so these points could be so used. The report sections for Tasks 2 and 3 show how these data were used to calibrate CFD and detailed kinetic models respectively.

Figures 3 and 4 summarize the data of Table 1, and show how conversion varied with residence time and temperature. 


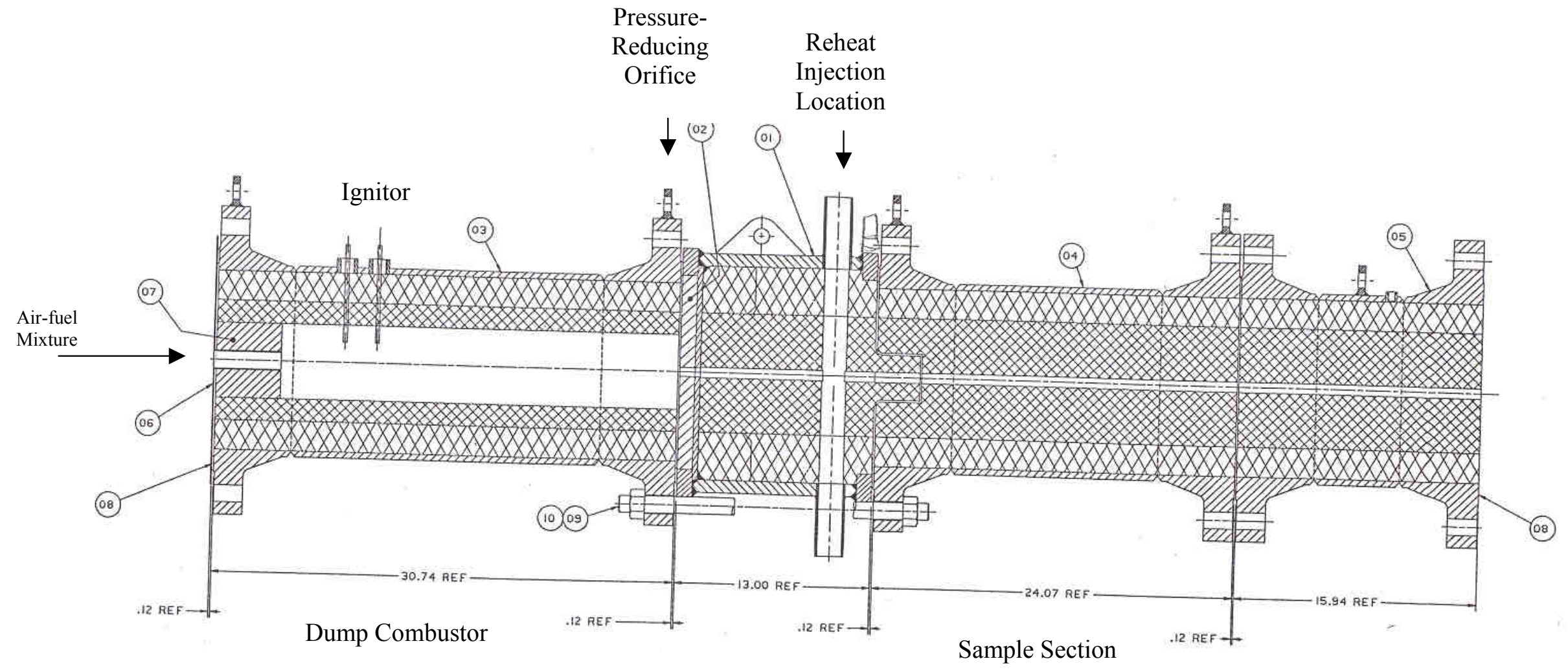

Figure 1 - Test Rig 

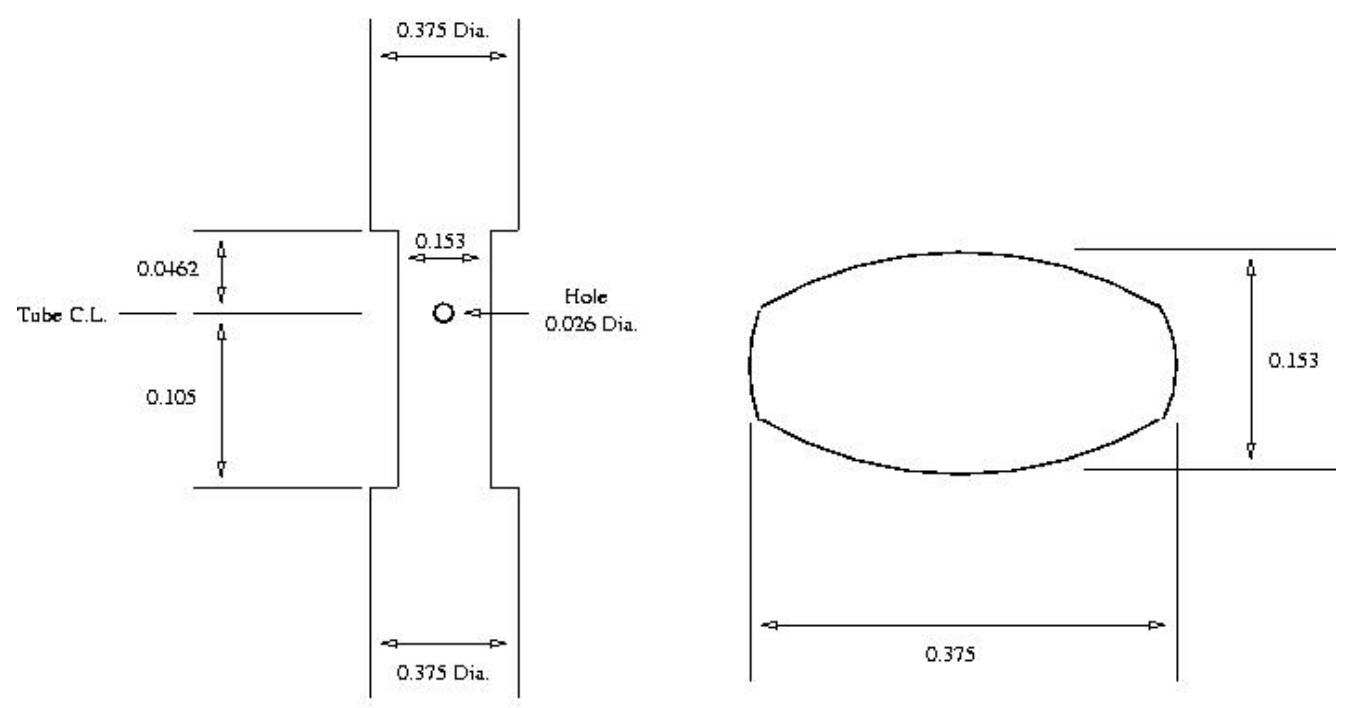

NOTE: Al] Lengths Shown in Lnches

Drawing Not To Scale

Figure 2-Combustion Probe

Table 1 - Small Rig Test Matrix

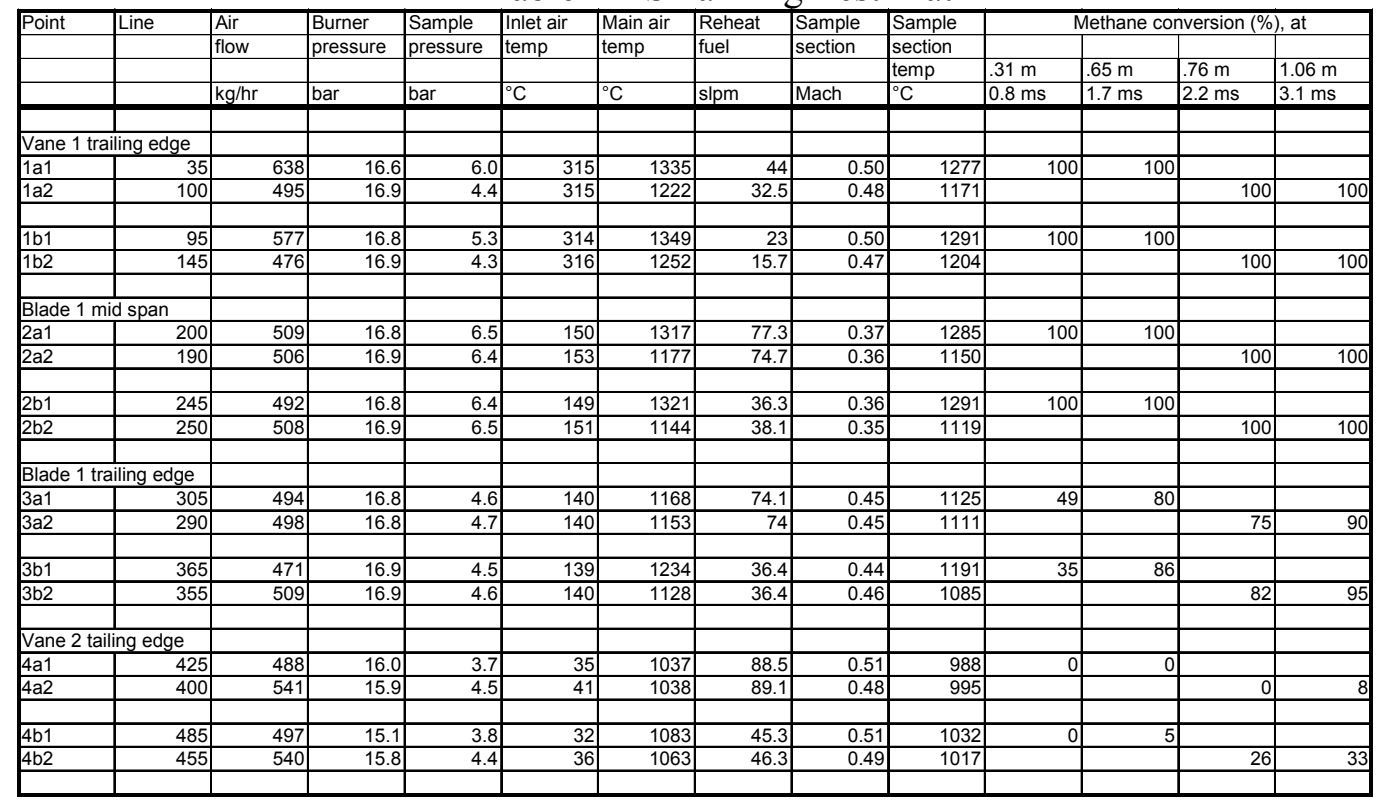




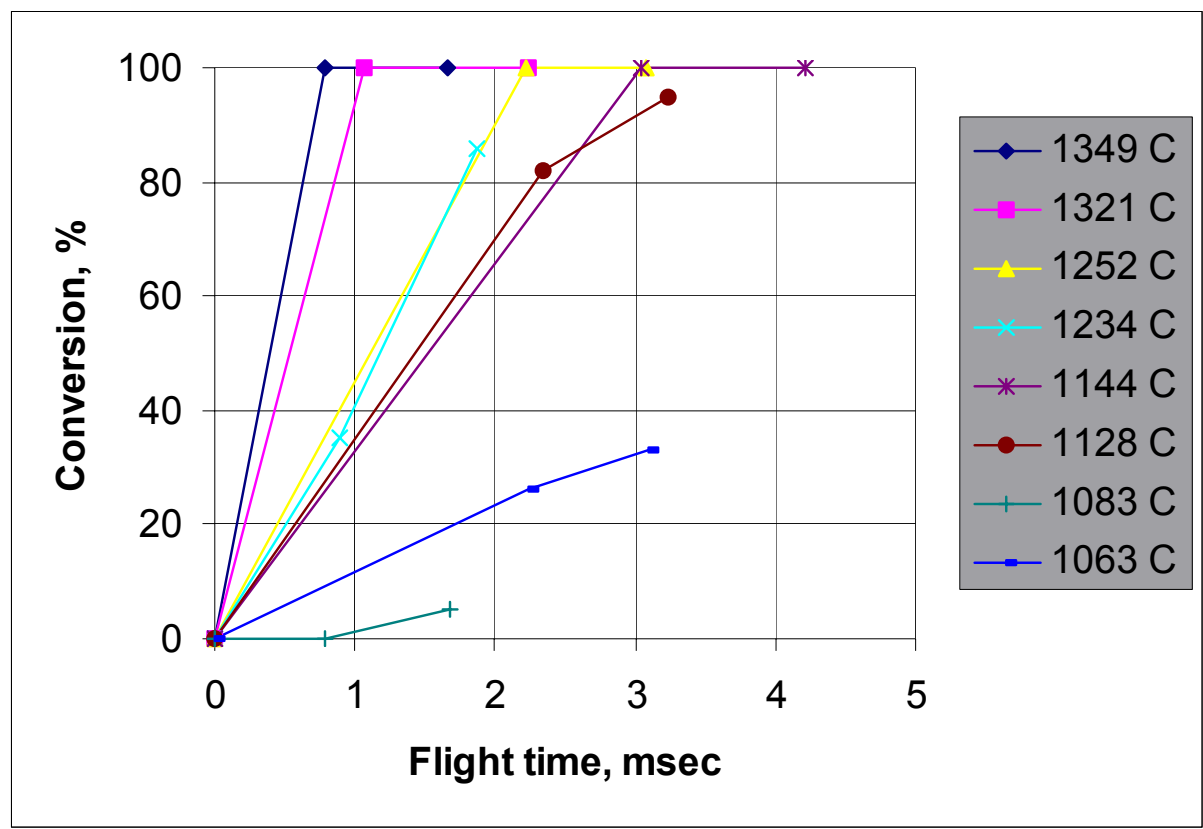

Figure 3 - Conversion vs. Residence Time, Low Injection Rate Points (b points)

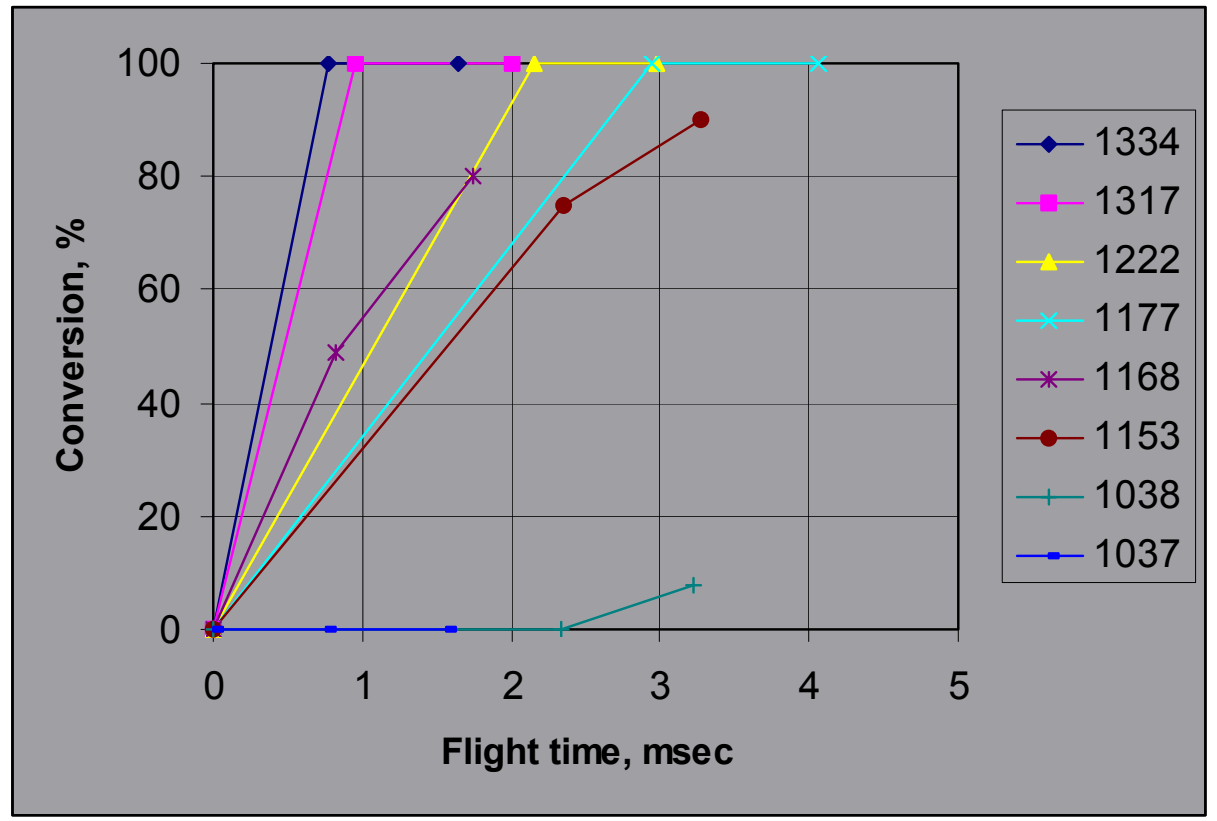

Figure 4 - Conversion vs. Residence Time, High Injection Rate Point (a points) 


\section{LARGER SCALE TEST RIG}

The larger rig was a $0.64 \mathrm{~kg} / \mathrm{sec}$ air built with Siemens Westinghouse capital for catalytic combustion testing. This unit was still undergoing shakedown at the end of this project, so reheat testing was not initiated.

The larger system uses up to $0.64 \mathrm{~kg} / \mathrm{s}(1.4 \mathrm{lb} / \mathrm{sec})$ of air at up to $870 \mathrm{~K}(1100 \mathrm{~F})$ at $200 \mathrm{psi}$. The design and operation are similar to the smaller unit, except the flow path dimensions are $3.48 \mathrm{~cm} \times 2.79 \mathrm{~cm}(1.37 \mathrm{in} \times 1.1 \mathrm{in})$ at the injection vane and $2.79 \mathrm{~cm}$ $\mathrm{x} 2.79 \mathrm{~cm}(1.1 \mathrm{in} \times 1.1 \mathrm{in})$ at the sample section.

Figures 5, 6, and 7 show the erected components. Figure 8 is a schematic of the test sections.

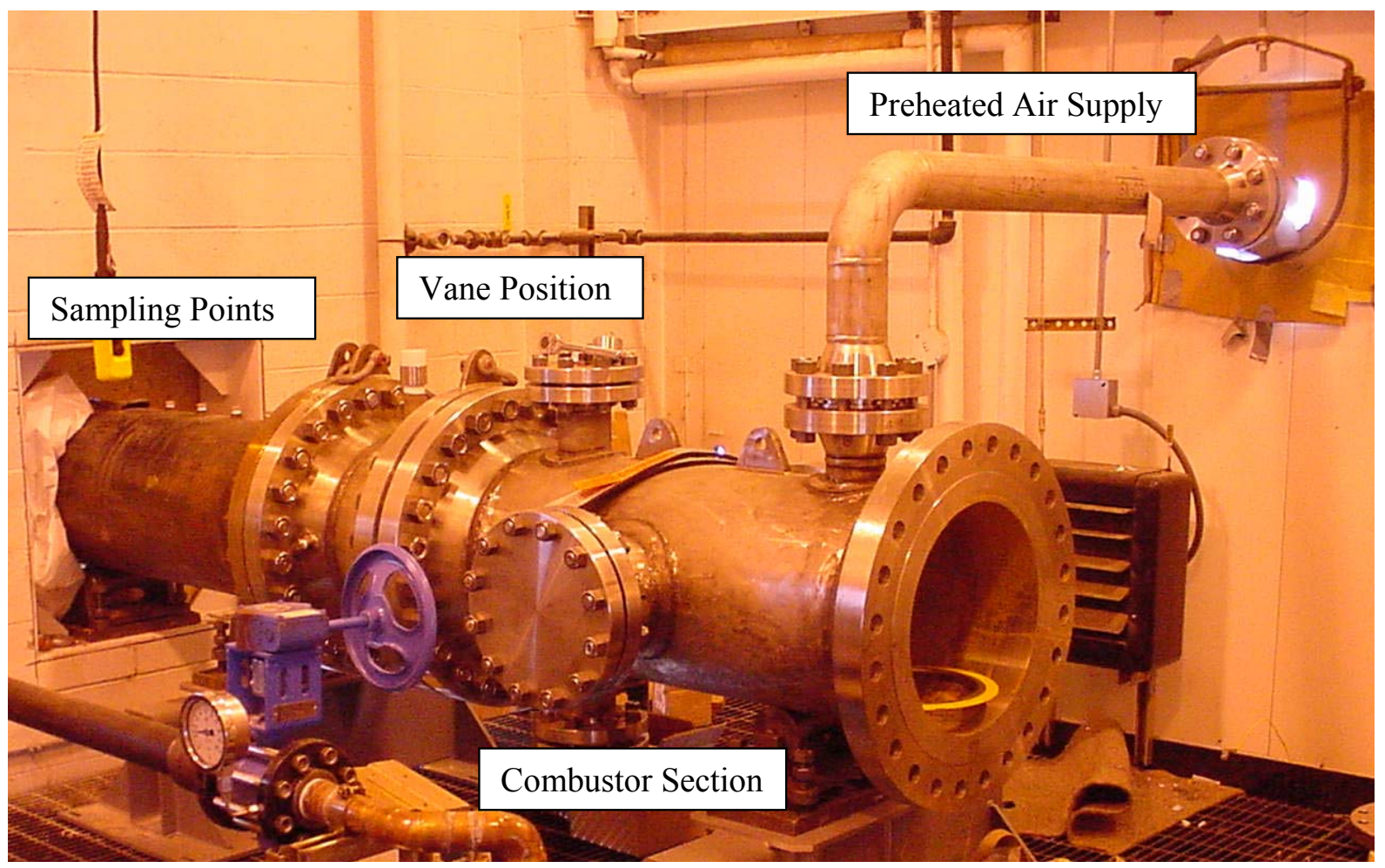

Figure 5 - Test Facility Combustion and Sampling Sections 


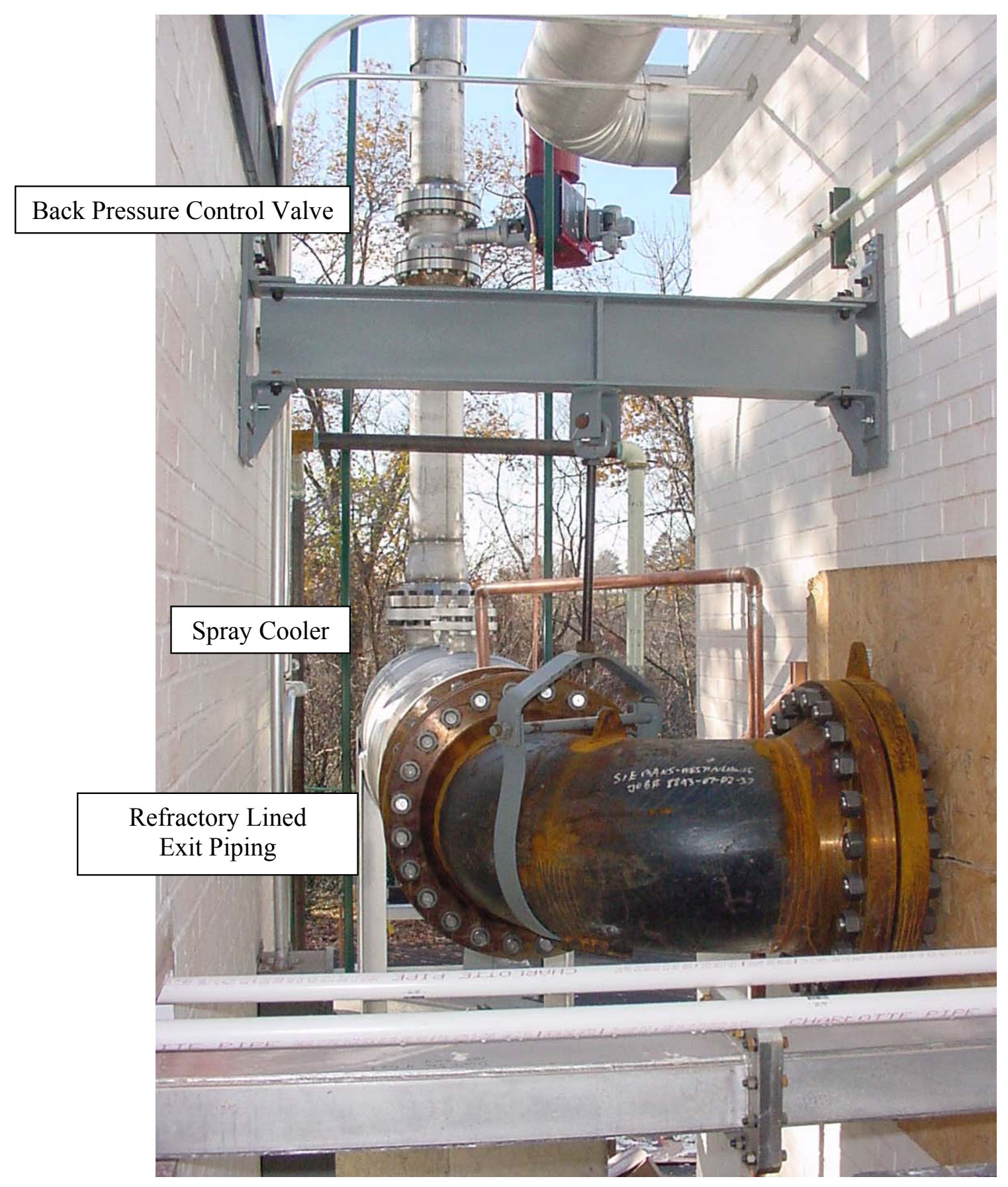

Figure 6 - Test Facility Exhaust and Back Pressure Control Sections 


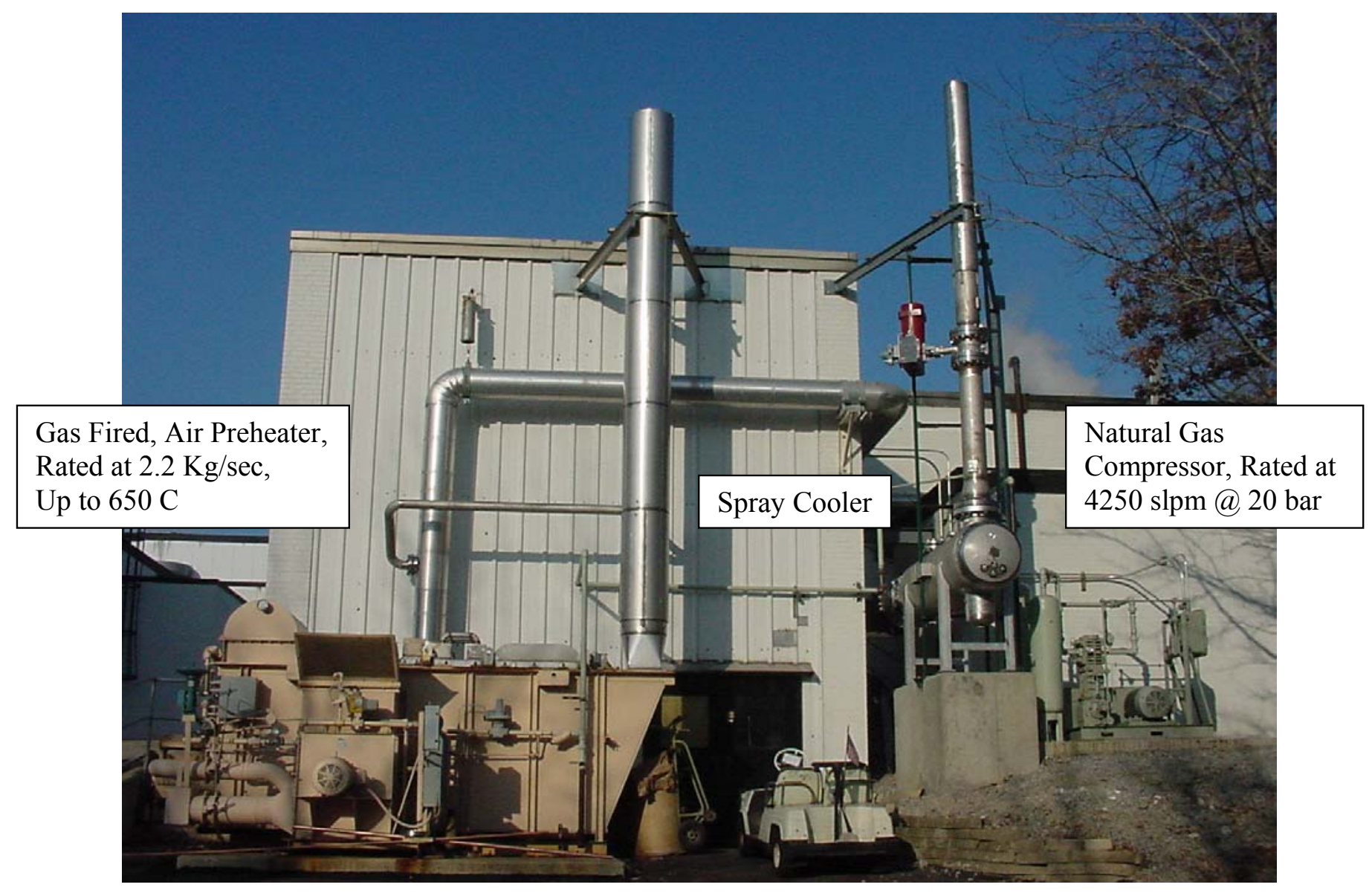

Figure 7 - Test Facility Sir Preheater and Fuel Compressor 


\section{Airfoil Insertion Ports}

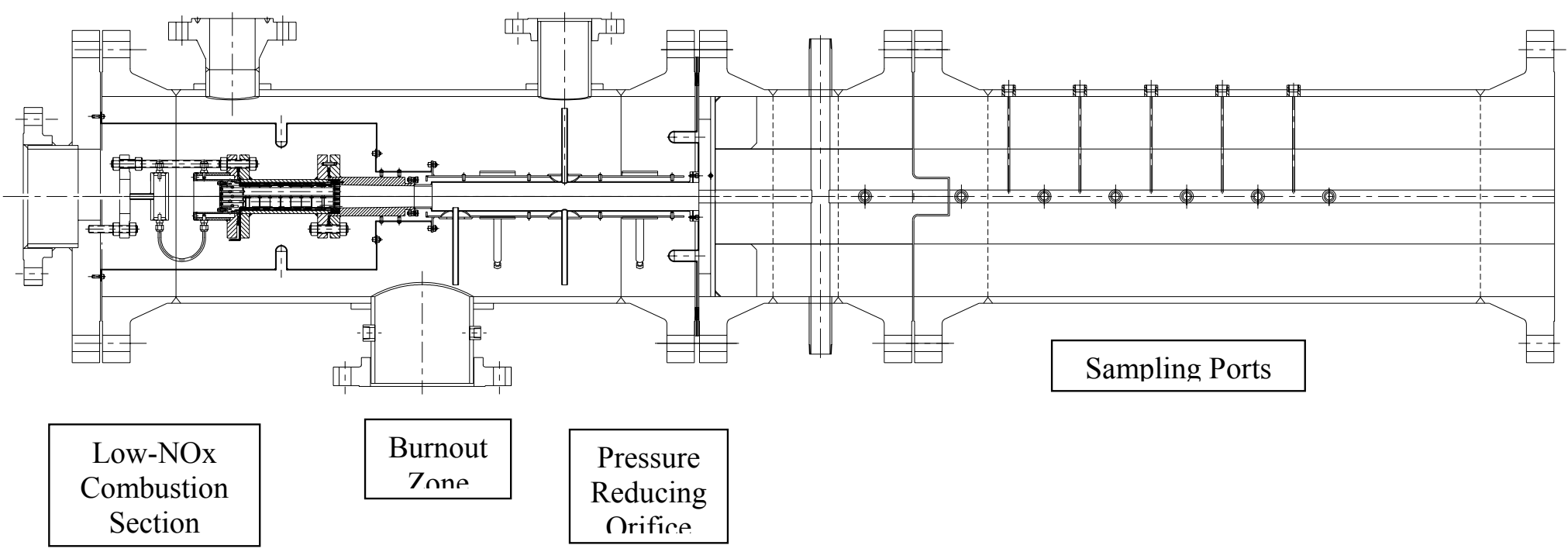

Figure 8 - Larger Scale Test Rig 


\section{Attachment IV: Task 4 - Conceptual Design and Development Plan}

\section{SUMMARY}

In-situ reheat is an alternative to traditional gas turbine reheat design in which fuel is fed through airfoils rather than in a bulky discrete combustor separating HP and LP turbines. The goals are to achieved increased power output and/or efficiency without higher emissions. In this program the scientific basis for achieving burnout with low emissions has been explored. In Task 1, Blade Path Aerodynamics, design options were evaluated using CFD terms of burnout, increase of power output, and possible hot streaking. It was concluded that Vane 1 injection in a conventional 4-stage turbine was preferred. Vane 2 injection after vane 1 injection was possible, but of marginal benefit. In Task 2, Combustion and Emissions, detailed chemical kinetics modeling, validated by Task 3 experiments, resulted in the same conclusions, with the added conclusion that some increase in emissions was expected.

In the present Task 4, Conceptual Design and Development Plan, Siemens Westinghouse power cycle analysis software packages have been used to evaluate alternative in-situ reheat design options in terms of increase in power output and increase in (simple and combined) cycle efficiency. Only single stage reheat, via vane 1, was found to have merit. This is again consistent with conclusions from previous tasks.

Unifying the results of all the tasks, a conceptual design for single stage reheat utilizing 24 holes, $1.8 \mathrm{~mm}$ diameter, at the trailing edge of vane 1 is presented.

A development plan is presented. Tasks include verification at scaled up conditions, analytical evaluation of a more extensive matrix of design options (in search of lower emissions), and investigation into the use of hydrogen-including reheat fuels for accelerated burnout and incorporation into advanced cycles. 


\section{CONCEPTUAL EVALUATION OF ALTERNATIVE REHEAT CONFIGURATIONS}

\subsection{Background And Objectives}

Several software tools have been established as useful for advanced cycle evaluations, each having advantages for certain types of cycles or for certain aspects of cycle evaluations: GateCycle, and ChemCad. In this report, these are exercised to perform a preliminary, conceptual evaluation of alternative turbine reheat approaches.

The term "reheat" is used to mean utilizing oxygen remaining in a turbine expansion gas to combust additional fuel, thereby increasing the expansion gas temperature and permitting further, efficient power extraction from that gas. Various means for achieving reheat-type performance in gas turbine systems have been proposed. The "sequential combustion reheat" power system adds a high-pressure air compressor, primary-fuel combustor, a high-pressure expander stage, and a reheat-combustor to an existing low-pressure turbine expander. This sequential combustion reheat system requires the development of new equipment components, and extensive integration of new components with existing equipment.

A proposed, novel reheat method, called "in-situ" reheat [1], utilizes the injection of fuel through the turbine airfoils rather than through reheat combustor baskets, with reheat combustion proceeding in the wakes of the airfoils. The base concept is to add enough fuel at the vane 1 trailing edge to restore gas temperature to the turbine inlet temperature. A variation, that we will call "fractional reheat" has been proposed that applies moderate in-situ reheat to restore temperature only partially. Its main purpose is to compensate for the gas cooling effect when cooling air from the vane and blades mix.

One additional form of reheat is identified in this report, "partial oxidation" reheat that may be applied with reheat combustor baskets or with in-situ reheat. In this reheat concept the turbine fuel is first subjected to partial oxidation to generate a low heating-value fuel gas that is expanded in one or more turbine stages that include partial combustion reheat of the fuel gas. The in-situ reheat version of the partial oxidation concept utilized cooling air ejected from the airfoils to provide the oxidant needed for combustion of the fuel gas expanding through the turbine.

This report describes these alternative approaches at a conceptual level and makes estimates of their relative performance. Cycle performance estimates are reported using GateCycle and ChemCad software simulations of typical $\mathrm{F}$ and $\mathrm{G}$ class engines modified for the alternative reheat cycles. In general, all of the reheat approaches show potential advantages over the conventional reheat approach, but considerable development is required for all of the reheat concepts considered. 


\subsection{Reference Turbine Performance}

Reference turbine cycles were first generated for the typical $\mathrm{F}$ and $\mathrm{G}$ class turbines to provide the framework for modification and comparison with the reheat turbine cycles. These simulations are only "representative" of the stage conditions and performance of turbines and do not function as detailed models of the turbines.

A conventional F-class simulation was set up using GateCycle (a power system simulator marketed by Enter Software, Inc.) and used to estimate the performance of the fractional and full in-situ reheat cycles at turbine off-design conditions. Standard F-class and G-class simulations were set up using ChemCad (a general process simulator marketed by Chemstations, Inc.) to be applied for full in-situ reheat and partial oxidation reheat cycles.

A process schematic of the Reference turbine model is shown in Figure 1. Ambient air is compressed, and vane and rotor coolant air streams are extracted from the compressor. The rotor coolant air is cooled and supplied to the four rotor stages of the turbine at near to the compressor outlet pressure. The vane coolant air is not cooled and is extracted at the appropriate pressure to supply coolant to each vane stage. Steam cooling of the combustor transition section is also shown. Representative compressor, combustor, and four-stage expander conditions (temperatures, pressures, flows, cooling flows, coolant temperatures, and component efficiencies) were used.

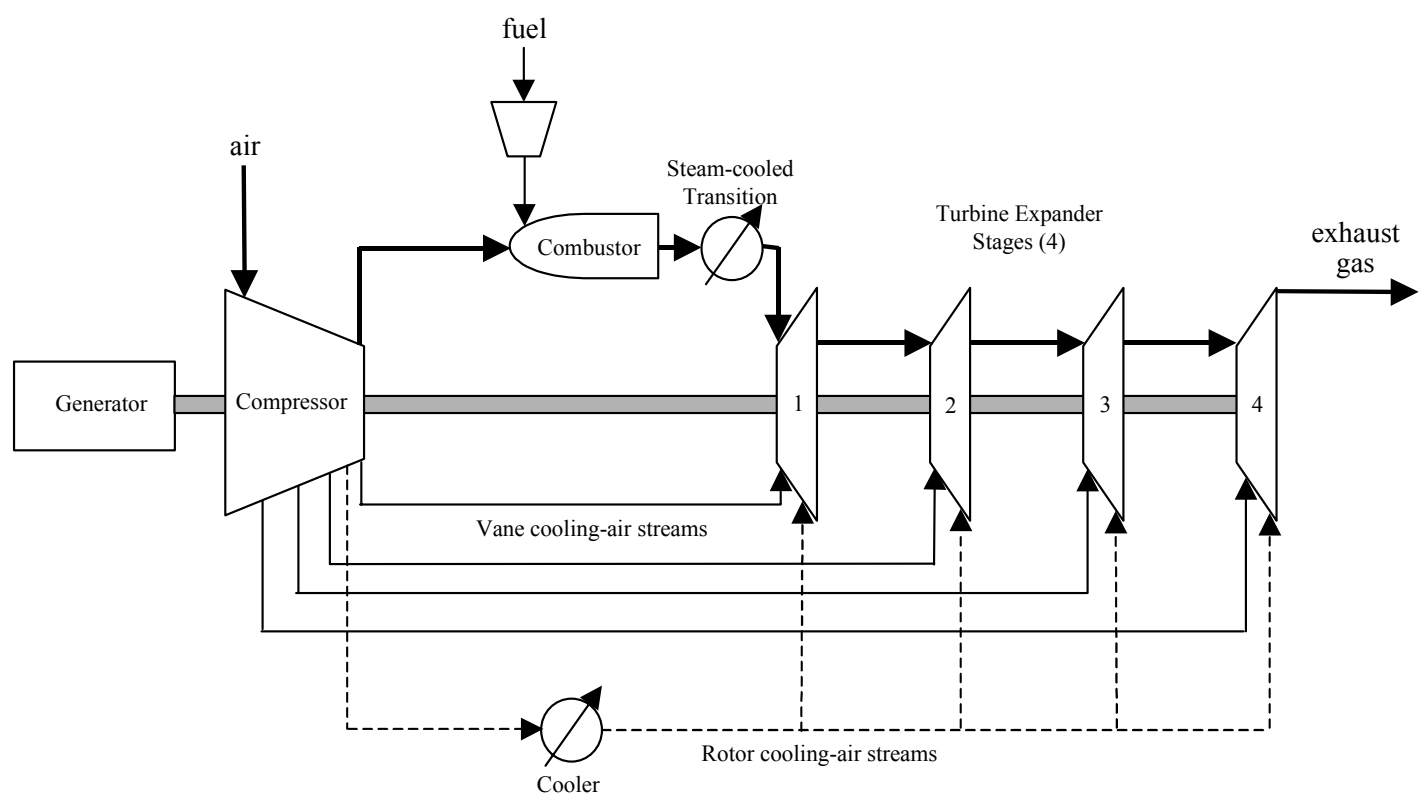

Figure 1 - Reference Turbine Model

ISO air inlet conditions were used in all of the simulations, and a natural gas fuel was applied. Natural gas was assumed available to the cycles at 300 psia. The air and natural gas compositions assumed were slightly different in the GateCycle and ChemCad simulations, and are listed in Table 1. The differences are relatively insignificant. All of the simulations assumed a compressor inlet air pressure loss of $0.14 \mathrm{psi}$, and representative exhaust system pressure losses were assumed for simple-cycle and combined-cycle cases. 
Table 1 - GateCycle and ChemCad Air and Natural Gas Compositions

\begin{tabular}{|l|c|c|}
\hline \multicolumn{2}{|c|}{ GateCycle } & ChemCad \\
\hline $\mathrm{O}_{2}$ & 20.74 & 20.72 \\
\hline $\mathrm{N}_{2}$ & 77.29 & 77.23 \\
\hline $\mathrm{Ar}$ & 0.92 & 1.01 \\
\hline $\mathrm{CO}_{2}$ & 0.03 & 0.03 \\
\hline $\mathrm{H}_{2} \mathrm{O}$ & 1.02 & 1.01 \\
\hline \multicolumn{3}{|c|}{} \\
\hline methane & Natural gas (vol\%) & 95.0 \\
\hline ethane & $\mathrm{H} / \mathrm{C}$ ratio $=3.8813$ & 2.0 \\
\hline propane & $3.42 \times 10^{5}$ & 0.5 \\
\hline I-butane & 0.5 \\
\hline nitrogen & $\begin{array}{l}\text { Lower heating value } \\
\text { (Btu/lb mole) }\end{array}$ & 2.0 \\
\hline
\end{tabular}

The simulation performances for the reference turbines with simple-cycle and combinedcycle configurations are listed in Table 2 . The steam bottoming cycle performance was estimated from Siemens Westinghouse correlations of steam bottoming cycle efficiency as a function of the turbine exhaust temperature.

The GateCycle model and ChemCad model provide comparable estimates of the simple-cycle power and efficiency, with some of the difference being due to fuel compression power not being included in the GateCycle estimate, and differences in generator efficiency assumptions. Overall, the performance results are close to performance numbers published in the open turbine literature.

Table 2 - GateCycle and ChemCad Reference Turbine Simulation Results

\begin{tabular}{|l|c|c|c|c|}
\hline & $\begin{array}{c}\text { GateCycle } \\
\text { F-class } \\
\text { S-C }\end{array}$ & $\begin{array}{c}\frac{\text { ChemCad }}{\text { F-class }} \\
\text { S-C }\end{array}$ & $\begin{array}{c}\frac{\text { ChemCad }}{\text { F-class }} \\
\text { C-C }\end{array}$ & $\begin{array}{c}\frac{\text { ChemCad }}{\text { G-class }} \\
\text { C-C }\end{array}$ \\
\hline Fuel input $\left(10^{9} \mathrm{Btu} / \mathrm{hr}\right)$ & 1.6974 & 1.698 & 1.666 & 2.100 \\
\hline TIT $\left({ }^{\circ} \mathrm{F}\right)$ & 2584 & 2598 & 2598 & 2782 \\
\hline RIT $\left({ }^{\circ} \mathrm{F}\right)$ & 2450 & 2453 & 2453 & 2609 \\
\hline Exhaust temperature $\left({ }^{\circ} \mathrm{F}\right)$ & 1096 & 1103 & 1100 & 1111 \\
\hline Exhaust oxygen $($ vol\%) & 12.5 & 12.4 & 12.4 & 11.9 \\
\hline Compression ratio & 15.9 & 15.9 & 17.1 & 19.2 \\
\hline GT shaft power $(\mathrm{MW})$ & 193.4 & 190.0 & 181.8 & 243.3 \\
\hline Fuel compressor $(\mathrm{MW})$ & 0 & 0.57 & 0.56 & 0.95 \\
\hline GT generator eff $(\%)$ & 98.0 & 98.5 & 98.5 & 99.0 \\
$/$ loss (MW) & $/ 3.9$ & $/ 2.8$ & 12.7 & $/ 2.4$ \\
\hline Net GT power $(\mathrm{MW})$ & 189.5 & 186.6 & 178.5 & 239.9 \\
\hline ST power $(\mathrm{MW})$ & 0 & 0 & 96.7 & 127.1 \\
\hline Aux. And BOP losses $(\mathrm{MW})$ & 0 & 0 & 6.4 & 8.4 \\
\hline Net plant power $(\mathrm{MW})$ & 189.5 & 186.6 & 268.8 & 358.6 \\
\hline $\begin{array}{l}\text { Net plant efficiency }- \text { LHV } \\
(\%)\end{array}$ & 38.1 & 37.5 & 55.0 & 58.3 \\
\hline
\end{tabular}




\subsection{Sequential Combustion Reheat And In-Situ Reheat Turbine Performance}

The sequential combustor reheat turbine concept consists of a high-pressure air compressor, a high-pressure combustor, a high-pressure expander stage, and a reheat-combustor added to an existing, low-pressure turbine expander. It is illustrated in Figure 2, and it is represented commercially by the ABB GT24/GT26 Sequential Combustion System. In the simulations made in this evaluation, vane and rotor coolant flows are provided to the high-pressure expander stage and to the four, low-pressure turbine stages. The possibility of transition steam cooling of both the high-pressure and the reheat combustor transitions is shown. Compression of high-pressure fuel and reheat fuel is required.

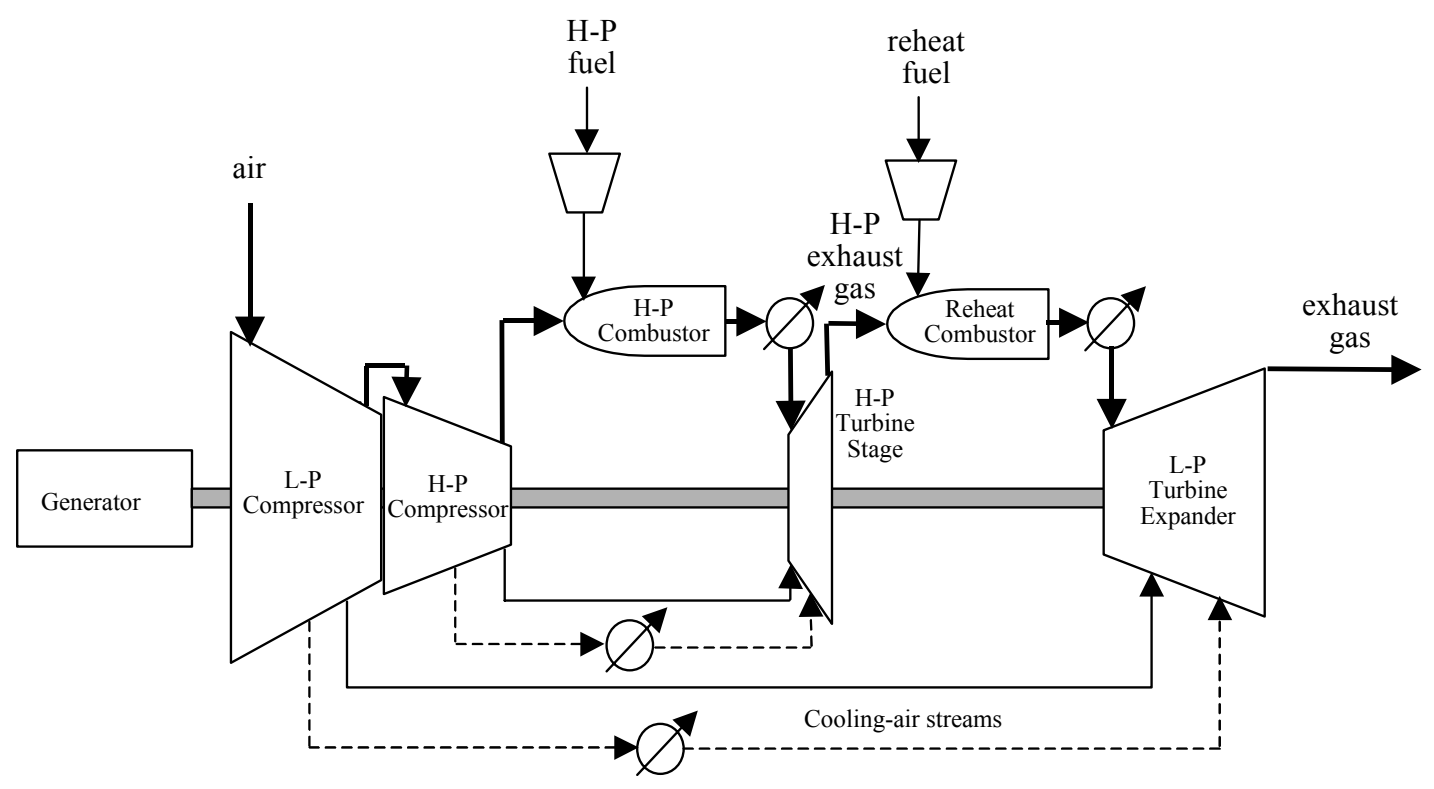

Figure 2 - Sequential Combustion Reheat Turbine Configuration

Simulations of the performance of sequential combustion reheat applied to the F-class and Gclass turbines have been made using ChemCad. A simulation of two reheat-fired stages has also been made to judge the relative merits of multiple sequential combustion reheat. The results are summarized in Table 3. The high-pressure turbine stage was assumed to have an expansion ratio similar to the expansion ratio of the reference turbine stages. The firing temperatures applied in the high-pressure combustors and reheat combustors are approximately the same as those used in the reference turbine combustors. Estimates of both the simple-cycle and combined-cycle efficiencies are made.

Comparison on the net power generation and net plant efficiencies of Tables 2 and 3 indicates the relative benefits of the sequential combustion reheat cycle. The F-class reheat simple cycle gains $8.9 \mathrm{MW}$ of power and 1.2 percentage points of efficiency, and the reheat combined cycle gains $18.4 \mathrm{MW}$ and 1.9 percentage points. The G-class reheat simple-cycle gains $24.1 \mathrm{MW}$ of power and 1.0 percentage points of efficiency, and the reheat combinedcycle gains $40.7 \mathrm{MW}$ and 0.7 percentage points. 
Table 3 - ChemCad Sequential Combustion Reheat Turbine Simulation Results

\begin{tabular}{|l|c|c|c|}
\hline & $501 \mathrm{FD}$ & $501 \mathrm{G}$ & $\begin{array}{c}501 \mathrm{FD} \\
\text { two-reheats }\end{array}$ \\
\hline Total fuel input $\left(10^{9} \mathrm{Btu} / \mathrm{hr}\right)$ & 1.72 & 2.308 & 1.946 \\
\hline Primary fuel $(\mathrm{lb} / \mathrm{hr})$ & 51,000 & 76,000 & 38,000 \\
\hline Reheat fuel $(\mathrm{lb} / \mathrm{hr})$ & 32,200 & 35,500 & 56,000 \\
\hline HP-Turbine TIT $\left({ }^{\circ} \mathrm{F}\right)$ & 2583 & 2778 & 2583 \\
\hline HP-turbine RIT $\left({ }^{\circ} \mathrm{F}\right)$ & 2450 & 2604 & 2450 \\
\hline Reheat-turbine TIT $\left({ }^{\circ} \mathrm{F}\right)$ & 2583 & 2782 & 2583 \\
\hline Reheat-turbine RIT $\left({ }^{\circ} \mathrm{F}\right)$ & 2450 & 2611 & 2450 \\
\hline Exhaust gas rate $(\mathrm{lb} / \mathrm{hr})$ & $3,714,684$ & $4,401,494$ & $3,725,503$ \\
\hline Exhaust temperature $\left({ }^{\circ} \mathrm{F}\right)$ & 1107 & 1153 & 1105 \\
\hline Exhaust $\left.\mathrm{O}_{2}(\text { vol } \%)^{\circ}\right)$ & 12.1 & 11.1 & 11.1 \\
\hline Compression ratio & 33.9 & 37.1 & 58.7 \\
\hline H-P turbine shaft power $(\mathrm{MW})$ & 15.7 & 21.9 & 26.0 \\
\hline Total GT shaft power $(\mathrm{MW})$ & 199.5 & 268.3 & 213.7 \\
\hline Fuel compressor $(\mathrm{MW})$ & 1.0 & 1.6 & 2.1 \\
\hline GT generator eff $(\%) /$ loss $(\mathrm{MW})$ & 98.5 & 99.0 & 98.5 \\
& $/ 3.0$ & 12.7 & $/ 3.2$ \\
\hline Net GT power $(\mathrm{MW})$ & 195.5 & 264.0 & 208.3 \\
\hline ST power $(\mathrm{MW})$ & 98.2 & 144.9 & 98.7 \\
\hline Aux. And BOP losses $(\mathrm{MW})$ & 6.5 & 9.6 & 6.5 \\
\hline Net plant power $(\mathrm{MW})$ & 287.2 & 399.3 & 300.5 \\
\hline Net C-C efficiency - LHV $(\%)$ & 56.9 & 59.0 & 52.7 \\
\hline Net S-C efficiency - LHV $(\%)$ & 38.7 & 39.0 & 36.5 \\
\hline
\end{tabular}

The benefits of two reheat stages diminishes greatly relative to one reheat stage, with the Fclass reheat simple cycle gaining $12.8 \mathrm{MW}$ of power and losing 2.2 percentage points of efficiency relative to the single reheat stage case, and the reheat combined-cycle gaining 13.3 MW and losing 4.2 percentage points relative to the single reheat stage case. The use of a single reheats stage results in substantial gains, but its cost and complexity must be weighed against those gains. A second reheat stage results in little additional gains and requires even greater complexity. The oxygen content of the turbine exhaust gas is lower in the reheat cases than in the reference cases, and is lower for two reheat stages than for a single reheat stage, showing a more effective utilization of compressed air in the reheat cases.

The in-situ reheat process model is basically identical to the sequential combustion reheat. The reheat combustor basket used with sequential combustion reheat is replaced by an "insitu combustor" representing the flow path between vane and blade. This is illustrated in Figure 3. In in-situ reheat, sufficient fuel gas is injected through the high-pressure turbine stage airfoils rather than through reheat combustor baskets, with reheat-combustion proceeding in the wakes of the airfoils. 


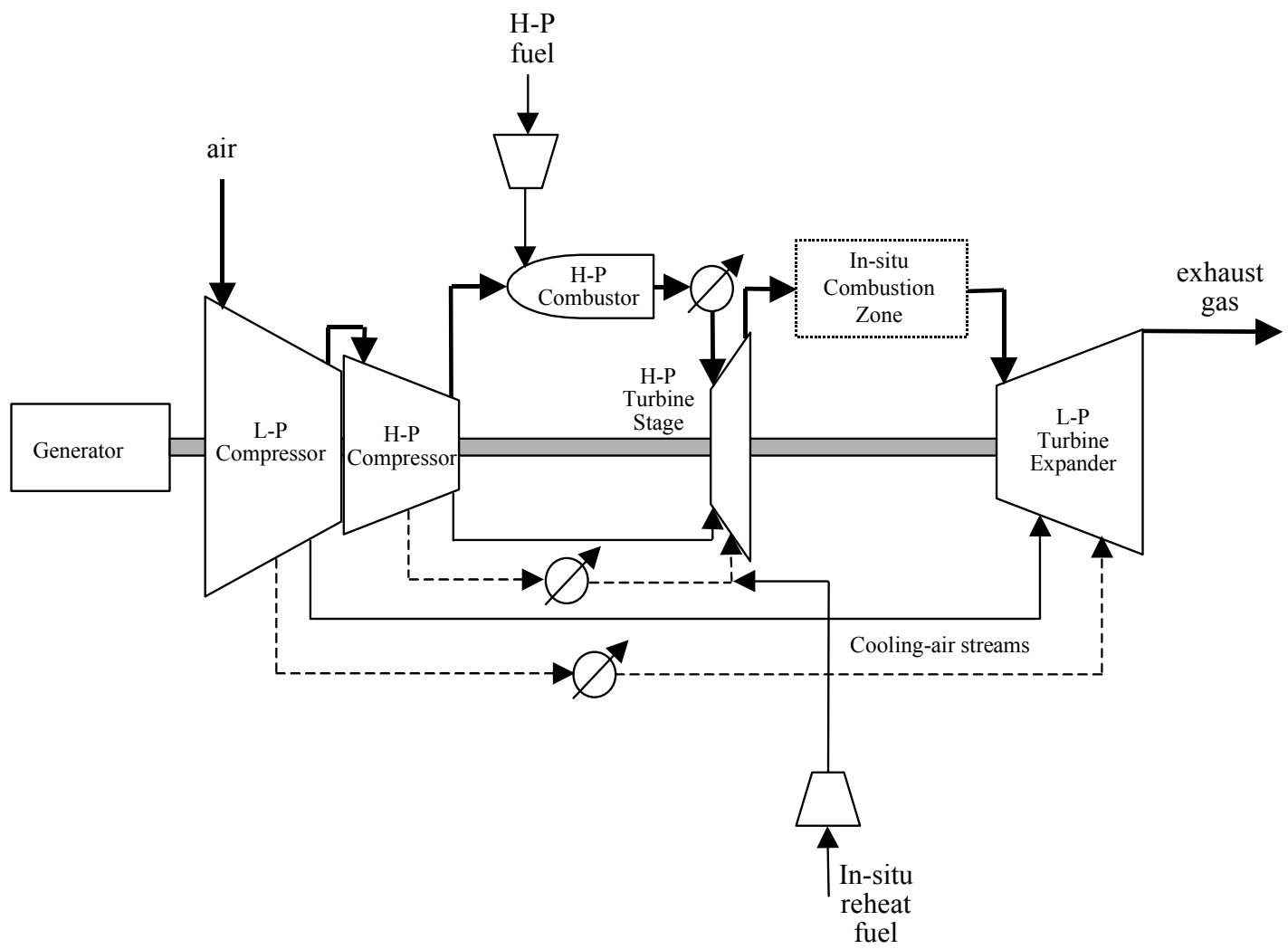

Figure 3 - Reheat Turbine Configuration with In-situ Reheat Combustion

Low- $\mathrm{NO}_{\mathrm{x}}$ versions of the in-situ combustors have been conceived, but are still in early laboratory development. It is conceptualized that the in-situ reheat combustor may be more compact, lower in cost, and have lower pressure drop than the sequential combustion reheat combustor. A schematic comparison of the turbine layouts with sequential combustion reheat and with in-situ reheat is shown in Figure 4. The ability to complete combustion between the high-pressure stage and the low-pressure turbine, while avoiding overheating of airfoils, has not been demonstrated. 


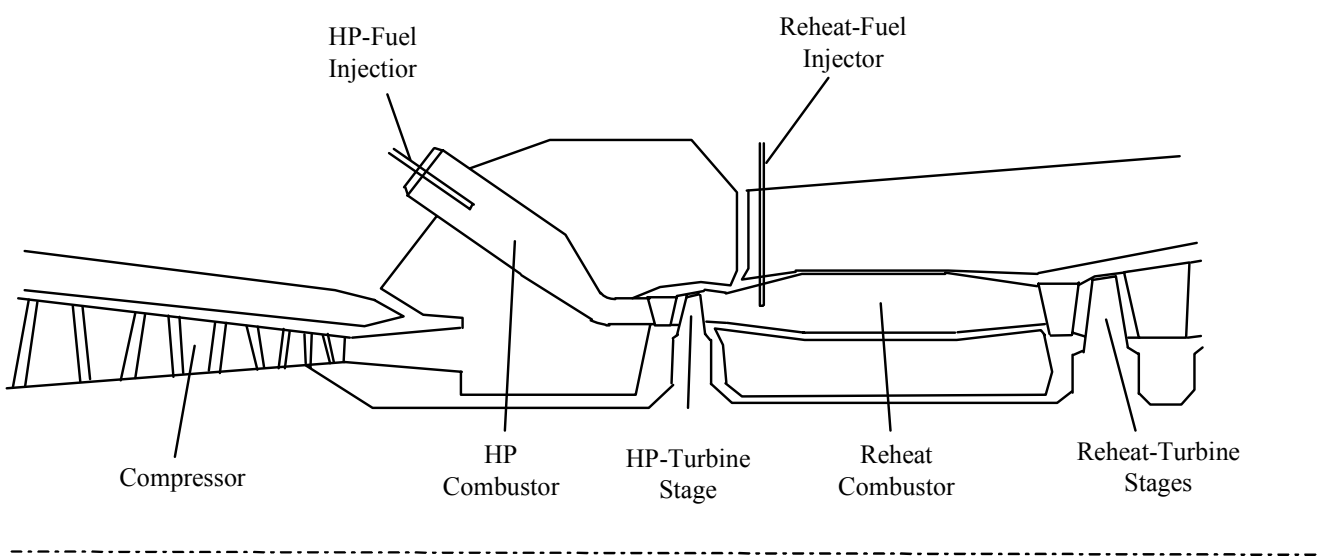

Conventional Reheat Configuration

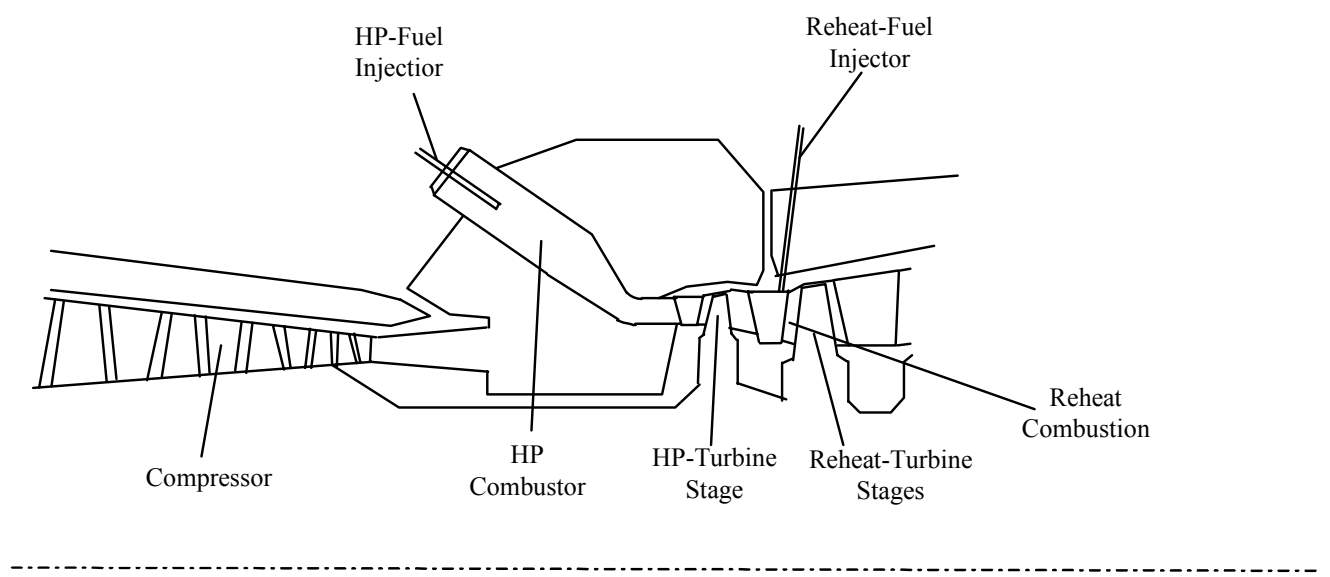

\section{In-Situ Reheat Concept Configuration}

Figure 4 - Comparison of Conventional and In-situ Reheat Structures

The results listed in Table 3 for sequential combustion reheat are then also comparable to the results expected if in-situ reheat combustion were used, with possible small additional performance gain due to lower pressure drop over the in-situ reheat combustors. It can also be concluded that only a single in-situ reheat stage will be beneficial. Note that optimum pressure ratios for the simple-cycle and combined-cycle cases were not identified; so further performance improvements might be possible.

\subsection{Fractional Reheat}

In this approach a lesser degree of in-situ reheat is employed for moderate degrees of reheat in an existing turbine. The concept applies the existing compressor and expander design and adds a small amount of fuel into the first-stage vane (vane cooled by an air-fuel mixture). 
The gas flowing past the first vane is heated by this limited in-situ combustion approximately back up to the temperature that would have existed with no first-vane cooling. Fractional reheat can also be applied over the stage- 1 rotor and stage- 2 vane. The concept is illustrated in Figure 5.

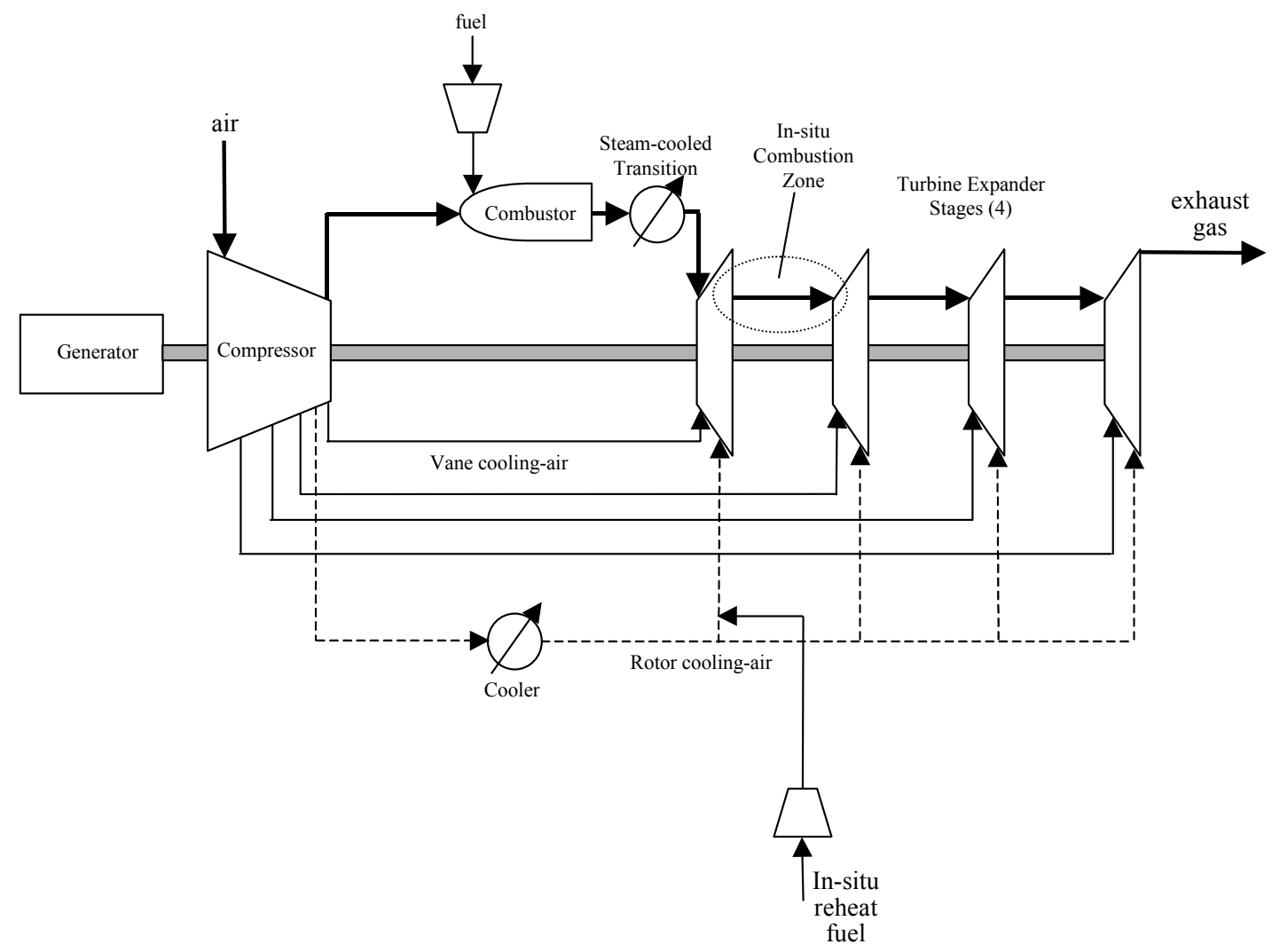

Figure 5 - Fractional In-situ Reheat Configuration

The cycle performance was simulated for an F-class application using GateCycle software. A design model of the engine was first generated and then modified to an off-design model to perform the simulation. A compressor map was utilized in the simulation that was not really representative of this compressor, so the off-design compressor simulation is not strictly accurate, but does show appropriate trends. Fractional reheat was roughly simulated in the GateCycle by placing a zero pressure drop reheat burner between the first and second expander stages and looking at the relative benefits of performing a small amount of reheat vs. the additional cooling air needed for cooling the subsequent airfoils. These heat transfer calculations are incorporated into the gate cycle program. The fuel flow is so small that it cannot replace significant cooling air or provide significant cooling of the airfoil.

At each level of fractional reheat, the compressor extraction control valves would need to be adjusted to accommodate the needed additional airfoil cooling. The primary combustor fuel rate and air rate were fixed at constant values throughout the range of reheats evaluated to give the same combustion temperature and turbine inlet conditions. The compressor surge margin must be sufficient to accommodate the increased air mass flow and expansion ratio for cooling the second-stage, and subsequent stages, which operate at higher temperatures with reheat. 
Performance is listed in Table 4. The primary fuel rate is fixed at $21.925 \mathrm{lb} / \mathrm{s}$. The compressor exit air rate is fixed at $894.9 \mathrm{lb} / \mathrm{s}$, resulting in a turbine inlet temperature of $2581.5^{\circ} \mathrm{F}$. The normal first-stage vane cooling air rate is $83.0 \mathrm{lb} / \mathrm{s}$ at $754^{\circ} \mathrm{F}$ and the first-stage rotor cooling air rate is $38.2 \mathrm{lb} / \mathrm{s}$ at $392^{\circ} \mathrm{F}$. As the fractional reheat fuel input increases, the turbine simple-cycle power increases. The turbine simple-cycle efficiency initially increases, but then drops as the turbine exhaust temperature becomes too large. The compressor inlet air rate increases as the reheat fuel input increases due to increased airfoil cooling needs.

Table 4 - Fractional Reheat Simulation Results Using F-class Conditions (Simple-Cycle)

\begin{tabular}{|c|c|c|c|c|c|c|c|}
\hline $\begin{array}{l}\text { Reheat } \\
\begin{array}{l}\text { Fuel } \\
(\mathbf{l b} / \mathbf{s})\end{array}\end{array}$ & $\begin{array}{l}\text { Turbine } \\
\text { Power } \\
(\mathbf{M w e})\end{array}$ & $\begin{array}{l}\text { Turbine } \\
\text { Efficiency } \\
\mathbf{( \% ,}, \mathbf{L H V})\end{array}$ & $\begin{array}{l}\text { Turbine } \\
\text { Exhaust } \\
\text { Temp } \\
\left({ }^{\circ} \mathbf{F}\right)\end{array}$ & $\begin{array}{l}\text { Compressor } \\
\text { Pressure } \\
\text { Ratio }\end{array}$ & $\begin{array}{l}\text { Compressor } \\
\text { Inlet Air } \\
\text { Flow }(\mathbf{l b} / \mathbf{s})\end{array}$ & $\begin{array}{l}\mathbf{2}^{\text {nd }} \text { Stage } \\
\text { Inlet } \\
\text { Temp } \\
\left({ }^{\circ} \mathbf{F}\right)\end{array}$ & $\begin{array}{l}\mathbf{2}^{\text {nd }} \text { Stage } \\
\text { Cooling } \\
\text { Air Flow } \\
(\mathbf{l b} / \mathbf{s})\end{array}$ \\
\hline 0 & 189.5 & 38.09 & 1097 & 16 & 1008.7 & 2050 & 55.1 \\
\hline 0.1 & 190.5 & 38.13 & 1099 & 16 & 1009.9 & 2056 & 55.4 \\
\hline 0.2 & 191.6 & 38.17 & 1101 & 16 & 1011.2 & 2063 & 55.8 \\
\hline 0.3 & 192.7 & 38.21 & 1104 & 16 & 1012.4 & 2069 & 56.1 \\
\hline 0.4 & 192.9 & 38.08 & 1108 & 16 & 1014.6 & 2078 & 56.6 \\
\hline 0.5 & 193.9 & 38.12 & 1112 & 16 & 1016.8 & 2085 & 56.9 \\
\hline 0.75 & 195.5 & 38.02 & 1119 & 16 & 1020.1 & 2104 & 57.9 \\
\hline 1.0 & 197.7 & 38.02 & 1126 & 16 & 1023.7 & 2121 & 58.7 \\
\hline 1.5 & 201.8 & 38.0 & 1140 & 16 & 1031.2 & 2159 & 60.5 \\
\hline 2.0 & 205.3 & 37.8 & 1156 & 16 & 1038.9 & 2196 & 62.1 \\
\hline 5.0 & 229.3 & 37.5 & 1243 & 16 & 1077.4 & 2408 & 70.8 \\
\hline 10.0 & 269.9 & 37.3 & 1382 & 16.2 & 1129.4 & 2744 & 82.0 \\
\hline
\end{tabular}

The table indicates that the maximum gain in simple-cycle efficiency is about 0.1 percentage points, or a $0.3 \%$ increase. The maximum gain in plant power is about $2.3 \%$ before the simple-cycle efficiency starts to drop. Fractional reheat results in greater cooling need after the turbine reheat stage(s) due to higher than normal subsequent-stage inlet temperatures. The higher turbine exhaust temperatures will also result in significant increases in combinedcycle power.

\subsection{Partial Oxidation Reheat}

Natural gas can be partially oxidized at high pressure by substoichiometric air to generate a low heating-value fuel gas and this is an important technology used to produce syngases for chemical synthesis. This fuel gas can be partially expanded across a high-pressure expander to generate power and to simultaneously cool the gas, and then applied for turbine reheat. The concept is illustrated in Figure 6. Steam is mixed with the preheated natural gas fuel to eliminate carbon formation in the partial oxidation burner. The generated fuel gas, having high hydrogen and carbon monoxide contents, has medium heating value and potential low$\mathrm{NO}_{\mathrm{x}}$ combustion behavior. It differs from the sequential combustion reheat cycle because 1) the H-P turbine expands a fuel gas rather than a combustion gas, and 2) the high-pressure expander is open-loop, steam cooled. The reheat is performed with combustor baskets, and the reheat combustor is much like a combustor used for medium heating value fuel gases in IGCC applications. This cycle was previously evaluated with $100 \%$ of the HRSG steam being added to the PO burner and found to have potential performance advantages [2]. 


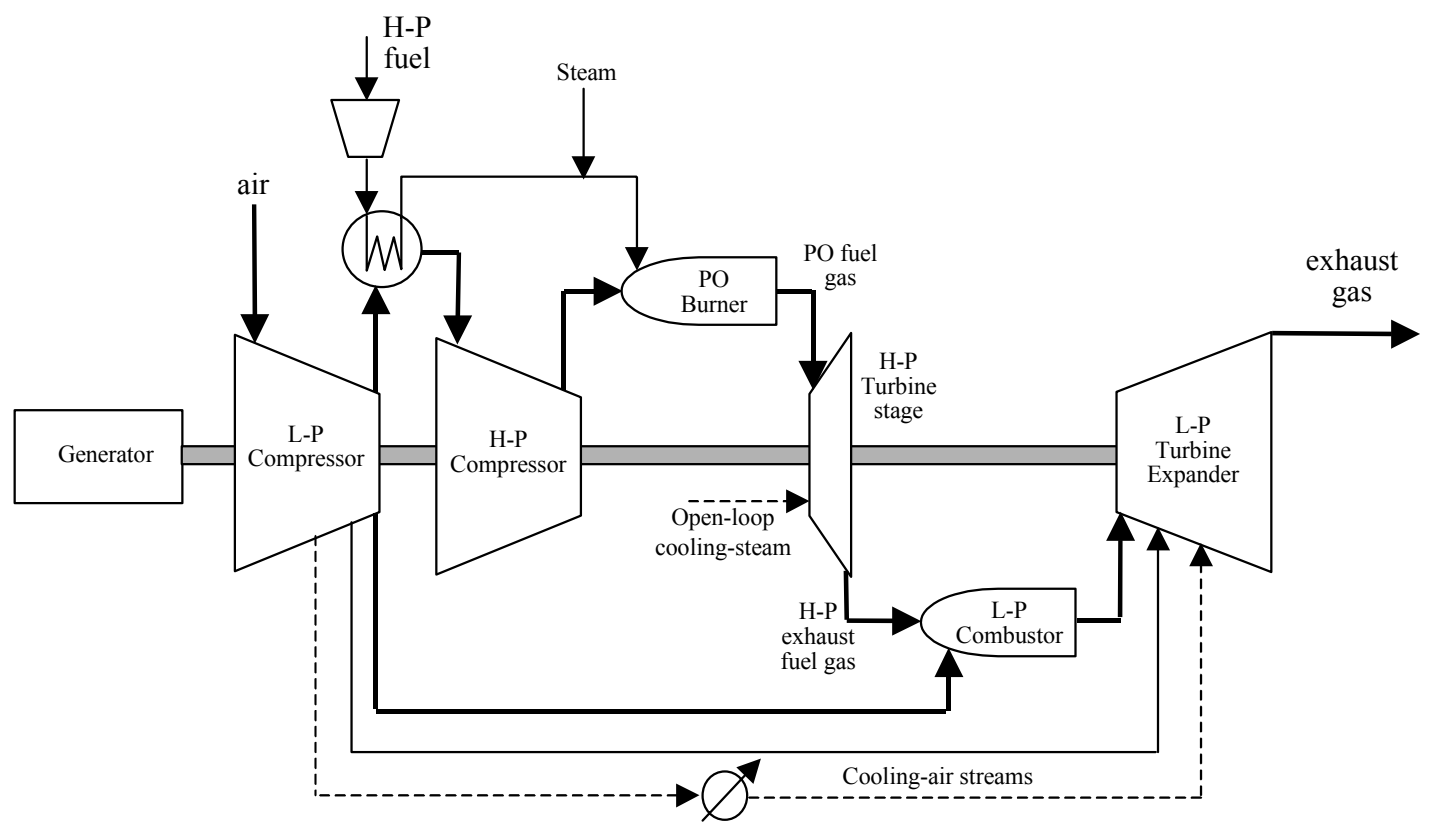

Figure 6 - Partial Oxidation Turbine Reheat Concept

If reheat is performed by in-situ reheat combustion, the airfoil coolant air in the reheat stages can also provide the oxidant needed for combustion of the fuel gas. The steam consumption can be minimized to levels needed for soot protection so that greater combined-cycle performance is achieved. Steam for the PO burner is generated by inter-cooling the H-P compressor. The fuel-rich nature of the partial oxidation combustors has the potential to improve cycle performance and reduce $\mathrm{NO}_{\mathrm{x}}$ emissions. A multiple in-situ reheat configuration is illustrated in Figure 7. A partial oxidation burner is followed by a highpressure expander and then three in-situ combustors before reaching the low-pressure turbine. The cooling air requirement for each reheat stage must be compatible with the reheat combustion needs on the subsequent stage. 


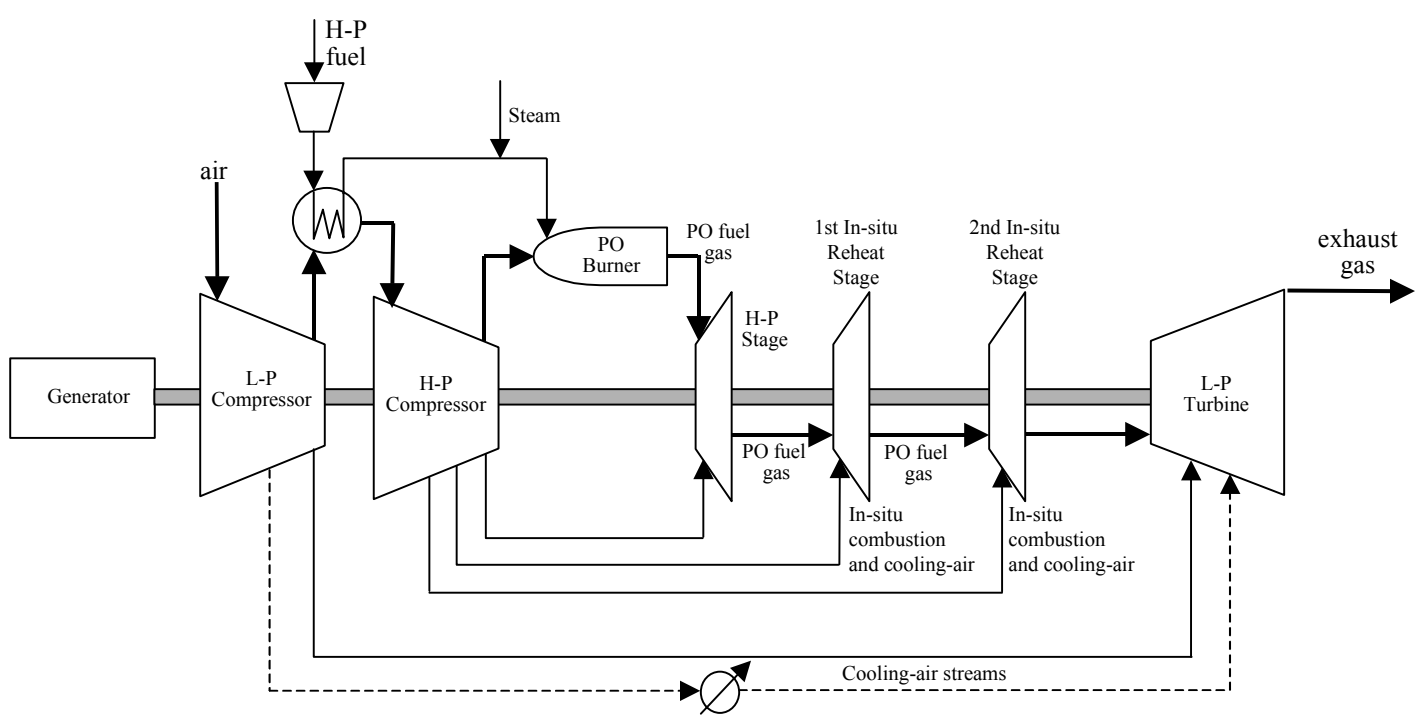

Task 3 - Blade Path Aeo Figure 7 - Partial Oxidation with Multiple In-situ Reheat Stages

The results in Table 5 are for a Figure 7 configuration with 2 H-P turbine stages. They show that the performance for the partial oxidation reheat concept using a PO burner, followed by a $\mathrm{H}-\mathrm{P}$ turbine (2 stages) having one in-situ reheat stage, with an expansion ratio of about 6.0 , is better than sequential combustion reheat. The H-P turbine is followed by an in-situ reheat combustor integrated into an L-P turbine whose design is conventional. The PO burner outlet gas and the H-P turbine exhaust gas are medium heating-value gases having acceptable hydrogen content and the combustion of the H-P turbine gas in the L-P turbine should result in low $\mathrm{NO}_{\mathrm{x}}$ emission: 
Table 5 - ChemCad PO-Reheat Turbine Simulation Results

\begin{tabular}{|l|c|}
\hline & $\begin{array}{c}\text { F-class } \\
\text { Two PO Expanders }\end{array}$ \\
\hline Fuel input $\left(10^{9} \mathrm{Btu} / \mathrm{hr}\right)$ & 2.48 \\
\hline Fuel input $(\mathrm{lb} / \mathrm{hr})$ & 120,000 \\
\hline Water input $(\mathrm{lb} / \mathrm{hr})$ & 200,000 \\
\hline HP-PO Turbine $\mathrm{TIT}\left({ }^{\circ} \mathrm{F}\right)$ & 2590 \\
\hline HP-PO turbine RIT $\left({ }^{\circ} \mathrm{F}\right)$ & 2450 \\
\hline Reheat-turbine TIT(F) & 2590 \\
\hline Reheat-turbine RIT $(\mathrm{F})$ & 2429 \\
\hline H-P turbine exhaust $(\mathrm{lb} / \mathrm{hr})$ & $1,635,140$ \\
\hline L-P turbine exhaust $(\mathrm{lb} / \mathrm{hr})$ & $3,957,383$ \\
\hline Exhaust temperature $\left({ }^{\circ} \mathrm{F}\right)$ & 1132 \\
\hline Exhaust $\mathrm{O}_{2}($ vol $\%)$ & 8.0 \\
\hline Compression ratio & 103 \\
\hline H-P turbine power $(\mathrm{MW})$ & 93.3 \\
\hline Total GT shaft power $(\mathrm{MW})$ & 318.5 \\
\hline Fuel compressor $(\mathrm{MW})$ & 6.3 \\
\hline GT generator eff $(\%) /$ loss $(\mathrm{MW})$ & $98.5 / 4.8$ \\
\hline Net GT power $(\mathrm{MW})$ & 307.5 \\
\hline ST power $(\mathrm{MW})$ & 115.5 \\
\hline Aux. And BOP losses $(\mathrm{MW})$ & 7.6 \\
\hline Net plant power $(\mathrm{MW})$ & 415.4 \\
\hline Net C-C efficiency - LHV $(\%)$ & 57.1 \\
\hline Net S-C efficiency $-\mathrm{LHV}(\%)$ & 42.2 \\
\hline
\end{tabular}

\begin{tabular}{lrr} 
& PO burner gas & H-P turbine gas \\
\cline { 2 - 3 } $\mathrm{H}_{2}($ vol\%): & 14.33 & 9.00 \\
$\mathrm{CO}$ & 7.41 & 5.39 \\
$\mathrm{CO}_{2}$ & 4.34 & 5.20 \\
$\mathrm{H}_{2} \mathrm{O}$ & 27.13 & 28.45 \\
$\mathrm{~N}_{2}$ & 46.20 & 51.29 \\
$\mathrm{Ar}$ & 0.60 & 0.67 \\
$\mathrm{Heating} \mathrm{value}$ & & \\
$\quad\left(10^{4}\right.$ Btu/lb-mole $)$ & 1.88 & 1.05
\end{tabular}




\subsection{Conclusions}

The following conclusions and recommendations can be drawn for the alternative reheat technologies:

- The sequential combustion reheat cycle can improve the performance (power output and efficiency) of both the simple-cycle and combined-cycle turbine power plant. A single reheat stage, with total turbine pressure ratio of about 30 may represent the upper limit of performance gains. Sequential combustion reheat requires major changes in compressor design, combustor design, reheat combustor design and turbine casing design.

- The in-situ reheat stage, with reheat fuel injected through the airfoils and into the expansion gas in the airfoil wakes, has the potential to provide a more compact turbine design than the sequential combustion reheat basket design, with comparable or better performance gains. The in-situ reheat design requirements, combustion behavior, and $\mathrm{NO}_{\mathrm{x}}$ emission potential have not yet been established. Cycle studies indicate that in-situ reheat should also be limited to a single reheat stage, with multiple-reheat stages providing only limited additional benefits.

- The fractional reheat cycle applies a form of in-situ reheat combustion, with an air-fuel mixture used as airfoil coolant and reheat combustion occurring in the airfoil wakes. The level of reheat is limited so that minimal equipment modifications are possible. Fractional reheat can provide moderate benefits of increased power and efficiency that are limited by maximum reheat temperature limits and the compressor surge margin. It could be a low cost alternative to improve the performance of the standard turbine cycle.

- Partial oxidation in-situ reheat expands a partial oxidation fuel gas through the turbine, using airfoil cooling air for inter-stage, in-situ reheat combustion. It can utilize multiple reheat stages and can have performance superior to the sequential combustion reheat cycle. The concept has the potential for low plant $\mathrm{NO}_{\mathrm{x}}$ emission, but carbon (soot) formation may be a technical issue. Design requirements and the ability to control the local temperature distribution have not been established.

- All of the reheat alternatives show performance merits, and differ in their relative complexity and technical risks. Small-scale testing of all of the reheat concepts is needed to advance the technologies to the state where technical feasibility potential can be judged, with parallel cycle evaluations being applied to assess design features, operation, control, and performance. 


\section{CONCEPTUAL DESIGN}

The results of this Task 4 study and of Task 1 (Blade Path Aerodynamics, q.v. topical report) and of Task 2 (Combustion and Emissions, q.v. topical report) are consistent in concluding that in-situ reheat as applied to the vane 1 trailing edge of an existing large turbine is the preferred design. In this conceptual design, combustion can be completed, efficiency and power gains are most significant, and emissions increments are smallest. Based on the results in the Task 2 Topical Report, each vane 1 tailing edge would have 24 holes of diameter 1.8 $\mathrm{mm}(0.07 \mathrm{in})$ on each vane.

The three Task results for vane 2 reheat after vane 1 reheat are also consistent. Combustion can be completed, but in this case vane 2 holes would need flameholders in the form of bluff bodies. The specific design optimum found is to use 8 holes of diameter $3.2 \mathrm{~mm}(0.125 \mathrm{inch})$ on the trailing edge of each vane 2 .

These designs are shown in Figure 8. The counter bores are used only for vane 2 reheat after vane 1 reheat. Since the burnout zone for vane 1 reheat is downstream of the injection point, no material changes would likely be needed. For vane 2 reheat, the Task 2 Topical Report shows that optimized design can also push the burnout zone for the stabilized flames off the metal.

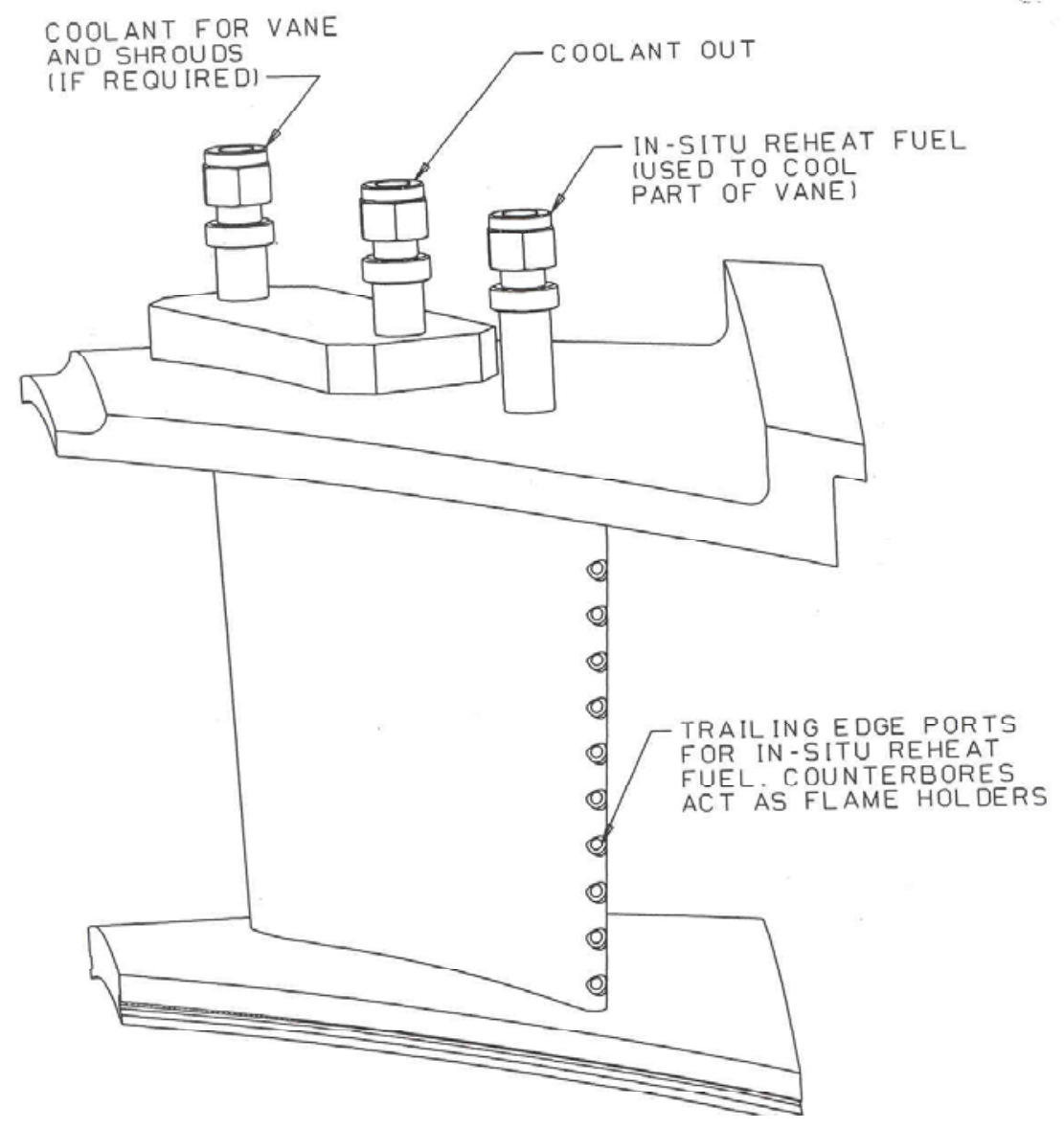

Task 4 - Blade Path Aeo Figure 8 - Vane 1 and Vane 2 Trailing Edge Conceptual Designs 


\section{DEVELOPMENT PLAN}

This program has used CFD; detailed chemical kinetics; high-pressure, high-temperature, full Mach number, sub-scale testing, and power cycle evaluation software to identify a preferred approach for in-situ reheat. The detailed kinetics suggests moderately increased emissions. Consequently, in-situ reheat development requires further experimental verification, scale-up verification, and theoretical and experimental looks at more design options.

Consequently the following development plan is proposed, prior to any detailed engine engineering:

- Parametrics. There are many parameters still to be explored using detailed kinetics, CFD, and testing. These include: leading edge or mid-span fuel injection; injection at an angle different from the local turbine gas angle; possible dilution of fuel to reduce NOx; injection mods to permit more rapid mix-out of injected fuel. All options are aimed at finding optimum designs that allow burnout of $\mathrm{CO}$ at low enough temperatures not to form NOx.

- $\quad$ Alternative fuels. Perform similar calculations and tests on reformed fuels, or hydrogen -containing fuels. There will be a possible increase in combustion rate with seeding of fuel with hydrogen. Also, advanced reheat cycles featuring integrated synthetic fuel technologies might offer efficiency benefits, so cycle evaluations are needed.

- $\quad$ Testing of stabilized flames. The flameholder model used in the Task 2 topical report must be experimentally verified.

- Verify results on larger scale. Verification of the small-scale tests in Task 3 of this program should be done on the now-completed (Siemens-owned) higher flow test facility.

- Verify with realistic rotors and stators. The next step is the experimental investigation of a scaled down, one-and-a-half stage turbine combustor. This experimental investigation would provide critical data on the interaction between the in-situ reheat, the rotor/stator interaction and the combustor hot streaks. This experiment would also provide the apparatus necessary to investigate different approaches for fuel injection and blade cooling. The experiment can be done at the blow down facility of the Texas A\&M University. This facility provides approximately $10 \mathrm{~kg} / \mathrm{sec}$ at $44 \mathrm{bar}$ for approximately 5 minutes. If necessary, the mass flow rate can be increased by reducing the operating time. 


\section{REFERENCES}

1. E.V. Carelli, R.D. Holm, T.E. Lippert, and D.M. Bachovchin, Reheat Combustor for Gas Combustion Turbine, U.S. Patent 6,619,026, Siemens Westinghouse Power Corporation, September 16, 2003.

2. Westinghouse Electric Corporation, "Advanced natural gas-Fired Turbine System Utilizing Thermochemical Recuperation and/or Partial Oxidation for Electric Generation, Greenfield and Repowering Applications," Final Report to DOE/METC, March 1997. 